PNL-6608

UC-510

\title{
Methods of Calculating the Post-Closure Performance of High-Level Waste Repositories
}

February 1989

Prepared by Disposal Safety, Inc. for Pacific Northwest Laboratory under Contract DE-ACO6-76RLO 1830

with the U.S. Department of Energy

Pacific Northwest Laboratory Operated for the U.S. Department of Energy by Battelle Memorial Institute 


\title{
DISCLAIMER
}

This report was prepared as an acrount of work spowsoned by an asency of the United States Covermmert. Neithezthe United States Covernment nor any agency

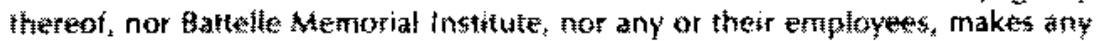

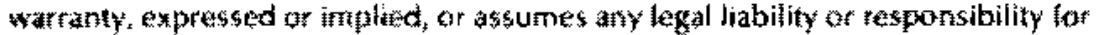
the accuracy, completeness, or usefulness of any intomation, appatatus, product, or process bisctosed, of represents that its use woutd hot infringe privately owned rights. Reterence herein to arty specific commercial product, process, or service by frade name, tradernatk, manufacturez, al otherwise does not necessatity constitute or imply its endert semant, recommendation, or favoring by the United States Cowernment or any agency thereor, or Battelle Acmorial lnstitute. The views and

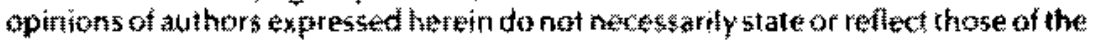
United ftatas Covernment of any agency thereor.

\author{
PACIICNORTHWEST LABORATORY \\ operated by \\ BATTELLE MEMORIAL INSTITUTE \\ for the \\ UNITED STATES DEPARTMENT OF ENERGY \\ under Contract DE,ACO6-76RLO 1830
}

\begin{tabular}{|c|c|}
\hline \multicolumn{2}{|c|}{ Prinked in the Linted 5tates at Amerfa } \\
\hline \multicolumn{2}{|c|}{ 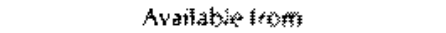 } \\
\hline \multirow{2}{*}{\multicolumn{2}{|c|}{ 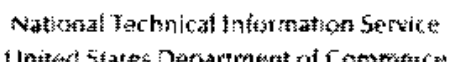 }} \\
\hline & \\
\hline \multicolumn{2}{|c|}{$52 f_{3}$ Foyt Royal Road } \\
\hline \multicolumn{2}{|c|}{ 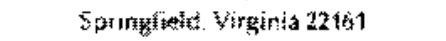 } \\
\hline \multicolumn{2}{|c|}{ Nils Price Coxtes: } \\
\hline \multicolumn{2}{|c|}{ Nicrotiche afis } \\
\hline \multicolumn{2}{|c|}{ Frinate copy } \\
\hline & opsice \\
\hline$P_{a y+3}$ & Cextes \\
\hline Giving & $\mathrm{A} \hat{\mathrm{A}}^{2} \mathrm{z}$ \\
\hline 0250 & 㭋集 \\
\hline $0 x+105$ & AD: \\
\hline 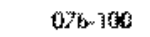 & $\mathrm{A}_{0} \overline{3}$ \\
\hline $104-125$ & $A_{106}$ \\
\hline $126-150$ & AOY \\
\hline 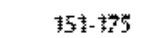 & Acta \\
\hline 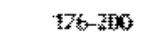 & Atos \\
\hline 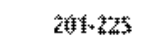 & A耗2 \\
\hline $226 \cdot 25$ & A11 \\
\hline $251 \cdot 2 \cdot 3$ & $A 12$ \\
\hline $276-300$ & $A \rightarrow 3$ \\
\hline
\end{tabular}




\section{METHODS OF CALCULATING THE POST-CLOSURE PERFORMANCE OF HIGH-LEVILL WASTE REPOSTTORIES}

Disposal Safety, Inc.

B. Ross, Editor

Washington, DC

P. G. Doxtor, PNL Project Manager

February 1989

Prepared by Disposal Safety, Inc: for Pacific Northwest Laboratory under Contract DE-AC06-76RLO 1830 with the U.S. Department of Energy under Agreement B-LL1010-A-E

Pacific Northwest Laboratory

Richland, Washington 99352 
•

, 


\section{EXECUTVVE SUMMARY}

A large number of different physical, chemical, and geological phenomena may have to be predicted to assess the likely performance of a high-level waste repository. A variety of approaches are used to deal with these phenomena. These include:

- Fundarnental models, which are systematic methods of calculation based explicitly on scientific first principles.

- Empirical models, systematic methods of calculation in whose derivation observations have been used to simplify or replace first principles.

- Models based on hypothesized relationships.

- Direct extrapolation of experiments or field studies.

- Expert judgment, without the use of any consistent, predetermined method of calculation.

Table ES-1 lists many of the types of problems that may have to be solved for performance assessment and indicates which types of models are currently available. The broad scope of this report makes it impossible to summarize all of these models here. Instead, some conclusions drawn in key areas are presented.

\section{Scenario Probabilities}

The 7 years since the preparation of the review by Koplik et al. (1982) have been notable for the lack of new iniriatives in the area of calculating scenario probabilities. This is especially noteworthy in view of the need for such calculations created by the U.S. Environmental Protection Agency's high-level waste tegulations. What progress has been made is primarily in refining earlier work.

Work published to date presents several techniques for combining probabilities of various events and processes to yield an overall scenario probability. Existing mathematical 
TYPE OF MODEL

$\begin{array}{lll}\text { Expent } & \text { Extrapow } & \text { Empirical } \\ \text { Judgment } & \text { lation of } & \text { Models } \\ & \text { Experi- } & \\ & \text { ments or } \\ & \text { Field } \\ & \text { Measures }\end{array}$

Funda- Hypothemental sized

Models Relationship

Scenario selection

Scenario probabilities

Heat transfer

Radiation fields

Geochernical speciation

Geochemical mass transfer

Sorption

Stress-induced permeability charge

Brine migration

Radiation eflects on chemistry

Coupled thermo-hydromechanical effects

Uniform corrosion

Pit + crevice corrosion

Stress corrosion cracking

Wash form dissolution

Diffusion through backfills

Surface diffusion in backfills

Seal degradation

Salt discolution

Ground-water flow

Ground-water contaminant ransport

Colloid transport

Transport in salt

Gas-phase transport

Biosphere transport

Table ES-1. Nature of current perfornance assessmen methods. 
techniques (many of them not requiring computer codes) seem reasonably adequate to this task, especially in view of the limited size of the data base that must be handled.

But it seems that, since 1980 , researchers in the field of repository safety have largely abandoned the effort to develop probability estimates for the elemental events and processes. As this abandonment is not due to lack of attention to the problem, it suggests that available scientific knowledge is not sufficient to reliably quantify many of these probabilities. If this is the case, it will be "practicable" (as the regulation puts it) to include in the calculation of the probability of various releases only some of the relevant scenarios.

\section{$\underline{\text { Heat }} \underline{\text { Transfer }}$}

Heat transfer models for most repository applications are well developed and widely accepted. For situations involving gas convection with water evaporation or condensation, codes are available but are at the frontiers of modeling research.

\section{Geochemistry}

The basic structure of geochemical equilibrium models is well established, and seems to have little need of modification. Compilation and critical evaluation of thermodynamic data are a necessary part of the development of a geochemical model, however, and the effort to evaluate thermodynamic data has lagged behind other aspects of model development. Especially troublesome is the lack of basic data for many of the species of interest to the topic of radioactive waste disposal. Deficiencies in the thermodynamic data base need to be identified and corrected if geochemical models are to be applied to waste-form dissolution or actinide sorption problems. In order to make temperature corrections, additional equilibrium constant and enthalpy data are required, especially for the actinides. Pressure corrections must also be added to models used at the depths of saturated-zone repositories.

Existing models carry out solubility calculations under the assumption that the activity of a solid is unity. This unit activity is correct for pure solids. However, many minerals are members of solid solution series or have variable and poorly characterized composition. A model for the activities of such solids must be developed for phases such as clays, 
zeolites, feldspars, and amorphous solids to be appropriately considered in geochemical calculations. The theoretical treatment of non-rystalline solids is not yet well established.

At this point in the research effort, more attention should be given to measuring reliable thermodynamic and kinetic data than to further model development. The models require detailed and accurate knowledge of the themodynamics and kinetics of a large number of possible geochemical reactions. The models may be used to guide experimentalists to areas where more accurate data are required.

\section{Radiation Effects on Chemistry}

Radiolysis produces equal amounts of oxidizing and reducing species; what is important to waste package performance assessment is the relative reactivity of these species. The most worrisome situation, and the one thought to be most likely in a saturated repository, is that oxidants will react more rapidly than reductunts, thus producing net oxidizing conditions.

In an unsaturated-zone repository, the environment is already oxidizing and the primary concern is the production of species that could significantly enhance corrosion rates. Probably the greatest concern is for the production of nitric acid or oxalic acids if $\mathrm{CO}_{2}$ is present in significant quantities. If copper is chosen as a container material, ammonia could also be an important radiolysis product.

\section{Container Cormsion}

The ability to model corrosion decreases with the complexity of the environment. With modeling often being difficult or impossible, laboratory testing and extrapolation are usually relied upon to provide data on container lifetime and corrosion rates. Tests with alloys in enviromments that closely simulate waste canisters under expected repository conditions would provide the best information on corrosion rates, but accurate long term data are still very difficult to obtain, particularly when lifetimes in the range of hundreds or thousands of years are needed. The determinstion of the corrosion rate is also dependent on the type of corrosion expected. 
The metal type and method of manufacture are as important as the environment in the corrosion process. Although all of the metals being considered for containers are quite corrosion-resistant, each has factors that need to be examined to better appreciate the strengths and weaknesses of the combined metal and environment. Factors such as the residual or "tramp" elements remaining after production, whether the metal is cast, forged, wrought, or welded, and the size of the grains (or the grain boundary area) are critical in considering corrosion resistance. The physical properties such as yield strength and ductility are also of considerable significance to corrosion properties.

\section{Waste-Form Dissolution}

Four regimes may be distinguished for the release of radioelements from waste forms:

- Elements released from the waste matrix in greater quantities than are soluble in the water immediately adjacent to the waste.

- More soluble elements in a matrix whose rate of dissolution is controlled by its equilibrium solubility.

- More soluble elements in a matrix whose rate of dissolution is kinetically controlled, with trace elements released congruently as the matrix dissolves.

- A matrix that dissolves so slowly that the release of the radionuclides it contains is controlled by their diffusion through the matrix.

Which of these regimes is controlling depends on the waste species in question, the form of the waste and on the physical and chemical environment. Researehers have developed a variety of competing models, which incorporate these regimes in different ways. Mass-transfer models based on equilibrium dissolution have been particularly well developed.

The application of mass-transfer theory based on the solubilities of individual radioelements would seem to be less complicated and more reliable as a basis for extrapolation than the use of the theory to determine the degradation rate of the waste marrix. In the former case, it does not matter whether radioactivity is retained within the original matrix or enters new precipitate phases; the quantity of interest is the dissolved concentration, which is what the theory predicts directly. Good physical models exist to analyze this case; some work remains to be done on their numerical implementation. 
For matrix dissolution, the situation is otherwise. When the waste matrix dissolves and reprecipitates, associated radioactivity may remain in solution, and so the rate of reprecipitation is important. For cerrain chemical systems, among them dissolved silica in ground water, kinetics will be relevant to a determination of reprecipitation rates. Published analytic solutions and numerical models do not systematically address this problem.

\section{Ground-Water Transport}

Ground water modeling is an active field of research and much remains to be done to develop computer codes capable of simulating the complex coupled processes that will take place around a repository. Nevertheless, code development must be a secondary priority compared to data acquisition. Already, codes have developed to a degree of complexity far beyond the ability of field hydrogeologists to measure the needed input variables. White new data-gathering techniques are being developed, it will not be possible even in the most optimistic scenario to measure all the variables needed by the more complicated models. Emphasis is therefore needed on techniques for doing bounding calculations with incomplete information and ways of ensuring the conservatism of these calculations.

Work on code development is needed, to be sure. The opinion is sometimes expressed that code development for the repository program should focus exclusively on developing ways to model phenomena not yet accurately modelable, because the program's large budget makes computational efficiency irrelevant. The extensive use of one-dimensional models in the Environmental Assessments and the code limitations that have been encountered in other modeling efforts suggest that computational efficiency is an important consideration, and that research on more efficient rumerical methods would be valuable.

Sensitivicy and Uncerrainty Analyses

Two questions are often raised in the discussion of performance assessnent models: which inputs have the most effect on the output, and how uncertain do the input uncertainties make the output? Sensitivity analyses answer the first question and uncertanty andlyses answer the second. 
Sensitivity analyses may be either deterministic or statistical. Deterministic methods start with the calculation of partial derivatives of model outputs with respect to all inputs, but a thorough analysis requires more. A statistical analysis of patterns of influence of the variables throughout the input variable space may be needed, but if so the deterministic methods would lose the relative simplicity which is their principal advantage.

Uncertainty analyses may be based on either perturbation of models about a fixed point or repeated simulation at multiple points in the input variable space. The perturbation method is more computationally efficient. However, experience shows that results obtained by the two methods often differ when (as is common) input variances are large. As a result, one cannot trust the results of perturbation analyses until they are verified by simulation. This seems to negate the method's apparent efficiency advantage.

\section{Natural analogues}

Natural analogues may be used in performance assessment as natural experiments to aid in extrapolation of laboratory experiments, for determining bounds on parameter values, to indicate qualitatively what phenomena may occur, or to empirically integrate the effects of many processes acting together at a site.

Qualitative analogues clearly remain an irreplaceable tool for identifying the relevant processes in a repository setting. They are valuable for increasing the confidence in models of specific processes and also in overall repository performance.

However, little in the way of quantitative data has resulted to date from natural analogue studies. There are indications that more quantitative data may be forthcoming in such areas as alteration of natural basaltic glass, near-field hydrogeochemistry, sorption, mineral alteration, and radionuclide migration. 
.

$\bullet$ 


\section{CONTENTS}

EXECUTTVE SUMMARY $\ldots \ldots \ldots \ldots \ldots \ldots \ldots \ldots \ldots \ldots \ldots \ldots$ ij

CHAPTER 1. INTRODUCTION . . . . . . . . . . . . .

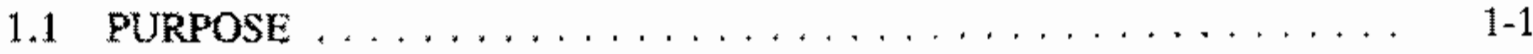

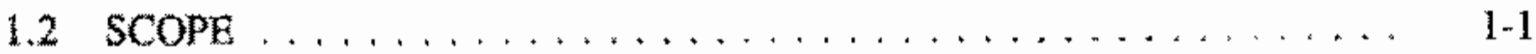

1.3 ORGANIZATION OF THE REPORT $\ldots \ldots \ldots \ldots \ldots \ldots \ldots \ldots, 1.2$

1.4 AUTHORSHIP $\ldots \ldots \ldots \ldots \ldots \ldots \ldots \ldots \ldots \ldots \ldots \ldots, 1.2$

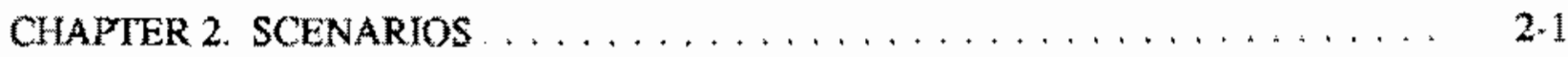

2.1 SCENARIO SELECTION METHODS $\ldots \ldots \ldots \ldots \ldots \ldots \ldots, 2-1$

2.1 .1 Simulation Methods $\ldots, \ldots \ldots \ldots \ldots \ldots \ldots, \ldots \ldots, 2-3$

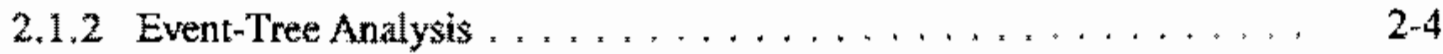

2.1 .3 Judgmental Methods . . . . . . . . . . . . . . . . . 2 2 10

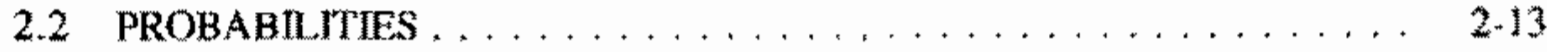

2.2 .1 EPA Srudies. . . . . . . . . . . . . . . . .

2.2 .2 Simulation Models $\ldots \ldots \ldots \ldots \ldots \ldots \ldots \ldots \ldots . \ldots \ldots$

2.2 .3 Event Trees $\ldots \ldots \ldots \ldots \ldots \ldots \ldots \ldots \ldots \ldots \ldots \ldots \ldots . \ldots \ldots$

2.2.4 Delphi Method $\ldots \ldots \ldots \ldots \ldots \ldots \ldots \ldots \ldots \ldots \ldots . \ldots \ldots$

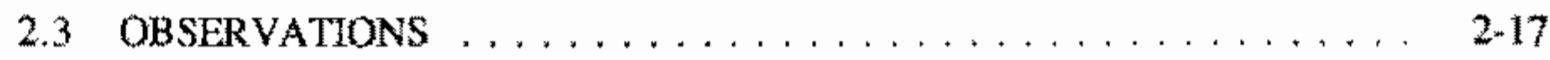

CHAPTER 3. ENVIRONMENTAL CONDITIONS $\ldots \ldots \ldots \ldots \ldots \ldots \ldots .3 .1$

3.1 HEAT TRANSFER $\ldots \ldots \ldots \ldots \ldots \ldots \ldots \ldots \ldots \ldots \ldots, \ldots \ldots$

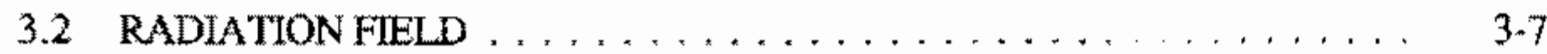

3.3 GEOCHEMICAL MODELLING $\ldots \ldots \ldots \ldots \ldots \ldots \ldots \ldots \ldots \ldots$

3.3.1 Aqueous Speciation and Mineral Solubility . . . . . . . . 3-11

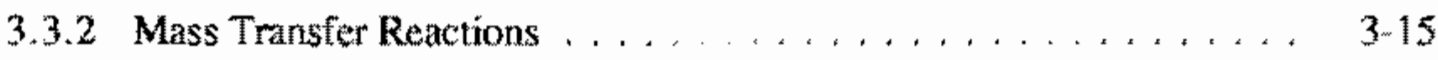

3.3 .3 Themodynamic Data $\ldots \ldots \ldots \ldots \ldots \ldots \ldots \ldots \ldots$

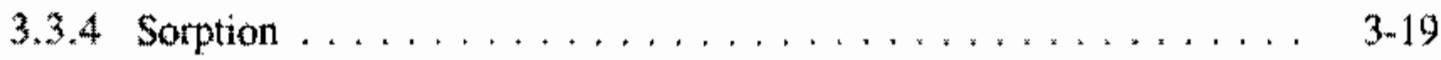




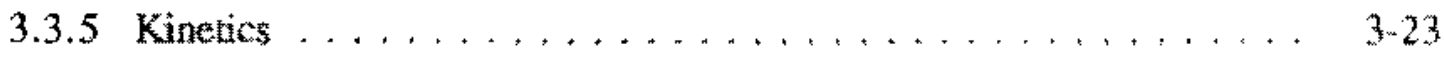

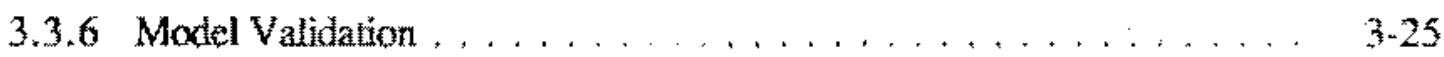

3.4 ROCK MECHANICS $\ldots \ldots \ldots \ldots \ldots \ldots \ldots \ldots \ldots, 3-26$

3.5 BRINE MIGRATION $\ldots \ldots \ldots \ldots \ldots \ldots \ldots \ldots \ldots \ldots \ldots, \quad \ldots \ldots \ldots$

3,6 RADIATION EFFECTS ON CHEMISTRY $\ldots \ldots \ldots \ldots \ldots \ldots \ldots .30$

3.7 COUPLED PROCESSES $\ldots \ldots \ldots \ldots \ldots \ldots \ldots \ldots \ldots \ldots \ldots$

CHAPTER 4. ENGINEERED BARRIER PERFORMANCE $\ldots \ldots \ldots \ldots \ldots, \ldots, 4-1$

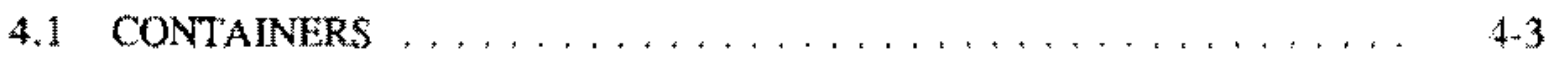

4.1.1 Factors Infuencing Corrosion $\ldots \ldots \ldots \ldots \ldots \ldots \ldots \ldots$ 4.3

4.1 .2 Uniform Corrosion $\ldots \ldots \ldots \ldots \ldots \ldots \ldots \ldots \ldots$

4.1 .3 Galvanic Corrosion $\ldots \ldots \ldots \ldots \ldots \ldots, \ldots \ldots \ldots, 4.6$

4.1 .4 Pitting $\ldots \ldots \ldots \ldots \ldots \ldots \ldots \ldots \ldots \ldots \ldots \ldots \ldots, 4$

4.1 .5 Crevice Corrosion $\ldots \ldots \ldots \ldots \ldots \ldots, \ldots \ldots \ldots, \ldots \ldots$

4.1 .6 Intergranular Cortosion $\ldots \ldots \ldots \ldots \ldots \ldots \ldots \ldots \ldots .4 .15$

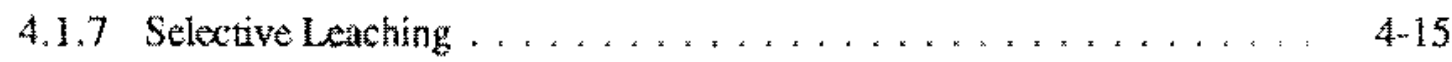

4.1 .8 Stress Corrosion Cracking $\ldots \ldots \ldots \ldots \ldots \ldots \ldots \ldots . \ldots \ldots$

4.1 .9 Dry Corrosion . . . . . . . . . . . . . . . 4.20

4.1 .10 Hydrogen Damage $\ldots \ldots \ldots \ldots \ldots \ldots \ldots \ldots .22$

4.2 WASTEFORMS $\ldots \ldots \ldots \ldots \ldots \ldots \ldots \ldots \ldots \ldots \ldots, \ldots \ldots \ldots$

4.2 .1 Solubility-Limited Releases $\ldots \ldots \ldots \ldots \ldots \ldots, \ldots \ldots \ldots$

4.2 .2 Kinetically Controlled Releases $\ldots \ldots \ldots \ldots \ldots \ldots \ldots .4 .31$

4.2.3 Gap Acúvity of Spent Fuel $\ldots \ldots \ldots \ldots \ldots \ldots \ldots \ldots, 4.36$

4.2 .4 Selection of Models of Waste Dissolution . . . . . . . . . . 4-37

4.3 BACKFLL . . . . . . . . . . . . . . . . . 4.40

4.4 COMPREHENSIVE PACKAGE MODELS $\ldots \ldots \ldots \ldots \ldots \ldots \ldots .4 .43$

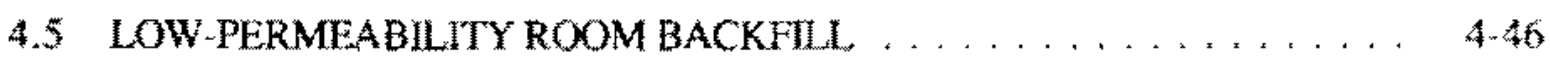


4.6 SHAFT AND BOREHOLE SEALS $\ldots \ldots \ldots \ldots \ldots \ldots \ldots, 4-47$

$4.6,1$ Seal Effectiveness $\ldots \ldots \ldots \ldots \ldots \ldots \ldots \ldots .4 .47$

4.6 .2 Consequences of Seal Failure $\ldots \ldots \ldots \ldots \ldots \ldots \ldots .4 .48$

4.7 WATER CONTROL DEVICES $\ldots \ldots \ldots \ldots \ldots \ldots \ldots \ldots \ldots$ 4-50

CLAPTER 5. NATURAL BARRIER PERFORMANCE $\ldots \ldots \ldots \ldots \ldots \ldots \ldots$ 5-1

5.1 SALT STABILTTY $\ldots \ldots \ldots \ldots \ldots \ldots \ldots \ldots, \ldots \ldots \ldots$. . . . . . . . .

5.1 .1 Salt Dissolution . . . . . . . . . . . . . . $5-1$

5.1.2 Extrapolations of Geological Observations $\ldots \ldots \ldots \ldots \ldots \ldots, 5-2$

5.1 .3 Numerical Calculations $\ldots \ldots \ldots \ldots \ldots \ldots \ldots \ldots \ldots$

5.1 .4 Coupled-Process Analyses of Dissolution . . . . . . . . . 54

5.1 .5 Salt Flow $\ldots \ldots \ldots \ldots \ldots \ldots \ldots \ldots \ldots \ldots \ldots \ldots$

5.2 GROUND WATER TRANSPORT $\ldots \ldots \ldots \ldots \ldots \ldots \ldots \ldots$

5.2 .1 Continuum Models $\ldots \ldots \ldots \ldots \ldots \ldots \ldots \ldots \ldots, \ldots \ldots$

5.2 .2 Fractured Rocks $\ldots \ldots \ldots \ldots \ldots \ldots \ldots \ldots \ldots . . . \ldots \ldots$

5.2 .3 The Unsaturated Zone $\ldots \ldots \ldots \ldots \ldots \ldots \ldots \ldots . \ldots . \ldots .22$

5.2 .4 Colloid Transport $\ldots \ldots \ldots \ldots \ldots \ldots \ldots \ldots \ldots \ldots \ldots, 5-26$

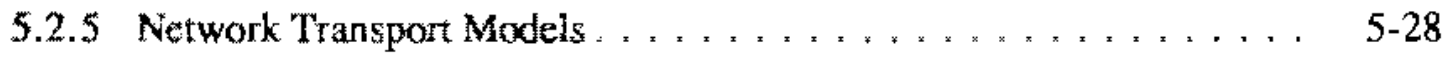

5.2 .6 Validity of the Solute Transport Equation $\ldots \ldots \ldots \ldots \ldots, 5-31$

5.2.7 Evaluation of Ground-Water Models . . , , , , , , , , . , , , 5-33

$\$ .2 .8$ Observations $\ldots \ldots \ldots \ldots \ldots \ldots \ldots \ldots \ldots \ldots \ldots \ldots . \ldots \ldots$

5.3 TRANSPORT IN SALT $\ldots \ldots \ldots \ldots \ldots \ldots \ldots \ldots \ldots \ldots \ldots$

5.4 GAS-PHASE TRANSPORT $\ldots \ldots \ldots \ldots \ldots \ldots \ldots \ldots \ldots$

5.4 .1 Gas Flow $\ldots \ldots \ldots \ldots \ldots \ldots \ldots \ldots \ldots, \ldots \ldots \ldots$

$\$ .4 .2$ Contaminant Transport $\ldots \ldots \ldots \ldots \ldots \ldots \ldots \ldots \ldots .5 .38$

5.5 RADIOLOGICAL ASSESSMENT $\ldots \ldots \ldots \ldots \ldots \ldots \ldots \ldots .5439$

5.5 .1 Exposure Pathway Analysis $\ldots \ldots \ldots \ldots \ldots \ldots \ldots \ldots, 5.41$ 
5.5 .2 Dosimetry $\ldots \ldots \ldots \ldots \ldots \ldots \ldots \ldots \ldots \ldots \ldots \ldots, 5 . \ldots \ldots$

5.5 .3 Health Effects Estimation . . . . . . . . . . . . . . . 54.3

CHAPTER 6. SENSITVITY AND UNCERTAINTYY ANALYSIS . . . . . . . . $6-1$

6.1 SENSTTIVITY ANALYSIS METHODS $\ldots, \ldots, \ldots, \ldots, \ldots, 6,2$

6.1.1 Deterministic Approach to Sensitivity Analysis . . . . . . . . . 6 -3

6.1 .2 Statistical Approach to Sensitivity Analysis $\ldots \ldots \ldots \ldots \ldots \ldots$. 6.4

6.1 .3 Comparison of Sensitivity Analysis Methods . . . . . . . . $6-5$

62 UNCERTAINTY ANALYSIS $\ldots \ldots \ldots \ldots \ldots \ldots \ldots, \ldots \ldots, \ldots \ldots$

6.2 .1 Statistical Methods for Spatial Variables . . . . . . . . . . .

6.2 .2 Perturbation Methods $\ldots \ldots \ldots \ldots \ldots \ldots \ldots \ldots \ldots \ldots, 6 \ldots \ldots$

6.2 .3 Simulation . . . . . . . . . . . . . . . . . . . 6 6-13

6.2 .4 "Deterministic" Uncertainty Analysis . . . . . . , , . . . , , . 6.18

6.2 .5 Comparison of Perturbation and Statistical Methods
of Uncertainty Analysis . . . . . . . . . . . . . . 6 6-20

CHAPTER 7. NATURAL ANALOGUES $\ldots \ldots \ldots \ldots \ldots \ldots \ldots \ldots$

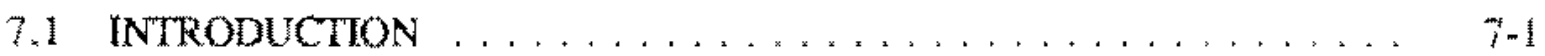

7.2 SUBSYSTEM ANALOGUES $\ldots \ldots \ldots \ldots \ldots \ldots \ldots \ldots \ldots .2$

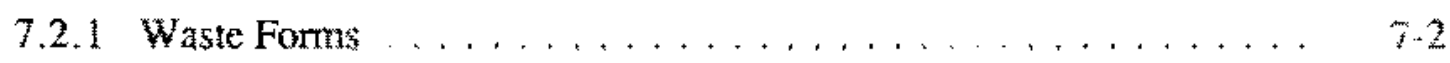

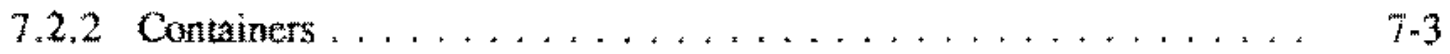

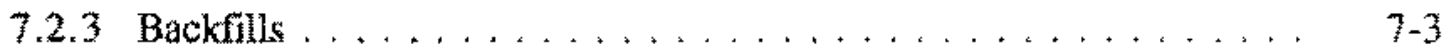

7.2 .4 Cement Seals $\ldots \ldots \ldots \ldots \ldots \ldots \ldots \ldots \ldots \ldots \ldots .4 .4$

7.2 .5 Alterations of Salt Beds . . . . . . . . . . . . 7.4

7.2 .6 Ground Water Transport and Nuclide Migration $\ldots \ldots \ldots \ldots .7-5$

7.3 INTEGRATED SYSTEM ANALOGUES $\ldots \ldots \ldots \ldots \ldots \ldots \ldots$

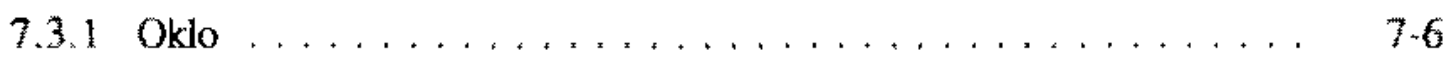

7.3 .2 Alligator Rivers Project, Austratia $\ldots \ldots \ldots \ldots \ldots \ldots \ldots$

7.3.3 Cigar Lake Uranium Deposit $\ldots \ldots \ldots \ldots \ldots \ldots \ldots \ldots$ 
7.3 .4 Pocos de Caldas $\ldots \ldots \ldots \ldots \ldots \ldots \ldots \ldots \ldots \ldots$

7.4 APPLICATION OF NATURAL ANALOCUES $\ldots \ldots \ldots \ldots \ldots$

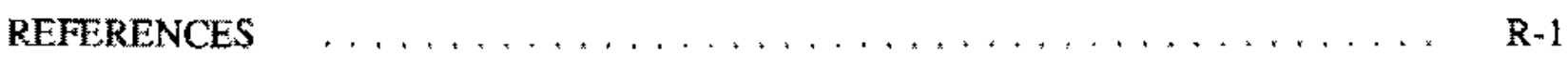


1

-

' 


\section{FIGURES}

2-1 Generalized Event Tree Discussed by Hunter $\ldots \ldots \ldots \ldots \ldots \ldots \ldots$

$2-2$ An Event Tree Constructed by the Method of Cranwell et al. . . . . . . . . 2-8

3.1-1 Generalized Repository Scale Thermal Model Description . . . . . . . . . . . 3-4

3.1-2 Generalized Waste Emplacement Room Scale Thermal

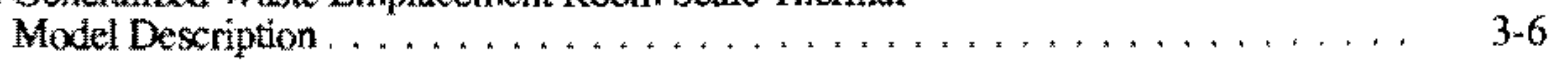

3.1-3 Generalized Spent.Fuel Waste Package Scale Thermal

Model Description . . . . . . . . . . . . . . . . . . . . 3-8

3.7-1 Interrelationships of Thermo-Hydro-Mechanical Processes

in the Geosphere $\ldots \ldots \ldots \ldots \ldots \ldots \ldots \ldots \ldots \ldots \ldots \ldots \ldots . \ldots \ldots$

4-1 A Hypothetical Waste Package Design $\ldots \ldots \ldots \ldots \ldots \ldots \ldots, \ldots \ldots \ldots$

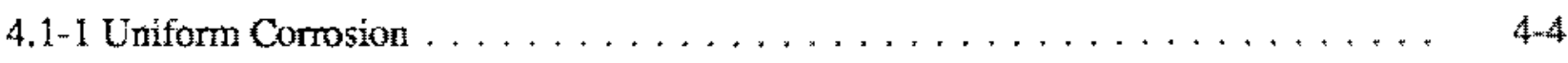

4.1 .2 Galvanic Corrosion $\ldots \ldots \ldots \ldots \ldots \ldots \ldots \ldots \ldots \ldots \ldots . \ldots \ldots$

4.1-3 Schematic Representation of the Pitting Mechanism . . . . . . . . . . 4-9

4.1-4 Pit Propagation Monitor $\ldots \ldots \ldots \ldots \ldots \ldots \ldots \ldots \ldots \ldots \ldots \ldots .12$

4.1-5 Crevice Formed by Shielding the Metal From the Environment

in the Presence of Chloride or Other Aggressive tons $\ldots \ldots \ldots \ldots \ldots \ldots$ 4-13

4.1-6 Intergranular Corrosion Oecurring at a Carbide Inclusion

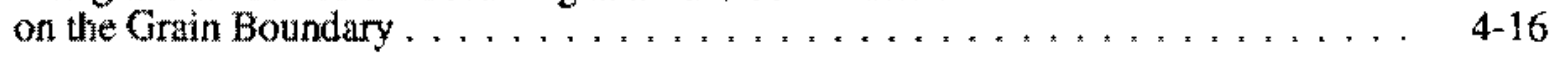

4.1-7 Comparison of Two Materials with Differing Susceptibility to $\mathrm{SCC} \ldots \ldots \ldots$. . . . .

4.2-1 Chambré's Model for Flow of Ground Water Past a Waste Cylinder . . . . . . 4.25

4.2-2 Schematic Variation of Free Energy of Silica as it Dissociates

From Glass, in the Model of Grambow . . . . . . . . . . . . . . 4-34

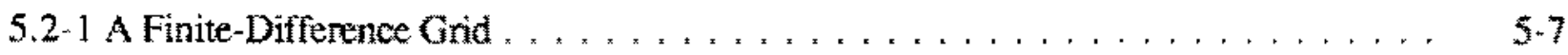

$5.2-2$ A Typical Path Network $\ldots \ldots \ldots \ldots \ldots \ldots \ldots \ldots \ldots \ldots \ldots . \ldots \ldots$

$5.5 \times 1$ Exposure Pathways to Man . . . . . . . . . . . . . . . . . . 540 
,

' 


\section{TABLES}

2-1 Phenomena Potentially Relevant to Scenarios for Waste Repositories . . . . . . . . 2 2-2

2-2 Marix of Sequences and Models Prepared by NAGRA . . . . . . . . . . . 2-11 
.

.

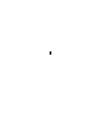




\section{CHAPTIR 1. INTRODUCTION}

\section{$1.1 \quad$ Purpose}

This report is intended as an overview of post-closure performance assessment methods for high-level radioactive waste repositories and is designed to give the reader a broad sense of the state of the art of this technology.

As described here, "the state of the art" includes only what has been reported in report, journal, and conference proceedings literature through August 1987; we have made no attempt to obtain up-to-date status reports on on going research in the Department of Energy repository projects or elsewhere.

\section{$1.2 \quad$ Scope}

There ix very large literature on the perfomance of high-level waste repositories. In order to make a review of this breadth manageable, its scope must be carefully defined. The essential principle followed is that only methods of calculating the long-term performance of waste repostories are described. Methods of field and laboratory testing, descriptions of repository sites, models used in repository design, and results of field work, inboratory tests, and calculations are all outside the scope of the report, although they are discussed when necessary to motivate mathematical models or assess their validity. Some relatively peripheral kinds of predictive models, such as models of climate change and models of air dispersion of radioactive dust after a volcanic eruption through a repository. have also been onitted.

The present report build on an earlier review of the sume subject matter by Ross (1984). Because of the limited availability of the 1984 report, material from it that has not been superseded has been incorporated into this document. 


\subsection{Organization of the Report}

The report is organized to reflect, in a generalized way, the logical order of steps that would be taken in a typical performance assessment.

Chapter 2 describes ways of identifying scenarios and estimating their probabilities. Chapter 3 presents models used to determine the physical and chemical environment of a repository, including models of heat transfer (Section 3.1), radiation (3.2), geochemistry (3.3), rock mechanics (3.4), brine migration (3.5), radiation effects on chemistry (3.6), and coupled processes (3.7).

The next two chapters address the performance of specific barriers to release of radioactivity. Chapter 4 treats engineered barriers, including containers (4.1), waste forms (4.2), backfills around waste packages (4.3), shaft and borehole seals (4.6), and repository design features (4.5 and 4.7). Chapter 5 discusses natural barriers, including ground wate: systems (5.2) and stability of salt formations (5.1).

The final chapters address topics of general applicability to performance assessment models. Methods of sensitivity and uncertainty analysis are described in Chapter 6, and natural analogues of repositories are treated in Chapter 7.

\section{$1.4 \quad$ Authorship}

The broad scope of this review required the cooperation of individuals with many different specialties. The report thus results from a collaboration among Disposal Safety Incorporated, Battelle Pacific Northwest Laboratories, and consultants. Authors of the various sections of the report were the following:

Chapter 2

Sections 3.1 and 3.2

Section 3.3

Section 3.4

Section 3.5

Section 3.6

Section 3.7
Benjamin Ross

Martin K. Altenhofen

Janet S. Herman and Elizabeth Behl

Benjamin Ross

Steven Amter

Jeff Serne

Benjamin Ross and Barrie Klaits 
Section 4.1

Sections 4.2 through 4.7

Section 5.1

Section 5.2

Section 5.3 and 5.4

Section 5.5

Chapter 6

Chapter 7
Anne Van Orden

Benjarnin Ross

Benjarnin Ross, Steven Amter, and Barrie Klaits

Benjamin Ross and Steven Amter

Benjamin Ross

Dennis L. Strenge and B.A. Napier

Pamela L. Doctor

Steven Amter 


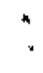

$\checkmark$

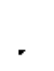

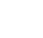




\section{CHAPTER 2. SCENARIOS}

Koplik at al, (1982) define a scenario as "a possible sequence of processes and events which is describable by equations involving specified physical parameters." Any repository safety analysis requires the identification of scenarios to analyze. In selecting scenarios, and in evaluating the significance of the consequences one calculates for each scenario, the analyst must also take into account the likelihood of the various scenarios. This chapter tiscusses the available methods of selecting scenarios and calculating their probabilities.

\subsection{Sceriario Selection Methods}

Three different approaches have been used to identify scenarios and choose significant ones for further analysis: simulation, event trees, and judgment. Koplik et al. (1982) describe the concepts behind these methods and review work on thern through the summer of 1980 . This section will summarize developments since that time.

All three methods begin from a list of potentially relevant physical processes and events. Such a list should be as complete as possible; one should therefore consider any physical phenomenon whose relevance has been suggested in the past. A working group of the International Atomic Energy Agency (1983) proposed a list of processes and events which incorporated previous work. This list, with a single addition (microbial activity), is reproduced as Table $2-1$.

Scenario identification methods address two distinet functions:

- Ensuring completeness of the list of mechanisms that are considered.

- Screening out irrelevant and incredible mechanisms so that a reasonably short tist of scenarios is produced. 
TABLE 2-1

Phenomena Potentially Relevant to

Scenarios for Waste Repositories

Natural processes and events

Climatic change

Hydrology change

Sea-level change

Denudation

Stream erosion

Glacial erosion

Flooling

Sedimentation

Diagenesis

Diapirism

Faulting/seismicity

Geochemical changes

Fluid interactions

- Ground water flow

- Dissolution

- Brine pocket
Uplift/subsidence

- Orogenic

- Epeirogenic

- Isostatic

Undetected features

- Faults, shear zones

- Breccia pipes

- Lava tubes

- Intrusive dikes

- Gas or brine pockets

Magnetic activity

- Intrusive

- Exrrusive

Meteorite impact

Microbial activity

Human activities

Faulty design

- Shaft seal fallure

- Exploration borehole seal failure

Faulty operation

- Faulty waste emplacement

Transport agent introduction

- Irrigation

- Reservoirs

- Intentional artificicial ground water techarge or withdrawal

- Chemical liquid waste disposal

Large-scale alteration of hydrology
Undetected past intrusion

- Undiscovered boreholes

- Mine shafts

Inadvertent future inrrusion

- Exploratory drilling

- Archaeological exhumation

- Resource mining (mineral, water, hydrocarbon, geothermal, salt, etc.)

Intentional intusion

- War

- Sabotage

- Waste recovery

Climate control

Waste and repository effects

Thermal effects

- Differential elastic response

- Nonelastie response

- Fluid pressure, density, viscosity changes

- Fluid migration

Mechanical effects

- Canister movement

- Local fracturing
Chemical effects

- Corrosion

- Waste package-rock interactions

- Gas generation

- Geochemical alterations

Radiological effects

- Material property changes

- Radiolysis

- Decay-product gas generation

- Nuclear criticality 
There is a heavy focus on the second function in the literature, suggesting that development of reliable screening methods may not be straightforward.

\subsubsection{Simulation Methods}

The principal development in scenario simulation since 1980 has been the completion and generalization of the Pacific Northwest Laboratory (PNL) Geologic Simulation Model (GSM). The GSM code is specifically tailored to the Pasco Basin, in which the Hanford site is located (Petrie et al., 1981; INTERA, 1983a). The GSM code uses rate equations to model the effects of continuing natural processes on the ground water system. In addition, sudden events may occur. The effects of various processes and events are combined in the code by linear superposition. Because it is not known whether certain events will occur, much less when, and because the values of many parameters are uncertain, the code is run in a Monte Carlo mode, in which repeated simulations are used to generate a statistical distribution of outcomes.

The input data requirements for this system are voluminous and include, among other things, 129 different probability distribution functions (pdfs), As the report by INTERA Environmental Consultants, Inc. (1983a), puts it, "the 129 pdfs currently used can . . be considered the driving fore behind the model," and so results from GSM deserve credence only to the extent that the pdf's are justified. The pdf's describe such variables as the "increase in hydraulic conductivity . . of Pasco Basin basalts due to earthquake in Rattlesnake or Yakima Ridge structures." Obviously, the pdf's used to describe these variables are necessarily very speculative, and so model results must also be considered speculative.

Other limitations of GSM are; (1) the ground-water model is two-dimensional, and (2) the model permits local permeable features to be created randomly by future events but does not allow small precxisting but undetected features to be included at random locations.

The GSM model was applied (Foley et al., 1982; Foley, 1982) to generate a 500 -sample Monte Carlo analysis of the future behavior of a repository in the Pasco Basin. The principal result was a pdf of ground-water travel time from the repository to the Columbia River over the next million years. The project that developed GSM did not use 
this result in its overall performance assessment of a Pasco Basin repository (Dove et al, 1982). The principal reason given by Dove et al for this omission was that GSMs conceptual model of ground-water flow had not been properiy calibrated against more detailed models.

FFSM, a non-site-specific model based on the same general principles as GSM, was developed by Hadlock and comworkers at Arthur D. Little, anc. (INTERA, 1983b). In addition to the regional ground water velocities that GSM emphasizes, this model gives future regional topography and the future existence of local features in the subsurface as outputs. It incorporates the following wide variety of cwents and processes:

- Undetected fealures.

- Climate.

- Glaciation.

- Folding,

- Diapirism.

- Magnatic events.

- Frulting

- Regional deformation.

- Geomorphic processes.

- Dissolution fronts.

- Brezcia pipes.

- Solution mining.

- Drilling.

Although FrSM is more general and more complete, it requires even mote input ditat than GSM. Thus, like GSM, the credibility of its outputs will be linited by the difficulty of obtaining rejiable inputs. No applications of the model have been reported.

\section{2,1.2 Event-Tree Analysis}

The most comprehensive recent work with event tress has been carried out by Regina Hunter, who continues the methods first used by Bingham and Bar (1979). In studies of the Yucca Mountain wut (Hunter et al. 1983) and Hanford basalt (Hunter, 1983) sites, Humer has developed elaborate event trees similar fo those Binghum and Bart used to 
describe the Waste Isolation Plot Plant in a salt bed in New Mexico. Hunter (1983) summarizes her procedure as follow:

Scenarios were constructed in the form of diagrams that have been called "event trees ${ }^{z}$ or "combinations of release and transport phenomena, hereinafter called "trees." The furst entry in the tree is a brief description of an event or process that might begin a sequence of phenomena leading to a release of radionuclides from the repository. "This initial event or process can be called a "breaching avent" or a "release phenomenon." Below it ane writen brief descriptions of other phenomena, called "transport phenomena," that could conceivably be second steps, third steps, and so forth, in sequences leading to radionuclide release.... No transport phenomena that might enhance, rather than degrade, the effectiveness of the repository are considered. Each phenomenon considered has been given a reference number to simplify the discussion of events, scenarios, and probabilities. The process of adding steps continues until each sequence has reached a final step in which radionuclides enter the biosphere.

Roberds et al. (1984) refer to such trees as "scenario trees" and reserve the term "event rees" for trees containing only discrete events, but we will adopt Hunter's definition. Figure 2-1 shows two ters of a generalized event tree as discussed by Hunter.

Cranwell et al. (1982) and Roberds et al. (1984) propose interesting systematizations of the event-tree approach to scenario selection. Cranwell et al. suggest the following steps:

1. An initial comprehensive identification of relevant events, features, and processes.

2. Classification of the events, features, and processes along two dimensions: natural, repository-induced, and human-induced; and (2) relextse phenomena those occurring in the near vicinity of the underground workings or capable of cansing release directly to the surface) and transport phenomena (those whose major effect is to influence the transport of radionuclides in ground water).

3. An initial screening of events, features, and processes based on physical reasonableness, probability of inducing significant rationuclide release, and potential consequences. 


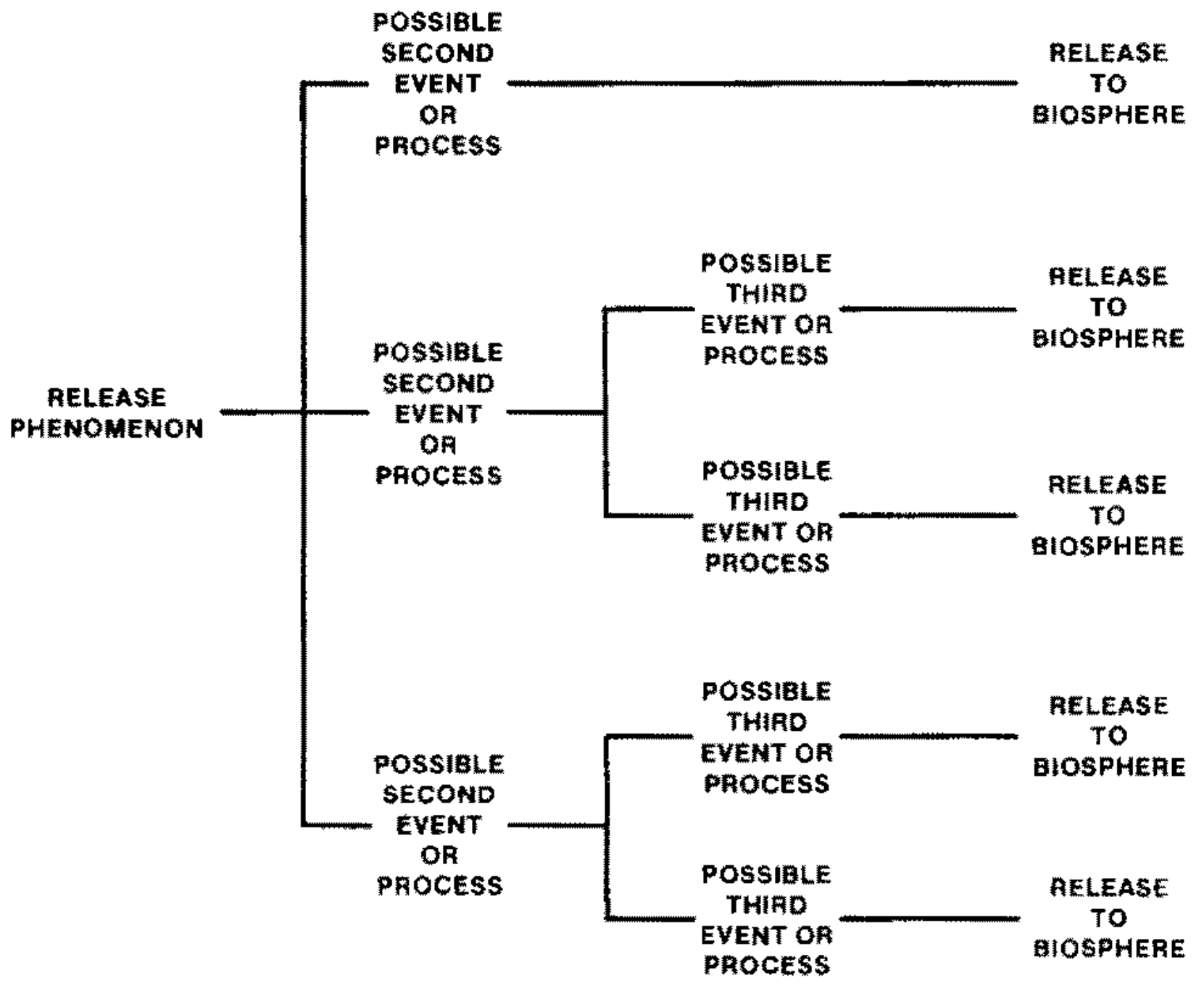

Figure 2-1. Generalized event tree discussed by Hunter 
4. Development of scenarios from the remaining events, features, and processes by creating event trees. Figure 2-2 shows the event tree that would be constructed from two release phenomena and three transport phenomena.

5. An initial screening of scenarios, using the same criteria as in Step 2.

6. A final screening using detailed consequence and (to a lesser extent) probability arguments.

Roberds et al, suggest that one proceed as follows:

1. Identify pertinent system perforrance measures.

2. Develop a "process tree" which identifies, in a format similar to a fault tree, how a system's characteristics, processes, and events affect the performance of the system. Branches not significantly affecting performance should be proned out.

3. Identify all branches of the process tree that are potentially significant scenario components.

4. Combine the scenario components in an event tree, deleting all branches with sufficiently low probability.

5. Identify the remaining branches of the tree as scenarios for further analysis.

One problem Hunter points out in constructing event trees is that pairs of scenarios may or may nor be mutually exclusive, and in the majority of cases, it is unknown whether scenarios are mutually exclusive. Furthermore, many scenarios corresponding to different branches of the tree are, for all practical purposes, equivalent. For example, a variety of causes could yield water conduits through a repository with identical hydrailic properties. Hunter gives such scenarios the same name but different numbers. 


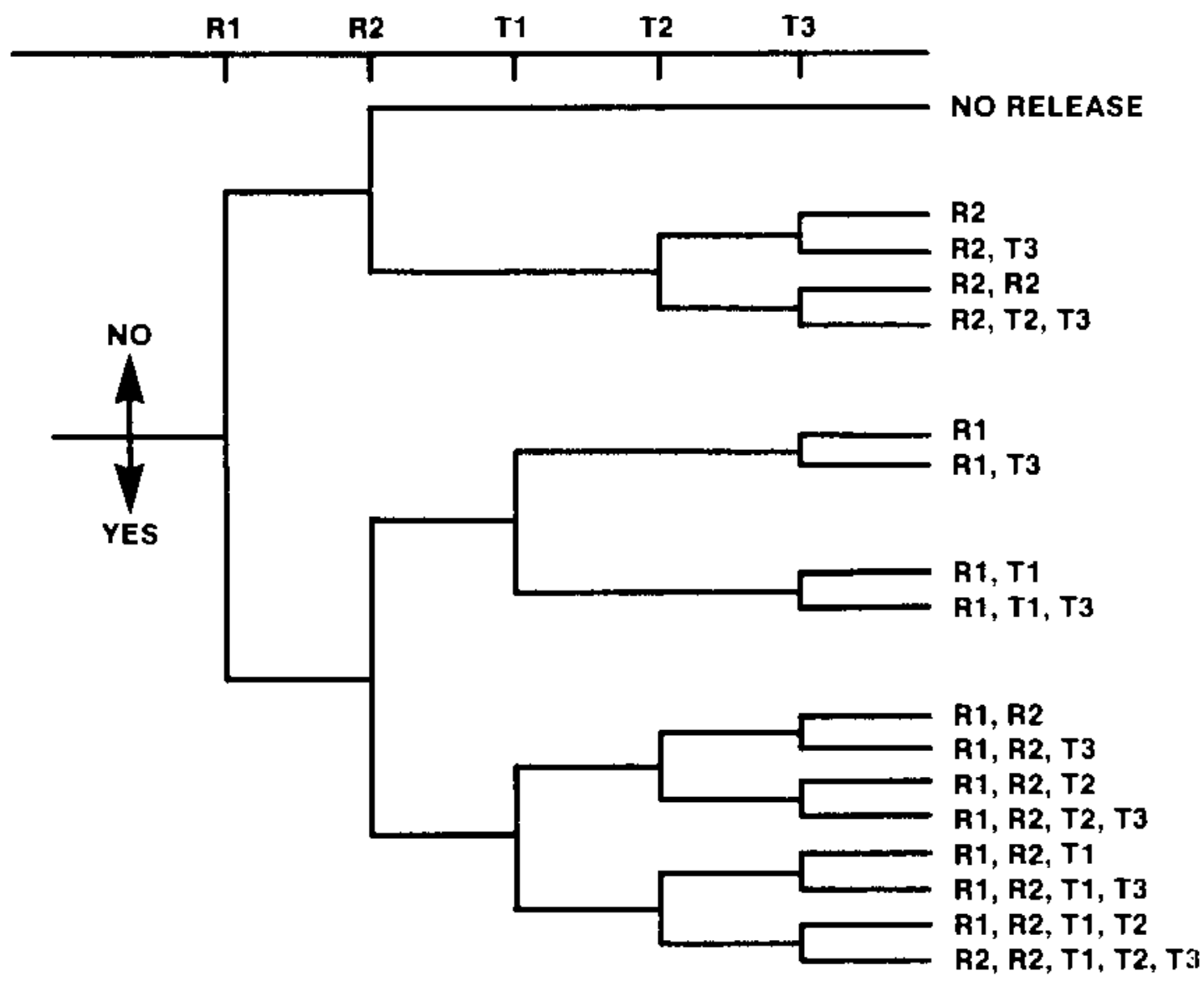

Figure 2-2. An event tree constructed by the method of Cranwell et al. 
Many of the scenarios that correspond to a branch of one of Hunter's event trees are described in rather general terms and would require further specification before a detailed analysis of consequences would be possible. "Fluids carry waste to the Columbia River or its tributaries" is a single event at the level of greatest detail in the basalt tree. Altemate conceptual models of the how regime near the repository are not distinguished as different branches of the tree. Even with individual scenarios so broadly defined, Hunter concedes, "the scenarios have not yet been screened down to a manageable number that are most likely to occur." "At the Hanford site, for instance, she identifies a total of 318 scenarios, of which several dozen have "probabilities" of 1.

As a rule, it appears that event tree methods are applied more easily in salt environments than in nonsalt environments. This is because undisturbed salt is essentially impermeabie, and a discrete event such as massive dissolution is generally required to induce waste release. In other media, release will occur without any disruptive event, with the effect of most disturbing processes being to merely change the rate and direction of the release. Consequently, a meaningful list of discrete branch points (which are needed to draw the trees) is hard to enumerate for nonsalt repositories.

A more general obstacle to the use of event trees seems to be the difficulty of reducing the number of scenarios to a manageable level. The last screening step in the method of Cranwell et al. (1982) is an effort to confront this problem, but it requires an analysis almost as detailed as the one that will be conducted on the final set of selected scenarios. As Roberds et al. (1984) point out, published event tree studies such as those of Hunter rely on the judgment of the authors to "prune" the tree down to a manageable size by eliminating tranches. This makes the results dependent on the opinions of arbitrarily selected individuals, leaving these studies open to the same criticisms as may be directed at purely judgmental methods of scenario development.

Another problem is that many of the branches in the trees represent possible misunderstandings of the initial situation rather than diserete random events. Branches that represent limited understanding are inherently difficult to eliminate by probability arguments: if we knew enough to estimate the probabilities of the branches at a screening step, the branch point likely would not appear on the tree at all. 


\subsubsection{Judgmental Methods}

Most repository performance assessments emumerate a small number of scenarios based on judgmental evaluation of atematives. This is the approach used by the Deat Smith County and Yucca Mountain Envimonental Assessments and the Multi-Atribute Utility Analysis (USDOE, 1986) as well as KBS (1983), Amet et al. (1980), Woolfolk and Baer (1983), Dove et al. (1982), Harwell (1982), Brüggeman et al. (1985), ELSAM (1981), and several studies reported by the International Atomic Energy Agency (1983), These reports vary in the degree to which they discuss scenarios that were eliminated from consideration and in how explicitly they give criteria for ruling out scenarios.

More detailed variants of judgnental scenario selection were applied to a granite repository in nothern Switzerland by NAORA (1985) and the Yucca Mountain site by Ross (1986a), In these studies, the repository system is decomposed into several bariers (Ross) or models (NAGRA). The IAEA list of events and processes is reviewed and sequences of events potentualy degrading the performance of on or more bariers or models are identiffed. This does not yet constitute a list of disruption scenarios, because there is sufficient redundancy in the system that many failures would not cause unacceptable performance of the entire system. NACRA then distinguishes between events and processes that can be described by changing the values of parameters in the baseline models of the system, and those that reguire new conceptual tnodels, producing a matrix shown in Table 2-2. Rosess study simply states that further analysis will be required to idenuty those credible barrier fallure sequences or combinations of sequences which have the potential of leading to unacceptable system perfomance; it is these that will be the disruption scenarios to be analyzed for this system.

There is eonsiderable similarity between the approach of these wo studies and the strategy of Roberds et al. (1984) etscussed in the previous section. The barrier failare sequences correspond to the scenario components to be identifted in Step 3 of Roberds' scheme. The distinct barriers of Ross or models of NAGRA would be brandhes on Roberds process tres. However, these two stuties do not explicity draw any trees. They rely (Ross only implicitly) on a matrix approach insted, examining the affect of each fundamental mechanism from the IaEA list on each barrier or model. This work has not yet reached Step 4 and 5 of the Roberds strategy, and it ramins to be seen what fomalism will be used at that point. 
Table $2-2$.

Matrix of sequences and models prepared by NAGRA (1985)

Scenario mectranism

Model chain

\section{RH LH NFH C NFC SL L RNTNF RNTFF RNTB}

Slow natumal processes

- climaric changes without glaciation wh glaciation

- erosion

fuvial glacial

-. sedimentation

- Lectonic crustal movement

- volcanism

- diagenesis

- metamorphosis

- weathering, mineralisation

Rapid natural events

- earthquakes

- meteor impact

- movements at faults

- new formation of frults

Repository and waste induced ofte

- radiation damage

- radiolysis

- carister movement in backfill

- decompressed zones

-mechanical canister damage

- differing thermal expansion of host rock zones:

- thermal convection

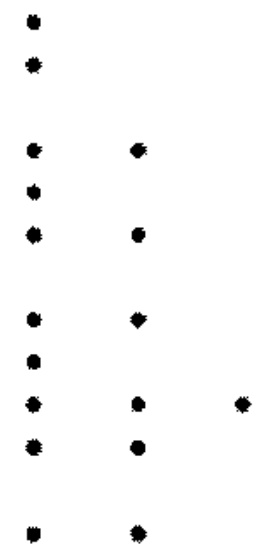


Table 2-2. Continued

Matrix of sequences and models prepared by NAGRA (1985)

Scenario mechanism

Model shain

\section{RH LH NFH C NFC SL $L$ RNTNF RNTFF RNTB}

- gas production

- thermally induced chemical changes

- resaturation

- chemical changes through corrosion

- colloid formation

-. microbiological processes

- failure of shatr sealing

Processes and events caused by man

- Direct changes in hydrology

- injection of liquid waste

- drilling into sediments

- geothermal energy production in crystalline rock

Legend

- Direct parameter change

o Change in conceptual model

RH Regional hydrology

LH Local hydrology

NFH Near-field hydrology

NFC Near-field chemistry

L. Leaching waste matrix
SL. Chemical speciation

C Canister corrosion

RNTNF Radionuclide transport-near-field

RNTFF Radionuelide transport-far-field

RNTB Biosphere transport 
Another approach to the systematic use of expert opinion is the "Delphi method". The Delphi technique generally consists of the following steps:

- Selection of an appropriate panel of experts.

- Initial administration of a written questionnaire that is accompanited by pertinent background information.

- Written summarization of the responses.

- Re-administration of the questionnaite, accompanied by the written summarization of previous responses, with instructions that prior tesponses should be reevaluated in light of panel feedback. This step thay be repeated to obtain more consensus.

Davis and Runchal (1984) uscu the Delphi technique to identify scenarios for the Hanford site. The Delphis panel added 13 scenarios to a list of 32 that had previously been prepared by project staff and consultants.

Comparison of the detailed scenario identification studies by Ross (1986a) and Davis and Runchal (1984) sheds some light on the different contributions that can be made to scenario identification by scenario analysts within project teams and pantels of outside experts. As more information becomes available about repository sites, scenarios can be described in more detail. Outside experts tend not to have a sufficient knowledge of the site configuration and repository design to effectively draw up a complete list of scenarios. On the other hand, it is nearly impossible for one or a few analysts to have a sufficiently broad technical background and imagination to be complete. Perhaps the strengths of both types of contributor can be drawn on by having outside experts teview reports like Ross's for completeness.

\subsection{Probabilities}

The 7 years since the preparation of the review by Koplik et al. (1982) have been notable for the lack of new initiatives in the area of calculating scenario probabilities. The few performance assessments that present numerical probabilities (such as USDOE, 1986a) continue to rely heaviy on judgmental estimates. This is noteworthy in view of the incentive for such calculations created by the U.S. Environmental Protection Agency's high-level waste regulations (USEPA, 1985). What progress has been made is primarily in refining earlier work. This includes work by Smith et al. (1982) for EPA, applications of 
the event tree and simulation methods described above, and a more recent attempt to use the Delphi method. These developments are discussed below.

\subsubsection{EPA Studies}

Smith et al. (1982) revise earlier work by Arthur D. Little, Inc. (ADL, 1980). Smith et al. discuss "generic" repositories located in salt beds, salt domes, granite, basalt, and shale. In analyzing scenarios involving faulting, breccia pipes, volcanoes, and meteorites, they use the same methods as in the earlier ADL work and rely heavily on the conclusions of that study.

The argument Smith et al. use to reanalyze drilling is simple. They hypothesize that knowledge of a repository's existence and of the lack of mineral resources at the site woutd be re-forgotten every 50 years. At a salt site, this would lead to immediate drilling, giving an intrusion frequency of $2 \times 10^{-2}$ per year. The implicit assumption, that drilling rates in salt will continue indefinitely at the high levels associated with an oil-based economy, seems unlikely.

Smith et al. then state that drilling frequencies would be the same in shale and less by a factor of at least 2 in basalt and 10 in granite because basalt and granite are less likely to contain useful resources. The salt rate of $2 \times 10^{-2}$ per year is divided by these factors to obtain the drilling rate in the other media. Because the salt frequency is based on the rate of forgetting rather than on the attraction of the salt as an exploration target, the logic used to estimate drilling rates in other media seems somewhat dubious; it is difficult to imagire why someone living above a granite repository would have a better memory than someone living above a salt repository.

The drilling frequencies calculated in this way are important because drilling is the major contributor to EPA's calculations of risk, which in turn is a key element of the rationale for the proposed standards. Considering the compounding of arbitrary assumptions in these calculations, it is easy to agree with Smith et al.'s comment that "any structured mathematical estimate of drilling frequency into a potential repository site is not very meaningful" (p. 96). 


\section{2 .2 Simulation Models}

Many scenario studies have involved "generic" or hypothetical sites. In a study of a hypothetical site, what one hypothesizes is by definition a "true" description of the site. At real sites, on the other hand, alternative parameter values and conceptual models of the ground water system can be fertile sources of scenarios. Site-specific calculations of probabilities of groundwater flow scenarios are therefore of great interest. Such a calculation was carried out by the GSM model described in Section 2,1.1, for a repository located at Hanford.

The various subrodels in the simulation codes GSM and FFSM vary in the degree to which they have physical content or, at the other extreme, the degree to which they simply generate random events at aser-defined rate. In general, these models are at their most "physical" when predicting topography and phenomena (such as groundwater head) that depend on it. The models have the least physical content in dealing with suddon releaseinducing events such as the failure of a borehole seal or the formation of a breccia pipe; the resolution of a model in treating low-probability events is limited by the number of Monte Carlo samples and by the ability of the random number generator to produce small numbers.

With this in mind, the most interesting result of the GSM simulation of the Pasco Basin (Foley et al., 1982) is a likely glacial advance through Wallula Gap approximately 60,000 years from now. In a simulation, the glacier croded away the ridge that served as a control on erosion by past glacial floods. Subsequent fooding of the basin led to erosion, increasing hydraulic gradients and consequenty raising ground water velocities. Comparison of the predicted glacial advance with pretictions drawn from the geologic record by other means might be a useful way to try to evaluate the credibitity of at least parts of the GSM model.

\subsubsection{Event Trees}

Like the event trees constructed by Bingham and Barr (1979), the event rees Hunter constructs are used to assign "relative probabilities" to the scenarios. Hunter does this by assigning probabilities to each event or process for each of four time periods: 0 to 100 years, 100 to 1,000 years, 1,000 to 10,000 years, and 10,000 to 100,000 years. The 
probability of each scenario (for periods of $100,1,000,10,000$ and 100,000 years) is found by multiplying together the probabilities of the appropriate events and processes. For example, if independent events $A$ and $B$ each have a probability of occurrence of $10^{-5}$ per year, the probability of each occurring within 1,000 years is $9.95 \times 10^{-3}$, and the probability of both oceurring within that period is $9.9 \times 10^{-5}$.

The event and process probabilities are taken, when possible, from data or expert opinion. Often, qualitative expert opinions have to be translated into numbers. In such cases, the following guide is used by Hunter (1983) to assign values to the total probability of occurrence of an event or process over the time period of concern:

1 Very likely or certain, or unknown (for conservatism).

$10^{-1} \quad$ Less than certain, but reasonably likely,

$10^{2}$ Not likely, but cannot be ruled out.

10-3 Probably will not occur (frequently used to indicate that the available data show that the event or process will not occur, but that the available data are questionable).

$10^{4}$ Very unlikely, based on reliable data.

$10^{-5}$ Extremely unlikely.

10-6 Physically possible, but aimost certain not to occur.

$0 \quad$ Assumed to be physically impossible, based on the currently available duta.

Hunter emphasizes that:

The probabilities assigned in this report, even though based on the available data, cannot be used in the same way that, say, the probability of 5 of heads in the flip of a coin can be used in deciding a tied election. The probabilities in this report are designed only to indicate areas of additional information needs. Furthermore, the probabilities are only relative.

Hunter also points out that such probabilities cannot be directly multiplied by consequences to obtain an overall measure of "risk" 


\subsubsection{Delphi Method}

The Delphit panel which identifed scenarios at the Hanford repository site toee Section 2.1.3) also estimated the probabilities of the scenarios. The panel members werc presented with a list of 45 potential repository disruptions and were asked to classify their chances of ever occurring as "reasonably foreseeable" (probability $>10^{-2}$ ), "very unlikely" $\left(10^{4}<\mathrm{p}<10^{-2}\right)$, or "extremely unilkely" $\left(\mathrm{p}<10^{-4}\right)$.

The panelists were not instructed about what methods to use in making these classifications. The reasonably foreseeable and very unlikely phenomena, in tum, were further divided into categories of anticipated and unanticipated phenomena on the basis of evidence of occurrence during Quatemary time.

The first attempts of this panel to estimate probabilities yielded conțiderable disagreement. In only 9 of the 45 potential disruptions was a consensus reached, and in 19 of them, not even 75 percent agreement could be obtained. If a scientific consensus is needed to support judgmental probability estimates, this experience suggests that it will not be easily obtained. On the other hand, the method does provide a clear record documenting how different opinions and comments contribute to what agreement is reached.

\section{$2.3 \quad$ Observations:}

The progress reviewed above does not present an encouraging picture when viewed against the requirements presented by some interpretations of the EPA high-level waste standard. The U.S. Nuctear Regulatory Commission has stated (U.S. Nuclear Regulatory Commission, 1986, p. 22291) that wnder that standard:

DOE must, to the extent practicable, combine these estimates into an overall probability distribution displaying the likelihood that the amount of radioactive material released to the environment will exceed specified values.

Work published to date presents several techniques for combining probabilities of various events and processes to yield an overall scenario probability. But it seems that, since 1980 , researchers in the field of repository safety have largety abandoned the effort to develop probability estimates for the elemental events and processes. The principal exception to this observed trend, 学共 analysis of the probability of fault movement in a 
tectonically active area by Kimball et al. (1987), underscores this point by its narrow scope. This trend is probably stimulated by the difficulties encountered in earlier work (Koplik et al, 1982; see also Kocher et al., 1983).

Recent publications discussing scenario probabilities (such as NAGRA, 1985, and Hunter et al., 1986a and 1986b) concede that it will not be possible to calculate the probabilities of many scenarios. In these works, it is suggested that such scenarios be screened to eliminate those with small consequences, with probabilities of the rest estimated by expert opinion. It appears that a technical consensus has emerged on the impossibility of obtaining probabilities of many scenarios by any means other than exper judgment. 


\section{CHAPTER 3. ENVIRONMENTAL CONDITIONS}

\section{$3.1 \quad$ Heat Transfer}

Heat transfer calculations are necessary to predict the temperatures of waste package components, repository seal components and the surrounding host rock. As discussed in Section 4, temperatures can have both direct and indirect effects on waste package and repository system performance. This section provides the basic equations used to describe the fundamental heat transfer modes, when they are important in repository performance assessment models and a typical modeling approach for predicting repository and waste package component temperatures.

There are three fundamental modes of heat transfer: conduction, convection and radiation (Welty ef al., 1976). The mechanisms for conductive heat transfer are molecular interaction and "free" electron energy exchange. The basic equation used to describe heat conduction is given by

$$
\mathrm{q}=-k \mathrm{~W}
$$

where $\mathrm{q}$ is the heat flux $\left(\mathrm{W} / \mathrm{m}^{2}\right), k$ is the themal conductivity $(\mathrm{W} / \mathrm{m} \cdot \mathrm{K})$, and $\mathrm{VT}$ is the temperature gradient $(\mathrm{K} / \mathrm{m})$. Equation $(3.1-1)$ is in vector form and known as Fourier's first law of heat conduction. The thermal conductivity of the conducting material may be non-isotropic, temperature dependent, or in the case of gases under high pressure, pressure dependent.

Convective heat transfer inwolves the entergy exchange between a surface and an adjacent fluid. The basic equation used to describe forced and natural convective heat transfer is given by

$$
q / A=h \Lambda T
$$


where $q$ is the heat transfer rate (W), $A$ is the area nonmal to the direction of heat flow $\left(\mathrm{m}^{2}\right), h$ is the convective heat transfer coefficient $\left(\mathrm{W} /\left(\mathrm{m}^{2}, \mathrm{~K}\right)\right.$ ), and $\Delta \mathrm{T}$ is the temperature difference between the solid surface and the fluid $(K)$. Equation $(3.1-2)$ is known as the Newton rate equation and used to define the convective heat transfer coefficient. The host transfer coefficient is a function of systern geometry, fluid and flow properties, and the magnitude of the temperature gradient.

Radiation affers from conduetion and convection in that no medium is required for energy transfer. The basic eguation used to describe ragiative heat transfer from a perfect radiator (i.e. black body) is given by

$$
q A=\sigma q
$$

where $q$ is the hest transfer rate $(W), A$ is the area of the emitting surface $\left(m^{2}\right)$, $\sigma$ is the Stefan-Boltzmann constant $\left(5.672 \mathrm{Wm}^{-2} \mathrm{~K}^{-4}\right)$, and $T$ is the absolute temperature of the sold surface (K). Equation (3.1-3) is known as the Stefan-Boltzmann law of themal radiation. Modifications to Equation $(3,1-3)$ are made to account for deviations from black body behavior ard geometric considerations.

Repository heat transfer is nomally dominated by conduction but may also involve convection and radiation, depending on site-specifite geohydrotogic conditions and repository design considerations. The methods used for repository system heat transfer analyses should have the following attributes, unless it can be shown that an alternative method tous an insignificant impact on the calculated results (Clabone et al., 1987):

- threc-dimensional geometry

- multiple regions and material inturfaces

- temperature-dependent material themal properties

- time-dependent heat generation source tem sharacteristics

- conduction, convection and radiation has transfer mode capability

General-purpose heat conduction codes, such as HEATNG5 (Tumer at a1., 1977) or ANSYS (Swanson, 1986), are suitable for evaluating repository systems dominated by thermal conduction. Using HEATNOS, the transient solution can be calculated by the 
implicit finite-difference technique (Crank-Nicholson or Backwards Euler) for problems with materials which are not allowed to undergo a phase change. HEATING5 has been verified by comparing the results with analytical solutions for 10 heat conduction problems, including problems with applied surface temperature or flux, temperature-dependent thermal conductivity, and time-dependent heat generation (Insalaco, 1987). HEATING6, an upgraded version of HEATING5, is available with SCALE: A Modular Code System for Performing Standardized Computer Analysis for Licensing Evaluations (ORNL, 1984). ANSYS is a widely used, general purpose finite-element code with both thermal and structural analysis capability. Several other heat conduction codes are available and have been used extensively for repository heat transfer calculations.

General purpose hydrothermal codes, such as TEMPEST (Eyler et al., 1983) and HYDRA (McCann, 1980; McCann et al., 1987 were developed for nuclear energy system applications and are recommended when convective heat transfer (e.g. room ventilation) is an important consideration. State-of-the-art thermal-hydrologic codes such as TOUGH (Pruess, 1986) and GEOTHER (INTERA, 1983e; Bian et al., 1987) were developed for geothermal energy and repository system applications and are recommended when two-phase groundwater flow and energy transfer (e.g. boiling and condensation) are important considerations. A description of coupled thermal-hydrologic process codes for repository performance applications is given in Section 5.2.3.

Repository and waste package heat transfer analysis involves the development of several different scale thermal models of the repository system (Altenhofen, 1981). The physical dimensions of these models are dependent on the underground repository layout, waste emplacement configuration, and waste package design. The following model development approach is given for illustrative purposes and generalized for a hypothetical repository system design description.

Figure 3.1-1(a) shows a plan view of typical spent fuel repository layout. The shaft pillar and main access corridor are shown to be centrally located along the line of symmetry between the waste emplacement panels. Separate panels are designated for pressurized and boiling water reactor (PWR and BWR) spent fuel and other high-level waste types. Within each panel, sub-regions may be specified for the waste heat characteristics (due to waste 


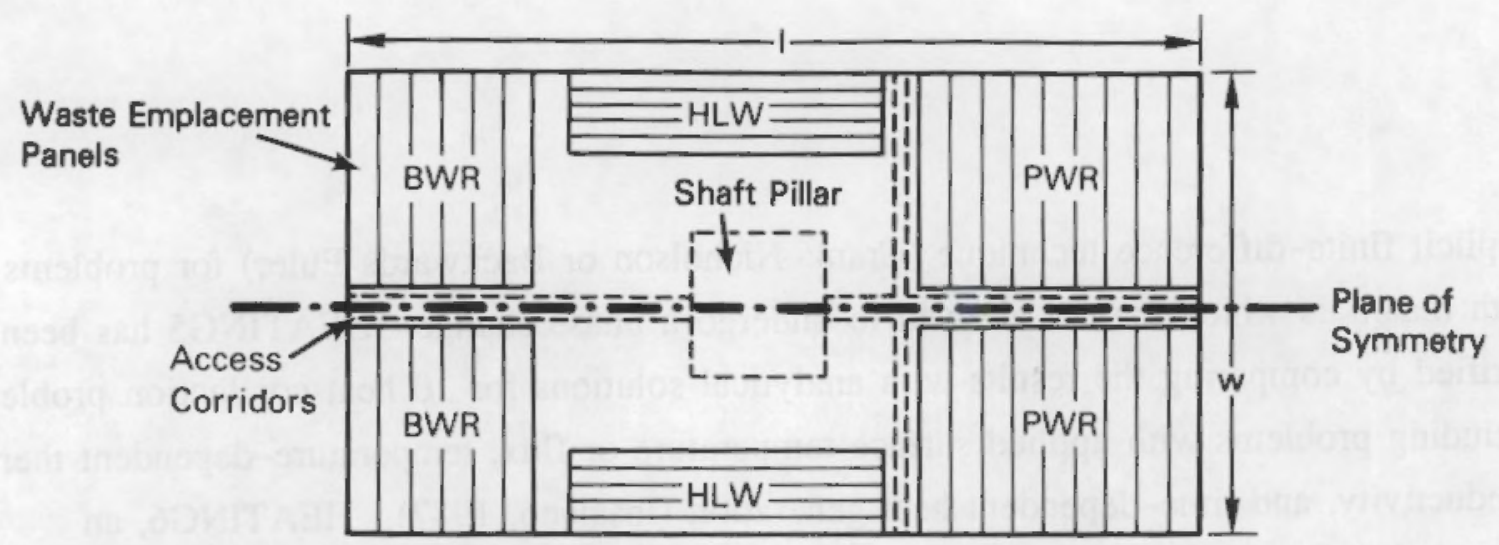

(a) Typical Repository Layout - Plan View

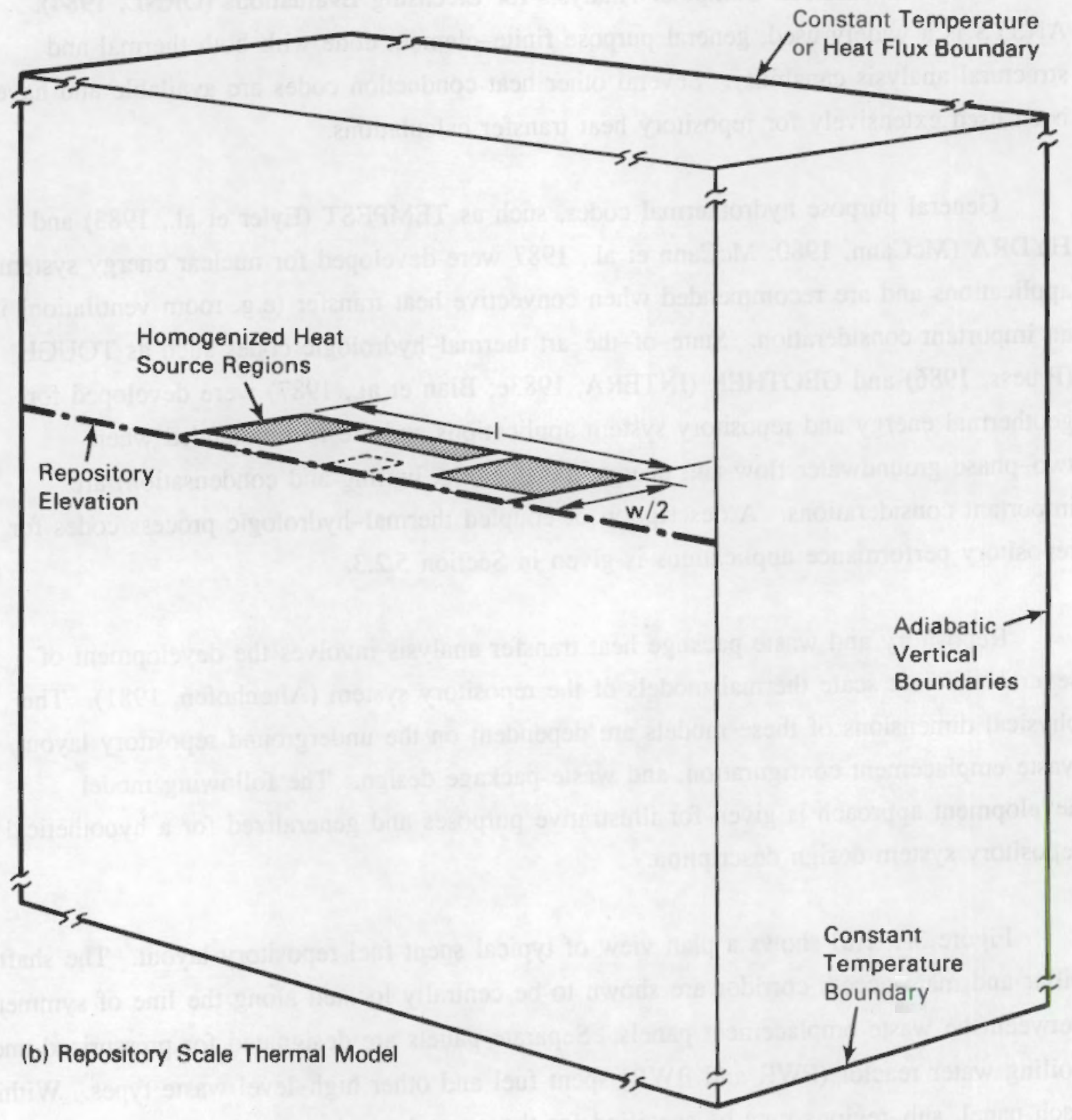

Figure 3.1-1. Generalized Repository Scale Thermal Model Description. 
age and exposure variations) or the waste emplacement schedule (with each sub-region representing an incremental time period of waste receipts).

A three-dimensional model for the repository layout is shown in Figure 3.1-1(b). An adiabatic (zero flux) vertical boundary condition is applied at the symmetry line of the repository layout. In this case, the individual heat generating source regions are assumed to be symmetric with respect to heat generation rate characteristics and specified within each emplacement panel. Symmetry may also exist at the repository elevation if stratigraphic features and geothermal temperature gradients can be neglected in the heat transfer calculations. The remaining vertical boundaries are adiabatic and specified at a distance sufficiently large enough not to influence the near-field repository temperatures. The horizontal boundaries are specified as constant temperatures based on the geothermal temperature gradient observed prior to emplacement. At ground surface, a constant heat flux boundary condition (simulating atmospheric conditions) may be used for repository systems that are constrained by surface temperature rise. The repository scale model provides far-field and near-field repository system temperatures throughout the 10,000-year isolation period.

Figure 3.1-2(a) shows plan and elevation views of a typical repository waste emplacement configuration. The waste package boreholes are vertically oriented and centrally located along the emplacement tunnels. A three-dimensional room-scale model for this waste emplacement configuration is shown in Figure 3.1-2(b). The vertical boundary conditions are adiabatic and specified at the planes of symmetry between adjacent boreholes and emplacement rooms. Rectangular coordinates are used for room and borehole regions based on equivalent dimensional parameters. The horizontal boundary conditions are specified as constant temperatures at a distance sufficiently large not to influence the near-field host rock and borehole wall temperatures. The waste form, canister, and overpack materials are represented by a homogenized heat generating source region within the borehole.

The room scale model is deterministic in that it simulates an infinite array of simultaneously emplaced waste packages with identical heat generation rate source term characteristics. If the code permits, the near-field results of repository scale models can be used for horizontal boundary conditions to simulate waste package temperatures throughout 


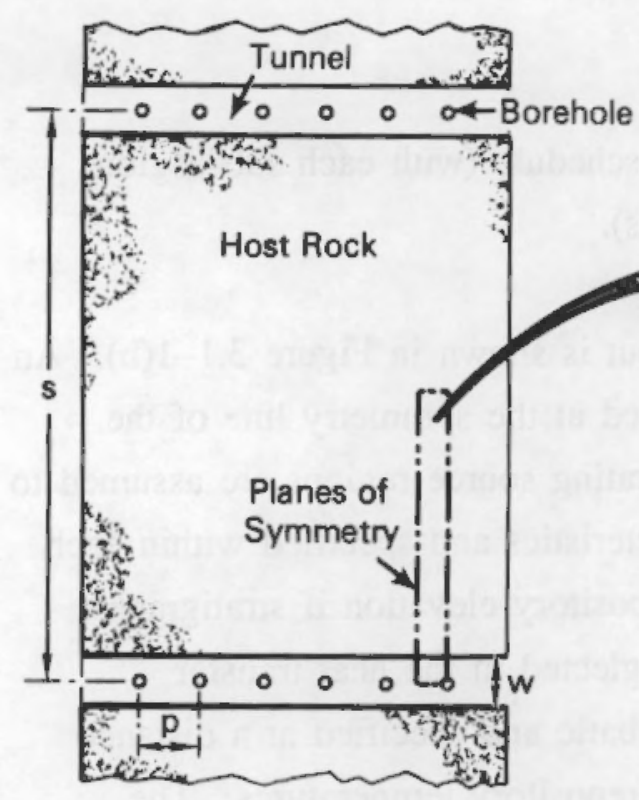

Plan View

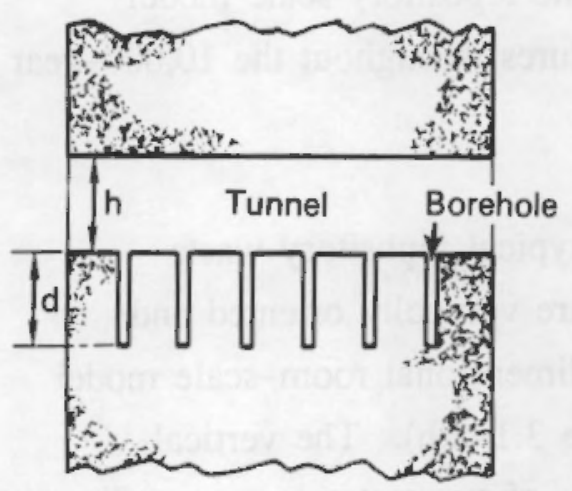

Elevation View

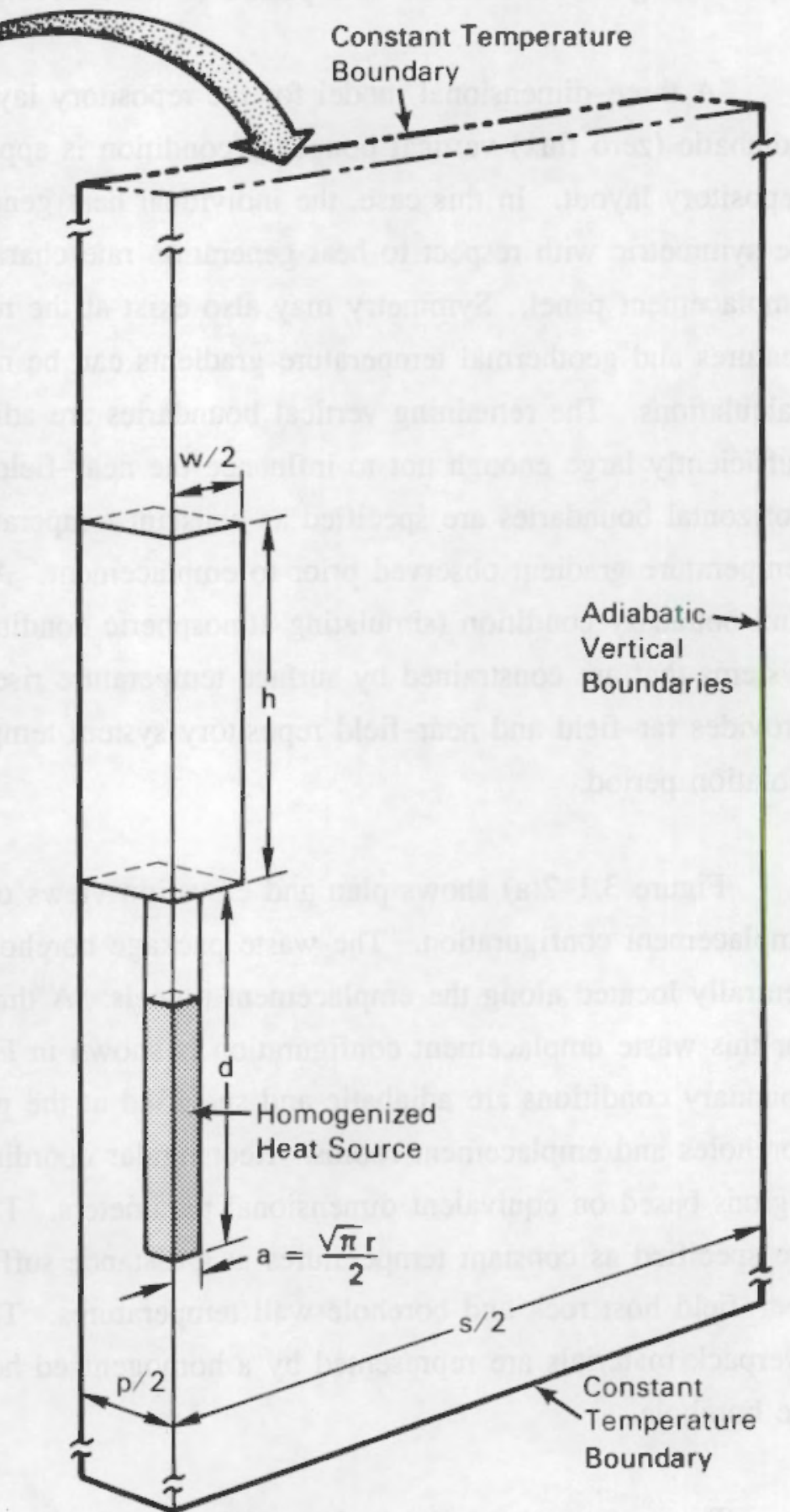

(b) Emplacement Room Scale Thermal Model

(a) Typical Emplacement Configuration Verticle Orientation

Figure 3.1-2. Generalized Waste Emplacement Room (Near-Field) Scale Thermal Model Description. 
the repository system. The tunnel and borehole regions are backfilled at some time after initial waste package emplacement. Generally, the room scale model is used to provide near-field and maximum borehole wall temperature estimates throughout the 1,000 year containment period.

Figure 3.1-3(a) shows a typical waste package design for spent fuel in the form of close-packed rods from consolidated assemblies. The waste package consists of metallic overpack, canister and internal fin components. The radial planes of symmetry correspond to the internal fin configuration. The internal fins are used for improved heat transfer from the spent fuel waste form and provide structural support to the canister. A non-metallic packing component (not shown) may also be included and used to fill the space between the overpack and borehole wall.

Figure 3.1-3(b) shows a two-dimensional model that simulates the spent fuel waste package configuration. The spent fuel rods are homogenized as an equivalent heat generating source region. Adiabatic boundary conditions are specified at the radial planes of symmetry. A constant temperature boundary condition is specified at the outer surface of the model. Steady-state calculations are made to evaluate the temperatures throughout the interior regions of the waste package. For problems which involve non-conductive heat transfer (e.g. radiative and convective heat transfer across air gaps) and/or temperature-dependent materials properties, the boundary temperature and heat generation rate should be consistent with the room scale model results.

The method used for repository heat transfer analysis is dependent on the level of accuracy required and site-specific repository system component designs. Closed form solutions (Carlsaw and Jaeger, 1959) can be used to approximate repository temperatures by using a simplified geometry and equivalent material thermal properties for repository system components. Rigorous thermal-hydraulic computer codes, such as COBRA-SFS (Rector et al., 1986), are designed to predict individual spent fuel rod thermal performance during dry storage.

\section{2 $\quad$ Radiation Field}

Radiation shielding calculations are necessary to predict the dose rates to the waste package components and near-field host rock. As discussed in Section 3.6, the radiation 


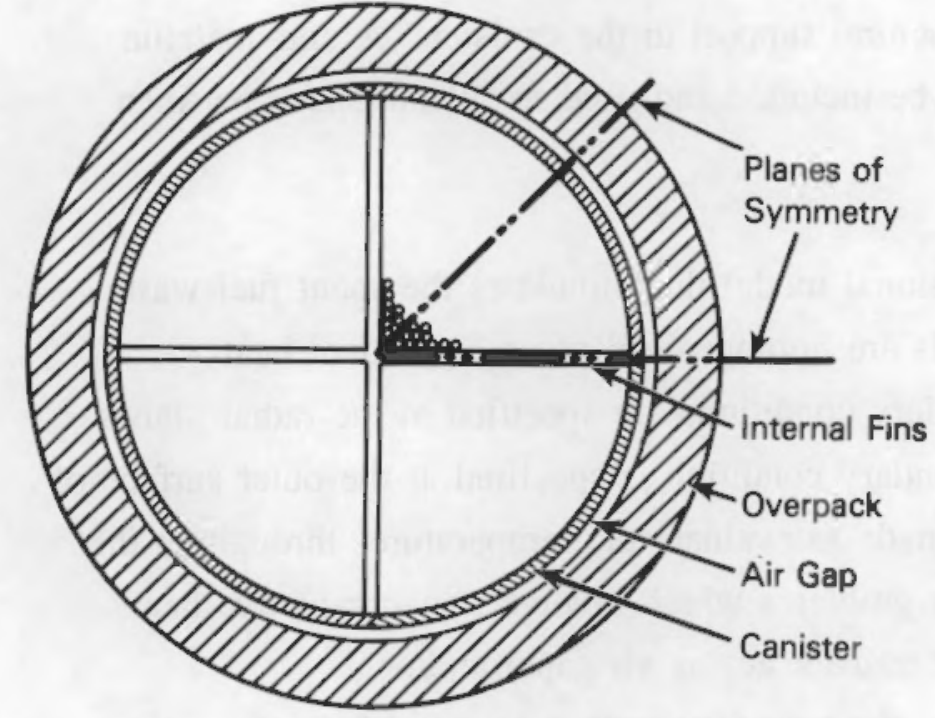

(a) Typical Spent Fuel Waste Package Cross-Section

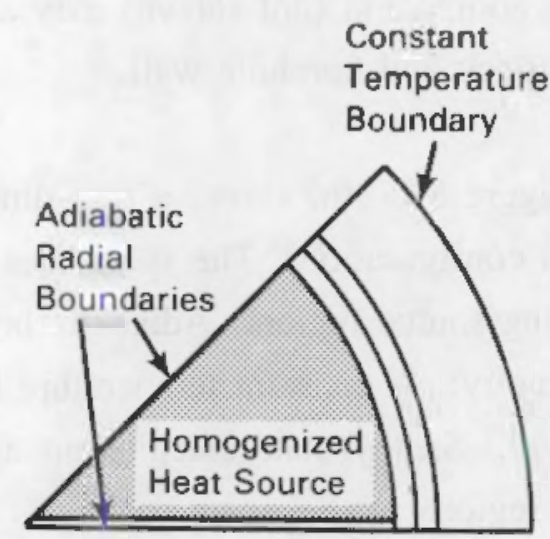

(b) Two-Dimensional Waste Package Scale Model

Figure 3.1-3 Generalized Spent-Fuel Waste Package (Very Near-Field) Scale Thermal Model Description 
dose effects on groundwater chemistry (e.g. radiolysis) can be important for predicting container corrosion and radionuclide transport behavior.

Radiation transport models should have the following attributes unless it can be shown that an alternative method has an insignificant impact on the calculated results (Claiborne, 1987):

- two-dimensional geometry

- multiple regions and material interfaces

- multi-energy group source term characteristics

- gamma- and neutron-radiation source terms

The methods used for radiation transport calculations have been developed primarily for reactor shielding design (Roussin et al., 1977). The Radiation Shielding Information Center at the Oak Ridge National Laboratory maintains a library of shielding codes and data for the scientific community. General purpose codes, such as MORSE-L (Wilcox, 1972), QAD-CG (ORNL, 1977), and DOT (Rhoades and Childs, 1982), are suitable for two-dimensional neutron- and gamma-radiation shielding problems. MORSE-L is a Monte-Carlo code based on the boundary-crossing technique. MORSE-SCG/S is an advanced version of MORSE and available with the SCALE system (ORNL, 1984) mentioned in Section 3.1. QAD-CG is based on the point-kernel method and contains the MORSE (Straker et al., 1970) combinatory geometry subroutines. DOT is based on the method of discrete ordinates to solve the Boltzmann transport equation. Doses from betaand alpha-particle radiations can be assumed to be essentially at the point of emission.

\subsection{Geochemical Modelling}

The current disposal concept of utilizing natural and engineered barriers to achieve containment and isolation in deep geologic formations allows many opportunities for geochemical processes to be a factor in waste containment (O'Kelley and Meyer, 1984). Geochemical processes may influence the extent of release and transport of radionuclides at the level of the waste form, canister, backfill, and the geologic environment. Geochemical processes may be fundamental in the dissolution of the waste form, corrosion of the canister, and interaction of radionuclides released to groundwater with materials of the engineered system and with the host rocks containing the repository. 
In fact the role of geochemical processes in understanding the repository environment is so pervasive that they must be considered in terms of present conditions, in light of potential changes in the geochemical environment due to emplacement, and in the long-range view to future geochemical conditions (Jacobs and Whatley, 1985). Since experimental or field studies cannot adequately assess these processes, especially on the time scale of the present objective, we must turn to geochemical models.

Geochemical models permit evaluation of chemical reactions. In general, models attempt to determine

- what chemical reactions have occurred.

- the extent to which reactions have proceeded.

- the conditions under which they occurred.

- how groundwater chemistry and aquifer mineralogy change in response to natural processes or to perturbations in the system.

The function of geochemical models is to interpret and predict chemical relationships in the geologic environment. The kinds of calculations that a model may perform include

- $\quad$ aqueous speciation.

- mineral solubility and saturation state of solutions.

- mass transfer reactions.

- reaction paths.

- sorption reactions.

- $\quad$ kinetics or rates of reactions.

- geochemical reactions coupled to groundwater flow.

The task of geochemical modelling is largely a conceptual process that is aided by calculations of equilibrium speciation, mass balance, and reaction path. A geochemical model is the series of mathematical expressions describing theoretical concepts, thermodynamic relationships, and empirical expressions on which speciation, solubility, adsorption, and mass transfer calculations are based. A code is the algorithm that expresses the conceptual model. Finally, all computerized models include data - thermodynamic 
data, empirical values, and rate constants - that allow the evaluation of the mathematical expressions.

In order to achieve reliability in extrapolation, the models must be based on firm theoretical ground. One may not rely on extrapolations of empirical relationships beyond the limits of existing data. However, if the basis of a code is a theoretically and fundamentally sound conceptual model, way reliably make physically meaningful extrapolations and predictions for conditions that are not readily tested by experimentation (Jacobs and Whatley, 1985). Ordinarily this objective is met by using thermodynamic relationships as the basis of a model. The theoretical basis of some pertinent geothemical processes is not yer adequately developed, for mstance for sorpton phenomena or kinetics. All results of model calculations must still be intepreted in light of many potential sources of error. Overinterpretution of modelled results must also be guarded against, since no model can be truly complete and accurate for all conditions (Plummer et al. 1983).

\subsubsection{Aqueous speciation and mineral solubilsty}

The chemical behavior of a ground-water system depends upon the exact nature of all the aqueous species present. Equilibrim speciation deternines the distribution and activities of all agueous spectess and the saturation state of a water with respect to various minerals and gases of interest. Speciation calculations are based on anceptual model of aqueous solutions, themodynamic data, and the observed chemical composition of the water under investigation.

A number of equilibrium speciation models have been published in the last 15 years, and a few of them are very widely used. Among them ate WATEQ Truesdell and Jones, 1974), WATEQF (Plummer et al., 1976), WATEQ2 (Ball et al., 1979), WATEQ3 (Ban et a1, 1981), WATEQ4 (Krupka et al., 1983), SOLMNEQ (Kharaka and Bames, 1973), MINEQL (Westall et al., 1976), GEOCHEM (Sposito and Matigod, 1979), WATSPEC (Wigley, 1977), EQ3NR (Wolery, 1979; 1983), and MINTEQ (Felmy et al 1984 ).

All of these models are based on series of balanced chemical reactions that satisfy the constraints of conservation of charge and mass of each element. Most aqueous models include a maser variable and a mass balance equation for each element. The master 
variables comprise a set of linearly independent aqueous species in terms of which all complexation and solubility reactions are written. In this equilibrim constant approach, mass action equations quantify the formation of all other aqueous species, namely ion pairs and complexes, from analytical information on each element. For example, the formation of the $\mathrm{MgSO}_{4}$ complex

$$
\mathrm{Mg}^{2+}+\mathrm{SO}_{4}^{2-} \rightleftharpoons \mathrm{MgSO}_{4}^{\circ}
$$

is described by the mass action exprestion and is quantified by the equilibrium constant, $K$,

$$
\frac{\left[\mathrm{MgSO}_{4}\right]}{\left[\mathrm{Mg}^{2}+\right]\left[\mathrm{SO}_{4}^{2}\right]}=\mathrm{KgSO}_{4}
$$

Equilibrium constant values, often calculated from Gibbs free energy of formation data, are a function of temperature and pressure, and if they are not corrected apply to conditions of $25^{\circ} \mathrm{C}$ and 1 bar. The dependence upon pressure over the range of conditions for aqueous solutions is weak and is not corrected for in most of the widely used programs. The temperature correction, however, is imponant and is incorporated into most models. The van't Hoff equation and enthalpy of reaction data are used unless empirical analytical expressions have been determined. Aqueous geochemical models can only consider solutions, so for most of them the temperature range is $0 \times \mathrm{T}<100^{\circ} \mathrm{C}$. A few models follow the liquid/vapor curve for elevated temperatures and pressures.

Individual ion activities, the thermodynamic parameters used to describe the extent to which species will participate in reactions, can be calculated from the distribution of ionic concentrations, usually expressed in molalities, by a relation

$$
a_{i}=\gamma_{i} m_{i}
$$

where $a_{j}$ is the acrivity of species $i_{,} m_{i}$ is the molality, and $\gamma_{i}$ is the activity coefficient, the factor accounting for nonideal solute behavior.

One model of the relation between molality and activity that is widely used is the Debye-Huckel theory of activity coefficients, the expression for which is 


$$
\log \gamma_{\mathrm{i}}=\frac{A z^{2} l^{1 / 2}}{l+B \mathrm{a}_{\mathrm{i}} l^{1 / 2}}
$$

where $z_{\mathrm{i}}$ is the ion charge, $I$ is the ionic strength, $A$ and $B$ are solvent parameters, and $a_{\mathrm{i}}$ is an empirical ion-size parameter.

A basic assumption of Debye-Huckel theory is that ions in solution behave as rigid point charges. This assumption is satistied in dilute aqueous solutions. Other expressions of the elementary ion association model are more appropriate for more concentrated solutions. Anong them ane the extended Debye-Huckel equation, the Davies equation, and Helgeson's B-dot formula (Helgeson, 1969). Most models use extended Debye-Huckel and Davies equations and are limited to consideration of ionic strengths less than 1.0 molal.

Higher order ion interaction models have been developed for dealing with solutions of high lonic strength, such as formation waters and brines (Harvie and Weare, 1980; Harvie et al., 1984). Expressions only recently incorporated into a few models to make them applicable at high ionic strengths (EQ3/6, Jackson and Wolery, 1985; PHREEQE, L. N. Plummer, pers. commun, MINTEQ, Krupka and Morrey, 1985) are Pitzer's equations (Pitzet, 1973), which are a series of empirically derived ion interaction terms for which a limited data base has been developed. These phenomenological non-ideality corrections for solutes and water must be more fully explored, especially for studying salt repositories. Interaction parameters for more complicared systems are required, and the treatment of brines seems far from adequate at this point.

The most successful description of solutions may be through a combination of ion association and ion interaction models (Moller et al, 1985).

Assumprions usually made in speciation and solubility modeling are that the activities of solids are 1 (that is, the solids are "pure"), the activities of gases are equal to their partial pressures, and a dilute-solution approximation can be used to relate the activity of $\mathrm{H}_{2} \mathrm{O}$ to the sum of the activitixs of all the dissolved species. Additional solution characteristics of $\mathrm{pH}$ and redox potential, expressed as Eh, pe, oxygen fugacity, or retox pair concentration ratios, satisfy the need for information on hydrogen and oxygen. These data, together with a chemical anslysis of a water, temperature of the solution, and thermodynamic data for all the reactions considered, are needed to complete the calculations. 
The system of mass action and mass balance equations is solved iteratively, for example by the continued fraction method of successive approximation or the Newton-Raphson method. The calculations are completed when the answers converge to the point of an acceptably small difference between consecutive iterations.

The saturation state of the solution with respect to mineral phases and equilibrium parial pressure of gases is calculated from the distribution of species, corrected to individual ion activities. It is ofen expressed as a saturation index, the logarithm of the ratio of ion activity product to equilibrium constant, both corrected to the temperature of the solution

$$
S I=\log \frac{L P(T)}{K(T)}
$$

Whether a particular mineral would tend to dissolve or precipitate in this particular aqueous environment is indicated by an undersaturated solution $(S T<0)$ or a supersaturated solution $(S I>0)$ respectively.

Some important sources of error in results obtained from equilibrium speciation models are the limited aceuracy and completeness of available ion pair constants, imperfect validity of activity coefficient theory, and uncertaintes in equilibrium constants (thermodynamic data).

A more fundamental problem is that the assumption of homogeneous equilibrium in the speciation models may not be appropriate in all cases. Although an acceptable assumption for most homogeneous reactions, redox species are widely observed to be in disequilibrium (Lindberg and Runnels, 1984). A calculation scheme for maintaining a disequilibrium state in the speciation calculations for redox species should be developed.

Thus from the gross chemical composition of a water sample, detailed chemical information about the nature of the solution and its thernodynamic state is obtained. Although each program accomplishes the same type of calculations, each is a little different from the others. A very complete description of the development of such a model is given by Wigley (1977). A comparison of a number of speciation programs is deseribed hy Nordstrom et a. (1979). 


\subsubsection{Mass Transfer Reactions}

Models that allow for heterogeneous reactions, specifically the transfer of mass into and out of the aqueous phase, are the mass balance and reaction path models. Mass balance calculations reflect changes in the total masses of element in solution. Reaction path models are built not only upon mass balance calculations, but also on the results of speciation calculations, such as the saturation indices and the definition of the redox state of solution.

Mass Balance

Mass balance models are based on observed net changes in total elemental concentrations in solution between some known initial and final conditions in a system in which mass is conserved. A mass balance expression is

$$
\left[\sum_{p=1}^{p} a_{\mathrm{p}} b_{\mathrm{p}, \mathrm{k}}=\Delta m_{\tau_{\mathrm{r}}}\right\} k=1, j
$$

where $\alpha_{\mathrm{p}}$ is the net mass transfer of the $p^{\text {th }}$ plausible phase among the $P$ total reactant and product phases in the reactions, $b_{\mathrm{p}, \mathrm{k}}$ is the stoichiometric coefficient of the $k_{\text {th }}$ element in the $p^{\text {th }}$ phase, $\Delta$ indicates difference, and $m_{T, k}$ is the total molality of the kth element in solution. Flectrons must also be conserved, and they are accounted for by change in redox state of the solution. Additional equations included to satisfy the need for independent equations are a charge balance equation and an equation for the conservation of mass of water (Plummer et al, 1983).

The model calculations determine amounts of assumed mineral and gas reactants and products that must dissolve or precipitate to account for observed chemical compositions. Thus, heterogeneous reactions are considered and final equilibrium concentrations are computed in a single step. The mass transfers or the masses of constituents that enter or leave the aqueous phase are quantified

Initial solution composition + "Reactant phases" - -

Final solution composition + "Product phases" 
The nature of the assurned reactant and product phases that enter or leave solution is constrained by information on mineralogy, aqueous speciation, geology, or some other sources of information about the specific systen. The number of phases considered must not exceed the number allowed by the avallability of linear independent equations (Plummer et al, 1983).

Themodynamic data are necessary only for the speciation calculations. Mass balance calculations can be applied to systems for which relatively much data is avaitable. This type of approach allows the evaluation of hypothetical reactions within the constraints of observed compositions. Satisfaction of thermodynamic constraints must be checked for separately.

Simple programs for mass balances have been published including BALANCE (Parkhurst ef al., 1982) and MIX2 (Plummer ef al, 1975). More commonly this type of calculation is incorporated into more sophisticated reaction-path programs.

\section{Reaction Paths}

Mass transfer due to evolution of a geochemical system along a partial equilibrium reaction path was first quantified in PATH1 (Helgeson, 1968; Helgeson et al., 1969). Intital conditions are ser as the result of an aqueous speciation calculation. Progressive reaction states are computed by incrementing the progress variable and checking the aqueous phase for thermodynamic constraints, allowing mass transfers in order to satisfy those requirements. Thus, a series of partial equilibria are computed until final equilibrium is obtained.

Reaction-path models are less constratined by observational data than mass balance models are. Given an observed or hypothetical starting water composition and an assumed set of reactions, the model predicts the evolution of water and rock chemistry as a function of reaction progress. Reaction-path models tell what the chernical composition of solutions should be and amounts of minerals dissolved and precipitated if a particular set of hypothetical reactions and themodynamic constraints are operative. Some of the types of reactions that may be considered are mixing of two solutions, varying temperature, irreversible reacrions of specified stoichiomerry, and equilibration with minerals or gases. 
This type of model allows reaction paths of dynamic systems to be calculated. Equilibration may occur as the result of instantaneous reactions, reaction-path calculations using arbitrary kinetics, or reaction-path calculations using actual kinetic rate laws.

The calcutations depend on a thermodynamic model, definitions of starting water composition, and assumed set of reactions. The reactions may be expressed as irreversible reactions or mineral/water equilibrium constraints. Non-equilibrium processes that lead to constant (steady-state) saturation states may also be constraints. Reactions occurring under conditions open or closed to exchange of mass may be considered. The model calculates the resulting reaction path of aqueous solution compesition and mass transfer.

The possible number of solutions to the equations describing the system increases dramatically if more than one irreversible reaction is considered since the relative rates of such reaction: are so poorly known.

As in the variety of detailed schemes evident in the speciation models, the various reaction part models also differ from each other. Published reaction-path simulation codes include PHREEQE (Parkhurst et al., 1980), EQ6 (Wolery, 1979; T. J. Wolery, in prep.), SOLVEQ (Reed, 1982), and MINTEQ (Krupka and Morrey, 1985). The results of a code-to-code verification of PHREEQE and EQ3/6 were virtually identical when applied to the same probiem and using the same aqueous model and thermodynamic data (Plummer and Parkhurst, 1985).

Since these models are applied to systerns for which there is relatively little data, there is a greater hypothetical element in the results. Their use, however, provides the opportunity to gain new information about possible reaction paths beyond that allowed by the exact differences between known conditions quantified in the mass balance approach. Also, thermodynamic constraints can be applied instead of just mass balances. While the solutions are hypothetical and are likely to be nonunique, reaction-path modelling allows questions to be asked and answers to be predicted in systems with incomplete or even no dati. The great freedom of these conditions is tempered by the need for a user to evaluate plausible phases, relative reaction rates for irreversible reactions, and thermodynamic criteria (for instance, the Gibbs phase rule may not be violated). Because of the sequential nature 
of the reaction path model calculations, omission of one or more significant minerals from the data base can have a major effect on the simulation (Jenne, 1981).

The conceptual model and methods of calculating reaction paths (e.g., in PHREEQR and EQ6) are consistent with all of the available data and satisfy the constraints of chemical thermodynamics. For any system, more than one reaction model can usually be found that satisfies these criteria and rarely, if ever, will the unique reaction which corresponds with reality be isolated (Plummer et al, 1983).

\subsubsection{Thermodynamic Data}

The compilation and critical evaluation of thermodynamic data should be part of the development of every model. Often, however, the effort to evaluate thermodynamic data lags behind other aspects of model development. Especially troublesome is the lack of basic data for many of the species of interest to the topic of radioactive waste disposal. Deficiencies in the thernodynamic data base must be identified and corected if the models are to be applied to such problems as waste-form dissolution and actinide retardation. Capabilities of the geochemical models will be expanded as themodynamic data are added for aqueous species and solid phases of additional elements. Just from the viewpoint of making temperature corrections, additional equitibrium constant and enthalpy data are required, especially for the actinides (Silva, 1985). Pressure corrections must also be added to models used to evaluate conditions at the depths of saturated-zone repositories.

Special care must be taken to assure that any given data set is internally consistent. Partial exchange of data between sets without assuring internal consistency can lead to significant errors. The need for an extensive, internally consistent thermodynamic data set for minerals remains (Haas, 1985). Of the data bases available, the MINTEQ thermodynamic data base, which was taken from the WATEQ dutabase, is one of the most complete and continues to be expanded (Peterson et al, 1986). Recent evaluations of thermodynamic data for the WATEQ family of programs were published by Ball et al. (1980), Krupka et al. (1983), and Nordstrom et al. (1984).

The solubility calculations are conducted under the assumption that the activity of a solid is unity. This unit activity is correct for pure solids. However, many minerals are 
member of solid solution series or have variable and poorly characterized composition. A model for the activities of such solids must be developed for phases such as ciays, zeolites, feidspars, and amorphous solids to be appropriately considered in geochemical calculations. The theoretical treatment of non-crystalline solids is not yet well established. A recently modified version of EQ6 is able to model less complex solid solutions by treating the solid as a combination of endmember minerals. The concentration of the solid solution is continuously adjusted to mantain equilibrium with the evolving fluid. An option allows hypothetical solid solutions to be predicted wher only the concentrations in the liquid phase are input. For example, solid solutions which contain trace amounts of radionuclides (Bourcier, 1985) can be modeled.

At this point in the research effor, more attention should be given to measuring reliable themodynamic and kinetic data than to further model development. The models require detailed and accurate knowledge of the thermodynamics and kinetics of a large number of possible geochemical reactions. The models may be used to guide experimentalists to areas where more accurate duta are required. The identification of inaccurate themodynamic data by model validation procedures can lead to a great reduction in the ovetall uncertainty of geochemical models (Jenne and Krupka, 1985).

\subsubsection{Sorption}

Sorption phenomena may be critical in reducing and delaying the release of radionuclides (Muller et at, 1984). Adsorption can be the limiting factor on the ocurrence of a trace dissolved constituent (Davis and Hayes, 1986). In order to understand and quantify sorption phenomena, a knowledge of a system's surface chemistry is required.

In comparison to complexation and mineral solubility, the themodynamic basis of surface chemical reactions is poorly defined.

Tha thee principal sorption processes are adsorption, absorption, and surface prectipitation. If the specific process leading to the loss of a solute from aqueous solution to a contiguous solid phase is not known, then the general term, sorption, may be used (Davis and Hayes, 1986). The principal mechanisms by which sorption processes occur are further defined (Sposito 1986): 
- Adsorption, an accumulation of matter at the interface between an aqueous solution and a solid adsorbent without the development of a three-dimensional indecular arrangement.

- Absorption, the diffusion or penetration of an aqueous chemical species into a solid phase.

- Precipiation, the growth of a solid phase at the solid-solution interface that is characterized by a molecular unit that repeats itself in three dimensions.

The macroscopic approaches that have commonly been used to study sorption processes, e.g. adsorption isotherns, solubility calculations, and kinatic models, cannot unequivocally distinguish between processes such as adsorption and surface precipitation (Davis and Hayes 1986). The essential characteristic of precipitation is the development of a solid phase whose molecular ordering is intrinsically three dimensional. An adsorption mechanism, on the other hand, inwolves only two-dimensional molecular arrangements on a surface, although there may be multiple layers (Sposito 1986).

Even though an ion exchange reaction could be classified as a type of adsorption reaction, it is usually treated as a separate sorption process as a matter of convenience and tradition. Ion exchange processes govem the distribution of major elements between solid and soil solutions. Describing ion exchange reatctions as those takirisg place at "constant charge" surfaces, e.g in the interiayer regions of clay minerals, distinguishes them from adsorption reactions that occur at "constant potential" surfaces, such as those of bydrous oxides (Davis and Hayes 1986).

Adsorption processes can take a number of forms, with the broadest distinction being whether there is a chemical reaction with the mineral surface, i.e. chemisorption, or not, in the case of physisorption (Adamson 1976; Tewari 1981; Goodman, 1986). There is no sharp dividing line between these two types of adsortion, although the extremes are easily distinguishable (Adamson, 1976).

Adsorption is characterized by specific interactions, the formation of chemical bonds, and selectivity of surfaces for certain species. Not enough is known about surfaces to develop a comprehensive themodynamic picture of these processes. For example, no theory describes the activity coefficients of surface sites or of species adsorbed to the surface. Without a relationship between activity and molality, expressions of these reactions 
become concentration-dependent, thus without a thermodynamic basis, Current descriptions are for the most part empirical and include assumptions whose fundamental basis and degree of generality have yet to be established.

Few of the geochemical models consider sorption reactions. GEOCHEM and PHREEQE focus on major cation chemistry, and can account for the processes of cation exchange and adsorption. They incorporate mass action expressions that adequately describe the exchange of like-charged ions. The adsorption of trace dissolved species is considered in MINTEQ and is planned in EQ6 (Wolery et al. 1984).

The two approaches used in geochemical models to describe reversible sorption ane adsorption tsotherms and the distribution coefficient. Adsorption isotherns relate the mass of ion adsorbed on the solid phase to the concentration of adsorbate ion in solution. $K_{\text {di }}$, the distribution coefficient, describes a linear relationship between dissolved concentration and amount sorbed; any isotherm will approach this behavior in the limit of very dilute concentrations. The following expressions have been incorporated into MINTEQ (Felmy et al., 1984).

1) The distribution coefficient. $K_{\mathrm{d}}$ expresses a linear relationship between the concentration of adsorbate ion in solution and the concentration adsorbed to the surface.

$$
m_{1}, \text { adsorted }=K_{\mathrm{d}} m_{\mathrm{i}}, \text { wolution }
$$

Linear adsorption best describes the behavior of trace species, whose low concentrations nearly satisfy the limiting assumptions of the linear adsorption isotherm.

The $K_{\mathrm{d}}$ expression has been widely incorporated into tlow models as a retardation factor. Although it is frequently used in modeling the adsorption of radionuclides, this approach does not account for variations in chemical environment, temperature, and the surface properties of the sorbent (Langmuir, 1987). If a $K_{d}$ expression is used in a model, the conditions to which the results apply are strictly limited to the conditions for which the value of the $K_{d}$ was determined. The validity of the $K_{\mathrm{d}}$ approach has been questioned (Reardon, 1981), as well as the applicability of laboratory-derived constants to simulations of field conditions. 
2) Langmuir adsorption isotherm. In this approach the solid surface is viewed as being composed of a finite number of identical sites. Each site may hold one molecule, thus the adsorbed ions may form up to a monolayer on the solid surface. No interaction between adsorbed ions is allowed. At trace concentrations of adsorbate, this expression reduces to the linear isotherm.

3) Freundlich adsorption isotherm. This model allows a distribution of energies of interaction, and thus a range in the nature of the surface sites. The adsorbed concentration is related to the concentration of the adsorbate raised to some power, and thus the relationship is non-linear. Such a model may be required for pollutants that are strongly bound (Kharickhoff, 1984).

Many data sets have been found to fit one of the above adsorption expressions. However, the fact that they fit the data does not prove that either the assumptions upon which they are based or the final adsorption expression is valid. It shoult be recognized that these expressions are empirical results which yield little mechanistic information and cannot be applied outside of the system for which they were obtained.

The surface complexation and ionization model is a comprehensive theory developed by Davis et al. (1978) to take into account the many variables that influence adsorption reactions. The model incorporates a description of the electrical nature of the solid surface as well as chemical reactions of solutes with the surface. In the adsorption process, surface complexes are formed with hydrolyzed ions in solution. These surface complexes are similar to mixed ligand complexes in that both a hydroxyl and a surface site contribute to the coordination of the adsorbed ion, and thus influence the $\mathrm{pH}$ dependence of the adsorption process. Intrinsic equilibrium association constants describe the complexation reaction. These are experimentally determined and help account for the nonidieal effects of surface electrical charge on the activity of jons near the surface.

This model allows the electrical nalure of the surface to be treated in two different ways:

1) Double layer surface complexation model. Species are either speciffically adsorbed to the surface or in the diffuse layer, and they do not influence the surface charge 
itself. The equilibrium constants for a given lonic strength and electrolyte composition apply only to those conditions for which the adsorption data were obtained. However, the equilibrium constant only needs to be measured at the condition of interest.

2) Triple layer surface complexation model. This model allows the adsorption of $\mathrm{H}^{+}$and $\mathrm{OH}^{-}$to influence surface charge. A second surface layer exists for the specific adsoption of other ions, and nonspectifically adsorbed counter ions reside in the diffuse layer. The equilibrium constants apply over a wide range of $\mathrm{pH}$, electrolyte, and adsorbate concentration. However, experimental data from a wide range of conditions must be collected to determine the constants.

Researchers have successfully used the surface complexation theory to model the adsorption of radionuclides on quartz, kaolinite, montmorillonite, goethite, and amorphous iron oxides. This model has been incorporated into the MINTEQ code, and is currently being modified to allow modeling of radionuclides in brines and at elevated temperatures (Langnuir, 1987).

The type of information needed to use these adsorption models includes detailed knowledge of solution chemistry, $\mathrm{pH}$ of zero-point-of-charge, surface area, surface site density, estimate of chemical part of adsorption (non-coulombic), intrinsic eguitibrium constants, and inner layer capacitance.

Any specified adsorption problem may have several solutions, as there are more possible phases and mechanisms than linearly independent equations to describe the system. The only way to decrease the number of possible solutions is to obtain more data (Peterson et al., 1986). Regardless of the level of sophistication with which sorption phenomena are treated conceptually and mathematically, there is a critical need for more sorption data that may be incorporated into these models. Much more work remains to be done to fully characterize the surface properties of solids.

\subsubsection{Kinetics}

Homogeneous reactions in solution are relatively rapid and often at equilibrium, Heterogeneous reactions between solid and solution, however, are often much slower and 
not at equilibrium (Lasaga and Kirkpatrick, 1981; Lasaga, 1984). In fact, the kinetics of reactions such as mineral dissolution or precipitation and redox reactions may dominate the geochemistry of a system.

The time-dependency of the reaction is a fundamental factor in attempts to make predictions about radionuclide migration. If reaction rates are fast relative to the rate of convective transport, local chemical equilibrium can be assumed at the macroscopic scales. Such an assumption is strictly valid only if the rate of change in concentration due to the reactions is fast relative to the rate of change in concentration due to flow. A review of recent papers which identify sets of conditions for which this equilibrium assumption applies is given by Bahr and Rubin (1987). If reactions are insufficiently fast, the assumption of local equilibrium will result in the incorrect prediction of a contaminant front. Although most transport problems involve a time frame in which solid phase equilibrium is not an appropriate assumption (Bahr and Rubin, 1987), kinetic data are scarce, and more difficult to obtain experimentally than equilibrium data. Thus, the absence of kinetic constraints on geochemical models is due principally to the lack of appropriate information on kinetic rate constants and rate laws (Hull and Hull, 1987).

Current research in kinetics is focused on establishing a firm theoretical basis for calculations. Most results come from phenomenological experimental studies. Widely applicable rate laws have been developed for only a few well-studied reactions, such as calcite and silica dissolution and precipitation (Delany et al., 1986).

Incorporation of existing rate laws into geochemical models has been linited. Models which contain kinetic rate Jaw expressions include EQ3/6 (Wolery et al, 1984); EQULIB, which allows kinetic constraints on precipitation of selected solids (Jenne, 1981); and a recent version of EQ6 which contains rate laws for precipitation and dissolution of solid phases (Delany et al., 1986). The reaction cooruinate in current reaction-path models neads to be related to time so that mineralogical sequences calculated by the model can be expressed as time-dependent phenomena. However, we are a long way from accomplishing this goal.

A much larger kinetic database is needed if kinetics are to be incorporated into geochemical models. Rate laws and rate constants are needed for more widely varying 
conditions and for additional aqueous species and minerals. The primary factor limiting progress toward modeling a complete and complex system is insufficient kinetic data (Aines, 1986). First, more information on rates and mechanisms of reactions of individual minerals with solution are needed. Second, information on mineral assemblages and their interactions with solution are needed (Lasaga, 1985). Some of the problems in extrapolating laboratory-derived rate laws to field application will include our lack of information on relative surface areas of the reactive phases and the effect of changing environmental conditions, such as temperature and redox state, on reaction rates. Kinetics and irreversibility of reactions are most important under near field conditions where thermal and chemical gradients are pronounced, yet the net effect of these reactions cannot currently be predicted (Langrnuir, 1987),

\subsubsection{Model Validation}

In any modeling effort, the accuracy of the simulations must be assessed. Validation studies and sensitivity analysis may be used to evaluate simulation errors and the credibility of model predictions. Through the validation process, inaccurate or contradictory tata in the thermodynamic or kinetic database of the model may be revealed. Some of the problems of model validation are addressed in Krupka et al. (1983), and several approaches to the validation of geochemical models are discussed in Jeme and Krupka (1985).

Need for additional laboratory and field experiments is often demonstrated during model validation efforts. A properly yalidated model greatly reduces the burden of demonstrating model competence for each application. However, since validation efforts are often limited by the availability of data, the limitations of the model as well as its merits must be understood (Jenne and Krupka, 1985).

Finally, the applicability of the equilibrium assumption (i.e., the neglect of kinetics) to the post-closure environment of a repository needs to be evaluared. Both natural analogue and laboratory reaction-rate studies of key radioelements, preferably under a yariety of conditions, will aid in such an assessment. 
Numerous rock-mechanics models may be used in design of a high-level waste repository. The prineipul issue addressed by these models is stability of the mined opening during repository operation. In line with the focus of this repon on long wterm perfarmance, this section will not attempt to broadly review these models. Instead, the focus will be on the most important long-term performance issue: changes in rock permeability.

The defomation of fractured rock and resulting changes in fracture permeability may be modeled in two different ways: by modeling discrete fractures, or by treating the fractured rock as a continuum. These two approaches correspond to the discrete-fracture and dual porosity methods of modeling ground water flow in fractured rock, which are uscussed in section 5.2 .

In the discrete-fracture technique, the model incorporates the position and orientation of each fracture. Siresses nomal to the fracture cause compression or ditation, while stresses tangent to it cause shear displacement which leads to some dilation as a result of dislocation. The fracture's resistance to fuid flow is calculated from the law for fluid tlow between flat plates. In this catculation, on must use an "effective aperture," which because of rouchness effects, is constderably smallet than the "geometric aperture, or the average physical separation between the two sides of the fracture (Barton, 1982). The effects of the individual fractures may be added together to obtain a bulk yemeability for the rock, or one can explicitly treat each fracture as a discrete flow conduit in a coupled rock mechanics-fuid flow model. Huyakorn and Pinder (1983) give a detailed formulation and exposition of solution methods for the second type of model.

One problem with the modeis decribed by Huyakon and Pinder is their assumption that the effective aperure for flow resistance is equal to the geometric aperture. Barton (1982) has developed a constituive relation between stress, effective aperture, and geometric aperture; use of such a relationship might improve the discrete-fracture models.

The fracture-continum approach treats the fractures as a continum that is coextensive with the rock matrix. To date, nodels of this type have assumed that the hydraulic conductivity is independent of the stress on the rock (Huyakom and Pinder, 1983). Such models obviousty cannot predict stress-related changes in hydraulic conductivity. A 
continum model of stress-induced permeability would require input that takes into account a constirutive relation between bulk fracture perneability and stress. Unfortunately, steh a relationship may not be easy to measure in the field.

The data-collection problems associated with discrete fracture models are no less formidable. Detailed mapping of fractures in three dimensions is necessary, and constirutive relations for the fractures (which will differ among fractures) must be obtained. The few published model applications are more often schematic analyses of hypothetical situations than studies of specific sites for instance, Kelsall et al., 1982); possibly the only exception is the study by Montazer and Hustrulid (1983). Fyen less is known about fracturing in tuff and basalt than has been described for granite.

An evatuation of potential perneability changes around a shaft in Hanford basat (Cotam, 1983) concluded that:

the response of the rock mass to excavation is sensitive to many effects that are not addressed in the analytic procedures and to factors that are unguuntifiable except by full scale, site-specific in situ testing. If systematic analysis shows the potential for radionuclide migration through the damaged rock zone to be critical to repository performance, full-scult in situ tests will be required.

\section{$3.5 \quad$ Brine Migration}

Naturat salt deposits contain a small volume of fluid-filled voids called inclusions. Inclusions are distributed throughout the solid matrix and encompass a range of sizes. The fluid may be a liquid such as brine, a gas such as $\mathrm{H}_{2} \mathrm{~S}, \mathrm{CH}_{4}$ or $\mathrm{N}_{2}$, or a combintation of both hquid and gas. Whether or not these inclusions form a connected pore space, they can in the presence of a temuerature gradient migrate towards or away from the heat soure. Becatuse the repository will generate considerable heat, there is concern that it might mobilize brine inelusions in ways that signifiemnly affect its performance.

Recent laboratory studies (Olander, 1984) have delineated some of the mechanisms and parumeters whith govern thernally driven inclusion migration. Of these perhaps the most important parameter is the composition of the inclusion, which controls whether the inclusion migrates towards or away from the heat source: 
Inclusions which contain $90 \%$ or more brine migrate toward a heat source. The reason for this is well understood; the migration results from the increase in salt solubility with temperature. A temperature gradient across the inclusion causes dissolution at the bot end (near the heat source), generating a salinity gradient in the liquid phase. Convective flow and molecular diffusion of dissolved salt drive undersaturated liquid to the hot end and supersaturated liquid to the cool end. Dissolution at the hot end and crystallization at the cool end result in continuous displacement of the inclusion toward the heat source. The flux of migrating brine is directly proportional to the initial brine content of the salt (USDOE, 19860).

The major control upon the migration velocity is the rate of dissolution, and this is influenced by the magnitude of the temperature gradient and mineral composition. Below a threshold gradient an inclusion is immobile. Above the threshold, the migration velocity varies as the square of the temperature gradient. In a formation of specified mineralogic composition, dissolution is controlled primarily by the number of imperfections in the ionic lattice that intersect the crystal face at the hot end of the inciusion. These imperfections permit dissolution at small undersaturation of the adjacent brine, and the number of imperfections is a function of mechanical loading and chemical impurity.

Inclusions which contain a gas bubble that oceupies $10 \%$ or more of the void migrate away from a heat source. Although the mechanisms governing this phenomenon have not been identified conclusively, migration is thought to be initiated by evaporation of brine at the hot side of the gas bubble, followed by condensation at the cold side. The condensed water, which is salt free and thus readily dissolves salt at the cold end of the inclusion, is continuously tecycled to the hot side by backflow of the brine. Continuous dissolution at the cold side of the inclusion results in migration away from the heat source.

Migration of both types of inclusions has been observed to occur both in single salt crystals and in natural crystalline aggregates. In aggregates, the inclusion may move along grain boundaries.

It is not certain whether gas-liquid inclusions exist naturally at the high-pressure conditions of a subsurface salt repository. However, it is possible that all-liquid inclusions could be transformed into gas-liquid inclusions as they impinge upon a heat source. For 
instance, contact between an inclusion and a breached fuel canister might cause partial evaporation of the brine, resealing after incorporation of an insoluble gas, and subsequent down-gradient transport of any radionuclide that it may have picked up. Olander has experimentally verified such a transport mechanism.

Brine migration toward a HLW canister in salt has been the subject of recent modeling efforts. The finite difference code BRINEMIG (USDOE, 1986b, p,6-212) has been coupled with a thermal code and a waste package analysis code to obtain inflow volumes and velocities. BRINEMIG uses radial temperature profiles provided by the thermal code and interpolates temperatures and thermal gradients which are then used in the empirical equation developed by Jenks and Claibome (USDOE, 1986b, p. 6-211):

$$
\log (V / G)=0.00656 \tau-0.6036
$$

where $\mathrm{V}$ is the velocity of brine migration in $\mathrm{cm} / \mathrm{yr}, G$ is the thermal gradient in ${ }^{\circ} \mathrm{C} / \mathrm{cm}$, and $T$ is the temperature in ${ }^{\circ} \mathrm{C}$. McCauley and Raines (1987) used BRINEMIG to model brine migration at seven sites.

Ratigan (1987) developed a finite element model that simulates the migration of inclusions both within grains and at intergranular boundaries. The model solves a coupled equation that is based on the assumption that intracrystalline flow is themaily driven, while intercrystalline flow is pressure driven.

Bloom and Raines (1986) have developed analytical and semianalytical models for estimating temperature-dependent brine migration and radionuclide transport around a repository. These may be useful for benchmarking numerical codes.

Large-scale fieid tests at the Asse salt mine in Germany (Rothfuchs, 1986; Coyle et al., 1987) and the Waste Isolation Pilot Plant (WIPP) in New Mexico (McTigue and Nowak, 1988 ) indicate that brine migration will occur under expected repository conditions and provide a basis for validating models. To simulate the effect of disposed HLW canisters, both experiments emplaced heat sources at depth in halite host rocks for approximately 2 years and collected brine that flowed into the boreholes around the heat sourees. 
At Asse, the collection volumes (much less than $1 \mathrm{~L} / \mathrm{yr}$ ) were less than predicted hy numerical models of brine and vapor transport developed by Jenks (1979). This discrepancy was ascribed to using in the simulation a laboratory-determined permeability that was several onders of magnitude too high.

At WIPP, inflows were greater than predicted by models of themal migration, and occurred even in the uneated boreholes. McTigue and Nowak (1988) concluded that the predominant mechanism involved was Darcy flow in the pressure gradient created by opening the excavation and by subsequent thermal expansion of the salt.

\section{$3.6 \quad$ Radiation Effects on Chemistry}

Radiation can affect the chemical environment within the solid waste form, within the air surrounding packages under unsaturated conditions and, within the waters present in the waste package after saturation. Alpha, beta, gamma, and neutron radiation are produced during the decay of radioactive wastes. The alpha and beta particles are stopped by the waste container and, therefore, do not affect the repository environment as long as the container remains intact. Gamma and neutron radiation will penetrate through the waste package into the host rock. Thus, the gamma and neutron radiation will have an immediate impact on the chemical environment surrounding the waste package during the early (contaiment) time period. The effects of neutron radiation are expected to be negligible because it has much lower intensify than gamma tadiation.

Radiolysis (either gamma, beta or alpha) has the net effect of producing equal amounts of oxidizing and reducing species. What is important from a waste package peffomance assestrment perspective is the relative reactivity of these species. If the oxidants and reductants readily recombine, there will be little overall effect. If the oxidants react more slowly than the reductants, then the environmen can be expected to remain relatively reducing and there should be little detrimental effect on performance. The most worrisome situation, and the one expected to be most likely in a saturated, initialy reducing repository, is that oxidants will react more rapidly than reductants, thus producing net exidizing conditions. This expectation is based on the obserytion that one of the predominant reducing species produced by radiolysis, $\mathrm{H}_{2}$, is a very sluggish rescunt at expected repository temperatures. Also, $\mathrm{H}_{2}$ is more mobile and nore apt to diffuse away 
from the reaction zone than the oxidants. Net oxidizing conditions would enhance both container cortosion rates and radionuclide solubilities, thus degrading waste package performance.

Because the environment in an unsaturated repository will be inherently oxidizing, the primary concern in such an environment will not be the change in oxidation potential produced by radiolysis but rather the production of species that could significantly enhance container or waste form corrosion rates. Probably the greatest concern is for the production of nitric acid or the production of formic or oxalic acids if $\mathrm{CO}_{2}$ is present in significant quantities. If copper is chosen as a container material, ammonia could also be an important radiolysis product.

Doses in the repository environment will depend on the history and age of the wastes, which deternine the concentration and type of radionuclides in the waste form, and the design of the waste package. Typical values for alpha and beta dose rates at the inside surface of a spent fuel container after various years of storage are shown in Table 3,6 1 for burnups of 33 to $38 \mathrm{Mwd} / \mathrm{t}$ (Christensen and Bjergbakke, 1985). Dose rates for typical glass waste forms are also shown in Table 3.6\%1 (after Burns et al, 1982b). The gamma dose rate at the outside surface of a DOE conceptual design waste package for the basalt repository (4 ten-year old PWR assemblies in a $8.3 \mathrm{~cm}$ thick low-carbon steel container) is $250 \mathrm{rud} / \mathrm{hr}$ (Reed, et al., 1985). The decay of the betu and gamma radiation is essentially complete within a few hundred years, thus leaving alpha decay as the principal long term radiation source. Reed, et ai., (1985) calculate that $85 \%$ of the gamma dose is absorbed in the BWIP packing material. They argue that the most useful quantity to consider when assessing radiation effects is the total energy absorbed; not absorbed dose. The total energy absorbed in the aqueous phase of the waste package in 1000 years (assuming container integrity) is $160 \times 10^{\circ}$ joules. (Reed, et al., 1985). 
TABLE 3.6-1

Typical Dose Rates Emanating From Waste Forms (R/hr)

Years of Storage

Spent Fuela

Waste Glass

40 to 50

300 to 500

1000

10,000

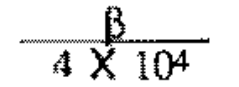

$1.8 \times 104$

$8.3 \times 10^{3}$

$1.8 \times 10^{3}$ $\frac{a}{1.1 \times 10^{5}}$

$5.8 \times 10^{4}$

$2.7 \times 10^{4}$

$5.8 \times 10^{3}$

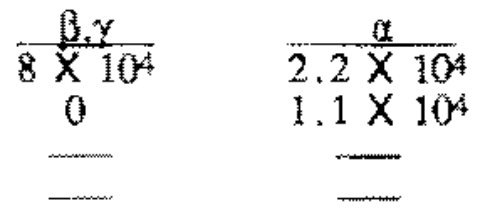

4 33 to 38 Mwdth bum-up

A quantitative model of the effects of radiation on the waste package and its geochemical surroundings is not currently available. Thus computer codes to quantify all effects are non-existent. One reason is that radiolytic processes can only be modeled using kinetic approaches as opposed to thermodynamic approaches. The free radicals, reactive ions and molecules formed when radiation impacts water ate highly reactive and exist for very short times compared to the length of time of interest. Further, the kinetic data base for reaction rates of the primary species (fomed from radiolysis of water) with other solutes and types of secondary species formed is limited to very simple systems. The number of potentially interacting species in groundwater is much larger than any system previously studied. Finally, the container, packing material, and host rock solid masses will dominate the geochemical system and likely moderate, if not eliminate, the changes caused by the reactive primary and secondary products formed in water.

Despite the lack of useful long term predictor codes for radiation effects, knowledge of the effects of ionizing radiation on simple solution systems in short-term laboratory experiments is available, and computer calculations on radiolysis products in waters including salt brine and dilute ground water (including iron, uranium and bicarbonate solutes) recently have been presented (Simonson and Kuhn, 1984; Christensen and Bjergbakke, 1982, 1983, 1985, 1987; Nicolosi, 1985, 1987; Nicolosi et al., 1987; Carver, et al., 1979; and Gray and Simonson, 1985). Nicolosi (1985) and Christensen and Bjergbakke (1987) approximate heterogeneous surface reactions for iron and $\mathrm{UO}_{2}$ solids by using a generic $\mathrm{Fe}$ and $\mathrm{UO}_{2}$ solution species because the codes can only deal with homogeneous solution reactions at present. 
The groundwater-radiolysis codes all have the same general structure. The codes assume a closed homegeneous solution system. That is, reactants and products cannot enter or leave the system and species cannot diffuse towards or away from the source of tadiation, which would create gradients. It is assumed that only the solvent, water, directly interacts with the radiation field to form primary reactants. The user specifies the primary reactions, reaction rate constants and the $\mathrm{G}$-yalues (described below) for each primary reactant for each type of radiation and the dose rate versus time. The code calculates the amount of each primary reactant formed and consumed (in secondary reactions) versus time. The radiolytic products produced in dilute waters predominanty are formed by interaction with the solvent (water) molecules $\left[\mathrm{e}, \mathrm{g}\right.$, ions $\left(\mathrm{H}^{+}, \mathrm{OH}^{-}\right.$, and solvated electron $\mathrm{e}^{-}{ }_{\mathrm{sq}}$ ), tree radicals $\left(\mathrm{OH} * \mathrm{H} * \mathrm{HO}_{2} \bullet\right)$ and molecules $\left(\mathrm{H}_{2}, \mathrm{H}_{2} \mathrm{O}_{2}\right)$. Their production rates are known as $\mathrm{G}$-values, which are defined as the number of a given species produced per $100 \mathrm{eV}$ of absorbed energy. The $G$ values, the dose rate, and the duration of radiation determine the quantity of each species formed, although not necessarily the quantity present at any given time, as many of the radiolytic species react rapidly to form more stable species. The codes take into account the various reactions involving radiolytic species, and they can be used to calculate species concentrations at apparent steady-state (i.c., when rate of production by radiolysis equals rate of consumption by secondary reactions).

Imrediately after formation, these solvent-generated radiation products (primary reactants) can react in three ways: 1) recombine to form water, 2 ) react with themselves to form other products (e.g., $\mathrm{H}^{+}+\mathrm{e}^{-} \rightarrow \mathrm{H} \cdot \mathrm{H} \cdot$ and $\mathrm{H}_{2}+\mathrm{OH} \rightarrow \mathrm{H}_{2} \mathrm{O}+\mathrm{H} \cdot$, and 3 ) react with other solutes in the water. The codes require a rate constant for each reaction. These rate constants are determined in laboratory experiments or found in radiation textbooks (e.g., Allen, 1961; Ausloos, 1968; and Draganic and Draganic, 1971). In simple systems, these reactions can be estimated, so that steady-state conditions for a given dose rate can be predicted (Simonson and Kuhn, 1984). For example, in pure wnter the steady-state $\mathrm{H}_{2}$ concentration is very low because of the rapid back-reaction: $\mathrm{H}_{2}+\mathrm{OH} \cdot \longrightarrow \mathrm{H}_{2} \mathrm{O}+\mathrm{H}$ *

If scavenger ions, such as $\mathrm{Br}$ and $\mathrm{Cl}^{\text {- }}$, are present, they compete with $\mathrm{H}_{2}$ for the $\mathrm{OH}$ radical, thereby raising the concentration of $\mathrm{H}_{2}$ in solution and increasing its pressure in the gas phase. The presence of $\mathrm{Cl}^{-}$also leads to the secondary products $\mathrm{Cl}_{2}, \mathrm{ClO}_{3} \mathrm{ClO}_{3}$, $\mathrm{ClO}_{4}^{-}$, and $\mathrm{ClO}$; analogous species would result from Br (Jenks, 1972; 1980). The presence of organic compounds considerably complicates this picture. Tabulations of 
reactions and rates are found in Nicolosi $(1985 ; 1987)$, Nicolosi et al, (1987) and Rosinger and Dixon (1977).

The waste package envitonment is much more complex than typical systems that have been studied in the past. The higher temperatures and pressures, the different redox states expected in repositories, and the presence of solids (e.g., rock, packing, container, and waste form) make extrapolation of the 'text-book' examples temuous. One attempt to use a radiolysis code for the basalt repository project groundwater with a high methane content was successful in some aspects (prediction of $\mathrm{H}_{2}$ ) but failed in prediction of organic end-products (Reed, et al, 1985). The basalt repository project's strategy was to rely upon experimental results, rather than modeling of radiolytic retaction systems, to determine the effect of ionizing radiation on the waste package. This philosophy is likely followed by all repository projects, although computer predictions may be used to guide future work and bound performance assessment calculations.

For simple aqueous systems, Draganic and Draganic (1971) show that between $\mathrm{pH}$ values 3 and 13 , gamma yields of solvent radiolysis products are fatrly constant. This does not imply that the subsequent reactions with solute species and the solid surfaces in the system will be independent of $\mathrm{pH}$, but does suggest that the ionizing reactions that form the initial reactive species are insensitive to $\mathrm{pH}$ changes.

The effect of temperatures between $2^{\circ}$ and $65^{\circ} \mathrm{C}$ on the primary yield of water radiolysis products has been studied by Hochanadel and Ghormiey (1962). In general, at higher temperatures the number of molecular products $\left(\mathrm{H}_{2}, \mathrm{H}_{2} \mathrm{O}_{2}\right)$ formed decreases and the number of ions and radicals $\left(\mathrm{H}^{+}, \mathrm{H} \bullet, \mathrm{OH} \bullet\right.$ ) increases. The specific increases or decreases are slight $(-0.1$ 管 increase or decrease per degree centigrade change). Thus, it takes a $100^{\circ} \mathrm{C}$ change to produce a $10 \%$ change in yield.

Increased pressures up to 6500 bars (expected repository pressures are 100 to 300 bars) have been shown not to affect the amount or types of primary yield products. At extremely high dose rates $(\$ 3 \times 1011 \mathrm{rad} / \mathrm{hr})$, the primary yield of solvent-derived ionization products drops, but this dose rate greatly exceeds the highest dose rates from spent fuel or high-level waste glass packages ( -1 to $8 \times 10^{4}$ ratuhr). Thus, radiolysis of simple dilute ground waters appears to be rather insensitive to the expected range of $\mathrm{pH}$, temperature, and pressure in repositories. It is unclear whether this conclusion also holds for sait brine. 
During the resaturation portion of a repository located in saturated rock, or for unsaturated repositories (e.g., Nevada tuff), the presence of a discrete gas phase may dramatically change the effects of radiolysis. Reed and Van Konynenburg (1988) review the available literature relevant to the tuff repository. They conclude that radiolytic effects on dry nitrogen/oxygen gas systems are relatively well characterized. Irradiation results in the formation of ozone, nitrous oxide and nitrogen dioxide. In closed systems, their respective concentrations depend on the total dose, temperature and initial gas composition. The presence of water vapor results in the formation of nitric acid and significantly changes the chemistry from that observed in dry air systems but Reed and Van Konynenburg (1988) also conclude there is much uncertainty in the moist air $\left(\mathrm{H}_{2} \mathrm{O}-\mathrm{N}_{2}-\mathrm{O}_{2}\right)$ system. Thus presently, an accurate description of the gas phase present in the vicinity of the tuff waste package can not be made. Bibler and Jantzen (1987) particularly mention a need for concern for $\mathrm{HNO}_{3}$ production in moist air.

Gamma radiolysis of nitrogen-saturated deionized water, but with no separate gas phase, produced no nitric acid (Burns et al., 1982). Because hard rock repositories will probably fill with water after a relatively short time, no separate gas phases should be present, and thus no significant amounts of nitric acid should be present (Burns et al., 1982). Few calculations have been performed to assess the scenario if nitric acid were produced. Most researchers are relying on laboratory studies, ongoing and planned, to provide data on whether nitric acid is expected to form and, if so, what the long-term effects are.

Nitric acid can form in solutions in contact with alpha-emitting solids, in both air-saturated solutions and $\mathrm{N}_{2}$-saturated solutions (Rai et al. 1980). Thus, after the waste form is breached, the possibility of nitric acid forming in a water-saturated environment because of alpha decay must also be considered. The opinion of many repository systems analysis geochemists is that the effects of ionizing radiation on the near field will be moderated by the large mass of solids (container, packing material and rock).

In summary, knowledge of radiation effects on pore waters surrounding waste forms in salt and basalt and on moist air surrounding waste forms in tuff is not complete. Available conceptual models and computer codes consider mainly the generation of solvent-generated reactants (e.g., for water $\mathrm{H}_{2}, \mathrm{H} \bullet, \mathrm{OH} \bullet, \mathrm{H}_{2} \mathrm{O}_{2}, \mathrm{e}^{-}{ }_{\text {aq }}$ and for air $\mathrm{N}_{2}{ }^{+}, \mathrm{N}^{+}$, 
$\left.\mathrm{N}_{2} \mathrm{O}_{5}, \mathrm{O}_{2}+, 0^{+}, 0 * \mathrm{e}\right)$. These reactive species then interact with other solutes in the solvent or themselves to form additional reactive intermediates or more stable products. Only a few solutes (e.g., $\mathrm{Fe}^{2+}, \mathrm{Fe}^{3+}, \mathrm{HCO}_{3}^{-}, \mathrm{CO}_{3}^{2+}, \mathrm{U}^{4+}$ and $\mathrm{UO}_{2}{ }^{2+}$ ) have been explicitly included in codes. These interactions are described using kinetic approaches. Calculations suggest that a steady state is reached rapidly (hours to days).

Due primarily to a lack of data and the current restriction to homogeneous (solution only) reactions, none of the conceptual models account for potential interactions with the various solids present in large quantities in the waste package and host rocks. To date, radiolysis experiments have generally ignored the effects of solids and will require additional effort to more realistically simulate repository and waste package environments. Because the rocks and waste package materials are the primary $\mathrm{pH}$, Eh, and chemical buffers in the system, radiolysis experiments that neglect their presence cannot definitively address the expected influence of radiation on solution chemistry.

Further, the codes that are available are closed system constructs that do not allow products to transport out or other reactants to transport into the region being simulated. Nicolosi (1987) suggests that radiolysis codes could be linked to transpont codes but gives no details.

Some experiments have been perforned to determine the effect of radiation on waste form leaching. on canister corrosion, and on clay and salt stability. These sudies do not allow the mechanisms to be isolated but do provide data on radionuclide release rates and container corrosion rates. Generalizations on the effects of radiation on waste form leaching, based on references cited, are that radiolysis will not cause significant changes in waste- form leaching. Some tests have shown increased leaching of waste glass up to a factor of 7 in short term tests (McVay and Pederson, 1981). But the inerease was found to be caused by creation of nitric acid in oxygenated waters. When tests were performed in anoxic solutions no leaching differences were observed between irradiated and non-imadiated systems (Pederson and McVay, 1983). Other references showing insignificant effects of radiation on glass leaching include Burns et al. (1982), McGrail (1985), Yokoyama et al. (1985), Ebert et al. (1987), McVay and Pederson (1981), McVay, et al., (1981), Barkatt et al., (1982a, b), Nash et al., (1982, 1983), DeNatale et al., (1982), Nuclear Energy Agency (1982), Weber et al. (1979), Mendel et al. (1976), Scheffler and Riege (1977), and Bibler (1982). 
Leach tests of $\mathrm{UO}_{2}$ in brines in the presence of $3 \times 10^{3} \mathrm{rad} / \mathrm{hr}$ gamma radiation showed elevated uranium concentrations compared to tests in basalt, tuff and deionized water. The researchers speculated that gamma radiation produced oxidizing species in the brine that increased uranium solubility (Means et al., 1987). Other investigators have found very little differences in leach rates of spent fuel under variable radiation doses. For example, see Forsyth and Werme (1985), Sunder et al. (1987) and Gray (1987). Shoesmith et al. (1985) showed that hydrogen peroxide can oxidize $\mathrm{UO}_{2}$ two hundred times faster than $\mathrm{O}_{2}$ but that the concentration of $\mathrm{H}_{2} \mathrm{O}_{2}$ had to exceed $5 \times 10^{-3} \mathrm{M}$ before $\mathrm{U}$ solution concentrations increased dramatically. The first step in $\mathrm{UO}_{2}$ oxidation forms $\mathrm{U}_{3} \mathrm{O}_{7}$ but does not entail U dissolution. Sunder et al. (1987) carry the work further and show that expected $\mathrm{H}_{2} \mathrm{O}_{2}$ production in repositories will be considerably below $5 \times 10^{-3} \mathrm{M}$.

There is no consensus among the active researchers on the effects of irradiation on metal canister corrosion. For some groundwater/metal combinations, irradjation did not noticeably influence corrosion. For other groundwater/metal combinations, radiation increased corrosion and facilitated additional corrosion processes. In general, increased corrosion rates are commonly found for carbon steel and Hastelloy when gamma irradiation is used in brine. Increases in corrosion up to $10 \mathrm{x}$ are observed when dose rates are $10^{5}$ $\mathrm{rad} / \mathrm{hr}$ (see Haijtink and Accary, 1984; Kim et al., 1984; Westerman et al., 1984). At lower dose rates, $\leq 10^{3} \mathrm{rad} / \mathrm{hr}$, the corrosion rates were indistinguishable from unirradiated tests. For non-brine environments the data are less conclusive. Some studies show slight increases in general corrosion, or initiation of stress corrosion cracking or hydrogen embrittlement in the presence of gamma radiation (see Furuya et al. 1982, Molecke et al., 1981, McCright et al., 1984 and Lewis and Reed, 1987).

The effects of gamma irradiation on solid salt have been studied. Gamma irradiation of crystalline sait produces sodium metal atoms and neutral chlorine atoms within the salt crystal (Levy, 1983). There is concern that the chlorine may mobilize, and if salt brine does enter the disturbed salt and dissolves the sodium metal, the resultant $\mathrm{pH}$ could be very alkaline (Pederson et al., 1984). Gamma irradiation of rock salt also generates numerous gases (e.g., $\mathrm{H}_{2}, \mathrm{O}_{2}, \mathrm{H}_{2} \mathrm{~S}, \mathrm{HCl}$ and $\mathrm{CH}_{4}$ ) depending on the salt impurities present. Jockwer (1984) and Jockwer and Gross (1985) irradiated rock salts with various water contents at $60^{\circ} \mathrm{C}$ at a dose rate of $2.3 \times 10^{6} \mathrm{rad} / \mathrm{hr}$ for $65 \mathrm{hr}$. The samples were in ampoules that contained pure $\mathrm{N}_{2}$ gas as the atmosphere. A few vol\% of $\mathrm{H}_{2}$, and $\mathrm{ppm}$ concentrations of $\mathrm{H}_{2} \mathrm{~S}, \mathrm{HCl}$, and methane were detected. A small amount $(<0.1 \%$ by volume) of oxygen was 
also found. Gray and Simonson (1985) found similar results. The $\mathrm{H}_{2} \mathrm{~S}$ and $\mathrm{HCl}$ could be very corrosive to metallic containers, and thus radiolysis effects in salt repository settings merit further investigation. Peterson (1985) suggests that heat causes the identical reactions in salt environments and will be more important than radiation. Kim et al. (1987) suggest that halide radicals and oxidants formed upon radiolysis of brines can oxidize actinides and increase their solubility.

At the dose rates expected in repositories there should be no significant degradation in the physical stability of clays or packing materials.

From this limited review, the effects of radiolysis on metallic container materials appear to warrant site-by-site or case-by-case study. No clear-cut trends are apparent and few quantitative studies are available to bound the effects of radiolysis on metal corrosion. The effects of radiation, both gamma and alpha (after loss of containment), on the packing material and host rock should be inconsequential on basalt (see Jantzen and Bibler, 1985 and Reed et al., 1985), but for salt, irradiation and heat could produce corrosive species that might effect canister corrosion and waste form leaching (see Pederson et al., 1984). The possibility of nitric acid formation in the moist air of the unsaturated tuff repository and subsequent enhancing effects on container corrosion also warrants attention (see Bibler and Jantzen, 1987; Reed and Van Konynenburg, 1988).

The radiolysis code that is most often used is MAKSIMA-CHEMIST (Carver et al., 1979) with added reactions (see Nicolosi, 1985; 1987; Nicolosi et al., 1987). The available data base for secondary reactions of ground water solutes with irradiation species is not very large. Further reactions with solids (rock, packing, containers and waste forms) are hardly ever quantified and currently not incorporable into radiolysis codes.

\subsection{Coupled Processes}

The thermal, hydrological and mechanical responses of the rock mass surrounding a nuclear fuel waste vault may, in general, be coupled phenomena. (That is, processes are interrelated, each process providing feedback upon all others.) The processes include heat transport, groundwater flow, solute transport, radionuclide transport, and mechanical equilibrium. 
Figure 3.7-1, taken from Chan et al. (1987), summarizes these interactions. The equilibrium stress state is altered by the heat generated from the decay of radionuclides, by changes in the thermal boundary conditions at the surface (e.g., due to glaciation), by changes in hydraulic pressure, or by other surficial processes such as erosion. Alteration of the stress state, in turn, produces changes in the hydraulic conductivity, porosity, and effective thermal conductivity of the medium, as well as generating heat during the expansion or contraction of the rock-water system. The flow field is thus affected by the state of stress. At the same time, the flow field governs the rate of convective transport of heat, solute, and radionuclides. Conversely, the changes in solute and radionuclide concentration and temperature also influence the flow field through changes in fluid density and viscosity. All of these interrelated effects translate into potential driving forces determining the rate of movement of radionuclides.

Other processes may also be involved, such as the alteration of mechanical properties due to geochemical reactions, hydrolysis, changes in permeability due to mineral precipitation, dissolution, or cycles of hydration and dehydration, and multi-phase transport (gas, vapor, fluid, etc.).

While coupled processes are often mentioned in the literature on nuclear waste management, the number of papers that analyze them in detail is relatively small. Frequently, systems in which one process influences another, but there is no feedback, are misleadingly described as coupled. Some genuinely coupled systems are addressed in other parts of this report: models with coupling between ground-water flow and heat transport, between flow and solute transport, or between solute transport and geochemical speciation are discussed in Section 5.2.1. In this section, we address systems in which there is coupling between ground-water flow and the hydraulic properties of rocks.

Several feedback mechanisms by which ground-water flow feeds back to affect permeability or other hydraulic properties of rocks have been discussed in the literature. The principal of these are:

- Pore pressures are large enough relative to rock stress that hydrofracking generates new fractures.

- Ground-water flow is a significant factor in heat transfer. Thermal expansion affects the stress field, which in turn changes fracture apertures and permeabilities. 


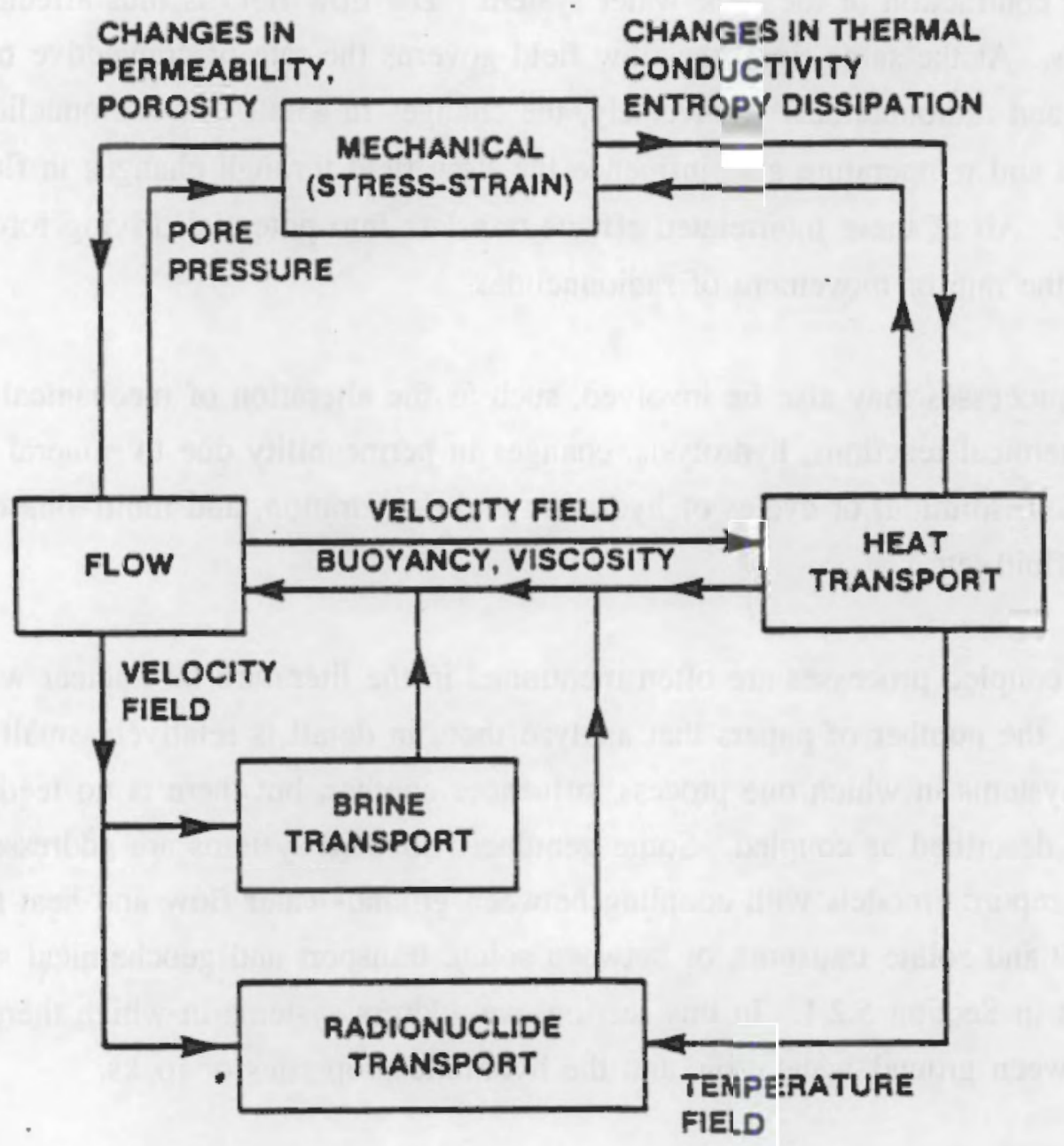

Figure 3-7-1. Interrelationships of thermo-hydro-mechanical processes in the geosphere (from Chan et al., 1987) 
- Rock constituents, such as silica, are dissolved in areas of high temperature, transported to areas of lower temperature, and precipitated there, increasing permeability at the former location and decreasing it at the latter.

- The dewatering of clay, influenced by the combination of temperature and pore pressure, changes the hydraulic properties of the clay.

The remainder of this section summarizes literature on these mechanisms.

While it is difficult to predict the extent of hydrofracking when it occurs, conditions under which it will not occur at all are well defined. Some effort has been devoted to modeling hydrofracking in the context of the petroleum industry (Heuze et al., 1987; Noorishad and Tsang, 1987), and if these models are successful they could presumably be adapted to deal with any issues that might arise in repositories.

Models describing the effects of fluid flow on temperature (Section 5.2.1), temperature on stress (primarily applicable to repository design, and therefore not reviewed here), and, to a lesser extent, stress on permeability (Section 3.4) are all available. These models can be applied in any particular situation to determine whether the feedback loop among these three processes is significant. If the feedback system needs to be analyzed, either of two approaches could be used: use three independent models iteratively to converge on a solution, or develop a model that solves all three coupled equations simultaneously. Development of the latter type of model has been much discussed (e.g., Chan et al., 1987), but we have not seen such a model presented in the literature.

The possible importance of dissolution and reprecipitation as a factor affecting permeability is suggested by a considerable body of field and experimental literature (e.g., Thornton and Seyfried, 1987; Vaughan, 1987). Rates of permeability change due to silica dissolution and reprecipitation have been modeled by Vaughan (1987), who uses a kinetic expression for the rates of reaction, and Braithwaite and Nimick (1984) and Verma and Pruess (1987), who assume chemical equilibrium. (The Braithwaite and Nimick analysis, although ostensibly addressing an unsaturated-zone repository, is more appropriate to a saturated-zone situation because it neglects vapor condensation as a source of water.) None of these models complete the coupling by changing the water flow rate as permeability changes. 
Closely related to this process is the possible precipitation on waste canisters of protective coatings composed of minerals whose solubility declines with increasing temperature (Langmuir, 1987). No analyses of this process have been found in the literature.

The coupling of thermo-plastic and hydraulic effects in the near field of a clay repository is addressed by Baldi et al. (1987). Focusing on skeletal deformation of low permeability clays, Baldi et al. analyze both microstructural and macroscopic aspects of thermal coupling. They offer scenarios of repository performance due to coupled processes in clay, and conclude that "thermally induced nonlinear mechanical behavior of clay has to be taken into account during repository design both to avoid negative effects by appropriate spacing of canisters, and in order to exploit beneficial effects, such as improved self sealing due to enhanced plastic behavior." 


\section{CHAPTER 4. ENGINEERED BARRIER PERFORMANCE}

Engineered barriers in a waste repository may be divided into two groups: those composing the waste package, which are discussed in the first four sections of this chapter, and those associated with the excavation and sealing of the repository, discussed in the final three sections.

The usual design for a waste package consists of the waste form (probably spent fuel, with a filler material possibly added to occupy the void spaces) surrounded by a metal canister and a clay backfill material (see Figure 4-1). Some designs involve multiple metal containers with buffer materials between them, while others omit the clay backfill entirely.

Terminology used to describe waste packages often varies. We will adopt the terms shown in Figure 4-1, with the word "container" used to refer to both canisters and overpacks. It should be noted that the literature uses various terms to refer to backfill in emplacement holes (not to be confused with backfill in repository rooms and tunnels); one example is the Swedish "buffer material."

Because no radionuclides can leave a waste package before the container leaks, this chapter will begin with a discussion of container lifetimes. Then, since current thinking closely associates the release of radionuclides from the waste form with their migration in the vicinity of the package, we will discuss waste forms and clay backfills together in the second and third sections of this chapter. In the Section 4.4, we will address integrated models of waste package performance.

The discussion of engineered barriers associated with the repository excavations begins with a treatment of room backfill in Section 4.5. The next section deals with shaft and borehole seals, and we conclude by addressing water diversion devices in Section 4.7. 


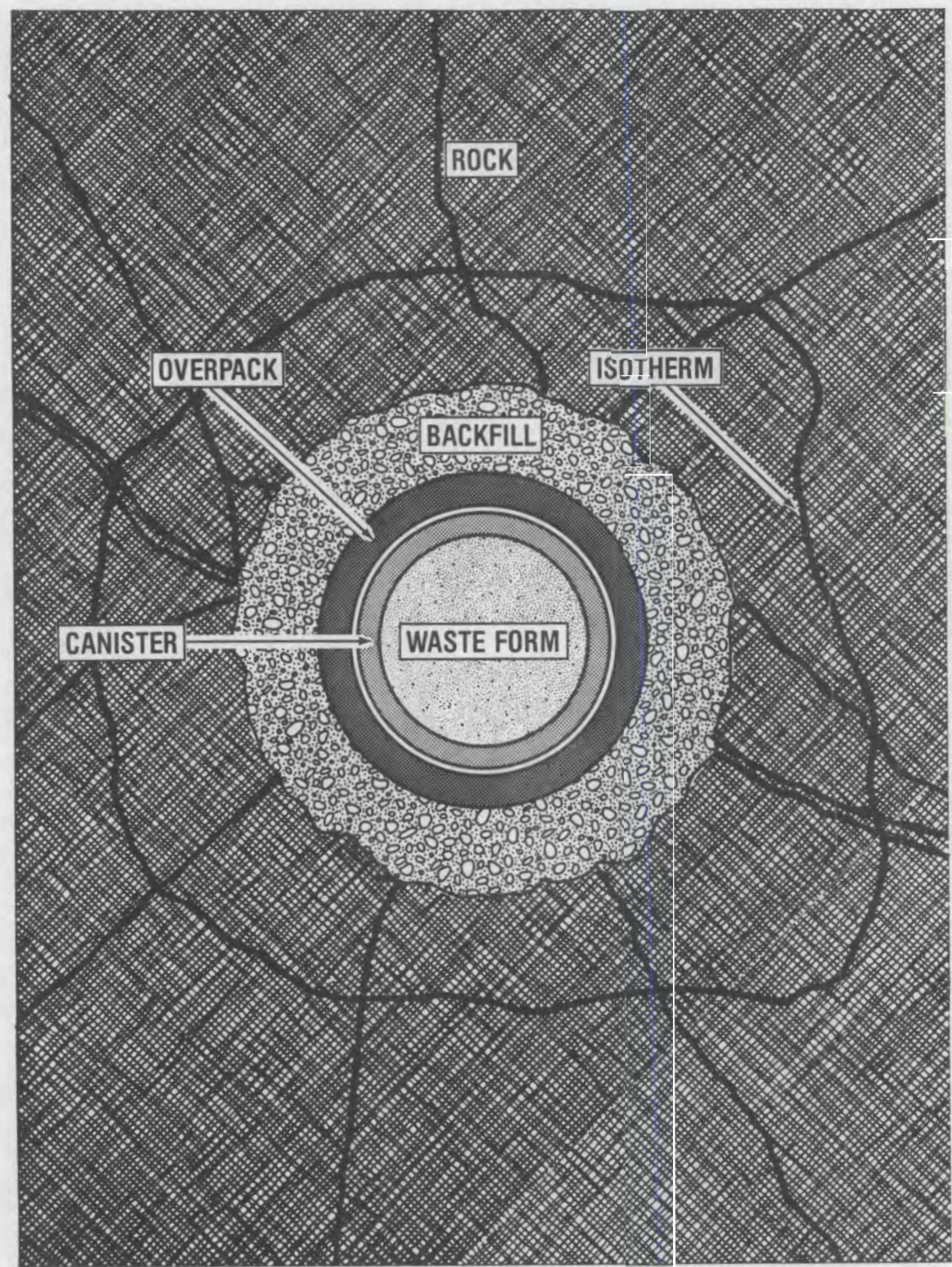

NOTE: SCHEMATIC REPRESENTATION, NOT TO SCALE

Figure 4-1. A hypothetical waste-package design 


\section{1 $\quad$ Containers}

\subsubsection{Factors influencing corrosion}

Most metals in their natural state are not pure metals, but are in the form of metallic salts. When these metal ores are refined or smelted, a losing battle with thermodynamics begins with the metal (except for some "inert" or "noble" metals such as gold) tending toward formation of metallic oxides or other salts. Fortunately, the rate at which most of these processes occur is very slow. Corrosion is defined as the destructive reaction of a substance, particularly a metal, with its environment. The environment associated with a waste container is an extremely complex one that is probably also very corrosive.

The electrochemical reactions which occur as a metal corrodes include an oxidation reaction at the anode and a reduction reaction at the cathode; both reactions must occur for corrosion to continue. These reactions can be described by the following general equations:

$$
\begin{aligned}
& \text { Oxidation: } \mathrm{M} \rightarrow \mathrm{M}^{+}+e^{-} \text {(anode) } \\
& \text { Reduction: } \mathrm{O}_{2}+2 \mathrm{H}_{2} \mathrm{O}+4 e^{-} \rightarrow 4 \mathrm{OH}^{-} \text {(cathode) }
\end{aligned}
$$

The anodic reaction causes the dissolution of the metal into solution. Electrons are produced at the anode and a corresponding cathodic reaction consumes electrons and maintains charge balance. These reactions will occur simultaneously on a metal surface, creating the situation shown in Figure 4.1-1. The thermodynamic force driving the flow of electrons results from a difference in electrostatic potential between the anodic and cathodic sites. The difference may be due to having the cathode composed of one metal and the anode of another metal. This is called galvanic corrosion and will be discussed in more detail later. The difference in potential may also be due to the thermodynamic nature of the site itself and both sites may be on a single metal. The flow rate of the metal ions and electrons may be very slow, resulting in a correspondingly slow corrosion rate.

The environment of the metal is also important in the corrosion process. Although corrosion rates can sometimes be reduced by the environment, nearly all environments are corrosive to some degree and thus the rate will never equal zero. 


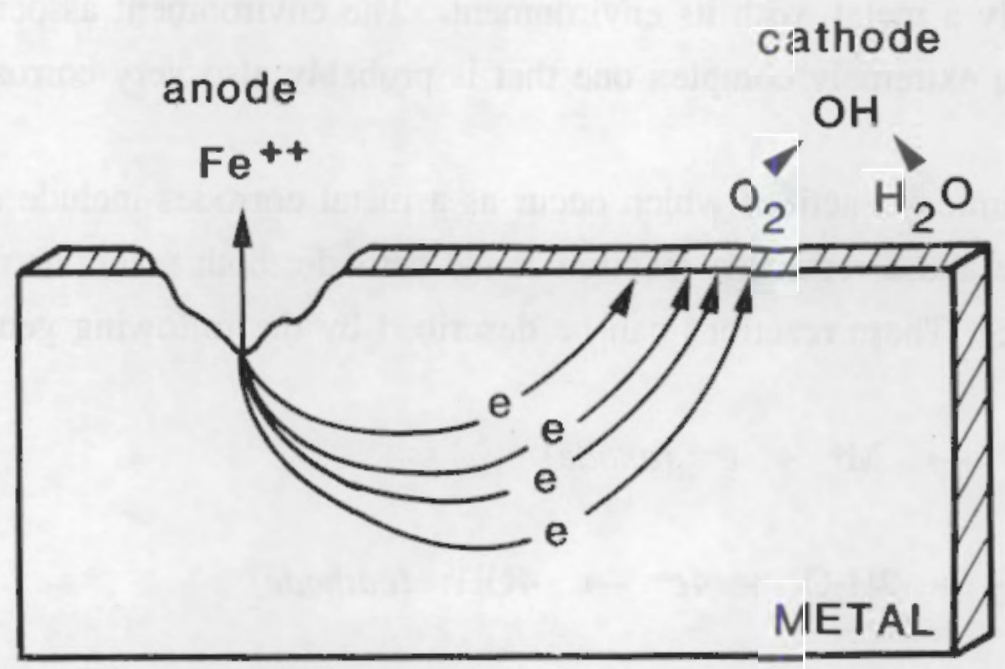

Figure 4.1-1. Uniform corrosion. Both anodic and cathodic reactions are shown.

$$
4-4
$$


Formation of a surface layer of metallic oxide may limit the flow of metal ions into solution. This is called passivity and all proposed container materials possess this property. In some materials or conditions, the film is more able to provide protection than with others. This, again, is a function of both the metal and the environment (West, 1975).

The ability to model corrosion decreases with the complexity of the environment. With modelling often being difficult or impossible, laboratory testing and extrapolation are usually relied upon to provide data on container lifetime and corrosion rates. Tests with alloys in environments that closely simulate waste canisters under expected repository conditions would provide the best information on corrosion rates, but accurate long term data are still very difficult to obtain, particularly when lifetimes in the range of hundreds or thousands of years are needed. The determination of the corrosion rate is also dependent on the type of corrosion expected.

The metal type and method of manufacture are as important as the environment in the corrosion process. Although all of the metals being considered for containers are quite corrosion-resistant, each has factors that need to be examined to better appreciate the strengths and weaknesses of the combined metal and environment. Factors such as the residual or "tramp" elements remaining after production, whether the metal is cast, forged, wrought, or welded, and the size of the grains (or the grain boundary area) are critical in considering corrosion resistance. The physical properties such as yield strength and ductility are also of considerable significance to corrosion properties.

Corrosion in the presence of a liquid (usually water) is called wet corrosion and is the most common type. Dry corrosion in the presence of vapors or gases is most often associated with high temperatures. (Fontana and Greene, 1978). Both types are of concern when examining waste container corrosion. In high level waste repositories, water of various compositions will impinge upon canisters at sufficiently elevated temperatures to cause vaporization, possibly adding gases such as hydrogen, hydrogen sulfide, and others to the environment (Fisher, 1984a).

The types of wet corrosion will be discussed here first since they are likely to occur for most of the lifetime of the container. Mechanisms of corrosion will be discussed whenever possible as well as methods of measurement and prediction. The types of dry 
corrosion and the specific effects of increased temperature will also be discussed. The definition of these types of corrosion is fairly well accepted and concise treatments of them may be found in texts by Fontana and Greene (1978), West (1975), and Skorchelletti (1976).

\subsubsection{Uniform Corrosion}

The type of attack known as uniform corrosion is characterized by uniform dissolution over the entire surface of the metal due to a general breakdown in the passive film that may result from mechanical or chemical effects. Mechanical breakdown may occur when the film is stressed and ruptures, when it flakes off (as in iron and some iron alloys), or as a result of abrasion. Chemical breakdown occurs when the film is dissolved or penetrated chemically. A large area, up to the entire surface, may be involved in this type of corrosion. Uniform corrosion is the most destructive in terms of tons of metal lost per year and is the type most easily modelled. Figure 4.1-1 shows the initiation of corrosion with the right side covered with a passive film. If this film were to be removed by some means, uniform corrosion would take place. Corrosion rates express this type of damage best, so the time to failure can be well estimated. Linear extrapolation methods, in which the container life is found by dividing the container thickness by the weight loss rate (in units of $\mu \mathrm{m} / \mathrm{yr}$ or $\mu \mathrm{g} / \mathrm{cm}^{2}$-day), are applicable.

Metallurgical factors affecting the uniform corrosion rate may include the fraction of the surface occupied by grain boundaries and the amount of cold working the material has had. Although uniform corrosion is the easiest to model, it is not the most serious of corrosion types. With proper monitoring, material which is susceptible to uniform corrosion can continue to perform well for many years, while other forms of corrosion are more difficult to predict. Occurring at specific sites in the material, localized corrosion mechanisms are of greater concern in the present application, since they tend to cause unexpected, premature and devastating failures.

\subsubsection{Galvanic Corrosion}

Galvanic corrosion occurs when two metals of different potentials are electrically connected in the electrolyte. Corrosion will often occur on the more anodic (or less noble) of the metals at a rate that is affected by the respective surface areas of the anode and the 
cathode. If the anode is small in relation to the cathode, enhanced corrosion is possible. This subject has been discussed with respect to nuclear waste containers by Escalante and Gerhold (1975; 1981). A recent overview edited by Hack (1987), although not directly related to high-level waste, covers the most recent work. A diagram of galvanic corrosion is included as Figure 4.1-2.

Although it is sometimes not thought of as being significant in repositories (Soo, 1982), galvanic corrosion has the potential for causing some problems. For example, if two metals are used in the canister package, or a packing material is not used between fuel and container, then metal to metal contact may result in galvanic corrosion. A galvanic series in seawater compiled by Uhlig (1972) can serve as a staning place for examining galvanic coupling.

Metals of nominally the same composition sometimes will corrode galvanically due to small differences in composition. Steels from different countries of origin have led to some rather graphic examples of this type of failure (ASTM, 1987). Occasionally, even different batches of metal manufactured within the same company lead to failure, because differences in grain size and inclusion content may be sufficient to establish the difference in potential required for galvanic corrosion to occur. Also, weldment corrosion can sometimes be traced to a difference in the weld rod content, which leads to a galvanic couple with the non-welded region. It is therefore clear that galvanic corrosion cannot be dismissed out of hand; consideration of even the uncommon type of scenario just presented is necessary to avoid situations where galvanic corrosion could be a problem.

\subsubsection{Pitting}

When chemical breakdown or disruption of the passive film occurs locally, specific sites on the metal may be exposed to damaging species such as chloride ions and pitting may occur. This is one of the most serious and insidious types of corrosion. It may be particularly harmful for waste containers, since a small pit could allow substantial amounts of radioactivity to pass through, even when the rest of the container is intact. Pits are not characterized by large weight loss since they are localized and often have very small diameters. They may be difficult to detect because they may be covered with corrosion products. Figure 4.1-3 shows a graphical representation of pitting. 


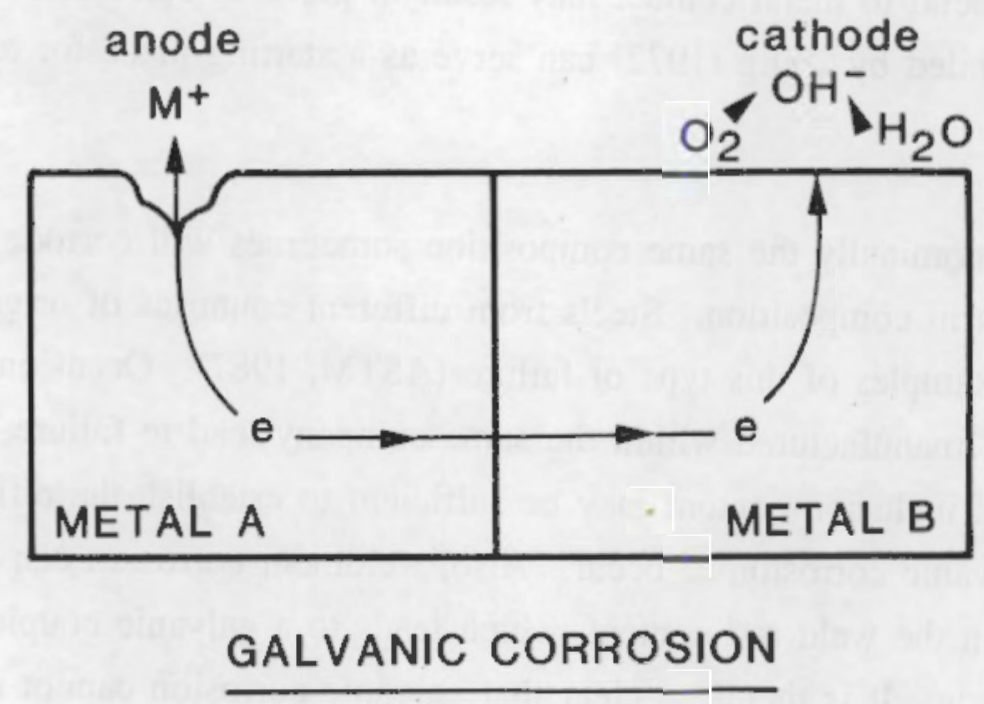

Figure 4.1-2 Galvanic corrosion. Two dissimilar metals electrically are connected in solution. This results in showing enhanced corrosion on the less noble metal (or anode).

$$
\text { 4-8 }
$$




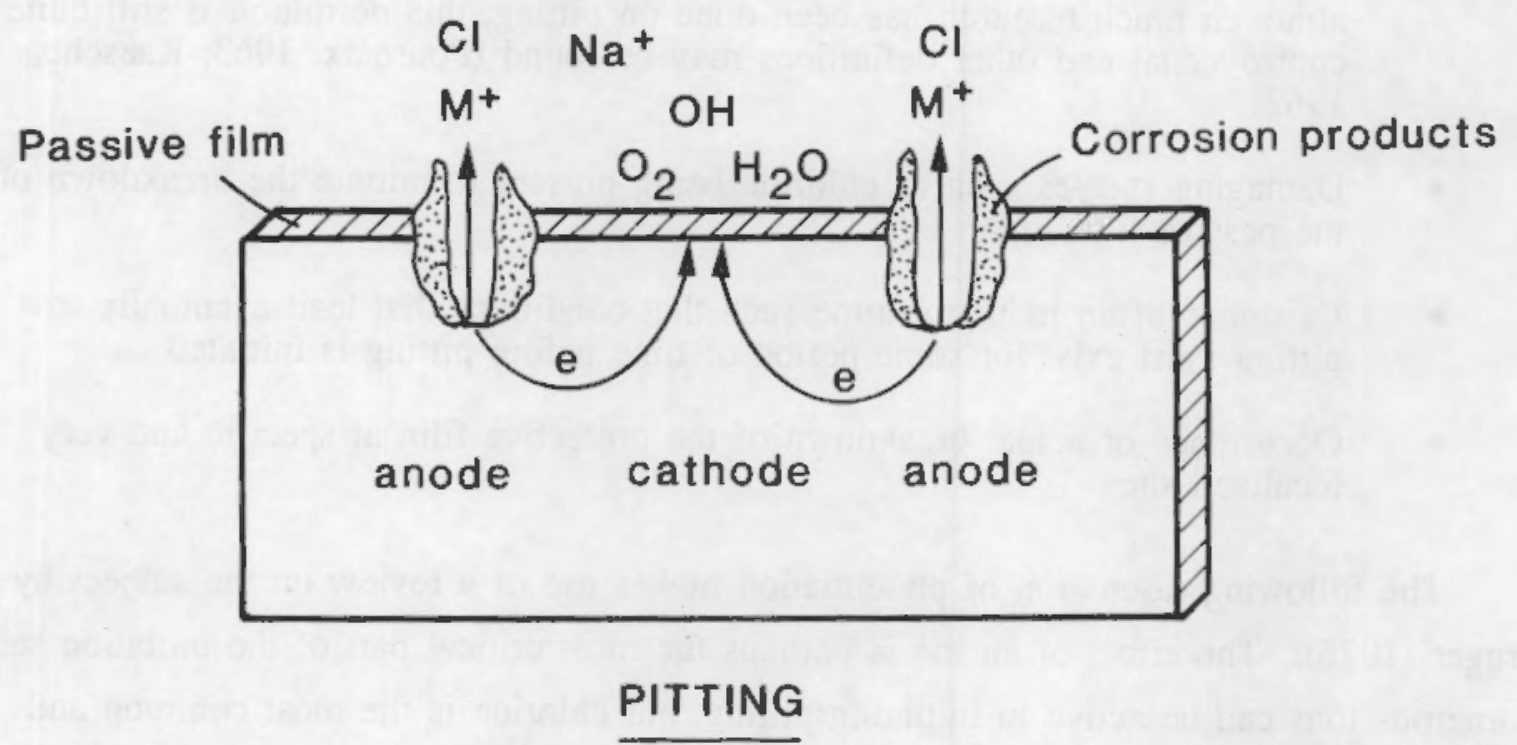

Figure 4.1-3. Schematic representation of the pitting mechanism. The breakdown of the passive film exposes fresh metal to the solution containing chloride ions, leading to the build-up of corrosion products around the site of the pit.

$$
\text { 4-9 }
$$


In examining pitting, it is useful to separate the two parts of pitting: initiation and propagation. This is especially true in considering the susceptibility of nuclear waste containers to localized attack because the mechanisms and tests are specific to each step. For instance, if the initiation step is slow enough to limit the onset of pitting to beyond the thousand year life requirement, propagation need not be considered. If, however, the initiation step is rapid, then the growth of the pit, or the propagation step, determines the useful lifetime of the canister.

Modelling of pitting initiation usually involves the following phenomena:

- Exceeding a certain critical potential, called the critical potential for pitting; although much research has been done on pitting, this definition is still quite controversial and other definitions may be found (Pourbaix, 1963; Kaesche, 1962).

- Damaging species such as chloride being present to initiate the breakdown of the passive film.

- Existence of an induction time such that conditions that lead eventually to pitting must exist for some period of time before pitting is initiated.

- Occurrence of actual breakdown of the protective film at specific and very localized sites.

The following discussion of pit initiation makes use of a review on the subject by Kruger (1976). The effect of an ion is perhaps the most critical part of the initiation step. Numerous ions can be active in initiating pitting, but chloride is the most common and likely to be present in the environment of the canister. The chloride ion (or other damaging species) is thought to either become adsorbed to or create a chloride-containing complex at the surface, contributing to breakdown or thinning of the film and thus pitting. The other type of model competing with this adsorbed species model is that designated "breakdown and repair". In this model, the damaging ion helps reduce the stress necessary to initiate the brittle fracture of the passive film. This model is a component to a model describing stress corrosion cracking and will be discussed in more detail in section 4.1.8. Many of the models of pit initiation are included in articles by Hoar (1967).

Initiation of pitting has been modelled mathematically as a stochastic process (Bertocci, 1985). These mathematical models are not yet sophisticated enough to model real conditions but have been tested for pitting in pure materials such as iron (Bertocci, 
1986). Once the film has been ruptured, the pitting process moves into the propagation phase. This step depends on the continuation of the conditions which lead to the dissolution or breakdown of the passive film. When the local environment becomes acidified due to the restricted flow of ionic species from the pit, the inside area is referred to as an occluded cell (Brown, 1974). This leads to "autocatalysis", wherein the growth of the pit is self-stimulated by the high concentration of hydrogen ions from the corrosion process (Fontana and Greene, 1978).

Some types of metals, such as stainless steel, are much more susceptible to pitting attack than other metals. The finish given the surface will also have an effect on the sensitivity to pitting. Although pitting is more likely to occur on less polished surfaces, pits that form on polished surfaces tend to be larger and penetrate more rapidly.

There are a number of standard methods which can test the sensitivity to pitting of different materials (ASTM, 1986). Tests to examine the propagation of pitting are more often done on nuclear waste canister material than are tests for the initiation of pitting. The test that is probably most common involves simulating a pit and then examining the conditions that will cause this simulated pit to grow. A schematic of this test set-up is shown in Figure 4.1-4.

Testing in high temperature brines under pressure to simulate the conditions thought possible for HLW containers has shown that pitting corrosion is increased dramatically (Beavers and Thompson, 1985; McCright, 1981).

\subsubsection{Crevice Corrosion}

A crevice is formed by covering or shielding a portion of the metal from the solution. Most engineered systems have crevices in their design and it is difficult to eliminate them entirely. In waste containers, the crevices may be formed by the overpacking or by the design of the canister itself; Figure 4.1-5 shows an idealized crevice and the surrounding environment.

The initiation step of both pitting and crevice formation is so similar that it has been suggested that they are two manifestations of one corrosion mechanism (Kruger, 1976). The localized nature of the attack, the self-sustaining or "autocatalysis" at later stages in development, and the occluded cells that lead to the attack are common to both. Both 


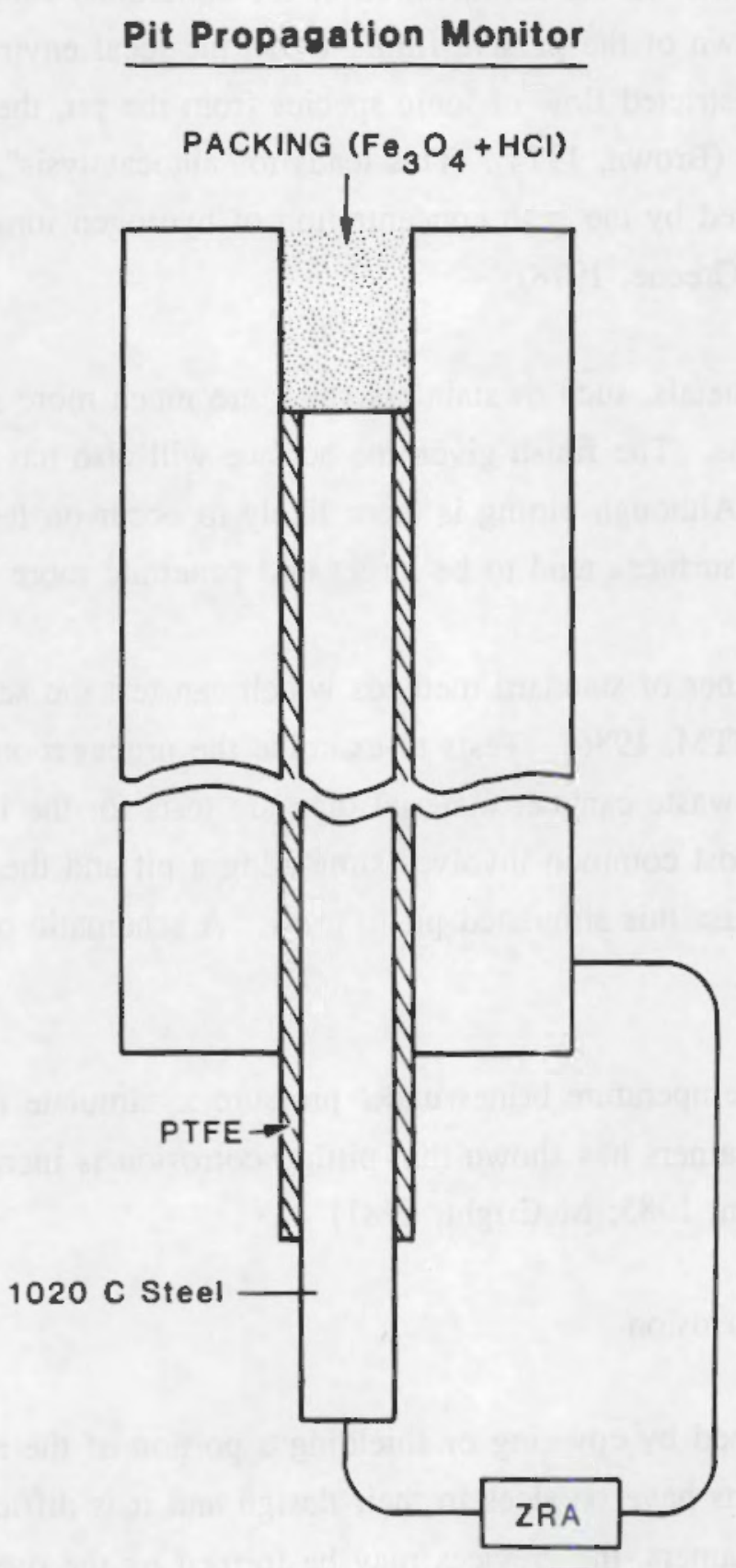

ZRA-Zero Resistance Ammeter

Figure 4.1-4. Pit propagation monitor. Device is shown in a cross section schematic and includes an example of the packing material that is often used for the study of steel pitting.

$$
4-12
$$




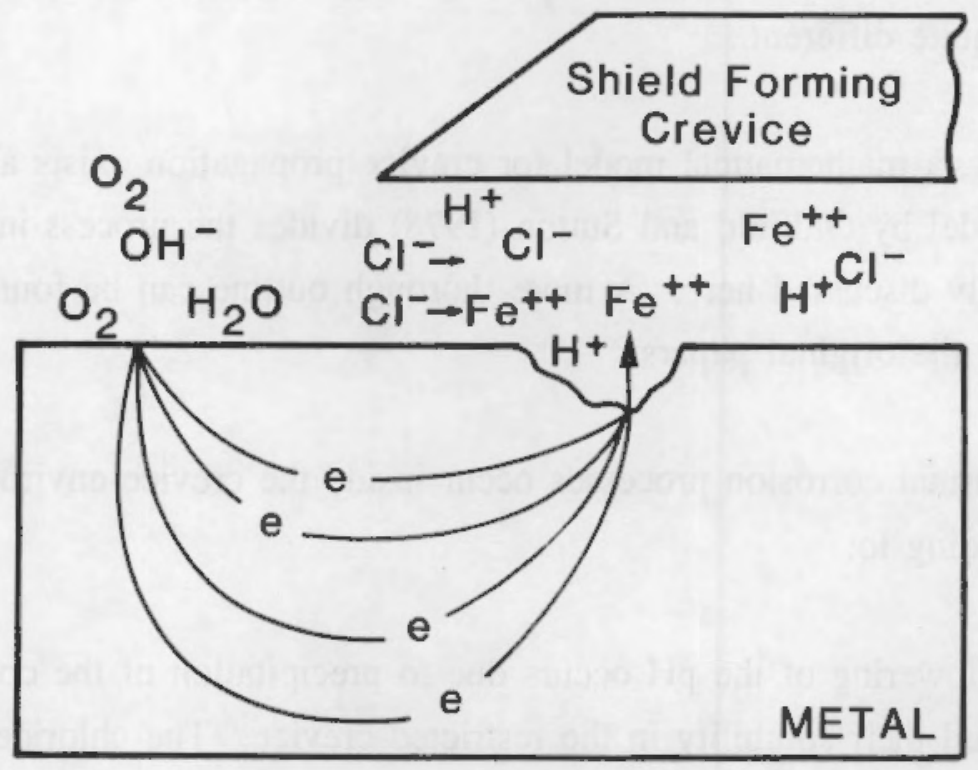

Figure 4.1-5. Crevice formed by shielding the metal from the environment in the presence of chloride or other aggressive ions. 
processes involve a pre-corrosion incubation period before which detection is not possible. Both processes rely on an aggressive species such as chloride ions to facilitate the dissolution or breakdown of the passive film. The differences between pitting and crevice corrosion are mainly geometrical. The crevice is flatter, shallower, and exists before corrosion begins. (An exception here is crevice corrosion that occurs at the water line when a metal is partially immersed in solution. This type of crevice might form under flooded conditions in the repository.) Mass transfer of reactants is more restricted in the case of crevices than in pits. As a result, probably, of these differences, the kinetics of the two processes may be quite different.

Unlike pitting, a mathematical model for crevice propagation exists and is quite well accepted. This model by Oldfield and Sutton (1978) divides the process into four stages, which will be briefly discussed here. A more thorough outline can be found in Kruger and Hardman (1982) or the original papers.

Stage 1 - Normal corrosion processes occur inside the crevice environment, depleting the oxygen and leading to:

Stage 2 - A lowering of the $\mathrm{pH}$ occurs due to precipitation of the corrosion products which have exceeded their solubility in the restricted crevice. The chloride concentration builds up and the crevice begins to self-propagate.

Stage 3 - The concentration of the solution in the crevice reaches a critical point ("critical crevice solution", as defined by Sutton and Oldfield) which can be defined by its $\mathrm{pH}$ and chloride concentration, and which can be calculated.

Stage 4 - Rapid dissolution of the alloy occurs and the crevice grows.

The model of Oldfield and Sutton can be used to characterize an alloy's resistance to crevice attack when the geometry of the crevice and the concentration of chloride in solution are known. As crevices are likely to be present in the environment of the waste package, the model will be of use to evaluate this prospective problem. 


\subsubsection{Intergranular Corrosion}

Grain boundaries in metals tend to be more reactive than the grains themselves (Fontana and Greene, 1978). Localized attack at and adjacent to grain boundaries is called intergranular corrosion. When this occurs, the metal will disintegrate with relatively little corrosion inside the grains. Figure 4.1-6 shows a schematic representation of intergranular corrosion. Both impurities at grain boundaries or depletion or enrichment of one of the alloying elements at the grain boundary can cause this localized attack.

Although none of the container materials presently being considered in repository programs of the U.S. or other countries are particularly sensitive to this type of corrosion, it can occur. Brasses and other copper alloys that some countries have considered are affected by this type of corrosion (Hendrikson, 1978), because the enrichment of zinc at the grain boundary leads to enhanced attack, as will be discussed further in the section on selective dissolution.

Certain stainless steels may become "sensitized" or susceptible to grain boundary attack when they are heated to between 950 and $1450^{\circ} \mathrm{F}$. The depletion of chromium at the grain boundaries and formation of chromium carbides is accepted as the mechanism for this sensitization. In stainless steels, proper handling and heat treatment or enrichment in chromium can virtually eliminate this type of corrosion. In fact, this is one of the few types of corrosion that can be eliminated by proper treatment and handling of the materials.

\subsubsection{Selective Leaching}

Selective leaching is the preferential removal of one element from an alloy by corrosion. This occurs in alloys consisting of metals of which one is much less noble than the others; this is the element that will be removed. The most common example occurs in brasses and is called dezincification since it is the removal of the zinc. Dealloying is the general term used for this process.

When one element is preferentially removed, the material loses its mechanical integrity and cracks or crumbles. On the microscopic level, the metal is porous, since one of its components has been removed. In some metals, there will be a visible change in the 


\section{Intergranular Corrosion}

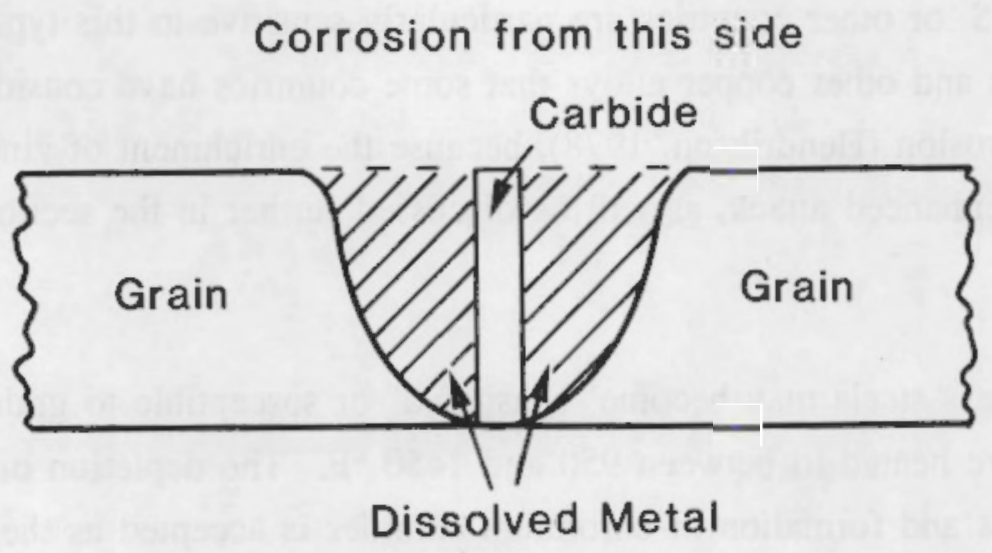

Figure 4.1-6. Intergranular corrosion occurring at a carbide inclusion on the grain boundary. 
color of the alloy. Dezincified brass, for example, is copper-colored instead of yellow. Some nickel-based alloys susceptible to this type of corrosion might be used for waste containers (Handwerker, 1987). The mechanism of dealloying is an active area of research (Van Orden, 1988); it is thought to involve either dissolution of the less noble component from the surface, followed by extremely rapid diffusion of that component from the bulk leaving islands of the more noble component, or dissolution of the entire alloy, followed by replating of the more noble component onto the surface.

A specific example of dealloying that occurs in steels is called "graphitization", and has the potential to become a problem with their use. It is really the preferential removal of the iron matrix, leaving the carbide particles on the surface. This is an extremely slow process but could be a problem over the lifetime of waste containers. This corrosion process must also be considered if nickel based alloys are used.

\subsubsection{Stress Corrosion Cracking}

The simultaneous presence of tensile stress and a specific corrosive environment can lead to stress corrosion cracking (SCC). This process requires synergism of two things: the stress, well below that leading to mechanical failure, and the specific environment which causes corrosion but would also not lead to as rapid or dramatic a failure as the combination does. There are two types of SCC: intergranular cracking, which proceeds along grain boundaries, and transgranular cracking, which proceeds across grains. Each type is thought to have a different mechanism, and both will be discussed later in this section.

Figure 4.1-7 shows a comparison of two materials, one in which SCC occurs and the other where it does not. When SCC occurs, the maximum load to failure is much less. The level of stress under which susceptible materials fail is often within the typical design stress. The process also proceeds rapidly and is difficult to detect prior to failure.

Not all materials are susceptible to SCC. It is the combination of a susceptible metal, environment, and stress that causes failure. The presence of aggressive ions such as chloride and magnesium also contributes. Steels, stainless steels and titanium alloys are all susceptible to SCC in environments not far different from those found in the repository sites (Fontana and Greene, 1978). The important variables affecting SCC are: temperature, 


\section{SCC PARAMETERS}

Ratio SCC : No SCC for time-to-failure, Maximum load (L), Elongation (e), Area (A),

True failure stress (Failure load (F) / Area at failure)

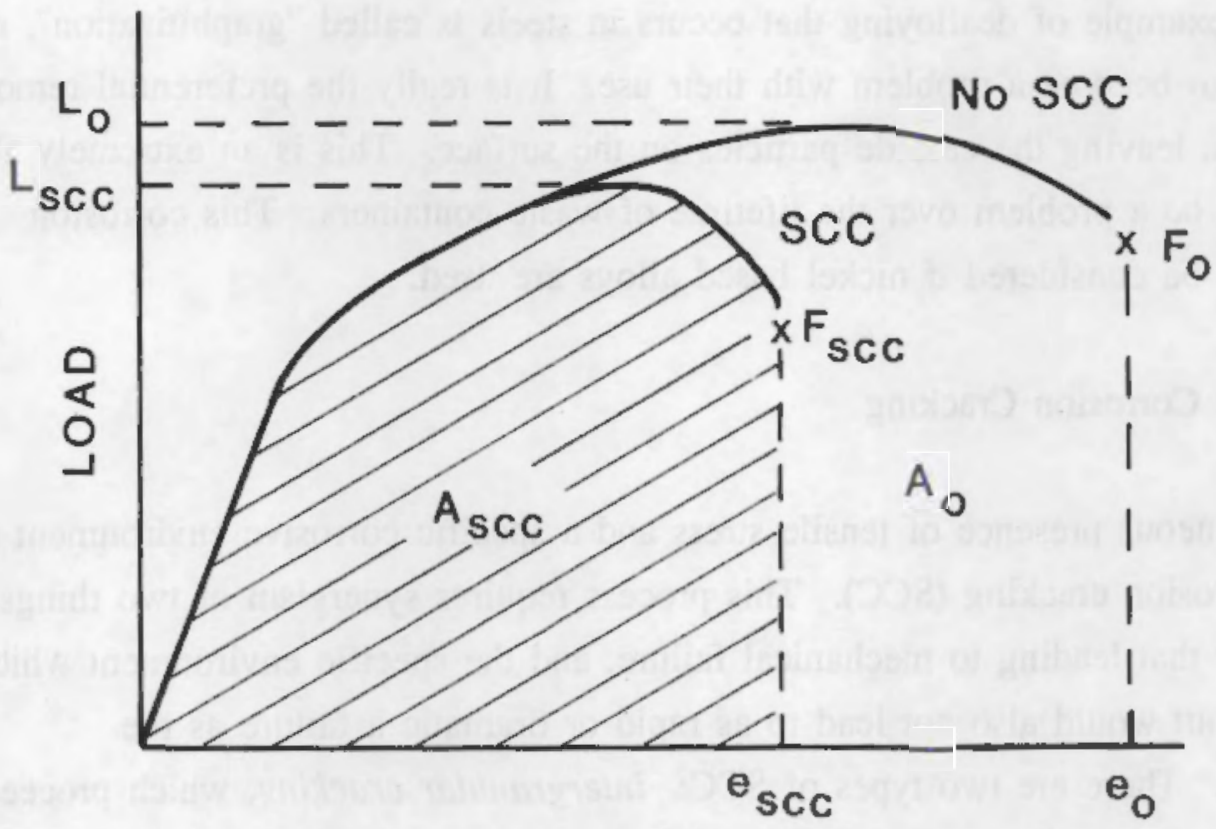

ELONGATION

Figure 4.1-7. Comparison of two materials with differing susceptibility to SCC. The susceptible material fails by SSC at a much lower load and at less elongation. 
solution composition, metal composition, stress and structure of the metal. In general, SCC is accelerated by increasing temperature. Dayal et al. (1982) reported for stainless steels in chloride environments a dependence of time to failure of the following form:

$$
t_{\mathrm{f}}=A^{\mathrm{B} / \mathrm{T}}
$$

where $A$ and $B$ are constants that depend on the steel composition and the chemical environment and $T$ is the absolute temperature.

Most alloys that are susceptible will begin cracking at temperatures as low as $100^{\circ} \mathrm{C}$. High temperatures that cause local boiling can lead to the concentration of aggressive ions and may contribute to SCC. The chemical breakdown of packing material may also add to the concentration of ions causing SCC.

The time to failure in SCC is a function of the crack depth. For that reason, tests should be conducted to failure; very little physical and mechanical evidence of cracking is apparent until failure occurs. Probably the preferred type of testing is "slow strain-rate testing," which was developed by Parkins (1979) in the early 1960's. Good correlation is obtained between these tests and service failures, and they can be used to rank materials as to their sensitivity to SCC in a specific environment (Payer, 1979).

Susceptibility to SCC is affected by the composition of the metal, the preferred orientation of the grains, the amount of precipitates present, the amount of cold work, and stability of the alloy (Fontana and Greene, 1978). Welded areas may be under greater stress than the rest of the container and heating during welding may sensitize the metal or modify the composition, thus enhancing SCC (Soo, 1984).

The mechanism of stress corrosion cracking differs, depending on whether the intergranular or transgranular type of cracking is occuring. Both mechanisms have in common the following cyclic steps:

- Breaking of the surface film at the tip of the crack.

- Rapid advance of the crack for a specific distance.

- An induction period while the internal stress builds up enough to break the surface film. 
The differences in the two mechanisms are in the means by which the first and third steps occur. In intergranular SCC, an anodic breakdown of the film is thought to precede the first step. The crack-tip is thought to be more anodic than the rest of the crack, and the film at the crack-tip is thinned or chemically broken-down, such that a small stress will cause the crack to advance along the anodic grain boundary (Pugh, 1966). During the induction time (final step) the anodic process that thins the film begins anew, leading to the first step. In transgranular SCC, the film itself is thought to be brittle. When a stress is applied, the crack forms in the brittle film and continues to propagate along slip lines into the ductile matrix. During the induction time the film reforms and the stress rebuilds on a slip plane (Pardue, 1961).

Stress corrosion cracking is perhaps the most difficult to deal with of the types of corrosion that containers may encounter. Even the slow strain-rate tests cannot adequately predict the rate of crack growth under the strain conditions expected in the repository site. Further discussions of the difficulty in this kind of extrapolation are included in papers by Thomas (1986) and Gopal (1984). An overview of the testing techniques commonly used is presented by Ugiansky (1979).

In addition to the above types of wet corrosion, there is another: erosion-corrosion. It results from motion of a corrosive solution with respect to the metal container. It does not seem likely that this type of corrosion would be a problem since the fluid around the canisters would not move rapidly.

\subsubsection{Dry Corrosion}

Dry corrosion is generally negligible at room temperatures. At higher temperatures, however, reactions between metals and oxygen or other gas-phase oxidants can be important.

At high temperatures the competition for oxygen increases. In an environment where oxygen is limited, such as one where the overpack has consumed most of the possible oxidants, those elements with a higher free energy of oxide formation are oxidized to a greater degree. In some cases (such as stainless steel) a protective scale forms. But even in this case, the substrate is depleted in chromium. 
Corrosion occurs even in de-oxygenated environments. If oxygen were eliminated entirely, the corrosion process would differ, and a different cathodic equation than (4.1-2) would be needed to describe it.

At higher temperatures the rate of most reactions is dominated by diffusion, either outward cation diffusion or diffusion of defects through the scale. The chemical compounds formed on the surfaces are found to be slightly different than those at room temperature but can be predicted by models designed for high-temperature applications (Kubaschewski, 1962). These models give information about the thermodynamic stability of the compounds which form, but do not describe their formation rate (kinetics).

An empirical law of weight gain versus time is often used to describe the kinetics. The simplest (but least desirable) is the linear law

$$
W=k_{1} t
$$

where $W$ is the weight gain per unit area, $t$ is time, and $k_{1}$ is the rate constant. It is least desirable because the oxide film forms at a rate constant with time.

Faster formation of the oxide is usually the case and diffusion controlled oxidation follows a parabolic law:

$$
W^{2}=k_{\mathrm{p}} t+c
$$

where $k_{\mathrm{p}}$ is the parabolic rate constant and $C$ is a constant. Metals characterized by this parabolic law have non-steady-state diffusion which is controlled by the diffusion through an ever increasing oxide thickness. Iron, cobalt, and copper exhibit this type of behavior.

At ambient or slightly elevated temperatures, aluminum, iron, copper, and cobalt follow a logarithmic law of the form:

$$
1 / W=C-k_{\mathrm{L}} \log t
$$


This type of oxidation results from the effect of electric fields within very thin oxide layers assisting ionic transport across the scale film. The above equations are based on work by Wagner (1933).

At high temperatures, sulfur-containing clay minerals may give up their sulfur and lead to the formation of $\mathrm{HS}, \mathrm{H}_{2} \mathrm{~S}$ or $\mathrm{SO}_{2}$. These corrosive elements are not present at lower temperatures and will contribute to the higher corrosion rates seen at higher temperatures.

\subsubsection{Hydrogen Damage}

Several types of damage in metals can be induced by the presence of hydrogen. Hydrogen blistering results from the penetration of hydrogen into a metal. The result is local deformation and sometimes the complete destruction of the metal. Hydrogen embrittlement is also caused by the penetration of hydrogen through the metal and results in the loss of ductility and tensile strength. Decarburization, the removal of carbon from steel, can be produced by moist hydrogen and occurs at high temperatures. Hydrogen blistering and embrittlement may occur as a result of corrosion, producing severe mechanical damage and often causing catastrophic failure. These phenomena are all of greatest importance at high temperatures, but in some circumstances they could be relevant to a repository.

Hydrogen damage is produced only by atomic hydrogen, which is the only species capable of diffusion through metals. The reduction of molecular hydrogen leads to the production of hydrogen atoms, as do some corrosion processes and electroplating. These are the major sources of hydrogen in metals. Other materials, such as sulfide ions, phosphorous, and arsenic compounds, reduce the rate of hydrogen ion reduction, generating a lesser concentration of atomic hydrogen in the metal.

If hydrogen atoms are produced on the metal surface and diffuse into a void in the metal, they combine to form molecular hydrogen. Since the gas cannot diffuse through the metal, its pressure may build up to several hundred thousand atmospheres and cause deformation, or hydrogen blistering (Rhodin, 1959). 
Hydrogen diffusing into titanium will form hydrides and degrade the mechanical properties. Embrittlement can also occur in other metals, such as iron and steel, but the interaction is not so well understood. It is thought that environmentally assisted cracking of some iton and titanium alloys is due to the interaction of hydrogen with the crack (Fontana, 1961). Hydrogen assisted cracking can be distinguished from stress corrosion cracking by applied currents. If an anodic current increases the cracking, it is SCC; if cathodic, then the growth is due to hydrogen.

Decarburization can adversely affect alloys that rely on interstitial carbon or carbides for strengthening. A reduction in tensile strength and creep properties will usually result.

Over a very long life, hydrogen damage could be quite severe and reductions in a number of the critical mechanical properties, such as tensile strength and creep resistance, might lead to mechanical failure of the canisters.

\subsection{Waste Forms}

Once a high-level waste container has breached, water will be able to contact the waste form inside. (There may be some additional delay while backfill material inside the package is wetted.) The usual practice in performance assessment is to assume the complete disappearance of the container as a physical barrier (metal and corrosion products may still affect water chemistry) as soon as it is breached. This has the advantages of simplicity and conservatism.

Four regimes may be distinguished for the release of radioelements from waste forms in contact with ground water (modified from Koplik et al., 1982):

- Elements released from the waste matrix in greater quantities than are soluble in the water immediately adjacent to the waste. The rate of release is determined by the solubility and the rate at which diffusion, dispersion, advection, or other processes transport the element in solution away from the interface between waste and water.

- More soluble elements in a matrix whose rate of dissolution is controlled by its equilibrium solubility. The radioelements are released congruently as the surrounding matrix dissolves.

- More soluble elements in a matrix whose rate of dissolution is kinetically controlled, with trace elements released congruently as the matrix dissolves. 
- A matrix that dissolves so slowly that the release of the radionuclides it contains is controlled by their diffusion through the matrix.

Which of these regimes is controlling depends on the nature of the waste and of the physical and chemical environment. In any given case, dissolution of different elements may be controlled by different regimes.

Early repository performance studies assumed that all radionuclides would dissolve in the same proportion and at a rate determined by the degradation of the waste matrix. The use of equilibrium solubilities and mass transfer calculations was first suggested by Neretnieks (1978). Since then, experimental work on waste leaching, thermodynamic calculations of actinide solubility, the popularity (in concept) of clay backfills, and the increasing probability that heterogeneous spent fuel will be the major waste form have all directed attention toward the solubilities of the radioactive elements as determining factors in radionuclide dissolution. The bulk of this section is therefore devoted to a review of formulas for calculating solubility-controlled releases. A short discussion of kinetically controlled release rates is also included.

\subsubsection{Solubility-limited releases}

Chambré and Pigford (1984) concisely review the evidence for the controlling role of mass transfer with radioelement solubilities as a boundary condition that determines the rate of release, and they present many of the available analytic solutions for radionuclide release rates. The most elaborate development of these solutions is by Chambré, Pigford, and their co-workers. Solutions for solubility-limited dissolution can be used in two ways:

- $\quad$ Release of each element can be assumed to be limited by its solubility.

- Solubility of major constituents (such as silica or uranium dioxide) can be assumed to determine the dissolution rate of the waste matrix, with other elements released congruently.

The basic Chambré model (illustrated in Figure 4.2-1) is based on the assumption that the concentration of an element in the water at the surface of the waste form is equal to its solubility. The waste form is treated as an infinite cylinder, with water flowing past in a direction normal to the cylinder axis and contaminants moving away from the cylinder by molecular diffusion and advection. In this model, the mechanism controlling the rate of dissolution is the transport of dissolved species across a boundary layer in the fluid 

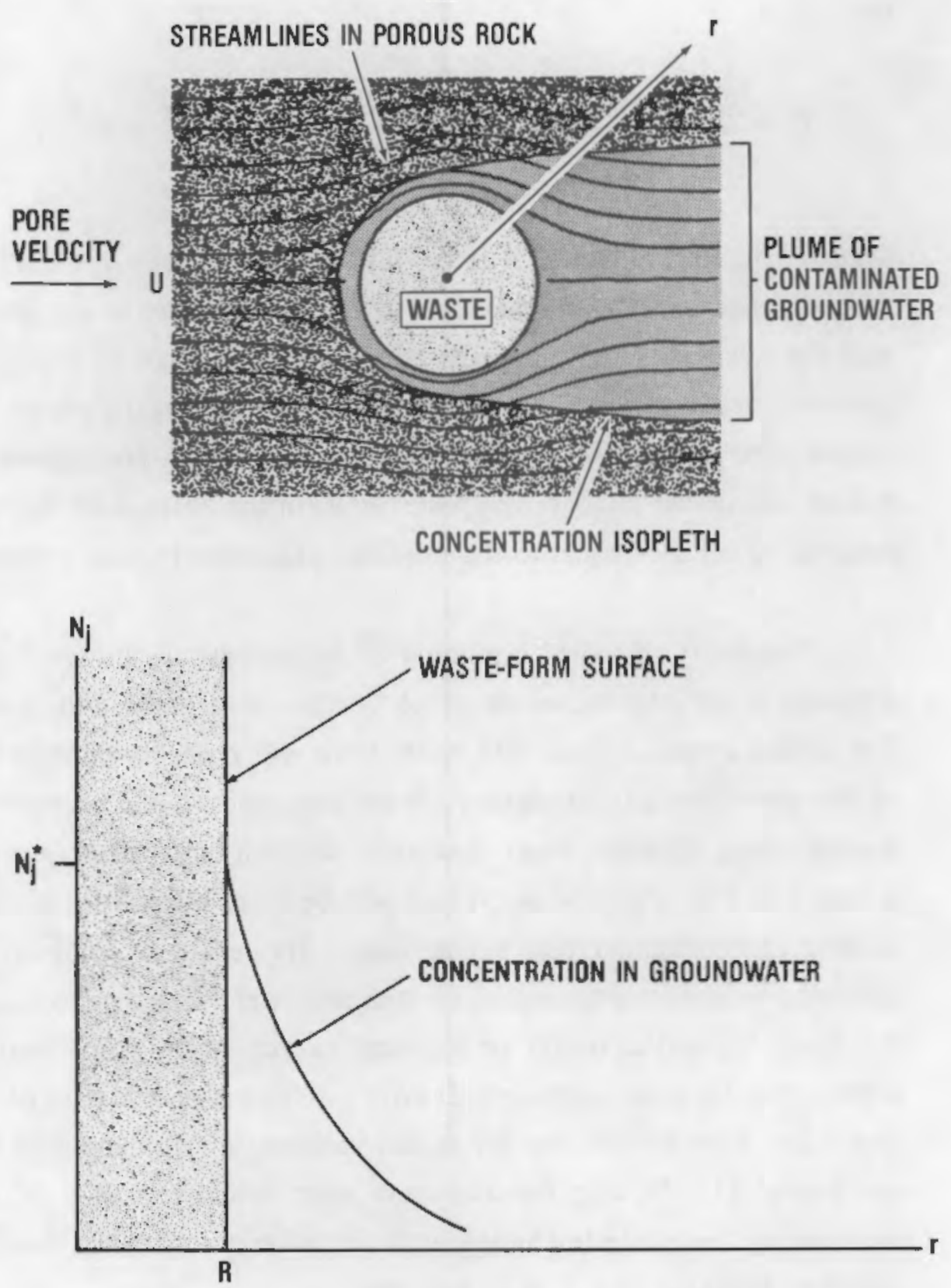

Figure 4.2-1. Chambré's model for flow of ground water past a waste cylinder 
immediately adjacent to the waste cylinder. (Note that the boundary layer is defined by solute concentration, not fluid velocity.) The steady-state fractional release rate $f$ of a nondecaying elemental species $j$ and of its isotopes is calculated by Chambré and Pigford to be:

$$
\dot{f}_{\mathrm{j}}=\frac{8 \in N_{\mathrm{j}}^{*}(D U)^{1 / 2}(1+R / L)}{(\pi R)^{3 / 2} n_{\mathrm{j}}} \quad \text { for } \quad \frac{U R}{D}>4
$$

where $N_{\mathrm{j}}^{*}$ is the solubility, $D$ is the diffusion coefficient in water, $L$ is the length of the waste cylinder, $R$ is its diameter, $U$ is the pore velocity of the ground water before it comes near the waste, $\epsilon$ is the porosity of the surrounding rock, and $n_{\mathrm{j}}$ is the bulk density of elemental species $j$ in the waste. It should be noted that $f_{\mathrm{j}}$ is the elemental fractional release rate; when both radioactive and stable isotopes are present in uniform mixture, the release rate of the radioactive species will (in the absence of differential kinetic effects) be reduced by a factor equal to the ratio of radioactive isotope to total element present.

One easily remedied limitation of this analysis is the assumption that molecular diffusion is the only means by which contaminants move transverse to the direction of flow. The region around a dissolving waste form will probably contain a heterogeneous collection of corrosion products, precipitated waste constituents, and products of chemical reactions among waste, package, water, and rock. In such circumstances, if the water flow is substantial, hydrodynamic dispersion will be more effective than molecular diffusion in moving contaminants across stream lines. The results of Chambré and co-workers can be extended to such circumstances by straightforward means. Because the governing equations for dispersion and diffusion are identical except for the name of the constant, one need only replace the diffusion coefficient $D$ with the dispersion constant $\alpha U$. (An approximation is introduced here by ignoring the spatial variation of ground-water velocity, but the error will not exceed $41 \%$ because the maximum water velocity is $2 U$.) If the porous medium surrounding the waste (including both corrosion products and rock) can be taken to be uniform, Equation (4.2-1) then becomes

$$
f_{\mathrm{j}}=\frac{8 \in N_{\mathrm{j}}^{*} \alpha^{1 / 2} U(1+R / L)}{(\pi R)^{3 / 2} n_{\mathrm{j}}} \quad \text { for } \alpha U>D
$$


where $\alpha$ is the lateral dispersivity. In this model, the boundary layer is still the controlling barrier, but its thickness is determined by hydrodynamic dispersion rather than molecular diffusion.

As another limiting case, suppose the emplacement hole is much more permeable than the surrounding rock. If the emplacement hole is elongated in shape, flow will tend to be channeled through the annulus around the waste and be nearly axial in direction. Flow through the less permeable rock outside the annulus will be small because gradients will be reduced by the "hydraulic short circuit" through the emplacement hole. With the longitudinal flow direction rather than the transverse flow assumed by the previous formulas, the fractional dissolution rate is (Scott and Koplik, 1984) one of the following:

$$
\begin{aligned}
& \dot{f}_{\mathrm{j}}=\frac{4 N_{\mathrm{j}}^{*} \epsilon^{*}\left(D U^{*}\right)^{1 / 2}}{(\pi L)^{1 / 2} R n_{\mathrm{j}}} \\
& \dot{f}_{\mathrm{j}}=\frac{\epsilon^{*} N_{\mathrm{j}}^{*} U^{*}\left(R^{*} 2 / R^{2}-1\right)}{L n_{\mathrm{j}}} \\
& \dot{f}_{\mathrm{j}}=\frac{4 N_{\mathrm{j}}^{*} \epsilon^{*}\left(D U_{\mathrm{s}}\right)^{1 / 2}}{(\pi L)^{1 / 2} R^{*} \mathrm{n}_{\mathrm{j}}}
\end{aligned}
$$

where $R^{*}, \epsilon^{*}, U_{\mathrm{s}}$ and $U^{*}$ are, respectively, the outer radius of the annulus, the porosity of the material in the annulus, the pore velocity of water in undisturbed rock immediately adjacent to the annulus, and the pore velocity of water in the annulus. In the limit where there are large differences between the values given by these expressions, the correct formula to apply is either (3) or the greater of (4) and (5), whichever is less. If dispersion exceeds diffusion, the same substitution as in (2) should be made in Equations (3) and (5), and Equation (3) will apply whenever $(\alpha L)^{1 / 2}<R^{*}-R$.

Equation (3) represents the case where the boundary layer within the annulus is the controlling barrier. Equations (4) and (5) represent the cases where the water in the annulus is well mixed. This could occur because the boundary layer would (if $R^{*}$ were assumed infinite) extend beyond the actual outer boundary of the hole, or because water density gradients due to temperature or concentration effects near the waste induce convective 
mixing (as observed at low flow rates in laboratory experiments by McGrail et al. [1985]). The release rate is then controlled by the transport of contaminants out of the annulus.

Equation (4) corresponds to the situation where advective transport exceeds lateral diffusion or dispersion into the surrounding rock; in this case, the controlling barrier is whatever resistance to flow limits the flux of water through the emplacement holes. Equation (5) represents the case where lateral diffusion into surrounding rock is important.

The above equations assume a significant ground water flow velocity $U$ through the emplacement medium. With lesser ground water velocity (the condition in the diffusion-dominated transverse flow case is that $U R / D$ is much less than four), they must be replaced by an equation (Chambré and Pigford, 1984) for the steady-state release from a package embedded in an infinite porous medium saturated with relatively stagnant water:

$$
\dot{f}_{\mathrm{j}}=\frac{\beta \in D N_{\mathrm{j}}^{*}}{n_{\mathrm{j}}} \text {, as } U \rightarrow O
$$

where $\beta$ is a geometrical factor. For a spherical waste form of radius $R$ :

$$
\beta=\frac{3}{R^{2}}
$$

The solutions (1) through (6) all rest on the assumption that the only means by which solutes leave the system is transport in ground water. If other processes which remove the solute from solution are present, the effect will be to lower the concentration at a distance from the waste while the concentration at the waste surface remains constant (our model assumes) at the solubility. This increase in concentration gradient will cause the fractional release rate from the waste form to exceed the values given by Eqs. (1) through (6). While the absolute amount of solute reaching large distances from the waste form may not increase, some regulations governing waste form performance address fractional release rates at the waste package surface.

Several processes which could increase fractional release rates by removing solute are discussed in the literature. These include:

- Radioactive decay. This will have a substantial effect on release rates of nuclides with half-lives less than or comparable to the time to pass across the 
boundary layer. A formula for the geometry of Figure $4.2-1$ is given by Chambré and Pigford (1984).

- Change in solubility. Decreases in temperature and changes in ground-water composition as one moves away from the waste may cause changes in solubilities. If the solubility of a species decreases rapidly enough away from the waste, it will tend to precipitate. Garisto and Garisto (1986a) have developed a one-dimensional numerical model which predicts the change in dissolution rate when this occurs.

Sorption has no effect on the steady-state release rates given by Equations (1) through (6). However, it can greatly delay the approach to steady state. At early times, sorption sharpens concentration gradients, increasing release rates from the waste form while reducing the amount transported beyond the boundary layer. For diffusion-controlled dissolution of a sphere of radius $R$, Chambré has derived (Chambré and Pigford, 1984) an equation for the time $t$ for the dissolution rate of a nondecaying species to equal $(1+u)$ times the steady state value:

$$
t=\frac{B R^{2}}{\pi D u^{2}}
$$

where $B$ is the retardation factor.

All of these analyses are for waste burial in the saturated zone. Above the water table, if waste packages are separated from surrounding rock by an air space or coarse material, a continuous water phase will not exist and it may be possible to define unambiguously a volume of water in contact with the waste package. One could then derive dissolution rates by assuming saturation of this water, along the lines of Equation (4).

Chambré and Pigford (1984) assess the value of these analyses as follows:

$\ldots$ analyses of the solubility-limited dissolution rates are useful for predicting the long-term release of radionuclides in a repository if the solubilities are known and if there are no other mechanisms that can release and transmit radioactivity to the biosphere. The solubilities of many of the species are sensitively affected by the local oxidizing-reducing conditions of the ground water and the host rock, the acidity or alkalinity, the temperature, and the presence of complexing species such as anions and some organics. The solubilities must be known for such analyses to be used as a basis for repository design. 
Solubilities may either be determined experimentally or calculated from the thermodynamic models described in Section 3.3. Rai et al. (1983) have summarized the research needed (it is considerable but not overwhelming) to determine the solubilities of the actinide elements under repository conditions. Allard (1984) presents an instructive calculation of actinide and technetium solubilities in waters from deep crystalline rocks, showing where data have not been measured and must be estimated.

As Chambré and Pigford point out, all analyses based on solubilities assume that contaminants can only be transported in the dissolved form. Some attention has been directed to the possibility that colloids could carry radioactivity away from a waste repository. The principal concerns are that insoluble elements could be released from a waste matrix in colloidal form (Avogadro and de Marsily, 1984) or that radioelements could bind to clay colloids (Shade et al., 1984).

A further complication arises when the dissolution rate of glass wastes is computed from the solubility of amorphous silica, as in the calculations by Zavoshy et al. (1985). Silica may exist in a geologic environment in a very large number of solid phases, including quartz, amorphous silica, feldspars, micas, clays, amphiboles, and pyroxenes. According to Hem $\left(1985\right.$, p. 72 ), the solubilities of these phases (expressed as $\mathrm{SiO}_{2}$ ) range from $6 \mathrm{mg} / \mathrm{L}$ for quartz to $115 \mathrm{mg} / \mathrm{L}$ for amorphous silica at $25^{\circ} \mathrm{C}$. (While amorphous silica is thermodynamically metastable and does not, strictly speaking, have a solubility, in practice the use of a solubility of amorphous silica yields reliable interpretations of geochemical reactions.) Hem states that:

Natural water normally has more dissolved silica than the quartz equilibrium value but less than the amorphous silica value, which is the likely upper equilibrium limit. The general tendency for silica concentrations in natural water to fall within a rather narrow range suggests that some other type of solubility control may exist.

These observations suggest several possibilities. If the concentration of dissolved silica at the surface of a waste form is controlled by the solubility of amorphous silica, precipitation of silicates on the surface of the glass or in the vicinity would be likely. Silicate layers are often observed on glass surfaces in long-term leaching tests. Indeed, thermodynamic calculations by Fritz et al. (1986) suggest that clay precipitation will be induced by heating around a granite repository even if the presence of the waste package is 
ignored. The nature of the precipitates would probably depend on the composition of ambient ground water and the cations released by degradation of waste, containers, and fuel cladding.

Precipitation of surface layers on the glass might reduce the rate of dissolution, by making the solubility of the precipitated phase rather than the solubility of amorphous silica the control on dissolution (Macedo et al., 1986). On the other hand, precipitation would constitute an additional sink for dissolved silica (Grauer, 1985), in addition to the diffusive transfer treated by Zavoshy et al., and models which neglect this silica sink may not be conservative. (Zavoshy et al. do treat cases in which silica is sorbed to the surrounding rock, but this is likely to be a crude approximation.) It is not obvious what the net effect of silicate precipitation on glass dissolution would be, because formation of protective surface layers (Macedo et al., 1986) or pore clogging will counteract the lowering of dissolved silica concentrations; a more sophisticated model, taking these competing phenomena into account, is not now available and might be worth developing.

The geochemistry of uranium, although complex, may be simpler than that of silica. It may be that a solubility can be defined well enough that the mass-transfer theory can be applied to matrix dissolution of spent fuel in the same way as to trace radionuclides. Apted et al. (1986) have developed a model of spent-fuel dissolution on this basis. But if low-solubility uranium phases precipitate near the waste, the use of solubility to calculate matrix dissolution rates will not be conservative (Johnson et al., 1985). Garisto and Garisto (1986b) have investigated the equilibrium thermodynamics of uranium dioxide dissolution in some detail; they conclude that the rate at which oxygen reaches the waste will limit the progress of dissolution reactions. A model of transport and oxidation of uranium has been developed by Carnahan (1987).

\subsubsection{Kinetically Controlled Releases}

Because many of the reactions between waste forms and aqueous solutions proceed slowly, kinetic effects may significantly influence the release of radioactivity from a waste form. The kinetic effects may be of particular importance if one must demonstrate low release rates for the more soluble waste constituents such as cesium and iodine. 
Unfortunately, the kinetics of waste-form dissolution are quite complex. A variety of factors can change dissolution rates, and it is possible that additional relevant variables have not yet been identified. Moody (1982) lists among the factors affecting waste-form dissolution such variables as $\mathrm{pH}$, temperature, fluid composition, radiation effects, and oxidation state. It is important to note that these parameters may change over time as a result of reactions between water and waste.

Borosilicate glasses are the waste forms whose dissolution kinetics have been studied most intensively. Experimental work on this subject and proposed extrapolations to repository conditions were reviewed by Pigford et al. (1983).

Because glasses are thermodynamically unstable, the dissolution of glass is an irreversible reaction that cannot, strictly speaking, be limited by solubility. Thermodynamics allows silica from glass to continue entering a solution that is saturated with respect to more stable silica phases. In principle, glass can dissolve and release trace constituents to a solution containing a high concentration of silica; the dissolved silica may reprecipitate in a more stable form (silica or silicates). To be sure, the rate of the dissolution reaction will generally decrease as dissolved silica concentrations increase.

A theory which explains the kinetics of dissolution of nuclear waste glasses under widely varying conditions has been developed by Grambow (1984). This theory is based on the assumption that the dissolution reaction occurs in a thin reaction zone at the surface of the glass, in which solution is intimately mixed with partially dissociated glass. A layer of precipitated low-solubility glass components may exist outside the reaction zone, but it will not affect the reaction rate.

In Grambow's model, the amorphous waste glass is approximated as a mixture of pure solid oxide and silicate minerals, in proportions which correspond to the elemental composition of the glass. It is assumed that the total reaction releases all glass constituents congruently, either to solution or to solid precipitate phases. The total free energy of glass dissolution, $G_{\mathrm{g}}$, is the sum, weighted according to glass composition, of the free energies of dissolution of the minerals of which the glass is composed. Complexation and reprecipitation reactions are taken into account in defining the composition of the water into which the glass is dissolving. The free energy $G_{\mathrm{g}}$ depends on the solution composition, and 
thus will tend to change as dissolution proceeds. Grambow finds it acceptable to assume that the solution in the reaction zone has the same composition as the immediately adjacent free solution.

The overall reaction is viewed as proceeding in two steps. First, the non-silica components of the glass are released and all but one of the bonds connecting a silanol group $\left(\mathrm{Si}(\mathrm{OH})_{3}\right)$ to the glass matrix are broken. In the second step, the remaining bond between the silanol group and the glass is cleaved, creating dissolved silicic acid $\left(\mathrm{H}_{4} \mathrm{SiO}_{4}\right)$. The progress of the first reaction is determined by the existence of a chemical equilibrium between silica in the glass network and partially bound silanol groups. The second reaction is rate-limiting; its progress is determined by the free energy of dissolution of the silanol groups, $G_{\mathrm{s}}$, and the magnitude of a potential barrier that must be overcome, $E$. The change in free energy as a silanol group dissolves is shown schematically in Figure 4.2-2. Note that the free energies $G_{\mathrm{g}}$ and $G_{\mathrm{s}}$ will differ, because $G_{\mathrm{s}}$ is the free energy of a hydrated silanol group alone, while $G_{\mathrm{g}}$ is an average taken over all glass components.

With these assumptions, Grambow shows that the fractional rate of dissolution of a glass cylinder is

$$
\dot{f}_{\mathrm{j}}=\left[\frac{2(1+R / L)}{n_{\mathrm{si} 1 \mathrm{ica}} R}\right] W \exp \left(-G_{\mathrm{g}} / N k T\right) \exp (-E / N k T)\left[1-\exp \left(G_{\mathrm{s}} / N k T\right)\right]
$$

where $N$ is Avogadro's number, $k$ is Boltzmann's constant, $T$ is absolute temperature, and $W$ is a constant that includes several factors that cannot practicably be independently evaluated. The first term in square brackets, which is included here for consistency with the notation of the rest of this section, is simply the ratio of the surface area of the waste to the total mass of silica in it. If this term is omitted, one recovers the form of equation published by Grambow, giving the mass of silica dissolved per unit surface area and time, independently of the shape of the waste.

Grambow finds that for a wide range of experimental conditions, a constant value is obtained for $W \exp (-E / N k T)$. The free energies $G_{\mathrm{g}}$ and $G_{\mathrm{s}}$ may be calculated by the chemical speciation models described in Section 3.3. When dissolved silica levels are not close to saturation, it is $G_{\mathrm{g}}$ that determines the reaction rate. Grambow et al. (1986a) have 


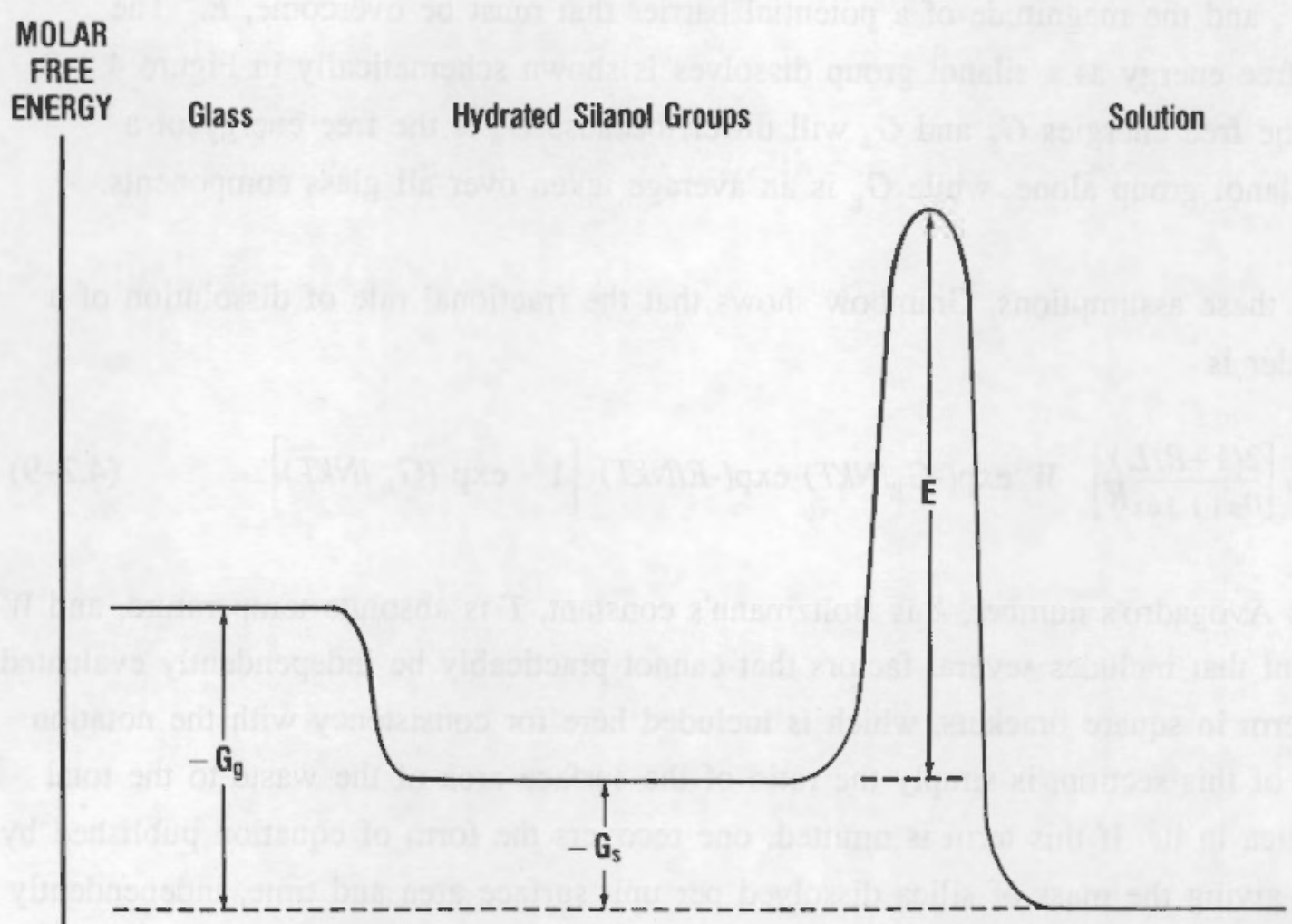

Figure 4.2-2. Schematic variation of free energy of silica as it dissociates from glass, in the model of Grambow.

$$
4-34
$$


developed a numerical model called GLASSOL which solves Eq. $(4.2-9)$ in this limit. "The equation reduces to a first-order kinetic equation

$$
f_{j}=k_{4}\left[1-\frac{N_{\text {silica }}}{N_{s \text { ilics }}^{*}}\right]
$$

where $k_{+}$is the rate constant, $N$ is the dissolved concentration, and $N^{*}$ is the solubility. The rate constant $k_{+}$incorporates many factors from Eq. $(4,2-9)$ and is evaluated in GLASSOL by using the themodynamic model PHREEQE (see Section 3.3 ).

A simpler thermodynamic theory has been developed by Carol Jantzen and comworkers (Plodinace al, 1984) and used to predict discolvtion rates in undersaturated solutions. In this approach, an average free energy of glass dissolution simitar to Grambow $G_{\mathrm{g}}$ is calculated. As in Grambow's theory, the glass composition is approximated by representing the starting point of the reaction as a mixture of silicate and oxide minerals. However, the endpoint of the reaction is not an actual solution composition, but a mixture of hydratect solids and an infinitely dilute solution, with each component either a solid ar dissolved. Because it doss not include solution composition in its thermodynamic fommlation, this model would appear to be better suited to a comparative evaluation of different glass compositions than to predicting the actunl rate of glass degradation in a repository environment.

An important feature of Equation $(4,2-9)$ is that it reflects the Iransition from a kinetically controlled to solubility-controlled dissolution regime. As the dissolved silica concentration approaches its solubility, $\sigma_{\text {s }}$ tends to zero and the reaction rate declines. However, when the solution is saturated and $G_{s}$ is zero, Crambow's physical model still predicas silica dissolution because the difference between $G_{\mathrm{B}}$ and $G_{\mathrm{s}}$ will continue to drive the reaction forward (Crambow et al., 1986a). Dissolved silica will then reprecipitate in another phase, as discussed in the previous section. Equation $(4,2-9)$ is inapplicable in this case.

Several authors (such acs Sullivan and Machels, 1984, and Banba et al, 1987) have ateveloped models of glass dissolution in which diffusion and ion exchange in altered surface layers of the glass play an important role. These models generally require use of 
empirical constants to a much greater degree than the themodynamic models of Grambow and Jantzen. Also, the imporance of diffusion in surface layers as a tate-limiting process seems generaly to decline as dissolution proceds, so that these models would be more applicable to the time scales of laboratory experiments than to the time seales of repository performance. Models of glass dissolution kinetics have been reviewed by Burker (1987).

The kinetics of spent fuel dissolution are even more difficult to assess than those of glass because of the radiation damage and redistribution of constituents occurring in the reactor. Some radioelements, such as cesitm, migrate cont of fuel pellets, and there may be a nonuniform composition within the pellets. In an oxidizing environment, the tendency $\alpha_{\sim}^{*}$ the $\mathrm{UO}_{2}$ of the fuel to oxidize is also significant.

\section{4,2.3 Gap Activity of Spent Fuel}

As mentioned above, some of the radioactivity of spent fuel is found outside the fuel pellets. Activity not bound within the uranium dioxide matrix, whether located on cladings, on pellet surfaces, or along boundaries between uranium dioxide grains, is referred to as gap activity, Radiotements most likely to be significant in gap activity include cesium, iodine. and carbon.

The release of this activity obviously will not be impeded by slow dissolution of the uranim dioxide fuel. Some activity is bound within the fuel cladding, and can be presumed to be released as the cladding corrodes (Apted th al, 1986). For the rematnder of the activaty, dissolution is limited only by solubility of individual radioelements, which in several cases can be high. Gap activity is therefore of particular concen in calculating the maximum wate at which radioastivity leaves the waste package.

One approach to this problem is to assume that the gap activity is uniformly dissolved in the water occupying the gap volume and calculutes how fast it cun leave that volume. If water flow through the waste package is small enowgh, diffusion will be the dominant mode of release; a formula for this case is given by Kim et al. (1986). With greater flow rates, formulas similar to $(4.2-3)$ through $(4.2-5)$ might be used.

An altemative approach is to concede that the gap activify in a single waste package would be released rapidly after the container falls and take alvantage of the distribution of

$$
4-36
$$


canister failures over time. A detaled mathematical treatment of this problem is given by Sagar et al. (1986). The distribution of canister falure times plays a large role in the calculations of the Swedish KBS-3 report (KBS, 1983) and the German PsE report (Briggemann et al, 1985).

\subsubsection{Selection of Models of Waste Dissolution}

Chambre and Pigford (1984) calculate typical release rates under repository conditions from Equation $(4.2-1)$ and observe:

Preticted solubility-limited fractional dissolution rates for the low-solubility species are much smaller than the fractional release rates estimated from labotatory leaching experiments, wherein the concentration boundary layer resistance is either negligible or absent. This scems true for borosilicate glass waste and for other waste solids, such as Synroc or unreprocessed spent fuel. Thus, for a waste form in the repository environment, surrounded by ground water in a porous rock, the rate of dissolution for these low-solubility species will be controlled by the rate of transport into the liquid boundary layer adjacent to the waste solid. For most radionuclides, exwept cesium, the kinetics of the solid-liquid interactions are rapid enotgh that the concentration of the dissolved species in the liquid at the waste surface will be near or only a little below the solubility limits for these spectes. Because the kineties of the solid liquid interactions are not controlling tor these low-solubility spectes, the laboratory leach rate data are irrelevant and are not useful for estimating the distolution of low-solubility species under repository conditions.

Use of Equation (4.2-2) instead of Equation (4.2-1), with a generously large dispersivity of $30 \mathrm{~cm}$, would increase the release rates calculatad by Chambre and Pigford by only one order of magnitude and would not change this conclusion. Reviews by Grambow (1984) and Grauer (1985) of experimentw on glass leaching also conclude that the reletase of numerous waste constituents will be controlled by the solubility of the constiuent, and some experimental work on spent fuel has indicated similar conclusions (Werme and Forsyth, 1985 ).

This emphasis on mass transfer and equilibrium solubility as controling wate dissolution has been challenged. Cohen (1985) asserts that natural rock constituents are dissolved much more slowly than the theory predicts. Macedo and Montrose (1986) contend that an extrapolation of laboratory experiments will provide a better prediction of the performance of unstable glassy wastes. 
Macedo et al. (1986) argue that, at large times, waste dissolution will be controlled by the solubility of surface layers formed by precipitation of silicates on the glass. They propose using the ratio of glass surface area to volumetric water flow tate as a basis for extrapolating from laboratory experiments. In the presence of many precipitation reactions having different rate constants, this parameter may be useful in deternining which phases precipitate, which will determine the relevant value of the solubility. But its applicability as an extrapolation variable has not been clearly demonstrated.

Pigford (1985) and Pigford and Chambre (1986a; 1986b) have replied to their ctritics at some length. In their view, the mass-trantsport modeling approach is of very general applicability and not restricted to cases where solubility controls surface concentrations. As an example of the use of mass-transport modeling with chemical kinetics, they and their co-workers have developed a mathematical model which combines diffusive mass transfer with first-order kineties (Eq. 4.2-10) (Zavoshy et al, 1985). A similar model is included in the waste package model CONDIMENT (Lewi el al., 1987). NAGRA (1985) presents a model in which Eq. $(4.2-10)$ is used with $N^{*}$ set equal to a value representing glass while $N$ is fixed at a lower value representing the equilibrium solubility of silicate precipitate phases. A model which combines Eq. (4.2-10) with flow of water through a defined mixing volune is presented by Stahl and Miller (1986). All of these models provide descriptions of the transition between leach-limited and solvbility-limited behavior.

Determining which of the conflicting theories most aceurntely describes the actual behavior of waste in a repository would require a review of experimental evidence and is beyond the scope of this report. This is a major concern of the reviews of experimental work on glass by Grambow (1984) and Grater (1985) as well as the entire experimental literature on spent fuel. For the purpose of ensuring the safety of waste repositories, however, it may not be the most importans point. Analyses of repository safety generally show that release rates from waste packages are expected to be far below the levels needed to protect public health-this is one pexint on which the conflicting studies cited in the previous paragraphs agree. The relevant safety issue is not to determine how slowly the waste packayes are really likely to release radioactivity, but to be as sure as possible that the release will not be much faster than expected. 
Now the principal source of uncerainty in predictions of high-level waste dissolution is the need to extrapolate laboratory measurements to repository conditions which may differ in temperature, pressure, water composition, radiation field, and time scale. This extrapolation necessarily introduces uncertainties in both equilibrium solubilities and reaction kinetics. But extrapolations will be mote reliable to the extent they are based on well understood physical and chemical principles and are scaled to quantities whose behavior can be predicted with confidence. The equilibrium theory seems to be preferable on both counts. Although much remains to be leamed about the relevant elemental solubilities, the general principles of equilibrium chemistry are better understood than the chemical kinetics of dissolution and reprecipitation. And as for the scaling quantities, Chambre and Pigford (1984) argue convincingly that

interior cracks in the waste solid, devitrification, and other such mechanisms that could increase the rate of the solid-liquid interaction are not expected to affect the solubility-limited dissolution rates.

For more soluble elements, such as cesium, bounds on release rates set by mass-transfer arguments will be relatively large. If low release rates for these elements must be demonstrated, recourse to kinetic arguments may be necessary. This is especially true in an unsaturated-zone repository for elements that will enter the gas phase, where diffusion constants are orders of magnitude larger than in the liquid phase.

The application of mass -transfer theory based on the solubilities of individual radioelements would seem to be less complicated and more reliable as a basis for extrapolation than the use of equilibrium models to determine the degradation rate of the waste matrix. In the former case, it does not matter whether radioactivity is retained within the original matrix or enters new precipitate phases; the quantity of interest is the dissolved concentration, which is what the theory predicts directly.

For matrix dissolution, the situation is otherwise. When the waste matrix dissolves and reprecipitates, associated radioactivity may remain in solution, and so the rate of reprecipitation is important. For certain chemical systems, among them dissolved silica in ground water, kinetics will be relevant to a determination of reprecipitation rates. At first glance, it would seem possible that the protective effect of surface layers of precipitates and pore clogging will outweigh the acceleration of matrix dissolution by reprecipitation, making 
andlyses that ignore reprecipitation conservative. But this guesticut has not been given detailed attention in the literature.

These considerations do not call into question the applicability of the mass transfer appronch to matrix dissolution, bat they do imply that an appropriate leve! of geochemical sophistication must be incorporated into the mass transfer models. The mass transter approach has been established as the most conviacing way to prodict the dissolution rate of nuclear waste, but it can be used reliably only if the reactions that control the dissolution process have been correctly identified.

\section{$4.3 \quad$ Backfill}

Use of clay backfill as the outer portion of a waste package was first proposed to reduce permetbility (KBS, 1978a), control the composition of waters contacting containers (KBS, 1978b), and delay the onset of radionuclide release once containers have been breached (Nowak. 1979). Nowak (1979) and Dayal et at. (1982) derived formulas for the time delay resulting from difusion through clay backfill, but Chambré and Pigford (1984) point out that these formulas overestimate the delay by calculating the time for the concentration to approsth its maximum value in a semi-infinite medium, rather than the time course of the mass transport rate in a finite medium.

With increasing attertion being directed at solubilities of radioclements, it was natural that researchers would want to investigate how backfills could help control solubuty-limited relezses. This question was addressed independently by Neretnieks (1978) and Wood (1982), using a model in which wection in the backfill is negligible and radioelements difuse outward from a satmated zone at the waste face to ground water ourstee the backfill. In the simplest case, when the flow ontside the backfil is so high as to give effectively infinite dilution, the ralease rate is given oy

$$
f_{\mathrm{j}}=\frac{2 N_{j}^{*} D}{n_{\mathrm{j}} R^{2} \ln _{\mathrm{n}} / R}
$$

where $f_{0}$ is the outer tatius of the backill cylinder. 
One can take into account nonzero concentrations at the outer boundary of the backfill in two ways. First, one can assume water flowing in an annulus (perhaps corresponding to a zone of fractured rock) outside the backfill is well-mixed and obtain, in the case of longitudinal flow, a result analogous to Equation (4.2-4) (Analytic Sciences Corporation, $1983):$

$$
\dot{f}_{\mathrm{j}}=\frac{N_{\mathrm{j} Q}^{*} \mathrm{R}}{\pi R^{2}{ }_{\mathrm{j}}^{L} L} \cdot \frac{a}{a+l}
$$

where

$$
a=\frac{2 \pi D L}{\left.Q \ln T R_{\mathrm{b}} / R\right)}, \quad Q=\pi U_{\mathrm{E}}^{*}\left(R^{*} \cdot R_{\mathrm{b}}{ }^{2}\right)
$$

More realsstically, one can treat the ground water outside the backfill as flowing unifornly and requiring tansport through a boundary layer. The resulting equations can then be solved by approximating the waste and backfill as prolate spheroids. Chambre and Pigford (1984) give the rather complicated solution to the resulting equations for the case of transverse flow with a diffusion-controlled boundary layer (analogous to Equation 4.2-1). The solution for a dispersion-controlled layer may be obtained from their formula in the same manner as Equation (4.3-2), by substituting $\alpha U$ for $D$. If the concentration at the backfill-rock interface is known, Equation (4.2-5) can be used with that concentration substituted for the solubility. Neretnieks (1978) also gives a simpler treatment in which flow outside the backfill is restricted to a few transverse fractures in the rock.

Chambre and Pigford also discuss time-dependent solutions for diffusion through backfill in the case where the water in the rock beyond the backfill is stagnant. In the cases they analyze, the onset of release can be significantly delayed by linear reversible sorption in the backfill. (1,000 years is calculated for a typical backfill, with a retardation factor of 1,000.) If the entire inventory of a species is released from the wuste form before steady state is reached, irreversibility effects can dramatically reduce release rates (Barney and Reed, 1986). However, it is likely that sorption in clay around a waste package would be nonlinear because the available sorption sites would be saturated. Chambre and Pigford show that saturation effects can greatly reduce breakthrough times. 
The equations describing diffusion in backfill may also be solved numerically. The numerical methods used are those discussed in Section 5.2. Andersson et al (1982a) use the integrated finite-difference method for this purpose while Bensky and Oliver (1986) and Jensen and Radke (1987) use finite-element codes.

At steady state, the quantity of a radionuclide sorbed on the backfill remains constant, and the dissolved spectes moves by diffusion as if the sorbed materal were not there. Consequenty, the sorptive properties of the backfill do not affect its performance, as shown by the absence of a dependence on sorption in Equations (4.3-1) and (4.3-2). This has important implications for selecing backfill materiats and waste coms.

In the steady state, long-lived radionuclides must enter and leave the backfill at the same rate. Then, if radionuclite release is govemed by the kinetics fof matrix leaching or solid-state diffusion rather than solubituy, the backfill provides no attenuation whatsover, To be sure, a transient atalysis of backfill diffusion migh wall show a significant effect in these cases, but such an analysis is impeded by the difficulty of reatisticaly estimating how soon saturation of sorption sites will occur.

The preceding discussion of backfils rests on the assumption that species migrate only in the dissolved state and sotbed lons are Immobile. Experimental work by Neretnieks (1985), Jahnke and Radke (1987), and Mutrinen ef al. (1987) shows that sorbed cesim. strontium, ant protactinium ions can migrate outward by surface diffusion. Physically, this phenomenon can be thought of as sorbed ions "hopping" from one sorption site to another, the potential barrier between sites not being too much more than the ion's thernal energy of kT. The surface diffusion phenomenon can increase the flux of radionuclides through the boundary layer to a rate above the mass transport rate in the absence of backfill, suggesting that in some circumstances wastes will dissolve faster at steady state when surrounded by a sorbing backfill than when surrounded by non-sorbing material. Neretnieks (1985a) and Mutinen et al. (1986) point out that cobalt, thorium, uranium, plutonium, nepturium, and americium ions seem to be bound more tightly, so that the potential barriers between sorption sites are greater and surface difusion does not seen to be als important effect. Additional data are needed before reliable predictive models of this phenomenon can bo developed. 
Another possible backfill configuration has been proposed by Neretnieks (1986a). He notes that many extrapolations of the corrosion rate of steel canisters by reaction with water imply that hydrogen gas will be produced faster than it can be transported away by diffusion through a clay backfill. As the equilibrium pressure of hydrogen in contact with water, iron, and the corrosion product magnetite approaches 1,090 bar, this implies that pockets of hydrogen gas will form around the canisters. If a layer of coarse material such as sand were placed between container and clay, the hydrogen might expel the water from this zone. The effect would be to greatly lower corrosion rates and to essentially prevent radionuclide transport in the period between an initial container breach due to localized corrosion and the subsequent consumption of all container material by the corrosion reaction. Sufficient data is not available at present to quantify these effect.

All of the analytic solutions for waste form and backfill performance assume constant temperature, although during the thermal phase in a repository, temperature (and with it solubilities and diffusion constants) will vary. Chambre and Pigford present some solutions for particular cases with varying temperatures, but practical calculations will no doubt require computer programs. The numerical models referred to above (Andersson et al., 1982; Bersky and Oliver, 1986; Jensen and Radke, 1987) assumed constant temperature, but they could presumably be extended to handle varying temperatures. The finite-difference model of Carnahan (1987) is designed with the capability of treating variable-temperature backfill diffusion problems, but no such calculations have yet been reported.

\subsection{Comprehensive Package Models}

Several computer programs have been developed that attemp: to comprehensively model the performance of waste packages. All of these programs combine the results of submodels that analyze such phenomena as corrosion, waste leaching, mechanical stress, heating, and tadiation. The submodels in two early models, BARIER and WAPPA, are summarized by Coffman et al. (1984) in more detail than is possible here.

BARIER (Stula et al., 1980; Lester et al., 1983) begins by computing the corrosion of a metal continer, which is assumed to proceed linearly, Rates of general and local corrosion in the absence of radiation are specified in the code for various metals. Different rates are specified for salt and hard rock repositories, for temperatures above and below 
$100^{\circ} \mathrm{C}$ and for "oxic" and "anoxic" conditions. Corrosion rates are then multiplied by a factor that depends on the logarithm of the radiation flux.

When the container becomes too thin to support the mechanical stress imposed on it, if is considered to have failed, and waste dissolution and diffusion through backfill begin. Concentration of each radionuclide at the waste surface is considered to remain constant at a user-supplied value (presumably the solubility) until the inventory in the waste has been exhausted. Transport proceeds, at different user-supplied diffusion constants, throagh the remains of the failed container and the backfill. Each of these barriers is treated mathematically as at flat slab, with a transient solution for release rate obtained by assuming that the concentration outside the backfill is zero.

The BARIER code is intended for approximate, comparative analyses. For such purposes, it is acceptable to use approximations like the flat-slab treatment of backfill with zero contaminant concentration as a boundary condition. But even for rough calculations, using poorly justified physical relationships (like those in BARIER in which corrosion rate depends on ratiation intensity, temperature, and ground water composition) makes the results questionable. Furthermore, Coffman et al. (1984) point out a number of deficiencies in the nodels formulation and documentation.

The WAPPA program (Brecher and Pearson, 1983; INTERA, 1983d; Tylock et al., 1987) tracks the entry of water past a series of concentric barriers and shen calculates the release of radioactivity. The corrosion model encompasses five ypes of corrosion: general, galvanic; dry, pitting and crevice. The rates of these processes as functions of fluid composition and temperature must be input by the user. It is assumed that pitting and crevice corrosion cause imrtediate penetration of the entire barrier as soon as they begin, with the areat of the hole then growing over time. Corrosion rates are increased in the presence of gamma radiation, using empitical factors supplied by the user.

In WAPPA, the release of radioactivity from the waste form is calculated by taking into account three of the four limiting processes listed at the beginning of Section 4.2: radionuclide solubility, kinetics of matrix dissolution, and solid-state diffusion of radionuclides in the waste form. Both diffusion and adyection can carry the contuminants out of the backfill. which is modeled as a single, well-mixed compartment rather than with a continuum model of the type described in Section 3.3. 
WAPPA's model of crevice and pitting corrosion has been severely criticized by Coffman et al. (2984). Pigford and Chambre (1985) point out that WAPPA's assumption that the diffusive mass-transfer through small holes in breached canisters will be proportional to the area of the holes is incorrect. The compartment model of backfill diffusion is also dubious. Even with these severe limitations, the WAPpA model represents a more detaited model of package degradation than BARIER. However, the price of increased detail is an even greater need for hard-to-get input data. Much of the required input data will be sensitive to detalls of ground water chemistry, which in turn may be affected by the degradation of the waste package. Thus, there is a significant danger that models like BARIER and WAPPA may tum out to evade the very questions they are meant to answer.

Two other models that do not model chemical interactions among system components are included in the comprehensive repository models SYVAC (LeNeven and Walker, 1986; Garisto, 1986) and MELODIE (Lewi et al, 1987), In the vault model of \$YVAC, a distribution of container failure times is input to the model. All radioustivity (other than gap activity) is released congruently with either the solubility-limited dissolution of uranium dioxide or the constant-rate dissolution of glass, as the case may be. A simplified mass-transfer calculation, based on the assumption of diffusion through a flat slab of backfill and approximation of mass transfer in the surrounding rock as a film resistance, is used to determine the dissolution rate of uranium. The release rate of gap activity is the total gap activity in the repository divided by the time over which container failures are spread.

The waste-package module of MELODIE is known as CONDIMENT. This code also accepts the container failure time as an input. The dissolution rate of waste glass is calculated from $\mathrm{Eq} \cdot(4.2-10)$, with diffusive mass transfer of silica through a layer of altered glass and surrounding cylinders of backfill and fractured granite. The boundary condition at the outside of the fractured granite is derived from a fas-mield transport model. Mass transfer calculations with the same geometry are carried out for contaminants; the inner boundary condition at the interface between fresh and unaltered glass is determined by the solubility for actinides and by congruent dissolution for fission products. It is planned in future code versions to explicitiy calculate solubilities from water chemistry and waste package interactions. 
While none of these models explicitly treats the chemical evolution of the water-rock-package system, a fully integrated package model would do so. A model of this type, called AREST, is currently under development at Pacific Northwest Laboratory (Liebetra et al, 1987). AREST currently incorporates several alternative models for container corrogion, treating utiform, pitting, and stress corrosion. These models either are empirical in nature or are mechanistic but poorly validated. Dissolution of spent fuel is calculated from a mass-transfer model which assumes the dissolved uranium concentration is equal to the solubility at the surface of a spherical waste form. For other elements, the model compares the rates of release given by solubility-limited mass transfer and congnuent dissolution, and chooses the lower of the two. Solubilitics are calculated by a geochemical equilibrium model which takes into account the presence of backfill and container materials. Like most package models, AREST is written in modular fashion to allow substitution of new physical and chemical models as they become available for particular processes.

\subsection{Low Permeability Room Backfill}

Two reports analyze the performance of repository storage rooms conaining low-permeability backfill.

Pentz et al. (1984) analyze the effect of using a low-permeability backfill in the storage rooms. The flow regime in and around the storage room is calculated using analytic solutions (Scott and Koplik, 1984) and by the three-dimensional finite-difference code SWIFT. The travel time to a point 1 mile downgratient for an unretarded contaminant is then calculated using the NUTRAN pipe-nerwork model. These models are described in Section 5.2.) Similar calculations are carried out for rooms backfilled with crusted basalt and similar high-permeability materials.

The effect of the low permeability backfill is to reduce the travel time. This occurs because flow is directed into the basalt, which has a much lower effective porosity than any of the suggested backfills.

Freshley et al. (1985) compute the flow of water through and around a drift in a repository in the unsaturated zone. With a coarse backfill of sand, the moisture flux near waste canisters in the floor of the drift is about 50 times lower than if a fine clay backfill 
is used, indicating that the sand forms an effective capillary tartier. These computations were carried out in two dimensions with the integrated finite-difference code TRUST.

\subsection{Shaft and Borehole Seals}

\subsubsection{Seal Effectiveness}

Most studies of repository sealing schemes address the question of whether a seal will function at all, rather than how well it will perform or for how long (for instance, $D^{\prime}$ Appolonia, 1981). This approach follows that of past borehole sealing practices in the petroleum industry, where little data currently exists on the effectiveness of plugging (South et al., 1981).

There are three routes by which water can move through a plug. These are the seal material itself, the interface between the seal material and the rock, and the disturbed zone in the rock.

Disturbed zones around shafts and boreholes arise in the same way they do around tunnels (Section 3,4), and the methods of analysis are similar. Excavation-induced disturbance is a function of the excavation method, and it also depends on the diameter of the hole. For smatl-diameter boreholes, the excavation disturbance is greatly reduced (Barton, 1982; Mathis and Daeman, 1982). With regard to fracturing and opening of existing fractures induced by stress release, sealed shafts and boreholes differ from unsealed tunnels because of the mechanical strength of the sealing material. Nonetheless, the same methods of numerica! modeling are used to analyze the problem (for instance, Jeffrey and Damen, 1981 ).

Flow through the seal material and interface are determined by laboratory and field testing. Little has been written tbout long-term changes in seals. Langton and Roy (1984) have reviewed the archaeological evidence on the long-term stability of cements, but few, if any, of the archacological cements have been subjected to stress conditions comparable to those that a repository seal would undergo. Atkinson et al. (1986) provide an empirical equation describing the depth of a deteriorated zone in concrete as a function of magnesium and sulfate concentration, The depth grows linearly with time. 


\subsubsection{Consequences of Seal Failure}

Analysis of the consequences of shaft or borehole seal failure is one of the most venerable traditions in repository performance assessment. Many non-site-spectfic studies have addressed the consequences of seal failure. Most commonly, the falled shaft has been treated as a one-dimensional "short circuit" allowing rapid flow between the repository and an overlying aquifer. However, such models often neglect the time reatured for flow within the repository from storage rooms to shaft. Because the shaft is so small in cross-section, the time needed for contaminants to reach if is a primary feature of seal failure scenarios; and neglect of this delay makes many of the earlier studies almost worthless for evaluating the importance of seal fatures.

Two more rent studies (Gureghian et al, 1983; Pentz et al ${ }_{*}$ 1984) model shaft seal failure in considerably mote detail. Both of these sudies still treat the failed shaft as a one-dimensional feature, and they compuse ground water flow using a resistor netwark approach (see Section 5.2.5). But they do incorporate additional mechanisms that will reduce the significance of seal fallure: Gureghian et al. calculate the time required for water to resaturate the sealing material in a salt repository, while Pentz et al, evaluate delays caused in a basal repository by the flow from storage rooms to shaft and the diversion of contaminated water into the basalt.

Gureghian et al, recall that moisture applied to dry soils usually propagates downward as a sharp "wetting front." Their infiltration model thus computes the movement of a wetting front through shaft sealing material from the lowest overlying aquifer to a repository in the Partdox Basin in Utah. The Green Ampt equation, an old and well-accepted fommula of soil physics, is used to calculate the velocity of the front rhe results indicate that tens or hundreds of thousands of years would be required for the front to reach the repository horizon. Acually the times implied by this physical model are much greater: if the repository workings were still open, a period many times longer than the time it would

take to wet the shaft would be needed to fill the underground cavily with water. And if the cavity had been closed by salt flow, the eventual arrival of water at the base of the shift would have litule signifucance, 
However, the model of Gureghian et al. has two limitations. First, it only treats flow through the seal material and ignores the seal-rock interface and disturbed zone, which may be more important pathways for flow. Moreover, at the seal rock interface, it is not even clear that soil-seience concepts like the Green-Ampt equation will be applicable. Second, Gureghian et al. neglect the possibility of preferential dissolution of disturbed-zone salt by the infiltrating water.

Gureghian et al. also calculate the transport of radioactivity away from the repository through an underiying aquifer after resaturation. This calculation is similar in spirit to earlier work. Its conclusion - that little radioactivity would reach the aquifer's discharge would apply equally to almost any release scenario and sheds little light on shaft seals as such.

Pentz at al. (1984) use a resistor network model to compute water flow within the repository. They conclude that:

in terms of performance, this conservative scenario is relatively insignificant because only a small fraction of water that flowed through the rooms of the repository was transmitted vertically up the shaft. The predominant movement of contaminated water continues to be vertical through the repository rooms and into the geologic setting, due to the relatively large distance between the shaft and the waste storage rooms, and the prevaling vertical flow regime in the dense basalt units.

Evaluation of the importance of shaft seals was not anong the purposes of this study, and Pentz et al. go on to say that a comprehensive three-dimensional analysis would be required to defend the conclusion that shaft seal failure is insignificant.

The BWIP environmental assessment (U.S. Dept of Energy, 1986\%, p. 6-303) computes releases through fractured zones around shafts from analytic solutions. Driving hydroulic grudients are simply estimated by engineering judgment.

Becalise of the sharp contrasts in geometric scale and hydraulic conductivity, a three-dimensional analysis of shaft seal failure by finite-difference or finite-element methods would face grave numerical difficulties. A power-series solution method for the flow around the shaft that Pollak developed (Ross et al. 1979) avoids some of the numerical problems but is cumbersome and difficult to use. Two-dimensional analysis, as 
proposed by Gureghian et al. lessens the severity of some numerical difficulties but may well obscure some of the physical phenomena involved. Quite possibly, more detailed analyses of shaf seal fallure will have to continue relying on resistor-network-flow models, supplemented by two- and three-dimensional analyses of a few important parts of the system.

\subsection{Water Control Devices}

Pentz at also analyze the effect of placing a concrete pad on the floor of the storage rooms to block flow between the roons and the waste-enplacement holes. The effect on how is analyzed in the same mannet as that of low-permeability backfill. The principal effect of the pad is to diven flow toward the side of the room, but the flow still proceds through the room because the backfill is more permeable than the host rock. The concrete further tends to improve the performance of the repository by sorbing carbon-14.

The principat proposed application of water diversion schemes is in an unsuturatedzone repository. The idea is to divert water above the waste canisters to the side, so the canisters remain dry. No quantitative evaluation of this concept has been found in the literature.

Similasly, one might try to reduce water flow rates through saturated-zone waste-emplatement holes by drilling pressure relief holes. An elaborate system of this type has been proposed in Sweden (Fairhurst, 1987), and its performance has been estimated with a thee-dimensional groundwater model.

The ground water flow problems described in this section and the two preceding ones are complex and often difficult to solve. The juxtaposition of natural and engineered porous media is unusuat in ground water model applications. As a result, in using nodels in this area, inventiveness is needed to an even greater degree than is usual in the ground water field. General-purpose ground water codes often need alteration if not replacement. The use of finte-difference methods, analytic solutons, and pipe-network models in tandem by Pentz at al. (1984) is a good example of the approach that must be raken. The requtrement for flexibility in the choice of codes that this stuation imposes should be taken into account in planing pefornance-assessment programs. 


\section{CHAPTER 5. NATURAL BARRER PERFORMANCE}

\subsection{Salt Stabulity}

The major mechanism affecting the stability of salt formations is dissolution by ground water. Heat generated by a repository has the potential to increase the dissolution rate by increasing solublity and also inducing mechanical allerations in overlying aquitards that increase permeability. The ability to calculate the dissolution rate in salt formations under expected repository conditions is therefore important to the assessment process.

\subsection{Salt Dissolution}

As geologie structures, salt deposits occur in three distinctive ways: as beds lying borizontally conformably with overlying and underlying sedimentary strata, as domes vertically transsecting overlying sedimentary formations, and as anticlines arehing conformably with overlying and underlying sedmentary formations. The Deaf Snith County site in Texas is an example of a bedded salt deposit; Richton Dome in Louisiana represents that structure, and Gorleben in Germany is an antolinal deposit. Salt deposits consist primarily of halite, but bands or splines of such impurities as clay and anhydrite ate folded within the salt. Salt structures are generally less permeable than abutting formations; however, leaks in salt mines containing dissolved substances from adjacent formations indicate that they are not always impermeable.

In bedded salt, geologists distinguish "deep" and "shallow" dissolution (Zand, 1982). Shallow dissolution, occurring at the top and margins of a salt deposit, is generally easier to understand. Because the density of water increases with greater satt content, continuous dissolution at the top of a bed requires a mechanism of lateral water movement to provide a continuing source of fresh water. Analysis of this mechunism can provide a means of botnding the potential for dissolution. 
At the bottom of a salt bed, dissolution brines can be removed by gravity and replaced by fresher waters even if there is no horizontal water flow in the beds adjacent to the salt. Consecutently, there is, at least in principle, potential for the development of localzed dissolution features. However, whether observed features such as breccia pipes arise by this mechanism is a matter of controversy (Zand, 1982).

Dissolution cavities slowly fill with such dertitus as clay gouge, or they may remain zones of weakness and collapse. Such a collapse occurred in West Texas (Johnson, 1986) as a result of ground-water now from overlyith aquifers into a deep salt formation via an abandoned well. The process may have begun as early as 1928, and resulted in the formarion of sink hole 360 feet across and 110 feet deep. In a sult dome, filled solution cavities at the top and sides lithify into sheath of clay, shate, antydrite and dolomite known as caprock. Caprock is relatively brittle, compared with alat.

A primary concern about placement of a repoxitory in salt is that thermal effects may accelerate dissolution. Higher temperature increases the solubility of the salt. Water from the surface could find is way to the salt at the interface between excavation shafts and the country rock. Thus, surface water and any ground water in the vicinity could, depending on the time after emplacement and the geometry, be heated and capable of rapicly dissolving salt.

Methods For determining rates for salt dissolution incude excrapolations of geological observations about present and past events to future vents, numerical calculations of dissolution rates, and analysis of coupled physical and chemical interactons. The computer code BORHOL (INTERA, 1984) has been developed for evaluating dissolution, precipitution, creep, and temperature effects in boreholes in salt.

\subsubsection{Extrapolations of Geological Observations}

Gupta et al (1985) offer estimates of salt dissolution at seven potential repository loctitions by analyzing the following factors: collapse features, loss or thinning of salt sequences, hydrochemistry of surface and ground waters, and caprock formation. They use well logs and freld data to describe past and ongoing processes of salt dissolution and deposition. 
Swenson (1974) describes rates of salt dissolution in the Perrmian Basin of Texas in terms of both backwasting toward the basin and as a rate of vertical dissolution. His discussion is expressed in terms of thickness of salt dissolved per thousand years.

\section{1 .3 Numerical Calculations}

Rates of dissolution must be estimated (or bounded) to determine whether a repository could be endangered. This demonstration is usually based on geological models of argument. Two general lines of reasoning may be followed:

- Past or present dissolution rates are estimated from geological evidence. These rates are extrapolated into the future.

- The maximum amount of water that could carry salt away is calculated. This is used to give an upper bound on future dissolution.

The following are some examples of evidence used to compute past and present dissolution rates:

- Discharge rates of saline ground water.

- Ages of collapse features reflecting past dissolution as deduced from surface geology.

- Chemical isotopic analyses of saline ground water and comparison with salt deposits.

Quantities of water available to dissolve salt can be computed either by considering the total amoum of water flowing in a ground water system or by perfoming a hydraulic analysis of confining beds.

Four geologic analyses of dissolution of bedded salt at the Waste Isolation Pilot Plant in New Mexico are presented by Zand (1982), Anderson (1982), Lambert (1983), and Chaturvedi and Rehfeldt (1984). A thorough analysis of salt dissolution in the region of the Deaf Smith County, Texas, site is presented by Gustavson et al. (1980).

Lindstrom-Jensen (1982) assumes that salt concentrations in groundwater correspond to current dissolution rates of a dome. He determines the rate of dissolution on the basis of 
measured salinity profiles above the dorne. He numerically deternines the concentration of salt water in the groundwater and then calculates the salt dissolution rate.

Lindstrom-Jensen $(1979,1980)$ had previousiy proposed a model for salt dissolution mechamisms involving groundwater flow, the caprock, overlying aquifer and underlying rock salt. He investigated parameter variations and used numerical calculations to determine that dissolution rate is almost inversely proportional to caprock thickness, and is also a function of the flow velocity in the caprock. Cakculated dissolution rates were on the order of tenths of a millimeter per year.

Dissolution in salt domes is often closely related to flow of the salt, as is discussed further in Section 5.2 ,

\subsubsection{Coupled-Process Analyses of Dissolution}

Gupta et al. (1987) address the question of dissolution as one of coupled processes. The processes of temperature, dissolution/precipitation and salt creep are coupled in the context of borehole analysis. While excavation induces increased dissolution, salt creep effects closure. Temperature and salt solubility are modifying factors. Based on data from boreholes at Cypress Creek Dome in Mississippi, these authors have developed a code to evaluate the progressive saturation of fluid flowing in a borehole through salt units. The code evaluates the process of salt dissolution from borehole walls and takes into account its dependence on temperature and salt solubility.

Authors of both coupled models and bounding analyses concede the limitations of their models in representing the complexities of events that cannot be readily isolated. This suggests that realistic analyses of sult stability under themal stress will be very diffeutt, and that safety analysts will have to rely on conservative bounding calculations or large safety factors.

\subsubsection{Salt Flow}

High plasticity makes salt a desirable host rock for isolating nuclear wastes. In the event of fracture, it tends to self-seal, 
In the presence of heat, salt expands. Berest et al. (1986) discuss the thermal loading and rock salt mechanical response expected in a repository setting. The relatively more brittle interbeds, caprock, and underlying and overlying suata fracture or flow at different rates when subjected to thermal stresses. Prij and Vons (1984) examine this process and conclude that relatively little fracturing will occur.

Salt domes are created by upward flow of salt from an underlying bed. Because the very existence of the dome is evidence of past flow, the potential for present and future salt Dow requires investigation. It may be studied through analyses of granular anhydrite at the salt-caprock interface, and through use of tiltmeters, precise leveling, and microseismic detection instrumentation.

Continued or revived now requinss a driving force, which may be of several types:

- The existing stress field may be such that the process of dome piercement actively continues. At potential repository sites, this possibility should be assessed using geologic evidence.

- Salt may be remobilized by sedimentation, perhaps in concert with repository heating.

- Salt can be removed from the top of the dome by dissolution.

The last of these processes has received the most attention in the literature. While the caprock usually acts as a barrier to water flow, it is also evidence that dissolution has occurred in the geologic past. Any salt dome will therefore have a potential mechanism for dissolution that must be evaluated. Present dissolution rates may be estimated by any of the methods described in the previous section.

Bedded salt also can flow, and salt basins often display anticlinal structures neflecting salt flow. When evidence of flow is present, the potential for salt movement to create new pathways for salt dissolution or radionuclide release must be evaluated. Often the flowage can be dated with geological evidence. For example, the thinning of a succession of overlying strata over anticlines suggests that the salt flow was contemporaneous with deposition of the thinned strata. 


\subsection{Ground Water Transpon}

Transport of contaminants in ground water is, it is widely believed, the most likely mechanism by far for the escape of radioactivity from a repository. Requirements that geologic barriers rather than engineered systems te given prime consideration in selection of repository sites emphasize the importance of this process even more. As a result, much attention has been given to the ground water systems near proposed sites. Indeed, studies related to high-level waste repositories have become a major component of research in hydrogeology.

The uswal approach in hydrogeologic modeling is to treat the porous medium through which ground water flows as a continuum. For this assumption to be valid, there must exist an averaging volume (known as a representative elementary volume, or REV) that is much Iarger than the scale of "microscopic" variability caused by the granular structure of rocks and yet is small enough to be treated as infinitesimal in writing partial differential equations for the porous medium. Methods of ground water modeling based on partial differential equations of a continum will be discussed in Section 5.2 .1 .

In rocks with large, widely spaced fractures, water in the fractures moves so much more rapidly than water in the pores of the blocks between the fractures that the water in the blocks does not reach equilibrium with the fracture water during transient processes. (This is true even with many very slow processes.) In such cases, porous-medium continum approaches are inapplicable, and other descriptions of the flow system nust be devised. Techniques for modeling such fractured systems are described in Section 5.2.2.

Section 5.2.3 summarizes methods of modeling unsaturated-zone flow. Section 5.2 .4 examines recent work to assess the role of colloids in the transport process. In Section 5.2.5, simplified "path network" methods of modeling contaminant transport are described, while Section 5.2 .6 reviews the validity of the usual solute transpont equation in the light of current research. The widespread use of numerical models of ground-water systems as a tool for prediction and characterization has spurred efforts to evaluate their results. Retrospective validation and intermodel comparison efforts are reviewed in Section 5.2.7. 


\subsubsection{Continuum Models}

\section{Ground-Water Dlow}

An equation describing unsteady ground water flow in three dimensions can be writen as

$$
\nabla \cdot \mathbf{K} \cdot \nabla h+R=S_{S} \frac{\partial h}{\partial t}
$$

in which $h$ is the hydraulic head; $K$ is the hydraulic conductivity tonsor; $R$ is a general source or sink term that is, volume of water injected per unil volume of aquifer per unit time; $S_{\mathrm{s}}$ is the specific storage; and $\nabla$ is a differential operator. For general problems, $\mathbf{K}_{\text {; }}$ $S_{\mathrm{s}}$, and $R$ are functions of position.

The two principal techniques for solving this equation in two or three dimensions are the finite difference method and finite-element method. Numerous computer programs using either of these methods are available.

The finite-difference method is based on the idea of dividing a region into an array of blocks whose edges are parallel to the coordinate axes (see Figure 5.2.1). Water flows into or out of the block across each boundary in proportion to the difference befween the head in the block and the head in the adjacent block. Using these assumptions, one oan

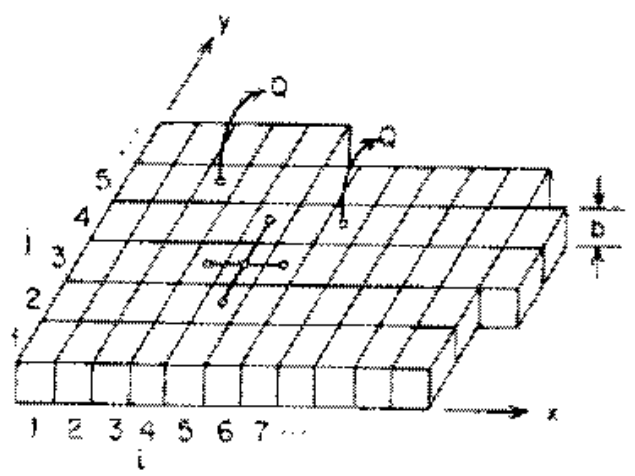

to\}

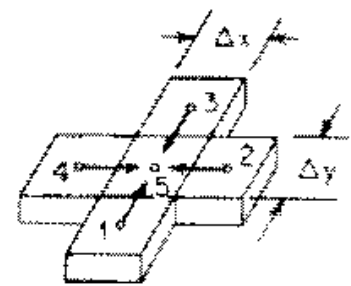

là

Figure 5.2m- A finite-difference grid 
easily write a first-order linear ordinary differenial equation for the head in each block. The system consisting of these equations can be converted to a system of algebraic equations and solved numerically using a variety of well-known methods. (This is the "block-centered" finite-difference method; there is also a "mesh-centered" version that differs slightly in derail.)

A prominent feature of the finite-difference method is its use of a tegular rectangular grid, a feature that makes data input easter but that can create diffuculties in designing grids for complicated problems. In the case where hydraulic conductivity is anisotropic, flexibilty of grid design is sometimes further restricted by a requirment that the finite-difference grid axes be parallel to the principal axes.

In the finite-element method, the region is divided into regions called "elements," which may be of any shape but in two dimensions are most conmonly triangles. Winth each element, the heod is approximated by a "basis function" that depends on a small number of unknown parameters. One then manipulates the parial differential equation to transforn it into an equation for the set of parameters of the basis functions that yields the "best" approximation to the solution of the pd: If a transient problem (Equation 5.2. I) is being solved, this again produces a system of first-order linear ortinary differential equations in time.

Whether the spatial discretization uses finite differences or finite elements, the time dependence is usually approximated with finite difference techniques to yidd a set of algebraic equations that san be solved numerically. Some modelers (e.g., Umari and Gorelick, 1986) solve the system of ordinary differential equations in time analytically, obtaining what are krown as semianalytic solutions.

The finite-element method, when used properly, tends to be more computationally efficient than the finite-difference method. Another advantage of the finite-element method is it greater flexibility in grid design, a feature that could be very important in some problems that will arise in repository analysis, such as detalled studies of flow in and around excavations. The choice of simulation methods is largely a matter of taste, however. There is a strong body of opinion that holds that the flextbility and simplicity of finite-difference codes outweighs in practice the numerical advantages of finite-element codes, espectally when solving flow problems. 
Both finite-difference and finite-element methods reduce the governing partial differential equation to a large-dimensional matrix equation that still must be solved. A detailed exposition of methods of formulating and solving these equations is presented by Huyakom and Pinder (1983). Detailed descriptions of a half-dozen specific computer programs are given by Thomas et al. (1982). A less detalled, but more comprehensive, survey of available software is by van der Heijde et al. (1985).

Some other numerical approaches have been proposed for solving the ground-water flow equation:

- Integrated finitedifference method. This vatiant (Narasimhan and Witherspoon, 1976) of the finite difference method, which has enjoyed great popularity at some of the national laboratories, permits use of nonrectangular grids. However, accuracy requires that angles at the corners of the blocks deviate from right angles by no more than $3^{\circ}$ to $5^{\circ}$.

- Boundary integral method. For certain two-dimensional problems, this method (Liggett and Liu, 1983) can sometimes offer great computational savings. But it has considerable disadvantages, in particular, a very limited ability to handie problems with nonuniform permeability. Recently, Lafe and Cheng (1987) have developed a perturbation based-boundary element code for steady flow in heterogeneous aquifer systems, while Elsworth (1987) advocates a coupled boundary element- finite element procedure to simulate both linear and non-linear fluid flow in porous and fractured aquifers. Unlike finite-difference and finite-element methods, the boundary-element method cannot be extended to handle transport problems.

Isothermal ground water-flow models are well established and well tested, and their ability to handle most of the problems of this type that will arise in repository pertormance assessment is uncontestable. However, one question that doss remain involves systems with small, very permeable features. In both finite-element and finite-difference methods, grid spacings cannot change too rapidly. As a result, the region of finer mesh needed to represent a very small feature can be much larger than the feature itself. It is possible that the resulting grids will contain too many elements to be practical.

For this reason, efforts to develop more efficient numerical methods for solving three-dimensional flow problems are needed. Recent work of this type includes that by Huyakom et al. (1986), Gambolati et al. (1986), and Kinnmark (1985). 
One means of improving the efficiency of flow simulations is by numerically simulating only the region of greatest interest, and using semi-malytic approximations to describe the behavior of less important peripheral regions. The influence of the periphery is incorporated into the simulation by means of boundary conditions. Kipp (1986a) describes how this may be done.

Another way to improve efficiency is to modify the way in which the grids defining elements and nodal points are used. The rules governing the construction of finite element and finite difference grids are restrictive and it is often difficult to change the grid resolution over short distances. For flow problems which have sharp contrasts in data point density, modelers are often forced to include a number of unnecessary nodes to accommodate the regions where accuracy considerations dictate fine grid resolution. This is time consuming and computationally inefficient, especially for three dimensional models. Telescopic mesh refinement (Ward et al., 1987) reduces these problems by allowing the various regions of the flow system to be discretized with grids of different nodal point densities. For example, in the modeling of a repository, a fine mesh and a coarse mesh might be applied to the near field and the far field, respectively.

For grids which must have a very large number of nodes, the multigrid technique (Cole and Foote, 1987; McKeon and Chu, 1987) can offer considerable increases in computational efficiency by reducing the number of steps necessary to approximate a solution. The standard relaxation techniques are efficient at reducing local errors in the solution, but they are inefficient at reducing global errors (i.e., errors between widely spaced portions of the flow field). The muttignid technique is an equation-solving algorithn that separates local errors in the solution from global errors by iteratively approximating the solution on a system of fine and coarse grids, thereby speeding convergence.

Additional research into ways of incorporating analytic solutions into numerical methods might uncover more ways of improving code efficiency and make possible simulations that are now impractical.

\section{Trace Contaminant Transport}

When contaminants in ground water are present at low concentrations, they do not change the density of the solution enough to change the water flow significantly. Such 
concentrations, referred to as "trace" amounts, would typically be encountered in repository ground waters because of the very low solubilities of many radioelements and the small amount of other radioelements in the waste and, hence, in the ground water under conditions of congruent dissolution.

When contaminants are present only at trace levels, the ground-water flow can be calculated by the methods described in the previous section, without consideration of the contaminants. The computed water velocities may then be used to model the contaminant transpor. This method (known as "uncoupled") for evaluating the movement of contaminants is presented in this section, while the "coupled" problem, in which contaminant levels change the flow, is discussed in the next section.

The standard equation for the motion of dissolved contaminants is referred to as the Solute Transport Equation and may be written:

$$
B \frac{\partial(\phi C)}{\partial t}=\nabla \cdot \phi \mathbf{D} \cdot \nabla C-\nabla \cdot \mathrm{q} C+R C^{*}
$$

where $\phi$ is the effective porosity, $C$ is the contaminant concentration, $\mathbf{q}$ is the water flux or "Darcy velocity" (equal to $\mathrm{K} \cdot \nabla h$ in Equation 5.2.1), $B$ is a "retardation factor" reflecting chemical interactions between contaminants and rock, $C^{*}$ is the concentration of contaminant in water added or removed through the source or sink, and $\mathrm{D}$ is the dispersion tensor. The four terms in this equation represent, respectively, the change in local concentration; mixing or "dispersion"; transport along with the water or "advection"; and fluid injection or withdrawal. Retardation and dispersion are complex phenomena that are not readily quantified; they are discussed further in Sections 3.3 and 5.2.6.

The Solute Transport Equation may be solved by the finite-element or finite-difference methods, using the same general approach as is used with the flow equation. However, the transport equation is much less tractable than Equation (5.2-1), and numerical problems arise with far greater frequency. These problems have stimulated much of the work that has been done to develop alternative modeling approaches. Abriola (1987) reviews recent work on the modeling of contaminant transport in saturated ground-water systems. 
Both finite-difference and finite-element methods have difficulty tracking the movement of sharp concentration fronts. Such fronts can maintain themselves in cases with little dispersion. The problem can be particularly severe with finite differences, where it takes the form of a smearing out the front referred to as "numerical dispersion." With finite elements, oscillations appear in the solution.

Grid spacings and time steps must be selected to avoid these problems. Formulas indicating whether discretizations ate likely to be acceptable are given by Reeves et al. (1986) for finite difference methods and Huyakom and Pinder (1983) for finite elements. When dispersivity is small and times are long, small grids and many time steps can be required by esther method.

An alternative solution technique that has been developed to avoid these problems is the "method of characteristics" (Konikow and Bredehoeft, 1978). In this approach, one solves the advective part of the transport equation by following the motion of reference "particles" that follow the water. "Particles" are initially placed in each grid block and are allowed to move a distance proportional to the velocity during each time step. At the end of the step, the new locations of the tracker particles are used to indicate local concentration as modified by advection. The relocated concentrations are then used as input to a finite-difference solution that accounts for the other terms in the equation. A related solution technique is the "particle tracker" method (Ahlstrom et al., 1977). Here, one follows the motion of individual contaminant particles. In each time step, each particle takes in advective step proportional to the velocity and then takes a randon step whose length depends on the dispersion coefficient.

Although these methods largely overcome the problems of numerical dispersion and overshoot, they have their disadvantages. The method of characteristics is difficult to program and would become much more so if used with a nonrectangular grid. As a result, it has been used in combination only with finite-difference solutions to flow. Particle irackers have very poor computational efficiency. Neither of these methods has yet been implemented in three dimensions.

Two other methods (Frind and Germain, 1986) have been developed to reduce the problem of numerical dispersion. They rely upon orienting the finite element grid with the 
principal directions of either the hydraulic conductivity tensor or the dispersion tensor. Frint and Matanga (1985) point out the mathematical relationship between stream functions and hydraulic head. The contours of these two functions, known as streamlines and equipotentais, are orthogonal to each other. Flow systems can therefore be described in terms of potential functions or stream functions, and the governing equations will be of the same form.

The principal-direction method is formulated by aligning the grit directions with the streamlines, hence also the principal directions of the dispersion tensor, and solving a stream-function based goveming equation. An alternating-direction Galerkin technique is used in the numerical solution. Although this reduces numerical dispersion and leads to significant increases in computational efficiency, difficulties arise when this method is applied to problems involving anisotropic, heterogeneous flow systems.

The principal-direction mathod has been modified (Daus and Frind, 1985; Frind and Hokkanen, 1987) so that it is more reatily applied to anisotropic and heterogeneous ground water systems. The molified method differs from the principal-direction method only in that it solves a potential based governing equation, and the finite element grid is aligned with the principal directions of the hydraulic conductivity tensor. Both the principal-firection method and the modified method are available in either wo dimensional or fully three dimensional versions (Bumett and Frind, 1987).

Wang ef al. (1986) have also proposed a model to better incorporate the three dimensional nature of dispersion. Called the apstream-weight muthple-cell balance finite element method, it uses both local mass balance and finite-element approximations to eliminate oscillation of tumerical solutions when convective transport dominates dispersive transport.

Another technique, called the finite analytic method, has recently been proposed for solving the Solute Transport Equation (Hwang et ai., 1985). In this method, analytic solutions of the equation are used to relate the rate of concentration change in a block to the concentration in stjoining blocks. This rnethod requires additional development before it is applicable in practice, and Hwang et at do not claim any clear prasticat advantage for it over conventionul methods. 
Much effort has also been devoted to improving the efficiency of finite element models (e.g., Huyakom et al., 1986; Yeh, 1986). As with flow models, all of the transport modeling techniques discussed in this section have trouble in treating small permeable features. For the finite-element and finite-difference models, the problems described previously for flow models are compounded when treating contaminant transport by the tendency of sharp concentration fronts to coincide with boundaries between zones of differing hydraulic conductivity. The method of characteristics requires that particles nove along a nearly straight line during a single time step. As a result, sherply curving streamlines can constrain time steps. The network models described in Section 5.2 .5 will, to some extent, avoid these problems, but at the price of simplifying the flow system.

Even with these limitations, numerical models for the transport of trace contaminants are well developed and are suitable for solving most problems normally encountered in hydrogeology. Javandel et al, (1984) and van der Heijde et al, (1985) briefly describe a large number of available models, and Thomas et al. (1982) describe some of them in more detail. It is quite possible, however, that the problems that need to be analyzed in repository perfornance assessment will require the further development of numerical methods.

\section{Coupled Flow and Transport}

In Equation (5.2-1), ground water flow was detennined from the gradient in hydraulic head. The head is defined in terms of pressure $p$ and clevation $z$ by

$$
h=z+\int_{p}^{p} \frac{d p^{\prime}}{g \rho(p)}
$$

where $p_{0}$ is any reference pressure, $g$ is the acceleration of gravity, and $p$ is the density of water. When the density is not a unique function of pressure (as it would not be in the presence of sizable temperature or salinity gradients), the head is not uniquely defined by Equation $(5.2-4)$. A more general form of Equation $(5.2 \cdots 1)$ must then be used.

$$
\nabla \cdot \frac{\rho k}{\mu} \cdot(\nabla p+\rho \& \hat{z})+\rho R=\frac{\partial(\phi \rho)}{\partial t}
$$


In this equation, $\mathrm{k}$ is the intrinsic pemeability tensor, $\mu$ is dynamic viscosity, and $\hat{z}$ is a unit vector pointing upward. This equation is more difficult than Equation (5.2-1) to solve because $\nabla p$ and $\rho g \hat{z}$ nearly cancel one another, leading to the numerical problems associated with small numbers obtained by subtracting large numbers.

In general, $\rho, \mu, R$, and $\phi$ can depend on the fluid pressure as well as temperature and concentration of dissolved materials. Consequently, to solve Equation (5.2-5), one must know the spatial distribution of contaminants and temperature. Equation (5.2-2) may still be used to calculate solute transport, but with the Darcy velocity given by:

$$
\mathbf{q}=-\frac{\rho \mathbf{k}}{\mu} \cdot(\nabla p+\rho g \hat{z})
$$

However, yet another equation is needed to compute temperature. This equation can take advantage of the fact that fluids and porous medium are in close contact in the subsurface, and so can usually be assumed to be at the same temperature at any location. But temperature still may be affected by convection by ground water, conduction by ground water, and conduction by rock. An equation that may be used to compute temperature in such circumstances is

$$
\nabla \cdot \mathrm{K}_{\mathrm{m}} \cdot \nabla T-\rho c_{\mathrm{v}} \mathrm{q} \cdot \nabla T+\rho R c_{\mathrm{v}} T^{*}=\left[\phi \rho c_{\mathrm{v}}+(l-\phi) \rho_{\mathrm{r}} c_{\mathrm{v}}\right] \frac{\partial T}{\partial t}
$$

where $\rho_{\mathrm{r}}$ is the density of the rock; $c_{\mathrm{v}}$ is the specific heat of water; $c_{\mathrm{vr}}$ is the specific heat of the rock; $T$ is temperature; $T^{*}$ is the temperature of water entering or leaving through the source term; and $K_{m}$ is the medium thermal conduction-dispersion tensor. The medium thermal conduction-dispersion tensor in Equation 5.2-7 includes the effects of thermal dispersion (which is analogous to solute dispersion) and heat conduction through both water and rock.

Although the heat and Solute Transport Equations are similar in form, the dispersion terms differ in nature. In solute transport, the dispersion is generally largely velocity-dependent (see Section 5.2.6). In heat transport, conduction is often comparable to, and in many repository applications much greater than, velocity-dependent mechanical dispersion. 
Huyakom and Pinder (1983) present finite-difference and finite-element formulations of the coupled flow and transport problem and discuss some of the difficulties that must be overcome to obtain numerical solutions. Coupled problems are not easy to solve. Nevertheless, the coupling between temperature and flow will determine water movement for a considerable distance around a repository and so cannot be ignored.

In some non-salt environments, salinity is low enough so that only the coupling between temperature and flow need be considered. Numerous computer codes using finite-difference, integrated-finite-difference, and finite-element methods are available for this purpose (Mercer et al., 1982). The majority of these codes were developed for geothermal energy or aquifer heat storage applications. A vanety of codes are also available for simulation of coupled flow solute transport problems (Javandel et al., 1984) and can be useful in studying points distant from a repository. Most of these codes (for example Sanford and Konikow, 1985; Huyakom et al., 1987) were developed for studying saltwater intrusion into aquifers.

However, there are very few codes that can handle the fully coupled water-solute-heat transport problem. Such codes will be essential to determine water movement near salt repositories, as well as at nonsait sites with significant salinity gradients. Pickens and Grisak (1979) have described a fully coupled finite-element model called SHALT, but development of this code was never completed. Gupta et al. (1982) describe a three-dimensional finite-element code called CFEST. Perhaps the most widely applied model of this type is a three-dimensional finite-difference model that exists in slightly different versions known as SWENT (INTERA, 1983c), SWIFT (Reeves and Cranwell, 1981), and SWIFT II (Reeves et al, 1986).

SWENT/SWIFT is difficult to use and tends to be computationally inefficient; CFEST has not been witely distributed, and no opinion on its ease of use can be offered. Given the complexity of the problems these codes can solve, some degree of user-unfriendiness and inefficiency (as compared to less complex codes) is probably unavoidable.

\section{Stochastic Methods}

A major focus of hydrogeological research in recent years has been the effect of spatial variability of geologic media on flow systems. In most, if not all, geologic units,

$$
5-16
$$


very considerable variations in hydraulic conductivity exist from place to place within the unit. As these variations are ubiquitous, it is not possible to characterize them in full detail. Instead, some kind of statistical description must be used to determine the large-scale effects of small-scale variability.

For the purposes of flow and solute transport simulation, the variations of primary interest are those in hydraulic conductivity. Because of spatial variability, a collection of local hydraulic conductivity measurements in a single geologic unit will give fairly widely scattered results. The properties of the unit as a whole cannot be fully described by only one measurement, or even by a single average value, but reflect the statistical properties of the set of measured values.

A contaminant particle in an aquifer of randomly varying hydraulic conductivity will not flow along a straight line, but will follow a tortuous path tending to keep in the more permeable zones of the aquifer. By modeling this tortuous flow path, it is argued, a more realistic estimate of the expected behavior of the flow system can be obtained from the available data. Stochastic methods also provide an estimate of the uncertainty in calculations of flow times and contaminant releases, but this aspect is outside the scope of this discussion and is addressed in Chapter 6.

Three approaches are available to calculate mean flow properties of a medium from the statistics of its hydraulic conductivity: application of Fourier transforms to the governing equations, perturbation methods, and Monte Carlo simulation. The mathematical bases of these approaches are concisely summarized by de Marsily (1986, Section 11.10). El-Kadi (1984) describes numerical models that apply them.

Only the Monte Carlo technique has been used in repository performance studies. This may be because it is the only one of the three approaches that can directly compute the quantities of greatest interest, ground-water travel times and radionuclide releases. Clifton et al. (1985) carried out a Monte Carlo simulation of flow at the Hanford repository site. In this study, numerous realizations of a random transmissivity field were generated from the statistics of measurements in basalt flow contacts. A finite-element flow model was used to calculate the flow field for each transmissivity flow field. The ground-water travel time was computed for each flow field, and the statistics of the ensemble of travel times were reported. 
In the application by Clifton et al., the transmissivity was treated as a homogeneous random field. In other words, available measurements were used to estimate the overall statistics of the random field, but no advantage was taken of the evident fact that measuring transmissivity at a given point gives additional information about the transmissivity there and in the vicinity, beyond what is known about the aquifer as a whole. As more information is gathered about repository sites, the local information contained in individual measurements would appear to offer a basis for a more detailed statistical description of the flow field.

Local measurements may be incorporated into stochastic models of aquifers by means of conditional simulation (Clifton and Neuman, 1982; Dagan, 1984). In this technique, which is described in more detail in Section 6.2.1, the kriging method is used to estimate the mean and variance of transmissivity (or its logarithm) at each point using both local measurements and the overall statistical description of the aquifer. Many realizations of the random transmissivity field are generated from this statistical model. The transmissivity fields may be generated in a way that reflects locally measured heads as well as transmissivities. Flow fields are then simulated and analyzed statistically, in the same way as with unconditional Monte Carlo simulations. Conditional simulation has not yet been applied to HLW repositories, but it is an obvious next step from the existing Hanford work.

One major obstacle to the use of these statistical methods is the difficulty of obtaining a statistical description of aquifer properties. Recent research has attempted to derive the statistics of hydraulic conductivity indirectly, by relating it to other, more easily measurable parameters through an understanding of the aquifer's depositional environment (Fogg, 1986a; Anderson, 1987) or through appropriate statistical methods (Phillips and Wilson, 1987). For example, Fogg (1986a) finds that the connected permeable units of the Wilcox Group of East Texas are thick channel sands deposited in a fluvial environment. The variable "presence of thick sands," easily discerned from boring logs, can be used as a proxy for hydraulic conductivity measurements in the estimation of statistical parameters (Fogg, 1986b). Similar work in other environments is described by Fogg and Lucia (1987) and Johnson and Dreiss (1987). 


\section{Combined Models of Flow and Geocherrical Equilibrium}

The Solute Transport Equation $(5.2-2)$ includes chemical reactions between solutes and the porous medium only through an extremely simplified sorption term. As discussed in Section 3.3.4, the linear sorption model, in which the ratio of solute to water velocity is a fixed value called the retardation factor, is an oversimplification in many situations. In general, radionuclide migration in groundwater depends both on the transport and the chemical evolution of water. It would therefore be desirable to couple transport models with geochemical models of the type described in Section 3.3.

This is a difficult task because of its mathematical complexity and the large computational expense. Cederterg et al. (1985) review past attempts at developing combined models and describe their own code of this type. Most of these models have been limited to one dimension by computational requirements. An abstract by Tripathi and Yeh (1985) describes a two-dimensional model. Narasimhan et al. (1986) developed a dynamic mixing model that combines the equilibrium speciation code PHREEQE, the heat flow model TRUMP, and the variably saturated flow code TRUST to simulate the infiltration and simultaneous migration of several species as a two dimensional plume.

This is still an area of exploratory research and routine application of such models is a good way away (see, for example, Ortoleva, 1985; Morrey and Hostetler, 1985; Moore, 1985). Considerable development will be required in both numerical technique and knowledge of the relevant chemical reactions before these models can be applied to repository problems. Unil we understand both aspects of this endeavor better, care must be taken so that the complexity of the model results does not totally obscure the usefulness of coupled modeling.

\subsubsection{Fractured Rocks}

Almost all consolidated rocks have fractures of some kind. Such rocks have two kinds of porosity; a "primary porosity" that originates at the time the rock is deposited (intergranular pores in sandstone, for example), and a "secondary porosity" that sterns from subsequent fracturing. Although the fracture porosity usually occupits a much smaller volume than the primary pores, its ability to transmit water is often much greater. Changes in pressure or solute concentration can sometimes be transmitted long distances through 
fractures without fully penetrating the primary pores in the rock matrix between the fractures. In such cases, the assumption of a homogeneous porous medium (which was implicit throughout the previous section) is not applicable. Two different approaches have been used to model the fractured porous medium: modeling of individual discrete fractures, and treatment as a "dual continuum"- that is, two interacting mathematical continua occupying the same physical volume.

The study of dual porosities began with the interest of petroleum engineers in the flow of oil. There are a variety of models for fluid flow in fractured porous media, but the time scales of repository performance assessment are so long that pressure equilibrium between fractures and rock matrix can safely be assumed and dual-porosity effects can be ignored in flow modeling. However, because solute concentrations are transmitted more slowly than pressure changes, dual-porosity effects are often important in modeling contaminant transport. Even in granite, whose bulk porosity had previously been ignored by hydrogeologists, a series of experiments by Neretnieks and co-workers (Abelin et al., 1984; Birgersson and Neretnieks, 1984; Neretnieks, 1980) has shown that solute diffusion into the rock matrix is an important feature to consider in assessing repository performance assessment. The discussion here will therefore be limited to modeling of solute transport.

In one dimension, the discrete-fracture and dual-continuum approaches are equivalent, and analytic solutions to solute transpor problems can be obtained. Rasmuson (1984) and references he cites provide such solutions. With more dimensions, numerical methods must be used; these are discussed below.

\section{Discrete-fracture Models}

The SWIFT finite-difference model described in Section 5.2.1 has been modified to permit inclusion of discrete fractures (Reeves et al., 1986). The fractures are represented by grid blocks that are still two- or three-dimensional but are shaped like a fracture. Diffusion into the rock surface adjacent to the fracture is treated by attaching a one-dimensional finite-difference "tentacle" (similar to the "tentacle" used in the dual-continuum models described in the next section) to each grid block representing a fracture.

Finite-element models can incorporate discrete fractures in a more natural way without resorting to the contorted grids required by finite differences. In a two-dimensional 
model, one may insert one-dimensional "line elements" representing individual fractures between the two-dimensional elements. A similar approach can be taken in a three-dimensional model by adding two-dimensional elements. This is the method employed in the MAGNUM2D flow code (Baca et al., 1981) used in some of the modeling work at the Basalt Waste Isolation Project.

To use any discrete-fracture model requires that one know the location and properties of all the transmissive fractures. Such models can be useful in representing known fracture zones (such as might be created by a fault) in large-scale regional models. Unfortunately, the knowledge required about individual fracture properties cannot feasibly be obtained for the many fractures involved in regional-scale matrix diffusion situations. Consequently, discrete-fracture models are not appropriate for such problems.

\section{Dual-continuum Models}

To treat a fractured porous medium as a dual continuum, some conceptual model of the interaction between the two continua is needed. Specifically, one must assume some size and shape for the blocks. One can then apply the solute concentration in the fractures as a boundary condition to compute the movement of solute into the blocks and back out of them.

The simplest assumption is to treat the fractures as parallel planes. This allows one to explicitly model advection and dispersion in both continua in two dimensions. Models of this type were developed by Grisak and Pickens (1980) and Noorishad and Mehran (1982), but such models are computationally inefficient because of the two-dimensional treatment of the blocks.

Another method is to model only one-dimensional diffusion in the blocks. Each grid block in the fracture continuum then has attached to it a "tentacle" representing the solute concentration in the blocks as a function of distance from the nearest fracture. Bibby (1981) introduced this approach, treating the "tentacle" with analytic solutions for one-dimensional diffusion into flat-plate blocks between parallel fractures. The TRUCHN integrated finite-difference model (Rasmuson et al., 1982), the SWIFT II finite-difference model (Reeves et al., 1986), and the FTRANS finite-element model (Huyakorn et al., 1983) 
take another approach to the "tentacle" by computing diffusion into a one-dimensional numerical model of the matrix. Each of these codes uses the same numerical method in the "tentacle" as in the continuum of fractures. The "tentacle" is composed of spherical blocks, which are modeled in one dimension by treating the spheres in radial coordinates. (The blocks must overlap to be spherical and occupy the proper volume, but this is an acceptable mathematical approximation, the essential point being that the blocks have the right surface-to-volume ratio). The fractures are treated as a two-dimensional continuum (three-dimensional in SWIFT II).

The models described above assume that the matrix blocks are all the same size. Neretnieks and Rasmuson (1984) present a method for treating a distribution of block sizes by giving the "tentacle" a shape that reflects contributions of all block sizes.

The dual-porosity concept is well supported by experiments, but while there has been extensive development work on numerical models, relatively few dual-porosity solute-transport models have been applied to large-scale field problems. Of these, Bibby (1981) is the most notable, but additional field applications of these models would increase one's confidence in their validity.

\subsubsection{The Unsaturated Zone}

The unsaturated zone extends from the soil surface down to the water table and can be conveniently divided into two regions: the root zone and the vadose zone. The root zone consists of the top 0.5 to 2 meters of the soil profile (depending upon crop or plant type) and is the region from which plant roots actively extract water in response to transpiration demand. Below the root zone is the vadose zone, whose thickness depends upon whether the water table is shallow or deep and may vary from a few meters to several hundred meters. It is the vadose zone that is of concern in waste repository studies.

Because not all pores are full of water in the unsaturated zone, additional variables not needed in the saturated zone must be used to describe moisture conditions. Specifically, the volumetric water content $\theta_{w}$ (defined as the fraction of the total volume of the porous medium occupied by water) must be distinguished from the porosity $\phi$. One sometimes also discusses the saturation, $S_{w}$, defined by

$$
S_{w}=\theta_{\Psi} / \phi
$$

$$
5-22
$$




\section{Water Llow}

In the saturated zone, flows are driven by differences in pressure or hydraulic head. Above the water table, however, water flows in response to gravity and to differences in the strength of attractive caplliary and adsorptive forces between water and the rock or soil matrix. The concept of pressure must be generulized into a more general "pressure potental" to account for these forces.

The hydraulic conductivity of unsaturated rocks (known as the "effective hydraulic conductivity't is less than when the same rocks are saturated and depends on the water content. The ratio of effective to saturated hydraulic conductivity is known as the relative permeability, $k$, which can be expressed as a function of $\theta_{\text {甲 }}, S_{w 4}$ or the pressure potential $y$. The governing equation for water movement in the unsaturated zone, known as Richards' Equation, can then be written as:

$$
\nabla \cdot k(\psi) \mathbf{K} \cdot\left(\nabla_{\psi}+z\right)+R=\frac{\partial \theta_{\psi}(\psi)}{\partial t}
$$

Solution of this equation requires knowledge of two constitutive relations, the relative permeability $k(\omega)$ and the "ohanacteristic curve" $\theta_{y}(\psi)$. These curves, as measured, usually exhibit hysteresis $-\cdots$ at a given potential, soils contain more moisture during drainage than during weting - but models rarely tak hysteresis into account.

Richards Equation is nonlinear, especially at low moisture contents. As a result, its solution is difficult, with iterative searches needed to find the solution at each time step. Huyakom and Pinder (1983) describe these methods in detal. As they report, much art is involved in selecting the proper search method, and various tricks fsuch as adjusting the size of time steps to improve the efficiency of the search) must be used to ensure convergence. Even so, there is not yet sufficient experience to show that present methods are adequate for solving all the problems involving very dry rocks that may arise in an unsaturated-zone repository.

Solutions may be obtained by finite-difference methods, which petroleum engineers have favored in solving closely related problems, or by finite-element techniques, which hydrogeologists have prefered. Among the better known finito-element models are 
UNSAT2 by Neuman et al. (1975) and FEMWATER by Reeves and Duguid (Yeh and Ward, 1980). The integrated-finite-difference code TRUST is another well-tested model. These three models, which were developed for wetter soils, have had trouble solving some very dry soil problems. A hybrid finite-element and integrated-finite-difference code, SUTRA (Voss, 1985), also is unsuited to dry conditions. Huyakom et al. (1986) repon the development of a fully three-dimensional model, expanded from the earlier two-dimensional SATURN code (Huyakom et al., 1984), that is better able to take into account dry soil conditions and also offers efficiency improventents. A model using the multigrid technique has been developed to solve steady state, unsaturated flow problems with a very large number of nodes (MCKeon and Chu, 1987).

Most of these and a large number of other unsaturated-zone codes were reviewed by Oster (1982). Kincaid et al. (1984) compared the performance of FEMWATER, SATURN, and TRUST in solving identical problems. Neither FEMWATER nor SATURN was able to solve a problem with a sharp discontinuity in moisture content. This difficulty could, in principle, have been overcome with a sufficiently fine grid, but project resources did not allow this to be attempted. The results of these tests suggest that of -the shelf models used to solve unsaturated flow problems arising in repository analyses cannot be viewed as "black boxes." Careful review of results by an experienced numerical analyst is essential, and a need for code modification is likely to arise.

Solute Transport

The mathematical methods used to simulate unsaturated solute transport are relatively straightforward adaptations of those used in the saturated zone. The water velocity is obtained from Equation $(5.2-9)$ rather than Equation $(5.2-1)$ or $(5.2-5)$. Equation $(5.2-2)$ may still be thought of as the governing equation, but some of the parameters $-B$ and $D$, in particular-can vary with the degree of saturation.

Perhaps because of the lack of well-measured input data and the lack of applications to be found below the root zone, there are few unsaturated solute transport codes in more than one dimension. FEMWASTE, the companion to FEMWATER (Yeh and Ward, 1981) and SATURN (Huyakorn et al., 1985), are the best known. These codes use the same numerical methods for transport as for flow. A simple model called MLTRAN has been 
developed to calculate non-dispersive transport in flow fields calculated by TRUST (Kincaid et al., 1984).

\section{Heat Transport}

Nonisothermal water transport in the unsaturated zone is an excedingly complicated topic in which both liquid and vapor transpon can be of importance. Pollock (1982) gives a detailed analysis of the relevant processes, but because of their complexity, we will not present the governing equations here.

There are a number of computer codes that describe movement of vapor and liquid water in porous media, probably the best known being SHAFT79 (Pruess and Schroeder, 1980), which uses the integrated-finite-difference method. This code was developed for geothermal energy applications and ignores any air in the pores, a limitation that is probably not acceptable for repository applications. A version of SHAFT79 that includes an air phase is known as TOUGH (Pruess, 1986). A finite-difference code developed by Pollock (1986) has also been applied to repository problerns.

\section{Fracture Flox}

The tuff at the Yucca Mountain repository site acts as a fractured porous medium that is similar to the media discussed in Section 5.2 .2 but is unsaturated. Conceptual models of the governing flow mechanisms have been developed by Montazer and Wilson (1984), Wang and Narasimhan (1985), and Klavetter and Peters (1986). Much remains to be learned abut the physical mechanisms of ground water behavior in such media, and modeling of them is still in its infancy. Evans (1983) and Evans and Nicholson (1987) have summarized relevant background knowledge.

Currently, there are no dual-continuum models for unsaturated materials. Indeed, the governing equations upon which such models would have to be based have not been clearly stated in the literature. Some discrete-fracture codes are being developed (Rasmussen, 1987; Wang and Narasimban, 1985; Travis et al., 1984), but these models are only beginning to be published and have not yet achieved general acceptance. Numerical problems have been an obstacle to simulation of cases with flow in both fractures and 
matrix (Klavetter and Peters, 1986). At this point, most research on unsaurated fractured porous media seems to focus quite properly on understanding basic physical mechanisms. Modeling undoubtedly will be a significant component of that research; at present, however, the physical basis of the models has not been fully confirmed.

\subsubsection{Colloid Transport}

In recent years, hydrogeologists have begun to think that in some environments collotis play a significant role in the movement of trace constituents. Literature showing the movement of colloidal particles in ground water has been reviewed by McDowell-Boyer et al. (1986).

Radionctive colloids can be generated in a high-level waste repository by several processes (Avogadro and de Marsily, 1984). These include

- Chemical reactions between waste and ground water.

- Corrosion of containers and other metal components of waste packages.

- Degradation of backfill materials.

- Sorption of radioelements on naturally oceurring colloids.

- Precipitation of colloids at a distance from the waste package, due to slow kinetics or changes in water chemistry or temperature.

The radioactive colloids formed by these processes may be classified as

- "True" radiocolloids, in which the collodal particle is composed of the radioelement.

- "Pseudcolloids," formed by sorption of a radioelement to the surtace of a non-radionctive colloid.

While the movement of colloids in porous media has ben addressed by ground water scientists only recently, this subject has been studied for a long time by engineers interested in filtration theory for applications in water treatment, mineral processing, and other aspects of chemical engineering. The extensive literature in these fields discusses three principal mechanisms of colloil hiltration (McDowell-Boyer et al, 1986): 
- Particles of size comparable to grains of the porous medium or larger do not enter the medium and form a "filter cake" on its surface; this is known as "surface" or "cake" filtration.

- Particles small enough to enter the porous medium, but larger than constrictions in the pores, can be removed by "straining" at the pore constrictions.

- Very small colloids can adhere to the pore walls if the thermodynamic surface potential of a colloid-rock interface is less than the total surface potential of the two solid-water interfaces. These surface potentials are determined by electrostatic and intermolecular forces, and the mechanism is called "physical-chemical" filtration.

Physical-chemical filtration is of primary interest in predicting the movement of radiocolloids. The surface interactions that cause it are sensitive to solution composition. For example, changes in $\mathrm{pH}$ can reverse the sign of the electrostatic charge on a surface, and increases in solution salinity can shield electrostatic interactions so that an attractive van der Waals force overcomes a repulsive electrostatic force. Physical-chemical filtration is also highly sensitive to the surface chemistry of the colloids and the porous medium, which in a natural environment can be characterized, if at all, only with great difficulty.

A simple model for removal of colloidal particles from solution, known as the "filtration equation," has been widely used in the filtration literature (McDowell-Boyer et al., 1986). In this model, the rate of removal of colloidal particles from solution is given (Avogadro and de Marsily, 1984) by:

$$
\frac{d P}{d t}=-\lambda q P
$$

where $P$ is the number of colloids per unit volume and $\lambda$ is the "filter coefficient." The value of $\lambda$ may depend on the size of the colloid particles. If the colloids are not all the same size, one defines $P$ in Equation (5.2-10) as a function of particle diameter as well as space and time. Travis and Nuttall $(1985 ; 1986)$ have developed a numerical model of colloid particle migration by adding a term like equation (5.2-10) to a conservation equation for colloid particles that is similar to the Solute Transport Equation (5.2-2).

This modeling approach has several important limitations. First, the filter coefficient $\lambda$ cannot be predicted a priori. While a variety of formulas have been used to relate $\lambda$ to water chemistry and flow rate (McDowell-Boyer et al., 1986; Bonano and Beyeler, 1985), available theories have had limited success in explaining experimental results. 
Secondly, Equation (5.2-10) only predicts the rate of particle removal from solution and does not address particle remobilization. This will probably be adequate for including colloidal transport in mass-transfer models of waste form dissolution like those discussed in Sections 4.2 and 4.3 . But if there is a concern about colloidal movement as a mechanism for carrying radioactivity away from the repository, moving distances of perhaps several kilometers over thousands of years, the filtration model will not serve to analyze this possibility. This model assumes the problem away by neglecting particle remobilization.

Finally, Equation (5.2-10) is intended for use on "clean" filters and does not address changes in medium permeability and filter coefficient as appreciable amounts of filtrate accumulate. These changes may be signifieant near waste packages if they release large amounts of colloidal material. Several formulas have been developed to describe filtrate effects on medium properties (McDowell-Boyer et al., 1986), but these formulas have very limited predictive validity.

\subsubsection{Network Transport Models}

The complexity and expense of solving the Solute Transport Equation in two or three dimensions has generated much interest in finding simpler approaches. Generally, the approach used is to represent the flow field as a network of one-dimensional path segments. As Ross and Koplik. (1979) have shown, the segments, with certain restrictions, need not be straight. The network is designed on the basis of an analysis of the flow field, which may be calculated from one of the two- or three-dimensional numerical models discussed above.

Under certain circumstances, as when analyzing flow through mined tunnels backfilled with material more permeable than the surrounding rock, the path network can be specified from physical considerations without numerical analysis. In this case, each path segment can be considered to have a "resistance" $R$ given by:

$$
R=\frac{L}{K A}
$$

where $L$ is the length of the segment, $K$ its hydraulic conductivity, and $A$ its cross-sectional area (Giuffre et al., 1980). Darcy's Law (Equation 5.2-6) then becomes 


$$
q=\frac{\mathrm{A} h}{R}
$$

where $h$ is the head difference between the ends of the segment. One can take advantage of the formal identity between Equation (5.2.12) and Ohms Law to find the water flows by using the methods of elementary electrical ciruit theory.

However one may have determined the ground water velocity in each path segment, the main advantage of the network approach is obtained by using that velocity to solve the Transport equation in one dimension within the segment. Analytic solutions or greatly simplified numerical methots may be used to do this, with the quantity of the contaminant output by one segment in a given time interval being used as input to the next segment. Where flows diverge into regions with different properties (as in the case in which some flow proceeds up througt a shaft and the remaining water flows through undisturbed rock), two parallel pathways can be defined and the input of contaminant may be appropriately divided. A typical network of flow segments is shown in Figure $5.2-2$.

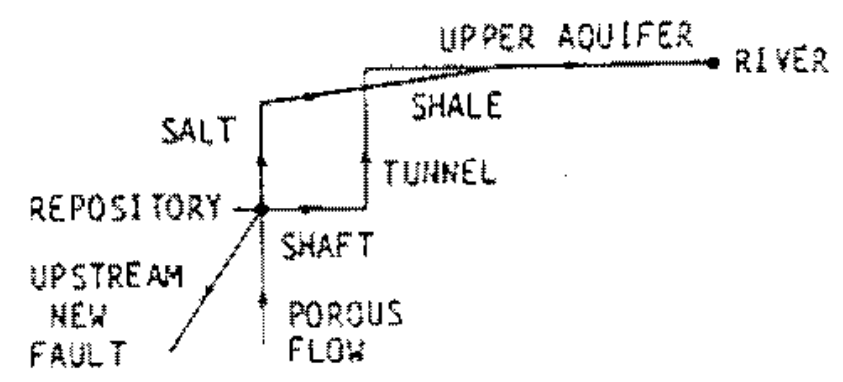

Figure 5.2-2. A lypical path network (from Giuffe at al. 1980)

The simplest possible network consists of a single segment. This network is equivalent to a one-dimensional solute transport problem with uniform velocity. The next simplest network consists of several segments connected in series. Aralytic solutions for both of these situations have been published by several authors, but the most thorough and complete solutions have been developed by Pigford and co-workers at Berkeley (Harada et al., 1980, Pigford et a.., 1980) and by Gureghian and Jansen (1985).

Analytic solutions to these problems tend to be very complex, especially when radioactive decay chains are involved. As a result, computer programs are required for their numericat evaluation. The number of terms that appear in the analytic solutions is so large 
that these programs encounter numerical difficulties similar to those encountered with purely numerical methods. The Berkeley group has developed programs for their solutions, and the results were compared with other solution methods in the international code comparison INTRACOIN (Andersson et al., 1982; NTRACOIN, 1984), Results of this exercise indicate that numerical limitations pose a significant problem for analytic solutions. In fact, analytic solutions seem to demand the same kind of cation as required in using numerical methots.

A somewhat different approach to the one dimensional problem is used in the LASSY fode (Sneider and Craig, 1985). LASSY represents dispersion by dividing the flow into several parallel one-dimensional paths having different velocities. The results are different from those given by Equation (5.2-2), but there is, as described in section 5.26 , a physical basis for this description of the phenomenon.

For more complicated networks, it is necessary to use a numerical or semi-analytic solution in each segment and treat the transfars among segments numerically. Two programs of this type have been used extensively: NUTRAN and NWFT.

NUTRAN (Analytic Sciences Corp., 1983) is the older of these two programs. It uses a semianalytic solution for nondecaying contaminant within each segment and corrects the final output to account for radioactive decay. This treatment of decay chains can introduce errots under some circumstances for the daughter nuclides, In addition, the code has an approximate trestment of the boundary condition between segments that can spread pulses too much in cases with larye dispersion. Recent versions of the cole incorporate a Teasonably accurate treatment of velocines that change wever time. The greatest advantage of the model is its flexibility in treating networks of any sizte and complexity.

NWFT (Campbell at al, 1981a) solves the tunsport equation within each path segment by a numerical method known as the "distributed velocity method" (Campbell et al., 1981b; 1981c). By this techritque, NUTRAN's limitations in handling decay chains are avoided, but numerical errors in solving the equation are introduced for certain combinations of parameter values. These are somewhat similar in nature to those encountered by finite-difference and finite-element codes, but the cases in which they arise are not at all the same. The published version of NWFT is restricted to an single specified network of path segments. A newer version, known as $\mathrm{GNE}^{\mathrm{T}}$, allows more flexibility in connecting segments, but details have not been published.

$$
5-30
$$


The simplifications involved in these codes have engendered much doubt about their usefulness in repository analyses. Yet it is noteworthy that the performance analyses of the Hanford and Yucca Mountain sites in the Environmental Assessments used an even more simplified approach - one dimensional models that ignore dispersion altogether. The simplicity of these models, called EPASTAT (Eslinger and Sagar, 1986) and SPARTAN (Sinnock et al., 1984), was in large part due to the need for computational efficiency when they were exercised many times in uncertainty analyses. The salt Environmental Assessments did not solve the Solute Transport Equation at all.

\section{5,2.6 Validity of the Solute Transport Equation}

The Solute Transport Equation, toward whose solution most of the work described above has been directed, stands on none too firm an experimental and theoretical foundation. Up to a point, this need not concern the modeler. If the parameters of the equation can be measured in the field, they can be used to produce empirical correlations whose usefulness requires no theoretical justification. But when, as is frequently the case in repository perfomance assessments, great extrapolations in time and space are required, the purely empirical approach becomes untenable. Some sort of theoretical understanding is required to justify the extrapolation.

Recently, two aspects of the Solute Transport Equation have attracted particular attention. These are the use of a linear retardation factor $(B$ in Equation 5.2-2) to represent sorption and the diffusion-like rreatment of dispersion. Sorption is discussed in Section 3.3.4. Current thinking on dispersion will be neviewed in this section.

The dispersion term in the Solute Transport Equation has lately been a major focus of research in hydrogeology. The accepted theory relates the dispersion coefficient $\mathrm{D}$ to the water velocity $v$ by

$$
\mathrm{D}=v \boldsymbol{\alpha}
$$

with $\alpha$, a tensor with units of length, known as the dispersivity.

Recent work has been largely stimulated by the observation (Lallemand-Barres and Peaudecerf, 1978) that the values of $\alpha$ measured in the field are roughly proportional to the 
scale of the observation. This comelation would be explained if it were found that pulses of contaminant spread, not with the square root of time as predicted by Equation (5.2-2) or any other equation with a second-spatial-derivative term, but in direct proportion to elapsed time. Physically, the scale-dependence of the dispersion coefficient has been taken as evidence that field dispersion is due to large-scale variability in hydraulic conductivity.

The most widely studied method of understanding this large-scale dispersion has been to try to statistically characterize conductivity variations and use them to explain dispersion (Gelhar and Axness, 1983, and references cited therein). This approach has the disadvantages of mathematical complexity and the need to make hard-to-test hypotheses about the spectrum of the fluctuations. An altemative view, presented by Neretnieks (1983), proposes that water moves through several independent channels at different speeds. Unlike Gelhar's approach, this has the merit of predicting the time proportional spreading which seemingly is observed. Moreno et al. (1985), Rasmuson (1985), and Ross (1986b) analyze conditions under which the channeling mechanism model will yield different predictions than models based upon the Solute Transport Equation. Neretnieks also stresses the importance of matrix diffusion (see Section 5.2.2) in causing spreading that has been interpreted as dispersion by hydrogeologists.

Recent large-scale experiments in which contaminant movement in sandy aquifers was observed at hundreds of sampling points (Goltz and Roberts, 1985; LeBlanc and Garabedian, 1986) add more force to the critigue of the Solute Transport Equation. Diffusion into clay layers (analogous to matrix diffusion in granite) and channeling seem to be as important as mechanical mixing in explaining the spreading of contaminant plumes. Also notable are the extremely small transverse dispersivities observed in the vertical direction in these experiments.

This research, while interesting, is of somewhat limited relevance to repository performance assessment because of the low sensitivity of performance to dispersivity. At most (except in very special casex), predicted release rates of radioactivity vary with the square root of the dispersivity. As field dispersivities fall in a narrow range of one or two orders of magnitude for a given experimental scale, reasonable estimates of dispersivity are unlikely to cause an error of more than about a factor of 3 . This is usually negligible in the context of other uncertainties about repository performance. 


\subsubsection{Evaluation of Ground Water Models}

\section{The HYOROCOIN Exercise}

As illustrated in the preceding sections, modification, refinement, and hybridization of the few basic numerical techniques has led to the generation of a vast diversity of codes. However, efforts to evaluate the relative merits of the various codes, especially as they pertain to safety assessment, have generally lagged behind. Recognizing this, the international repository assessment community has undertaken a coordinated investigation called the HYDROlogic COde INtercomparison (HYDROCOIN). This is a two year effort, completed in late 1987 , in which twenty organizations from eleven countries have applied 25 or more codes to a standard set of problems.

The exercise is divided into three levels corresponding to ground-water performance assessment requirements:

- Level 1 includes seven benchmark and verification problems. The problems have been formulated such that the numerical accuracy of a code can be evaluated by intercomparison with other codes or comparison with analytical solutions.

- Level 2 includes five validation problems, designed to test the various codest ability to reproduce laboratory and field data.

- Level 3 includes seven problems and data sets designed to test the codes when used for sensitivity and uncertainty analysis of complex systems.,

Level 1 and 2 exercises have been completed; results of the level 3 exercises have not yet been reponted. The results and the lessons leamed from the HYROCOIN exercises to date have been surumarized by Cole (1986), Cole et al. (1987), Raimbault and Goblet (1987), and Nicholson et al. (1987). These results include (Cole et al., 1987):

- While the agreement between calculated scalar quantities such as hydraulic head were good, agreemert was lacking between calculated vector or field derived quantities such as flow velocity and travel time.

- Intercomparison illuminated subtle differences between the codes, revealed some code specific difficulties and means to correct them, and yielded useful information concerning numerical implementation strategies. 
- Interaction between the various participating teams led to an exchange of "tricks of the trade", and the recognition that repeated attempts and code modification were often necessary to obtain accurate and efficient solutions.

- The importance of the time step size, grid size, and grid orientation in solution convergence and the need for accuracy in post-processor codes were underscored. This was particularly true for calculations based upon scalar quantities. Finite elements with quadratic basis functions were shown to produce more accurate results than those with linear basis functions.

- Currently available numerical techniques cannot be counted upon to solve extremely non-linear, transient flow problems. At least one problem (unsaturated, heterogeneous flow) could not be solved by any model. Small grid-block and time-step size were crucial to obtaining solutions in those problems which could be solved.

- The data bases selected for model validation were found to be inadequate to evaluate model output. Data bases sufficient to validate complex flow models have yet to be amasseil.

- Future efforts will require better planned field and laboratory experiments to lead into "iterative validation exercises" which proceed stepwise through laboratory, field, and large field scale validations. The selection of an appropriate performance measure is crucial for evaluating the model results.

- Quantifying the uncertainties must include the spatial variability of hydrogeologic properties. This is especially true for uncertainties associated with assigning boundary conditions.

- The uncertainty inherent in formulating conceptual ground-water flow models is not currently subject to quantification.

- Because the accuracy of calculated quantities was seen in the exercise to depend upon spatial and temporal grid configuration, modelers should make it a normal practice to perform a series of discretizations to demonstrate the correctness of solutions.

- Because of the complexity of the codes and the problems they are applied to, independent modeling teams working on the same problem may be the only way to check the results and provide confidence in the interpretation of the results.

\section{Retrospective Validation of Ground-water Models}

Enough time has now passed since the use of ground-water models began that the predictions of early modeling studies can be compared with what has actually happened. Retrospective evaluations of model predictions have now been reported by Konikow (1986) for a flow model and Lewis and Goldstein (1982) for a transport model. 
The agraement between prediction and experience is not very close. As Konikow observes,

The example discussed in this paper showed that calibrating a model with more than 40 years of data, in itself, did not provide a reliable basis for predicting changes in ground-water levels for a 10-year period. This example, although certainly neither exhaustive in scope nor firmly conclusiye in implication, at least tends to raise serious questions concerning our ability to forecast the future state of groundwater systems. At a minimum it can be called on to question the credibility and validity of predictions of waste transport in ground water for perhaps thousands of years in areas where there may be no historical observations of flow or transport phenomena... In light of the predictive accuracy demonstrated by the model in the example presented in this paper, one might legitimately question the value of deterministic ground-water models.

It should be noted, however, that the discrepancies between predictions and outcome do not appear to be due to any deficiency in the computer codes, but to an inability to correcty identify the governing parameters and accoun for the complexities of the field situation. Thus they point not so much to a limitation of modeling, as to a limitation in our ability to characterize hyorogeological systems in the ficld.

Models remain a method of marshaling available hytrogeological information, combining it into a self consistent description of the ground-water system, and simulating future behavior from the given assumptions. Better model performance depends principally on more insightful and accurate data gathering and conceptual models rather than better codes.

\subsection{Observations}

Ground water modeling is an active field of research and much remains to be done to develop computer codes capable of simulating the complex coupled processes that will take place around a repository. Nevertheless, code development must be a secondary priority compared to data acuisition. Already, coles have developed to a degree of complexity far beyond the ability of field hytrogeologists to measure the needed input variables. While new data-gathering technictues are being developed, it will not be possible even in the most optimistic scenario to measure all the variables needed by the more complicated models. Emphasis is therefore needed on techniques for doing bounding calculations with incomplete information and on ways of ensuring the conservatism of these calculations. 
Work on code development is needed, to be sure. The opinion is sometimes expressed that code development for the repository program should focus exclusively on developing ways to model phenomena not yet accurately modelable, because the program's large budget makes computational efficiency irrelevant. The extensive use of one-dimensional models in the Environmental Assessments and the code limitations that have been encountered in other modeling efforts suggest that computational efficiency is an important consideration, and that continued research on more efficient numerical methods would be valuabie.

\section{$5.3 \quad$ Transport in salt}

Possible mechanisms for the transport of radionuclides in salt include brine migration away from breached fuel canisters (Section 3.5) and ground-water flow towards the accessible environment (USDOE, 1986b, p.6-244). Because the mechanisms governing brine migration away from a heat source have not yet been rigorously defined, transport studies have relied upon vaguely defined "diffusion mechanisms" with empirically derived coefficients.

Although salt has void spaces, it is not clear whether they are sufficiently connected in undisturbed salt fomations to permit Darcy flow. While Darcy flow has been invoked as an explanation of inflows into waste emplacement holes in salt, the occurrence of such flow on a small scale does not necessarily imply the existence of a continuous domain of interconnected pore space throughout the salt deposit (McTigue and Nowak, 1987).

Although experimental determinations of permeability have been problematic, they indicate values less than $10^{-10} \mathrm{~cm} / \mathrm{s}$, which is near the detection limit. Because of the plastic behavior of salt at depth, increased permeability due to fracturing is not considered to be likely.

\subsection{Gas-phase Transport}

Certain of the radioelements in high-level waste can enter the gas phase in significant concentrations. These elements can then migrate by diffusion or advection toward the surface. Generally, there will be a chemical equilibrium between the gas phase, a dissolved phase in the pore water, and perhaps also a solid phase. The rate of migration depends on the concentrations in these three phases. 
This section will first discuss models for calculating the bulk flow of gas, and then will address radionuclide transport. The geochemical models described in Section 3.3 can be used directly to compute the relevant chemical equilibria, so that topic will not be treated here.

\subsubsection{Gas Flow}

Like ground water, soil gas moves under the influence of pressure, with flux proportional to the pressure gradient according to Darcy's Law. There are, however, several differences between the movement of gas and liquid:

- Gases are much more compressible than liquids, so that storativities of gases are much greater than storativities of liquids.

- Evaporation and condensation of vapor can provide a significant source or sink of gas, especially as temperatures rise toward $100^{\circ} \mathrm{C}$.

- The temperature coefficient of expansion is much greater for gases than for liquids.

- Gases are less dense than liquids.

As a result of the second and third of these considerations, temperature is far more important in determining gas flows than in water flows.

At temperatures close to ambient, the principal driving force is the difference between relatively constant subsurface temperatures and surface temperatures which fluctuate daily and annually. In the presence of topographic relief, these temperature differences can drive a considerable air flow (Weeks, 1987). This phenomenon can be modeled by treating subsurface temperature as constant and prescribing the variation of surface temperature. A model of this type has been developed by Kipp (1987).

After waste is emplaced in a repository, subsurface temperatures can no longer be treated as constant. Furthermore, the latent heat of moving water vapor will probably make a major, if not dominant, contribution to heat transfer. Under these conditions, the only way to calculate gas flows would seem to be the use of complex two-phase models like TOUGH, as described in Section 5.2.3. 


\subsubsection{Contaminant Transport}

A governing equation for diffusive transport of gas-phase contaminants, in the case where transport in the liquid phase can be neglected, is given by Thorstenson et al. (1983). A somewhat more general equation can be obtained by adding an advection term:

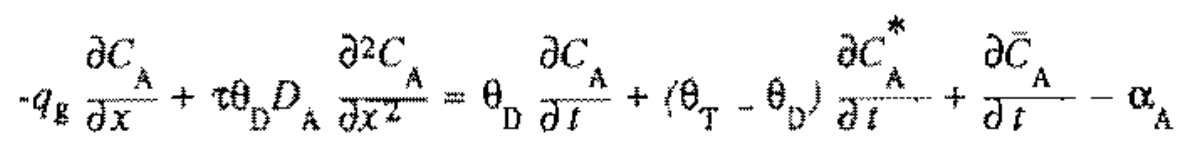

where

$q_{\mathrm{g}}=\quad$ Darcy velocity of mass llow of the pore gas (cm/sec);

$C_{\text {A }}=$ concentration of gats $\mathrm{A}\left(\mathrm{mole} / \mathrm{cm}^{3}\right)$;

$C_{A}=\quad$ Concentration of gas $A$ and its reaction products in the soil water(mole/ $\mathrm{cm}^{3}$ of water; note that Thorstenson et al. define this variable as a concentration per unit mass;

$\ddot{C}_{A}=\quad$ concentration of substance $A$ and its reaction products in the solid phase mole/[ $\mathrm{cm}^{3}$ of medium], where $\left[\mathrm{cm}^{3}\right.$ of medium] refers to the space occupied by solids + hiquids + gases);

$x=\quad$ dimension increasing with depth; 0 at land surface $(\mathrm{cm}) ;$

$\tau=\quad$ a tortuosity factor accouring for the added resistance to diffusion imposed by the structure of the porous medium (dimensionless);

$\theta_{\mathrm{D}}=\quad$ drained or gas $\mathrm{gitlled}$ porosity (dimensionless)

$D_{A}=$ molecular diffuston consant for diffusion of gas A into the pore gas $\left(\mathrm{cm}^{2} / \mathrm{sec}^{2}\right)$;

$t=\quad$ time $(\sec )$

$\theta_{\mathrm{T}}=\quad$ total porosity (dimensionless);

and $\alpha_{1}=$

a production term for substance A [molet/cm ${ }^{3}$ of medium)/sec].

White this is a onedimensional equation, the generatization to thres dimensions is obvious. 
This equation describes molecular diffusion and advection by steady or slowly changing gas flows. (Note that molecular diffusion is much more important in the gas phase than in the liquid phase, because diffusion constants are three orders of magnitude larger.) Oscillatory flows, like those induced by varying surface temperatures, will presumably cause some sort of mixing effect rather than a steady flux of contaminant; the appropriate governing equation for transport by this means is not obvious.

Thorstenson et al. (1983) have written a computer model that solves Eq. (5.4-1) without advection in one dimension for carbon-14 in a system where the water is saturated with respect to calcite. The difficulty in solving the equation lies not so much in the transport terms, which are very similar to those for ground-water transport, as in finding a simple chemical model to relate $C_{\mathrm{A}}, C_{\mathrm{A}}{ }^{*}$, and if necessary $\partial \bar{C}_{\mathrm{A}} / \partial \mathrm{t}$.

\subsection{Radiological Assessment}

The transport models described in the previous sections interface with the radiological consequences models by defining selected locations in the environment where radionuclides may enter exposure pathways. At these locations, a transport pathway is in contact with a medium (or media) from which the radionuclides can reach man, either by direct exposure to the medium, or by subsequent transfer through soil, food, air, or surface waters to man. A summary of possible exposure pathways is indicated in Figure 5.5-1, which shows transfer from groundwater, soil, and air to man through pathways generally considered in consequences analyses. For geologic repositories, groundwater is the expected route of release to the biosphere.

The exposure of individuals in the post-closure phase of the repository will most likely be thousands of years after closure, especially for the groundwater transport pathways. Disruptive events could happen at any time but are largely unpredictable. The large uncertainty in the rime of exposure adds to the uncertainty in defining the values of variables and parameters used in the exposure pathway model. Because of these and other uncertainties, the assumption is usually made that future exposures will occur under conditions similar to those that presently exist in the vicinity of the site. Exceptions to this assumption may be made for specific scenarios, such as the climate change scenario, which may require use of pathway parameters that are different than current conditions. 


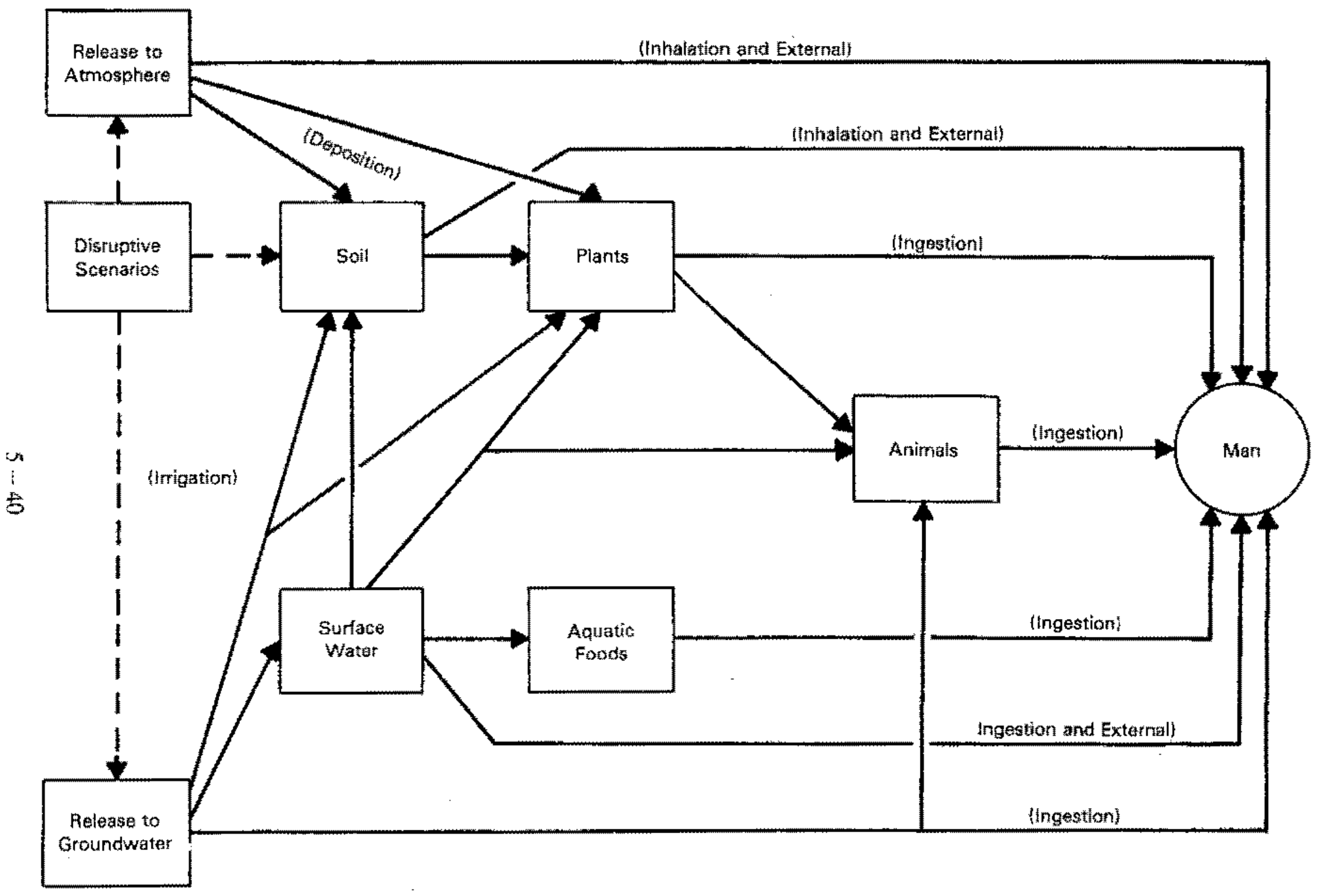

Figure 5.5-1 Exposure Pathwavs to Man 
The following sections describe models generally used for radiological consequence analysis following release of radionuclides to the atmosphere or water. The major components of a radiological consequence analysis include exposure pathway analysis, dosimetric determinations, and health effects estimation.

\section{$5.5 .1 \quad$ Exposure Pathway Analysis}

The exposure pathway analysis considers potential exposure of the individuals in the accessible environment near the disposal site through the following exposure routes: 1) external dose from radiation; 2) inhalation of airbome contaminants; and 3) ingestion of contaminated drinking water, crops, animal products, and aquatic foods. The exposure analysis usually provides the average annual intake rate by individuals in the exposed population. Estimation of the average annual exposure is based on simple multiplicative models describing the transfer of pollutants from water, air, or soil to humans. The exposure pathways generally considered include:

- drinking water ingestion - for groundwater and surface water transport pathways. Average annual intake is estimated using average intake rates of drinking water.

- aquatic food ingestion (fish and invertebrates) - - for surface water trinsport pathways. This pathway may result from secondary contamination of surface waters from groundwater sources. Concentrations in aquatic foods are estimated using water-to food concentration ratios. Average annual intake is estimated using average intake rates of aquatic foods considered.

- crop ingestion - for groundwater, surface water, and airborne transport pathways. Crops may be contaminated from imgation with contaminated water or by direct deposition onto plants and soil. Crop concentrations are estimated using soil-to-plant transfer factors and air-to-edible-plant transfer factors.

- animal product ingestion - for groundwater, sufface water, and airbone transport pathways. Contaminated animal products result from animal ingestion of contaminated water and contaminated feed. Feed contamination may occur from airect deposition onto feed crops or pasture from air or through use of contaminated irrigation water. Use of contarninated animal drinking water may also contribute to animal product contamination.

- external exposure (to air, water and soil) -.-. for groundwater, surface water, and airbome transport pathways. External exposure may result from: 1) proximity to the passing plume of radionuclides, 2) standing on contaminated ground or shoreline, or 3) swimming in contaminated water. The annual average radiation dose is calculated for these exposure pathways based on average exposure times during the year for each activity. The conversion from media concentrations 
(air, soil, or water) is based on precalculated dose conversion factors defined for each radionuclide.

- inhalation - for the groundwater, surface water, and airborne transport pathway. The annual average intake via inhalation is estimated using an annual average inhalation rate. The waterborne pathways may result in inhalation after resuspension of contaminants deposited onto land via irrigation.

The above is a summary of the exposure pathways that may be of concern for the various scenarios put forth in a performance assessment study. While other pathways may be of equal or more importance, the drinking water pathway is the simplest to evaluate and will be ased to lllustrate the estimation of dose. The intake of radionuclides in drinking water is quite simply estimated as the product of water concentration and water intake rate:

$$
I_{1}=C_{1} U
$$

where $I_{\mathrm{j}}=$ average annual intake of radionuclide $\mathrm{i}$ by an individual $(\mathrm{Cl} / \mathrm{yr})$

$C_{\hat{1}}=$ average annual concentration of radionuclide $i$ in water $(\mathrm{Ci} / \mathrm{L})$

$U=$ average consumption rate of water by an individual (L/yr)

The water concentration is provided by the transport analysis and the water consumption rate is required in the regulations to be set to $2 \mathrm{~L} / \mathrm{day}(730 \mathrm{~L} / \mathrm{yr})$. Formulas for other pathways involke additional multiplicative factors, but the general approach is the same.

\subsubsection{Dosimetry}

Average annual radiation doses (for inhalation, ingestion, and external exposure) are estimated using precalculated dose conversion factors to give lifetime doses (rem), as defined below. External dose conversion factors consider the geometry of exposure situations to provide dose rate conversion factors, which are multiplied by annual exposure times to estimate average annual exposures.

Ingestion and inhalation dosimetry is based on metabolic models and parameters defined in publications of the Intemational Commission on Radiological Protection (International Commission on Radiological Protection, 1977; 1979-1982). These models consider the distribution and retention of adionuclides within the body in estimating the dose to specific organs. The organ doses are then weighted by cancer risk-based weighting 
factors and summed to arrive at an effective dose equivalent for each radionuclide for intake by ingestion and inhalation. The effective dose equivalent is intended to represent a dose of equivalent risk of cancer to external whole body exposure.

The effective dose equivalent as defined above is the dose received over the lifetime (50 years) of an individual from one year of intake. The total lifetime dose is generally estimated by multiplying the annual dose commiment value by the average lifespan of 70 years. The dose calculation can be represented by:

$$
D_{\mathrm{i}}=\int_{0}^{70} I_{\mathrm{i}} D F_{i}(t) d t
$$

where $D_{\mathrm{i}}$ = individual dose from exposure to radionuclide $i$ (rem),

$D F_{1}(t)$ = effective dose equivalent conversion factor for radionuclide $\mathrm{i}$, for activity ingested during year $\mathrm{t}(\mathrm{rem} / \mathrm{Ci})$,

$I_{1}=$ average stnual intake rate $(\mathrm{Cl} / \mathrm{yr})$.

In practice, the dose conversion factor is often calculated for a 50 year commitment period from one year of ingestion, and is then assumed to be independent of time.

\subsubsection{Health Effects Estimation}

The conversion of effective dose equivalent to health effects is not required by EPA regulations. However, risk analyses are often perforned for radiological consequence analyses. The following discussion is included to summarize current practice in converting dose estimates to the risk of incurring premature fatal cancers and genetic effects. The discussion is based on matetial presented in the draft environmental impact statement on disposal of Hanford defense high-level, transuranic and tank wastes (U.S. Dept. of Energy, 1986), as follows:

Because expected releases of radioactive materials are small and the radiation dose to any individual is small, the effects considered are long-delayed somatic and genesic effects; these will occur, if at ail, in a very small fraction of the persons exposed. Except as a consequence of the unusually severe accident involving larger doses, no possibility exists for an acute radiation effect. The effects that must be considered are 1) cancers that may result from whole-body exposures and, more 
specifically, from radioactive materials deposited in lung, bone, and thyroid and 2) genetic effects that are reflected in future generations because of exposure of the germ cells.

Knowledge of these delayed effects of low doses of radiation is necessarily indirect. ... Hence only a relationship between health effect and radiation dose can be estimated, basing this estimate on observations made at very much higher exposure levels, where effects have been observed in man, and on carefully conducted animal experiments. In this context the National Council on Radiation Protection and Measurements (NCRP) has said: "The NCRP wishes to caution govemmental policy-making agencies of the unreasonableness of interpreting or assuming upper limit estimates of carcinogenic risks at low radiation levels derived by linear extrapolation from data obtained at high doses and dose rates, as actual risks, and of basing unduly restrictive policies on such interpretation or assumption' [reference in originall.

Several publications have attempted to quantify risks of late somatic effects and genetic effects. The most extensive of these are; 1) the Biological Effects of lonizing Radiations (BEIR IID) Report, issued in 1980 by the National Academy of Sciences (BEIR, 1980); 2) the UNSCEAR Report, a report to the General Assembly by the United Nations Scientific Committe on the Effects of Atomic Radiation published in 1977 (UNSCEAR, $1977 \%$, and a report prepared for the Health Effects Model for Nuclear Power Plant Accident Consequence Study of the Nuclear Regulatory Commission (U.S. Nuclear Regulatory Commission, 1985). Based on these reports, ranges of health effects per person-rem of lifetime exposure are given in the table below. It is noted that the possibility of zero risk at very low exposure levels is not excluded by the available data.

Ranges of Health Effects Bisk Factors for Use in Radiation Protection

Fatal cancers from:

Type of Risk

Total body exposure

Lung exposure

Bone exposure

Thyroid exposure

Specific genetic efects to

all generations from

Total body exposure

Total
Predicted Incidence per 10 person-rem

50 10 500

10 to 100

1 to 5

1 to 15

50 to 500

100 to 1000 
Values in the lower to middle range of risk estimates of the above table may be more appropriate for comparison with the estimated risks of other energy technologies; values in the upper range may be more appropriate for radiation protection considerations. The range of risk factors encompasses the range of values commonly used in making risk estimates based on radiation dose. 


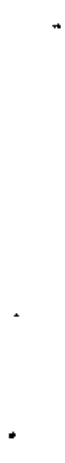




\section{CHAPTER 6, SENSITTVITY AND UNCERTAINIY ANALYSES}

Sensitivity and uncertainty analysis methods are numerical methods for determining the relationships among the input and output variables of a mathematical model. Since most of the postclosure perfomance assessment activities revolve around models, sensitivity and uncertainty analyses are becoming an integral part of the model evaluation process with respest to mode: validation and the interprotation of model results.

The importance of uncertainties in performance assessment modeling for the high-level waste repositories was recognized in the late 1970 s and has been the subject of several workshops and symposia. The furst, entilled a Workshop on Uncertainty Analysis of Post-Closure Nuclear Waste Isolation System Performance and sponsored by the Office of Nuclear Waste Isolation, was held in 1980 (INTERA, 1983f). In 1981, the Nuclear Regulatory Commission sponsored "Symposium on Uncertanties Associated with the Regulation of the Geologic Disposal of High-Level Radioactive Waste" (NRC, 1982). In 1987, the Department of Energy co-sponsored two mextings on the subject. The frrst was a workshop on uncertainy analysis with the Nuclear Energy Agency (NEA, 1987), and the second was a symposium entitled Geostatistical Sensitivizy and Uncertainty Methods for Ground-Water Flow and Radionuclide Transport Modeling with Atomic Energy of Canada Limited.

As was seen in the earlier chapters, many of the models used for performance assessment contain numerous input zariables, and the constitutive relationships among the variables are complex. It is not enough to calibrate and run the models to get the desired output, such as groundwater travel time. In addition, the relative importance of the various input variables to the output must be known for two reasons: to better understand the workings of the model as part of the validation process and to guide the allocation of site-characterization resources to the collection of the data that have the most effect on the physión procsss being modeled. 
Most of the models described here are deterministic, in that the input is assumed to be known without error and therefore the output is also assumed to be known without error. In reality, if the input variables are either measured quantitities or derived from measured quantities, there is an uncertainty in the input variable values, which in turn implies that there is an unertainty in the value of the output. Knowledge of this uncertainty is needed to interpret the meaning of the output variable in the proper context.

Oiven this situation, two questions are often raised in the discussion of performance assessment models. The first concerns which input variable(s) have the most ffect on the model output, and the second involves the uncertainty in the model output as a function of the uncertainty in the model inputs. Sensitivity analyses answer the first question and uncertainty analyses answer the second. This chapter briefly describes the two types of analyses and the major approaches to the analyses with a comparison of their relative strengths and weaknesses. Sensitivity analysis methods are described in Section 6.1 and uncertainty analysis methods in Section 6.2 .

\subsection{Sensitivity Analysis Methods}

The senstivity of one variable to another in a mathematical relationship is described by the partial derivative. If $Y$ is a function $f$ of $n$ input variables $X_{1}, \ldots, X_{n}$, say,

$$
Y=f\left(X_{1 \times \cdots+\cdots} X_{n}\right)
$$

then

$$
\frac{\partial Y}{\partial X_{1}} \mid x_{1} \ldots, x_{\mathrm{n}}
$$

is the partial derivative of $Y$ with respect to $X_{1}$ at the fixed point $\left(x_{1}, \ldots, x_{n}\right)$ in the input variable space. Since the units and cumerical scale of $Y$ and the $X$ are often different, the partial derivatives are usually nomalized by dividing the differential by the nominal value so the partial derivatives are on a more comparable basis. Therfore the nomalized sensitivity of $Y$ with respec to $X_{1}$ at the point $x_{1}, \ldots, x_{n}$ where its value is $y$ is given by:

$$
\frac{\partial Y / y}{\partial X_{1} / x_{1}}: x_{1, \ldots x_{n}}
$$


Determining the sentitivity of the variable $Y$ to each of the input variables $X_{1, \ldots,} X_{\mathrm{n}}$ at the point $\left(x_{1}, \ldots, x_{n}\right)$ requires the calculation of $n$ partial derivatives. The standardized partial derivatives can be ordered from largest to smallest with the variable with the largest partial derivative having the largest effect on the output variable. However, these partial derivatives can be misleading in the case where two input variables appear to be equally important because they are highy correlated. For complex models with nonlinear behavior in some or all of the input variables, the ordering of the variables at different points in the input variable space will not be the same.

There are two types of sensituvity analyses, deterministic and statistical. The deterministic methods will be discussed in Section 6.1 .1 , the statistical methods in Section 6.1 .2 and the two approaches will be compared in Section 6.1.3.

\subsubsection{Deterministie Approach to Sensitivity Analysis}

The traditional deteministic sensitivity analysis method calculates a numerical estimate of the partial derivative of $y$ with respect to $X_{1}$ at the point $x_{1}, \ldots, x_{5}$ tor example, as

$$
\frac{Y\left(x_{1}+\Delta / 2, x_{2}, \ldots x_{n}\right)-Y\left(x_{1}-\Delta / 2, x_{2}, \ldots x_{n}\right)}{A}
$$

where all variables but $X_{1}$ are held fixed. Calculating the numerical estimate of the partial derivative of $w$ with respect to ach variable $X_{3}$ can be mather time consuming if the model has many variables.

The adjoint form of a partal differental equation has been exploited to produce a system of linear equations (Tomovic et. 1. 1972; Oblow, 1978). The solution of the system of aquations at a fixed point produces estimates of the partial derivatives with respext to all input variables simulaneously. The process of adjointing a large model with many variables by hand can be very time-consuming. The process of compung derivatives has been computerized, for example in the GRESS and ADOEN codes (Oblow, 1983a and b; Horwedel and Pin, 1986; Pin et al, 1987), but the partials are computed only ane point in the domain of the input variables. However, once the equation has had the adjotnt form computed, the partial derivatives at additional points can be evaluated in a 
straight-forward manner. Pin et al. (1986) and Worley et al. (1986) provide examples of the application of the automated adjoint capability to models used in the repository program.

\subsubsection{Statistical Approach to Sensitivity Analysis}

The difficulty with the deterministic sensitivity analysis methods of dealing with the effect of the correlation of input variables on the interpretation of the partial derivatives led Iman et al. (1978) to develop a statistical approach to sensitivity analysis. The method, based on partial regression techniques, consists of evaluating the model at a number of points in the input space and fitting a response surface (linear model) of the input variables to the output variables. The linear model is of the form:

$$
Y=\alpha+\sum_{i} \beta_{i} X_{i}+E
$$

The coefficients $\beta_{i}$, the partial regression coefficients, are the estimates of the partial derivatives. However, since the units of the input variables may differ substantially, it is recommended that the model be reparametrized so that it does not have the usual intercept (a) as

$$
y^{*}=\Sigma \beta_{i}^{*} x_{i}^{*}+*
$$

where the coefficients $\beta_{i}^{*}$ are now the standardized partial regression coefficients, Iman et al. (1985) developed a computer code to calculate the standardized partial regression coeftuients specifically for sensitivity analysis applications.

Before the standardized partial regression coefficients can be accepted as estimates of the partial derivatives, the linear model approximation to the model must be sufficiently close. A criterion of the adequacy of the fit is given by the multiple correlation coefficient, $R^{2}$, defined as:

$$
R^{2}=1 \cdot \frac{\sum\left(Y^{*}-\hat{Y}^{*}\right)^{2}}{\sum\left(Y^{*}-\bar{Y}^{*}\right)^{2}}
$$

where $\hat{Y}^{*}$ is the estinated value of $Y^{*}$ and $\hat{Y}^{*}$ is the mean of $Y^{*}$. If $R^{2}$ is sufficienty large, then the response surface gives an adequate representation of the function, and the partial

$$
6-\frac{3}{4}
$$


regression coefficients are estimates of the "average" partial derivative over the range of the input variables. The relative magnitudes of these standardized partial regression coefficients give the relative importance of the input variables over the range of the input variatle regression.

Even for complex models with nonlinear behavior, the output variable is at least a monotonic function of the input variables in subregions of the input space. Iman and Conover (1979) suggested the use of the rank transformation to linearize a monotonic relationship, so the response function can be used to estimate the sensitivity coefficients in the subregions. Therefore, the response surface approach to sensitivity analysis can be applied to a larger class of models than just linear models.

For large models with many input variables which are usually not independent, Iman et al. (1978) recommended the use of a step-wise regression procedure to approximate the model output by sequentially adding or deleting variables to the response surface model. When the $R^{2}$ criterion cannot be improved by adding more variables, the variables that are in the linear model can be considered to have a significant effect on the model output. The magnitude of the $F$ statistic which is the criterion of selection or inclusion of a variable in the model is also a measure of the vartable's relative importance with respect to the other variables. The advantage of doing a step-wise regression is that one can then work with a reduced set of the imporant variables, which makes the interpretation of the results easier.

\subsubsection{Comparison of Sensitivity Analysis Methods}

Inan et al. (1979) applied the statistical sensitivity analysis method to a hydrologic flow model. Campbell et al. (1980) evaluated the sensitivities of a transpor model using response surface methodologies and rank transformation to linearize the model output. The same methodology was applied to a dose model by Helton et al. (1980). The types of models considered in these studies are representative of the models used in performance assessment calculations,

INTERA (1983g) described the problems with the two types of sensitivity analysis approaches and suggested that the choice of method depended on the complexicy and level of detail af the model, with the simpler models more amenable to the statistical approach. 
Harper (1983) concurred in this assessment and concluded that the adjoint method of sensitivity analysis was more appropriate for codes with large numbers of variables and that the statistical methods were most effective for models with snall numbers of variables, although quantitative estimates of "large" and "small" were not given. Harper et al. (1983) compared the partial regression method with the direct and adjoint method of calculating derivatives for a simple model of flow through a borehole. The two methods produced similar results.

Thomas (1983) compared the adjoint method of calculating sensitivities to the statistical method for a linear problem and concluded that the adjoint method gave the best results, althougb they appeared to be similar. The problem was a very simple linear one, and the ability to generalize the conchusions to the complex nonlinear problems encountered in performance assessment applications is therefore limited.

A criticism often leveled against the statistical method is that it cannot deal with complex models. Harper states that the response surface methodology treats the model as a black box. However, the work by Helton et al. (1986) showed that a statistical sensitivity analysis can be done effectively for a complex model with the approprate attention to the technical detalls of the model.

For complex functions, the partial derivative with respect to the same variable will change, so that the most influential variable at one point in the input variabie space will not be the same at another point. For functions with large numbers of input variables, interpreting the meaning of all of the partial derivatives at even a telatively few number of points in the input variable space can be a daunting task. Since it is impractical to compute the partial derivatives at all locations in the input variable space, the selection of the input variable points at which to evaluate the derivative is an important consideration. (This is also importan for simulation as weil.) However, a thorough deterministic sensitivity analysis requires more than the calculation of all partial derivatives with respect to each other. To do this would possibly require a statistical analysis of the partial derivatives to determine the patterns of influence of the variables throughout the input variable space. This work has barely gotten underway.

Sutcliffe et al. (1981) evaluated sensitivity analysis methods for a system of models that are used in performance assessment and concluded that the assessment of smali changes 
may not be appropitate for these types of modes. The PSAC committee (1987), in reviewing the submitals for its performance assessment system code intercomparison study, concluded that many of the differences in results occtred because the participants had not agreed in advance on what they would do, A major unresolved issue in sensitivity analyses for porformance assessment models is the absence of a consensus on the pupose, scope, and thethods of these analyses.

\subsection{Uncertatinty Analysis}

Uncertatinty analyses provide infomation on the variability in the model output as a function of uncertainty in the input variables. The uncertainty in the input variable can be described as a probability density function (pdf), so the uncertainty in the output variable can also be described by a pdf. The purpose of an uncertainty analysis is to characterize the pdf of $Y$ as a function of the pdfs of the input variables $X_{i}$.

As with sensitivity analysis, there are two major approaches to uncertainty analysis. One is deterministic ... an analytic perturbation method based on a Taylor series expansion about a fixed point, usually the mate of the input variable. The second approach is simulation. In the perturbation method, usually only the first-or at most the second-orker terms are used; hence the terms first- or second-order method are sometimes used to describe this type of uncertainty analysis. The statistical approach is simulation, in which the model is evaluated at multiple points in the input variable space. However, the use of either the perturbation of simulation method of uncentainy analysis in performance assescrment requires the estimation of variables, for example, bydraulic potential and transmissivity, that are spatially dependent in two or three dimensions. Therefore, statistical methods for spatial variables will be discussed first in Section 6.2 .1 , followed by a discussion of the perturbation methods in Section 6.2 .2 and the simulation method in Section 6.2.3. A new approach to uncertainty analysis, called deterministic uncertinty analysis, is teseribed in Section 6.2.4, and the methods are compared in Section 6.2 .5 .

\subsubsection{Statistical Methode for Spatinal Variables}

A thajor barrier to the use of uncertainty analysis methods in repository performance assessment has been the need to lent with input variables that are correlated over space, in 
either wo or three dimensions. Classical statistical methods assume that the observations are independent, which hydrologic variables such as porosity and hydraulic conductivity clearly are no: The development of statistical methods for estimating spatial distributions, which are briefly described in this section, provided the needed input into the performance assessment models.

\section{Geostaristics}

Kriging, referred to more generally as geostatistics, is a statistical spatial estimation method designed for relatively sparse and inegularly-spaced data that provides estimation errors. Kriging was developed in the early 1960 's by a mathematician at the Paris School of Mines, Georges Matheron (1963; 1971), to deal with the problems of estimating spatially correlated data. The technique was named after D.K. Krige (1951), a South African mining engineer, who was one of the first to tecognize that the variance of the block ore grade was not estimated correctly by assuming that the core samples within the block were statistically independent. The problem got much attention because the failure of some mining enterprises could be traced to the setting of inappropriate ore-grade cutoff points for deciding which blocks were to be discarded and which were to be processed. The potential for application to other earth science areas, such as the estimation of hydraulic head distributions and transmissivity fields in hydrology, was seen by Delhomme (1976). The appearance of geostatistics in the earth science literature during the early years of the repository program may have been partially responsible for the strong interest in quantifying uncertainty in performance assessments in the program.

There are two types of statistical techniques for spatial estimation, trend surface fitting and geostatistics. The trend surface approach, which is identical muthematically to the response surface methodology described in Section 6.1 .2 , is based on a relationship of the form:

$$
Z(x)=f(x)+z(x)
$$

The term $Z(x)$ is the observed value of the phenomenon at location $x ; F(x)$ is a function that describes a systematic or predictable component; and $\ell(x)$, called noise or error, is a random component. The trend surface method assumes that for various locations $x_{1}$ the terms $Z(x)$ are not related, because the object of the analysis is to find a function $F(x)$ that 
reduces the terms $x(x)$ to white noise. However, when real data are fitted to this equation the errors often appear correlated.

The geostatistical approach is also based on a linear relationship:

$$
Z(x)=m(x)+n(x)
$$

which looks similar to Equation $(6.2-1)$, but the tems $m(x)$ and $u(x)$ are interpreted differently than in the trend surface analysis approach. The term $m(x)$, called the drift, is a function that describes a deteministic component. However, in contrast to the trend surface method, geostatistics places importance on the tem $u(x)$, which is not assumed to be totally random, but to have a suructure. This means that for wo locations, say $x_{1}$ and $x_{2}$, wa $\left(x_{1}\right)$ and $u\left(x_{2}\right)$ are related and the relationstip can be described as a function of the distance $\left|x_{1}-x_{2}\right|$, That function is the squared difference of $Z$, which is called the variogram, and it is given as

$$
\gamma(h)=\frac{1}{2} E[2(x+h)-Z(x))^{2}
$$

where $E$ is the expectation operator.

The estimate of $Z(x)$ at some location where there is no measured value, say $x_{0}$ is given by a weighted average of the nearest data points $x_{1}, \ldots, x_{n}$ as

$$
Z^{*}\left(x_{i}\right)=\sum_{i=1}^{N} A_{i} z\left(x_{j}\right)
$$

where the $h_{i}$ are the weights. Because this is atatistical approuch, the $Z$ should have cerrain optimal properties, such as unbiasedness:

$$
\tan (x))=Z(x)
$$

that is, at action where there is a measured value, the value of $Z^{*}(x)$ should be that vatue, and minimum variance: 


$$
\operatorname{Var}\left(Z^{*}(x) \cdot Z(x)\right) \text { is minimized }
$$

The process of minimizing the variance subject to the constraint of unbiasedness leads to a system of linear equations of the form:

$\mathrm{A} \boldsymbol{\Omega}=\Gamma$

where $A$ is a matrix whose elements are functions of the variogram $\gamma$ and algebraic expressions of the drift at the locations of the observed data, $\Omega$ is the vector of weights and $\Gamma$ is a vector of functions of $\gamma$ and the drift with respect to the location where one is estimating $Z$. The result of a geostatistical analysis is an estimate of the spatial variable $Z$ at the desired locations, say on a regular grid which then can be contoured automatically, and, in what separates it from other trend surface methods and other interpolation schemes, an accompanying error of estimation for that location, which can also be contoured.

There are many uses of the geostatistical techniques in site characterization and performance assessment. The study by Doctor (1980) of the contouring of the water table elevations and depth to the top of the basalt formation at the Hanford site was one of the first evaluations of geostatistics in site charaterization and perfornance assessment applications in the high-level radioactive waste repository program. The flexibility of the methodology is attested to by the fact that an entire conference in September 1987 was devored to geostatistical sensitivity and uncertainty methods for ground-water flow and radionuclide transport modeling. An example of the use of the results of a geostatistical analysis is provided in the discussion on the statistical inverse technique in hydrology in the next section.

\section{Statistical Paraneter Estimation In Hystrology}

As the models used for performance assessment become mon detailed and hence more complex, the issue of calibration of the model to a particular application becomes of increasing importance. Calibration is usually done by trial and error, and for complex models the time involved is substantial. Unfortunately, even if the model is satisfactorily calibrated, the estimates of the parameters are not unique. In the late 1970's, Neuman (1980) developed a statistical method of estimating aquifer characteristics that produces a 
calibrated two-dimensional steady-state bydrologic flow model. The technique is referred to as parameter estimation or the solution of the inverse problem. The method is briefly described below atter Doctor et as. (1988). The governing equation for two-dimensional steady-state flow is given by

$$
\nabla \cdot T h-q=0
$$

within some defined region subject to known boundary conditions. The terms in the equation are as follows: $h$ is hydraulic head, $T$ is transmissivity, and $q$ is the sink term. Discretizing Equation $(6.2-8)$ using a finite element method produces a set of linear equations written in matrix form as:

$$
\mathrm{A}(\mathrm{T}) \mathrm{h}=\mathrm{Q}
$$

where $T$ is the vector of element transmissivities, $A$ is a square matrix whose elements contain information about the grid and are also functions of $\mathrm{T}, \mathrm{Q}$ is a vector containing source and sink terms and boundary flux information at the nodal points, and $\mathrm{h}$ is the vector of hylraulic heads at the nodal points. Neuman assumes that $\mathbf{h}$ and $\mathrm{Y}=\log \mathrm{T}$ are Gaussian randon variables, with means $\mathrm{h}^{*}$ and $\mathrm{Y}^{*}$ and variances

$$
\begin{aligned}
& \operatorname{Var}(h)=\sigma_{h} V_{k} \\
& \operatorname{Var}(Y)=\sigma_{y} V_{Y}
\end{aligned}
$$

where $V_{x}$ and $V_{Y}$ are the covariance matrices of, respectively, hydrawlic head and $\log$ transmissivities at the nodal points. These parameters of the distributions of $h$ and $Y$ can be estinated by the geostatistics technique described earlier in the section.

The estimate of $\log$ transmissivity $J(\hat{Y})$ that minimizes a composite least squares criterion is given by

$$
I(\hat{\mathbf{Y}})=J_{5}(\hat{\mathbf{Y}})+\lambda_{Y}(\hat{\mathbf{Y}})
$$

where $A$ is a non-negative scalar. The two terms in Equation $(6.2-11)$ are the quadratic ioms:

$$
6-11
$$




$$
J_{\mathrm{h}}(\hat{\mathbf{Y}})=\left[\mathrm{h}^{*}-\mathrm{A}^{-1} \hat{\mathrm{Y}} \mathrm{Q} \mathrm{V}_{\mathrm{h}^{-1}}\left[\mathrm{~h}^{*}-\mathrm{A}^{-1}(\hat{\mathbf{Y}}) \mathrm{Q}\right]\right.
$$

which is the criterion for the fitting of the model, and

$$
J_{Y}(\hat{\mathbf{Y}})=\left(\mathbf{Y}^{*} \cdot \hat{\mathbf{Y}}\right)^{+} \mathrm{V}_{\mathrm{Y}}{ }^{-1}\left(\mathbf{Y}^{*}-\hat{\mathbf{Y}}\right)
$$

which is the criterion on the variance of the sransmissivities. The parameter $\lambda$ is treated as fixed and puts more or less emphasis on the information on transmissivities at the discretion of the modeler. The choice of the values of $\lambda$ is discussed further by Neuman (1980).

The outputs of the application of the statistical inverse methodology are estimates of transmissivity at the required grid locations and an accompaning estimate of the error. Clifton and Neuman (1982) applied the inverse method for calibrating a flow model of the Avra Valley aquifer in Arizona. The technique recquires much data, and for that reason its use may be limited in performance assessment applications. De Marsily (1986) gives a description of other statistical methods applicable to hydrology.

\subsubsection{Perurbation Methods}

The first-order perturbation method utilizes a Taylor series expansion about the mean of the input watiables. For example, if the model is the same as in Equation $(6.1-1)$, the Taylor series expansion of $Y$ can be written as

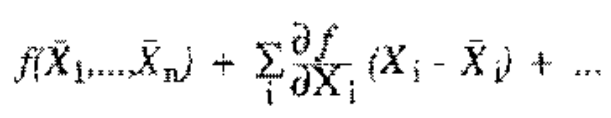

where $X_{1}, \ldots, X_{n}$ is the point representing the mean of the variables $X_{1}, \ldots, X_{\mathrm{n}}$. The first-order method neglects terms in the series expansion that involve second-order or higher partial derivatives.

The mean and wariance, respectively, of the output variable $Y$, can be obtained from the first two terms of the series expansion as

$$
E(Y)=f\left(\bar{X}_{1, \ldots, \ldots} \bar{X}_{\mathrm{n}}\right.
$$




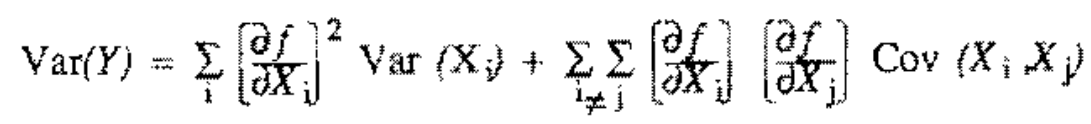

The mean of $Y$ is simply the value of the function $f$ evaluated at the mean of the input variables. The variance of $y$ requires the variznces and covariances of the input variables be extimated.

The second order method is identical to the first-order method except that the second as well as the first-order tem of the Taylor series expansion is propagated through the analysis.

In order to calculate a pdr of the output variable lor the first-or second-order method, one must assume a distributional form. For all but the simplext linear motel, the form of the pdf camot be derived analytically, so the usual recourse is to assume a Gaussian pif bectuse of the similarity of the stimates of the mean and variance to the multipliers of the partial derivatives in the tems of the Taylor series expansion. If the pdf is not Gaussian, then the extent to whth the conclusions based on such a pdf are troneous depends on the magnitude of the of difference between the trut pdf and a Caussian.

\section{$6.23 \quad$ Simulation}

A second approach to uncertainty analysis is simulation, in which a model is evaluated a a large number of points in the input parameter space and an empinical pdf for the output variabe $y$ is constructed from the results. This method differs from the firstand second-order analysis in making no assumption about the functional form of the output variable pdi.

The simulation approach is computer-intensive, perhaps requiring several thousand separate evaluations of the model, which car be a problem if the model is complex and requires a significant mmount of computer time to run. Usually, the points in the input variable space for which the model is to be evaluated are selected randomly according to an assumed pdf for the input variables. This type of selection is called unconstratned sampling in the statistical literature. The usual approach to simulation is saturation sampling of the input variable space - that is, a large number of runs are made so that all areas of the input 
space are represented. The more rusis there are, the better the output wariable pdf can be estimated. This is a particularly important issue if the performance measure is a function of the tail of the distribution such as the complementary cumulative distribution function (ccdn). Methods are needed for selecting input variable values to ensure that the pdf is estimated well with a mimimum number of runs. Therefore, for the simulation approach to uncertainty analysis, a major technical issue is the efficient selection of the points in the input space upon which to run the model.

For computational tractibility, it is often assumed that the input variables are independent. If $\mathrm{so}$, then the joint paf of the input variables is simply the product of the univariate (single variable) pdfs and the joint pdf can be approximated by generating random samples from the appropriate univariate pdf and then matching them randomly to provide the points in the input variable space for ruming the model. The problem with this approach is that many of the variables are not independent, so that some of the points in the input space selected for the model evaluations are impossible from a physical standpoint. For example, in a given type of rock porosity is positively correlated with hycraulic conductivity, so that a low porosity value often cannot be paired with a high hydraulic conductivity value. The best outcome of an impossible matching is that the numerical model blows up and cannot be evaluated; otherwise the results of such a simulation run, although they are erroneous, may be included in the pdf of the output variable and lead to misleading interpretations.

The construction of random, dependent samples for a simulation run is not easily done unless all of the variables are Gaussian. In that case, the variables with the appropriate dependencies can be generated using a Cholesky decomposition of the covariance matrix. Suppose that it is tesired to gencrate samples with a multivariale Gaussian distribution with mean $Y$ and variance $V$. Then the samples ate generated from vectors $X$ of independent unit Gaussiun random variables (mean 0 , variance 1 ) as

$$
Y=\bar{Y}+\mathbf{M} X
$$

where M is the Cholesky decomposition of $\mathrm{V}$ :

$$
\mathrm{V}=\mathrm{MM}^{\prime}
$$


Therefore, there are wo issues that complicate the use of simulation for uncertainty andilysis.

1) the number of computer runs required may be excessive because of the time needed to run the model

2) the input variables may be dependent and not all Gauseian

The next subsection discusses Latin Hyperevbe sampling, a method of selecting input variables that is more efficient than unconstrained sampling. It is followed by discussion of the rank correlation method for generating dependencies among input variables that are not necessarily Gaussian.

\section{Latin Hypercube Sampling}

Latin Hypercube sampling was first proposed by McKay, Conover and Beckman (1979) to efficiently select values of input variables for performing sensitivity analyses for complex computer codes. The method gets its name from a statistical experimental design called the Latin Square (Kempthome, 1952), which is an efficient method of assigning treaments to experimental units that have been categorized by fwo indeperdent schemes. The concept of the Latin Square is also used in the context of statistical sampling as a means of stratifying populations to reduce the variance of the estimates of the characteristics of interest (Cochran, 1963).

Latin Hypercube sampling is a generalization of Latin Square sampling to $K$ dimensions, which correspond to the number of input variables of the model. Each input variable is assumed to be a random variable, which is governed by a pdr. flnput variables which are constants can be described by a degenerase density function.) The stratification is accomplished by dividing the range of the inpul variabe into $N$ intervals of equal (1/N) probubility. Each equi probable interval is randomly sampled once for each yariable. "The output of the sampling can be considered an $N \times K$ matrix $Y$ where the columns represent variables and the rows contain the sample values for the appropriate interval. The values within a column are then randomly permuted, so that a row represents a random vector of the input viriables. The computer model is then ron $N$ times with the values of the input variables equal to the rows of the matrix. Iman et al, (1990) developed a computer code to generate Latin Hypercube samples from arbitrary pdfs. 
The advantages of Latin Hypercube sampling over unconstrained sampling methods are that it provides:

- an efficient method for sampling the entire range of each variable in accordance with the assumed probability distribution

- an estimate of the pdf of the model output variables that is an unbiased estimate of the true patf.

The reduction in variance of the estimates is a property of the stratification of the probability density function.

Rank Correlation Method for Generating Dependemt Mulivariate Samples

When Latin Hypercube sampling was first proposed, the input variables were assumed to be independent. However, for many modeling situations, the input variables are clearly not independent, and the dependencies can be highly nonlinear. Iman and Conover (1982) developed a method for inducing dependencies among the variables using rank correlation. Dependencies among random variables are usually described by a bivariate correlation coefficient; higher order dependencies are difficult so deal with in practice. The Pearson product moment correlation coefficien for random variables $Y_{i}$ and $Y_{j}$

$$
\rho_{p}=\frac{\operatorname{Cov}\left(Y_{j}, Y_{j}\right)}{\operatorname{Var}(X) \operatorname{Var}\left(Y_{j}\right)}
$$

is commonly used to guantify the degree of dependence; however, it is meaningful only for linear relationships and the nomal distribution. Iman and Conover concluded that most dependencies, even the ones that are highly nonlinear, are monotone or monotone over some range of values. The Spearman rank correlation coefficient

$$
\rho_{\mathrm{s}}=\frac{\operatorname{Cov}\left[R\left(Y_{\mathrm{i}}\right)_{i} R\left(Y_{\mathrm{j}}\right)\right]}{\left(\operatorname{Var}\left[R\left(Y_{j}\right)\right] \text { Var }\left[R\left(Y_{j}\right)\right)^{1 / 2}\right.}
$$

which is the Pearson product moment correlation coefficient computed on the ranks of the data, measures the degree of monotonicity between random variables. Iman and Conover devised a method of using bivariate rank correlations to induce the desired dependencies between randorn variables while mantaining the desired marginal distributions obtained with the original Latin Hypercube sample.

$$
6-16
$$


The method for inducing dependencies among the variables is based on the Cholesky decomposition of the desired rank correlation matrix to generate a restricted pairing of the elements of the columns of the Latin Hypercube sample matrix Y. The specific values of the variables generated by the Latin Hypercube sampling method described earlier are not changed, but the values are paired in such a way to induce the desired dependencies between the variables. This technique, although designed to work with a Latin Hypercube sample, would be applicable to unconstrained sampling as well.

The process of obtaining the appropriate association of the sample values in order to get the desired variable dependence structure is as follows. Assume, as before, that there are $K$ input variables and $N$ intervals per variable. By the construction of the Latin Hypercube sample, $Y$ theoretically has rank correlation matrix I (identity matrix); that is, the $K$ variables are independent. Let $\mathrm{C}$ be the desired rank correlation matrix of a linear transformation of $\mathrm{Y}$. Because $\mathrm{C}$ is a symmetric positive definite matrix, it can be decomposed into the product of a lower triangular matrix with its transpose:

$$
\mathrm{C}=\mathrm{PP}^{\prime}
$$

Then the vector $\mathrm{YP}^{\prime}$ should have the correlation matrix $\mathrm{C}$.

The random matrix $\mathrm{Y}$, consisting of $N$ observations of $K$ independent variables, is obtained by the Latin Hypercube Sampling algorithm explained above. Let the matrix $\mathbf{R}$ be the matrix of scores, $\left\{a_{\mathrm{i}}\right\}$, resulting from the rankings of the columns of $\mathbf{Y}$. The scores used by Iman and Conover are van der Waarden scores,

$$
a_{\mathrm{i}}=\phi^{-1}(i / N+I)
$$

where $\phi^{-1}$ is the inverse of the standard normal probability density function and $i$ is the rank of the element in the column. Let $\mathbf{R}^{*}$ be the matrix of scores after selective pairings of the elements of the columns of $\mathbf{R}$. The objective is to have the Spearman rank correlation matrix of $\mathrm{R}^{*}$ close to the desired rank correlation matrix $\mathrm{C}$. If the rank correlation matrix $U$ of every realization of $R$ were exactly the identity $I$, then there would be no problem in using the Cholesky decomposition directly. However, since $\mathrm{R}$ is a random matrix, for any 
realization $U$ will approximate, but not equal, $I$. Therefore, $U$ must be pre- and post-multiplied by a matrix $\mathbf{S}$ so that

$$
\text { SUS }^{\prime}=\mathrm{C}
$$

In order to find $S$, the Cholesky decomposition, $U=Q Q$ is performed. (U must be positive definite, so R must not contain identical columns,) Therefore, Equation (6.2-23) becomes

$$
\mathrm{SQQ}^{\prime}=\mathrm{PP}
$$

and

$$
S=\mathrm{Q}^{-1}
$$

Then

$$
\mathrm{R}^{*}=\mathrm{RS}
$$

The elements of the columns of $Y$ are then rearranged according to the ranking matrix $\mathrm{R}^{*}$ to produce a new Latin Hypercube sample matrix, $\mathrm{Y}^{*}$, which has a rank correlation matrix close to the desired $\mathrm{C}$.

\subsection{4 "Deterministic" Uncertainty Analysis}

Recently, Worley (1987) proposed an uncertainty analysis methodology which is a combination of deterministic and statistical approaches. The approach uses derivatives of the dependent variables with respect to the independent variables, and a key part of the methodology is a linear response surface approximation to the model which is easier to ewatuate than the model itself for large, complex models. The derivatives are assumed to be readily available, because the model his been adjointed using the GRESS code tsee Section 6.1.1).

Worley calls his uncertainty analysis approach "deterministic", but the term is sonewhat of a misnomer. The fitting of a linear response surface to the model output is a

$$
6-18
$$


statistical process, although he does not directly use statistical measures (such as equation (6.1-7) to evaluate the adequacy of the model approximation. Worley proposes a method of fitting the response surface using the derivatives in such a way that a good representation of the model output is obtained, but the number of samples (runs of the model) that are required is much fewer than required by the conventional response surface fitting techniques. Two key assumptions behind the method are that the model output is linear throughout the range of extrapolation and the response function is an adequate representation of the model throughout the range.

Once the model has been approximated satisfactorily with the response surface function (the analytical model in Worley's terminology), the input variable domain is partitioned into a mesh, analogous to the partitioning in Latin Hypercube sampling. In this case, the equiprobable assumption is not used, but the model response is assumed to be linear within each mesh element and the functional form of the joint probability density $p\left(m_{i}\right)$ is known in each mesh element $m_{\mathrm{i}}$. Because the $p\left(m_{\mathrm{i}}\right)$ are known, then the expectation of the response function $r$ in that mesh element, denoted $E\left(r_{i}\right)$, can be computed directly from the response function or extrapolated from the nearest point used to fit the response function and is the estimate of $r$ in that mesh element. The $E\left(r_{i}\right)$ are reordered from smallest to largest and the cumulative probability function of $r$, denoted $F(r)$, is given by the partial sum of the $p\left(m_{i}\right)$ over the domain of $E(r)$. That is

$$
F\left(r=E\left[r_{\mathrm{k}}\right]\right)=\sum_{\mathrm{i}=-\infty}^{m_{\mathrm{k}}} p\left(m_{\mathrm{i}}\right)
$$

In this way, a cumulative probability density function of the model output $r$ can be constructed without running the model multiple times as would have to be done for a simulation uncertainty analysis. The example that Worley gives is for a very simple system of equations of flow down a borehole in which the input variables are assumed to be mutually independent. The result of fitting a response surface with only two sample points and extrapolating to a mesh of 144 elements does appear to be close to a 2304 sample point simulation exercise. 


\subsubsection{Compatison of Perturbation and Statistical Methods of Uncertainty Analysis}

Devary et al. (1982) used the first order method to calculate the mean and variance of pore velocity from uncertainties in hydraulic head and conductivities. For uncertainty anaiysis methods, Harper (1983) stated a preference for the adjotnt method with error propagation to simulation for large codes, based primarily on the cost of roultiple runs of the large complex codes. He assumed that the method would give realistic estimates of the variance of the model output.

Sagar and Clifton (1984) used the second-order method to determine the uncertainty in a ground-water flow problem. They compared it to the sirnulation method and found that the resulis of the second-order method increasingly diverged from the simulation results as the coefficient of variation increased. After that experience, they (Clifton et al., 1984; Clifton, 1985) chose the simulation method for the uncertainty analysis of hydrologic moxtels.

Jacobson et al. (1985) compared the first order method to simulation to characterize suturated-zone travel time uncertainties in the vicinity of Yucca Mountain, Nevada. They found that the first order method underestimated the mean and variance of travel time and suggested that simulation be used to estimate these parameters.

Porn et at. (1985) compared the simulation method using Latin Hypercube sampling to a type of response surface replacement method for several simple problems and found that the simulation method produced fewer problems.

The advantage of the first- and second-order nethods is that they are simple to use. The model and the partial derivatives need only be evaluated at the mean value of the input variables. However, implicit in the ase of the these methods is the assumption that the uncertainty in the model output can be completely described by a mean and variance, which is only the case if the pdf is Gaussian. If the pdf is other than Gaussian, inferences drawn from the distribution such as confidence and toletance lirrits may be incorrect. This can have tather severe consequences if, for example, the performance measure of interest is the earliest ground-water travel time. Therefore, the first- or second-order method should be 
used with caution, after it has been shown that the model output has a Gaussian distribution.

Doctor et al. (1988) compared the first-order method and simulation for generating the tolerance limits on the output of a hydrologic flow model. The first order method was found to not produce realistic estimates of the variance of travel time at all locations on the outflow curve. They also compared the simulation results with unconstrained sampling and the regular Cholesky decomposition method for generating dependent Gaussian variables to the Latin Hypercube sampling method using the rank correlation method of generating dependent variables. The work demonstrated that the rank correlation method produced model input values with the appropriate dependence structure.

Since the deterministic uncertainty analysis approach has been introduced only recently, there are several issues that need to be investigated concerning the application of this technique to the large complex models typical of performance assessment applications.

- A key assumption in the method is that the model output is linear in the range of the extrapolation; however, the verification of the linearity assumption would be difficult to obtain, particularly for complex models, without running the model throughout the range of extrapolation, which is what the method is designed to avoid.

- The response surface fitting algorithm does not appear to be totally worked out, since there are problems with the dependence of input variables that are dealt with rather laboriously and which a statistical method such as step-wise regression handles well.

- Although it is noted that the choice of points from which to fit the response surface is very important, no guidance is given on how to select the points.

- There is no explanation of how to determine the functional form of the joint pdf of the independent variables in practice, since it can be described analytically for only a few special cases:

a) the input variables mutually independent and

b) the input variables follow multivariate Gaussian distribution.

It would seem that this uncertainty analysis technique is restricted to these cases unless one performs some lengthy empirical estimation of $p\left(m_{i}\right)$ by simulation using Iman and Conover's rank correlation methods.

- For large models with many input variables, the number of mesh elements may be very large, which could necessitate extensive computing that may rival the running of the original model in simulation mode. 
At the bottom of this discussion is a concern common to the perturbation uncertainty analyses techriques when applied to realistically complex modeling problems such as the ones encountered in performance assessment. That is, one cannot trust the results of the deterministic uncertainty analysis until they are verified with a simulation. So it can be argued that one of the main reasons for doing a deterministic uncertainty analysis, to save computing resources, may not be a good reason for its use unless a simulation has already been done.

In 1985, Iman et al. updated their comparison of sensitivity and uncertainty analysis techniques. After close to ten years of experience with the methods, there appears to be more movement towards developing hybrid techniques that use the strengths of each type of method. Examples are the use of Latin Hypercube sampling to select points to calculate derivatives using the deterministic method and the use of derivatives as variables in the statistical method. 


\section{CHAPTER 7. NATURAL ANALOGUES}

\subsection{Introduction}

As defined by the Commission of the European Communities' Natural Analogue working group (Come and Chapman, 1985), natural analogues are occurrences of materials or processes which are analogous to expected materials or processes in a waste repository. Natural analogues can include examples as diverse as the geothermal circulation of groundwater above a deep heat source in the earth's crust, the immobilization of uranium ores at interfaces of oxidized and reduced zones in geological materials, or even iron nails which have survived buried in a near-surface environment since Roman times (an archaeological analogue).

The primary purpose of natural analogue studies is to clarify the ability of the geologic environment and engineered system associated with an underground radioactive waste repository to mitigate the transport of radionuclides of concem toward the biosphere (Shea, 1985). It is hoped that natural analogues can provide data on processes which, because of the large geometric or temporal scales involved, camot be studied solely in laboratory or field experiments (Neretnieks, 1986b). The nature of the data acquired through analogue studies may be qualitative, helping to validate models, or quantitative, providing parameter values.

In their 1985 meeting, the Natural Analogue Working Group (NAWG) list four principal means of application of analogues in the modelling and assessment process:

- As natural experiments which duplicate processes that are being considered in a model. This can be a quantitative application, and can aid in the extrapolation of laboratory experiments to larger time or geometric scales.

- For determining bounds on parameter values. This application provides a modeler with limiting values on a parameter which need not be site specific. 
- As signposts which indicate in a purely qualitative way how and which phenomena can occur in the system being referenced to a parallel natural system.

- In an empirical sense to integrate the results of many processes at a potential repository site, over long time periods. An example might be to determine whether there is any sufface radiological manifestation of a deeply buried ore body.

A number of areas of uncertainy for which analogue studies may be useful have become apparent. The can be grouped into three broad areas:

- Mechanisms and processes affecting the degradation of the engineered barriers, including the waste matrix, canisters, and backfill.

- Mechanisms and processes affecting transport and retardation in the near field, including ambient geochemistry, mineral fomation, alpha recoll, colloid and pseudocolloid tomation, the effect of geomicrobial activity, nuclide sorption, radiolysis, and uranium disquilibria.

- Mechanisms and processes affecting transport and retardation in the far field, including matrix diffusion, dispersion, sorption, and colloid and pseudocolloid formation.

There is considerable overlap and the specifics in all categories will very much depend upon the acual location, design, and waste content of the repository.

The body of work devoted to natural analogues is increasing rapidly. Many recent and current studes are focused upon one or a few of the mechanisms or processes under consideration; these will be covered in section 7.2. Others, especially the latrge international program, involve many processex; these will be covered in section 7.3

\section{$7.2 \quad$ Subsustem Analogues}

\subsubsection{Wiste Forms}

The stability of the various components of the waste package has been studied with respect to various speeffic package designs. The use of volcanic glusses as analogues has been reviewed by Lutze and Crambow (1987). Ancient basalt glasses as analogues for the long term subility and atteration of botosilucate glass have been examined by Allen (1982), 
Byers et al. (1985), and Grambow et al (1986b). In France, the dissolution of basaltic glass by seawater was investigated, and a themodynamic code (DISSOL) was used to predict the resulting mineralogical alterations. This code will also be applied to HLW glasses under repository conditions (Petit, 1986).

\section{$7.2 .2 \quad$ Containers}

Repository designs call for either steel or copper canisters to contatn the solidified waste. The corrosion of these metals (Section 4.1) will depend upon the nature of the waste, the physical and chemical environment, the composition of the backfill, and possibly the influence of geomicrobiological activity. Some analogues for copper canisters have been suggested. A bronze cannon buried in marine clays (a potential backfill material) for three hundred years was found to have experienced minimal corrosion - theoretical caiculations indicate that only a few millimeters of corrosion can be expected in 100,000 years (Hallberg and Neretnieks, 1986; Hallberg et al., 1987) under the observed conditions. Native copper deposits in volcanic deposits in Michigan, exceeding 500 million years in age, have been observed to be stable in their present setting.

\subsubsection{Backfills}

Lee (1986) documents an example where a 1 to 2 -meter-thick layer of kaolinite clay around a 2100 year old Chinese burial chamber led to the exceptional preservation of a cadiver and associated burial objects. Although the tomb was located in a wet climate adjacent to surface water, bair, skin, organs, delicate art objects, and even food were well preserved, as a result of the clay's effectiveness as a barier to moisture and air flow and the resulting reducing conditions,

Clay alteration by a sub-volcanic body has been studied by Brondi et al. (1985) as an analogue to changes that may occur in a clay backfill surrounding hot waste packages. At the Orciatico site in Italy, physical, chernical, and mineralogical transformations resulting from contact with a geothermal body with initial temperature of $800^{\circ} \mathrm{C}$ were determined. After thousands of years of cooling, the immediately adjacent $1.5 \mathrm{~m}$ of clay was observed to be hard, britle, and fractured. Mineral alteration and cation migration 
extended $15 \mathrm{~m}$ into the clay. Brondi et al. also describe other studies in Italy that may have relevance to repository conditions: (1) thick clay deposits were deternined to be impermeable to hot $\left(150-250^{\circ} \mathrm{C}\right)$, highly pressurized $(20-60 \mathrm{~atm})$ springs; (2) clays observed in deep tunnels had little secondary permeability; (3) clays surrounding oxidizing sand uquifers were found to maintain their reducing character. A study by Antonioli et al. (1985) confirms (2) and (3).

Chapman (1985; 1986) describes an analogue study which yielded quantitative data on bromide diffusivities in clay. The study looked at the 5000 -year-old Br diffusion profiles under Loch Lomond, emanating from a marine sediment sandwiched by fresh-water clays. Although it was hoped that the data could be used to validate diffusion models and laboratory chemical data, it has not yet been possible to determine the initial $\mathrm{Br}$ concentrations and geochemical conditions with any degree of certainty. A program to determine radionuclide diffusion from pitchblende veins into clay sediments at Needle's Eye, Scotland (Chapman, 1986; Hooker et al., 1987) has also been initiated.

The presence of microbes in the disposal environment could potentially affect the conosion of engineered barriers and the mobility of the radionuclides. Lzzo (1986) describes investigations which indicated the presence of microbes in ancient marine clays and clays from a quarry.

\subsubsection{Cement Seals}

Cement constituents, which are a gel, spontaneously convert into the crystalline phase portlundite, and in concrete the free lime slowly reacts with silica. Archeological concretes, some of which have been known to survive for thousands of years, have been offered by Steddman (1986) as analogues for quantifying this spontaneous internal degradation of repository cements.

\section{$7.2 .5 \quad$ Alterations of Salt Beds}

A repository located in a salt rock may cause minerai aiteration at the repository boundary. At the Salton Sea geothermal field (Elders, 1987), mineral alterations, uranium 
and thorium distributions in both the rock and the ground waters, and uranium series disequilibria are being investigated. An important component of this study is the use of the data to validate hydrogeochemical computer codes under development, and the coupling of these with mass and heat transfer codes.

\subsubsection{Ground-Water Transport and Nuclide Migration}

To determine matrix diffusion in granite resulting after a far longer time than is possible in laboratory experiments, the diffusion of chloride ion from seawater into large granite blocks forming a 100-150-year-old seawall is being investigated. Because the source of the granite is known and the composition of sea water is essentially constant, the initial and boundary hydrochemical conditions of this natural experiment are well specified. This study is expected to yield fully quantitative data, and the results will be modeled (Come, 1986).

A French study focusing on a geothernal system in granite (Petit, 1986) has demonstrated that fluid circulates in fissures which range from decimeter to micrometer scales. The circulation caused most fissures to be coated with clay minerals, which are hypothesized to retard radionuclide diffusion into the matrix.

Colloids (section 5.2.4) have been recognized as a potentially important transport mechanism because radionuclides sorbed to or incorporated into colloids are free to migrate with the ground water, even though they are not in solution. This is a relatively new field of investigation, and studies to date have for the most part concentrated on colloid characteristics in natural systems, and sampling and measurement techniques. Ivanovich and Hardy (1986) provide a summary of this. Kim (1986) has looked at the generation of colloids in natural aquifer systems, and geochemical interactions, while Kim et al. (1987) examine the generation of actinide pseudocolloids in ground water.

Gascoyne (1987) gives a concise description of the use of uranium decay series disequilibrium as an analogue for actinide migration and site characterization. Uranium decay series activity ratios are affected by alpha-recoil, sorption, mineral precipitation and alteration, colloid formation and sorption, and ground-water circulation. Uranium decay 
series isotopic disequilibrium can indicate (1) the time since a rock or mineral has altered, (2) past rock-water interactions and chemical conditions, and (3) actinide migration in natural ground water. Disequilibriun in a whole rock or mineral sample indicates that one of the nuclide pairs has been mobilized in the last million years. Uranium diseguilibrum studies are a component of many of the major analogue programs discussed in the next section.

\subsection{Integrated System Analogues}

A number of analogue studies have centered upon intrusive uranium ore bodies in various ypes of host rock. Airey et al. (1985) hist a number of advantages to using uranium deposits as natural analogues; (1) they comprise a large range of radionuclides and heswy metals, including actinides, rare earth elemen*s, lead, and radium, (2) they contain transuranic elements (in ultra low concentrations), and (3) they involve a wide tange of time sales (ess than 1 to $5 \times 10^{5}$ years).

Uranium ore bodies are often used as empirical, integrated analogues to examine overall aspects of geologic containment, but they are also used to study more spectific processes related to radionuclide migration, such as the advance of secondary unanim mineralization, watrix dicusion, and the transport of fission products, rationaclides, and transuranic elements. Both types of uses will be discussed in this section.

\section{$7.3 .1 \quad$ Oklo}

Pertaps the best known example of a nanural analogue is that of the Oklo uranium deposit in Gabon, Africa (Airey and Ivanovich, 1985; Brookins, 1987). About two billion yeurs ago, thick lenses of uraninite were formed by enrohment of low grade ores, suffictently pure to start fission chain reactions. The natural abundance of $235 \mathrm{U}$ was then about four times higher than today's value, making a chain reaction possible in natural uranim with ordinary wate as moderator. The reaclors operated for about 2 to $5 \times 10$ : years. leaving behind thirty or so fission products with relative abundances not nomally found is uranium ore deposits. 
Several features made the study of these fossil reactors significant. The nuclide migration or contanment occurred over geological time; the radionuclides present in the areas of fossil teactors were identical to those in modern high-level wastes; average thermal loading within the reactor zones ( 300 to $400^{\circ} \mathrm{C}$ ) during operation is estimated to have been several times greater than the thermal loadings proposed in HLW repositories, and the reactors were surrounded by alternating layers of sandstone, shale, and conglonerate with higher permeabilities than proposed repository host rocks.

Because many of the fission and activation products are radioactive, as is uranium itself, their decay can be dated and used to determine rates of migration of individual elements. Most elements were contained in crystailine uraninite, which has remained mechanically unattered since the period of sustained nuclear reactions. Some sadionuclides have been released, but the quantities removed were limited by the rate of diffusion from the crystals. Migration of these nuclides in groundwater was, for the most part, severely retarded by clay mineral adsorption (129I is a possible exception) and overall reducing conditions. However conditions near the reactors were slightly oxidizing, suggesting that in a repository seting, near field mobilization will be mitigated by far field retatdation.

A number of workers in the field, including D.G. Brookins and F.P. Sargent, have advocated renewed and intensive research at this site (Come and Chapman, 1987).

\subsubsection{Alligator Rivers Project, Australia}

This project (Airey of al., 1985; Hardy 1986) has looked extensively at the processes affecting the fong-range migration of members of the uranium decay series associated with forr uranium ore deposits, including the Koongarra deposit. Systematic studies of uranium and thorium decay chain nuclides from drill cores and borehole water samples up gradient, within, and down-gradient of several are deposits provide a large amount of basic data.

Large 230 Th excesses were found close to the surface of all ore bodies except the Koongarra, Isotopic distribution of uranium, thorium, and radium within minerals comprising the weathered ore assemblage in these bodies revealed that most of the uranium and thorium were associated with the iron phases, while most of the radium was found in 
the quartz and clay phases, due in part to the alpha-recoil effect. Uranim incorporated in the amorphous iron phase is directly accessible to ground water whereas that incorporated in the crystalline iron phases is not. However, in the long term, uranium wachange occurs between the wo phases.

At Koongarra, lesching and deposition of uranium and other elements by a strong ground water flow whin the weathered zone created a well defined tongue-like fan of secondary mineralization downslope for $50 \mathrm{~m}$. Lever (1987) describes an effort to simulate the multiple processes occurring in this zone using a model that incorporates many of the essential features of iransport models used in perfomance assessment models. Two independent estimates of migration time were developed, one using $238 \mathrm{U}$ distribution coefficients and estimated groundwater flow yelocity, and the other utilizing uranium disequllbrium and the spatial gradient of $238 \mathrm{U}$ activity on rock samples. The results of 1 and 3 million years, respectively, are comparable.

For the other three ore bodies a four-zone matiomatical model of leaching and deposition of uranium at the ore bodies was used to describe the protile and the rate of loss of the nuclides due to ground-water transport and erosion. The cole has been valudated by comparison with independent mineralogleal, hydrological, and isotopic evidence, and comparison with oher open system models.

\subsubsection{Cigar Lake Uranium Deposit}

The Cigar Lake Uranium Deposit (Cramer, 1985; Sargent and Cramer, 1986; Cramer et al, 1987) is a very large, rich aranium ore body in nothern Saskatehewan. The ore body is separated from the sumounding sandstone by a cluy-rich halo, 1 to $10 \mathrm{~m}$ thick, and the entire assemblage is intersected by extensive fatuturing and abundant ground water. Hydrutur conductivities range from $10^{-4} \mathrm{~m} / \mathrm{s}$ in the ore body, clay halo, and basement rok, to $10^{\text {* }}$ in the altered sandstone overlying the ore. Het from the uranim ore generated the hydrothernal fuids responsible for the alteration of the sandstone and production of the halo.

Trace element distributions have been measured in the sandstone host rock, the halo, and in ground-water. Alhough the first few meters of the clay-rich halo closest to the ore 
contact are enriched in uranium, thorium, radium, lead, lanthanides, and several other trace elements, the presence of this deposit is not manifested in surface water chemistry. This probably resulted from sorption by the clay minerals and the reducing character of the ground water in the deposit. A noteworthy feature of this analogue is that ground water flowing towards the deposit is oxidizing in character, suggesting that the ore assemblage has an important redox buffering capacity. Geomicrobiological activity, radiolysis, and iron redox chemistry are thought to be the major controls on the chemistry.

\subsubsection{Pocos de Caldas}

The Morro de Ferro thorium deposit (Airey et al., 1985; Smellie, 1985, 1986; Smellie et al., 1987) is situated on the Pocos de Caldas plateau in the state of Minas Gerais, Brazil. The plateau is believed to be a deeply eroded caldera and the Morro do Ferro deposit rises $140 \mathrm{~m}$ above surrounding rocks near its center. This body of alkalic igneous rocks was built by piecemeal additions over some 20 million years towards the end of the Cretaceous Period. The caldera must have formed later by collapse of the intruded rocks. The underlying rock has been and continues to be subject to extensive alteration by both weathering and hydrothermal activity. The only outcrop rock is magnetite, which occurs as a set of subparallel dikes a few meters thick.

Thorium and rare earth elements are especially concentrated near some of the dike contacts and also on the surface of clay and oxide minerals. Mobilization of thorium and lanthanum, due either to surface erosion by rainfall and solubilization by ground water, is so low $\left(10^{-9} \mathrm{yr}^{-1}\right)$ that essentially complete in situ decay would take place if actinides in high-level waste had the same behavior. Thus, if it is assumed that the annual ground water mobilization rate of ${ }^{239} \mathrm{Pu}$ remained constant at the present measured rate for thorium, the mean life of the deposit would be $7 \times 10^{8} \mathrm{yr}$ compared to a half-life of $3.4 \times 10^{4}$ for ${ }^{230} \mathrm{Th}$. The results are all the more remarkable in view of the fact that the Morro do Ferro deposit does not meet selection criteria for geological repositories - that the repository be placed at great depth, in unweathered rock, under hydrological conditions that would assure long transit times for nuclides carried by ground water. 
The investigation program is in its early stages and includes the following components:

- Radionuclide behavior in contrasting redox environments present within a crystalline bedrock; preliminary findings indicate that the ground-water flow system is more porous and less fracture controlled than had been previously thought.

- The influence of colloids on the behavior of nuclides.

- Influence of geomicrobiological activity upon geochemistry.

- Element redistribution due to hydrothermal activity.

\subsection{Application of Natural Analogues}

Although it is generally agreed that no analogue can exactly replicate the performance of a complete repository system, no agreement has been reached concerning their actual degree of utility in the assessment process. Quantitative data on relevant parameters are required for model validation and performance assessment, but to date little in the way of fully quantitative data have resulted from natural analogue studies. Major problems have involved determining with certainty dates, initial conditions, boundary conditions, and changes in conditions since a specified process began. The highly interactive nature of the many processes has also made it difficult to isolate and cuantify specific parameters.

There are indications that more quantitative data may be forthcoming in some areas; for instance, the alteration of natural basaltic glass is expected to provide degradation parameters applicable to borosilicate glass. An aim of the major international programs, such as Alligator River, Pocos de Caldas, and Cigar Lake is to eventually supply this quantitative data on near-field hydrogeochemistry, sorption, mineral alteration, and radionuclide migration.

Qualitative analogues, however, clearly remain an irreplaceable tool for identifying the relevant processes in a repository setting. They are valuable for increasing the confidence in models of specific processes and also overall repository performance. 


\section{REFERENCES}

H. Abelin, J. Gidlund, L. Moreno, and I. Neretnieks, Migration in a single fracture in granitic rock, in G.L. McVay, ed., Scientific Basis for Nuclear Waste Management VII, North-Holland, New York, 1984, pp. 239-246.

L.M. Abriola, Modeling contaminant transport in the subsurface: An interdisciplinary challenge, Reviews of Geophysics, vol. 25, pp. 125-134 (1987).

A.W. Adamson, Physical Chemistry of Surfaces, 3rd edition. John Wiley \& Sons, New York, 1976.

S.W. Ahlstrom, H.P. Foote, R.C. Arnett, C.R. Cole, and R.J. Serne, Multicomponent mass transport model: theory and numerical implementation (discrete-parcel-random-walk version), Battelle Pacific Northwest Laboratory Report BNWL-2127, 1977.

R.D. Aines, Application of EQ3/6 to modeling of nuclear waste glass behavior in a tuff repository, Lawrence Livermore National Laboratory Report UCID-20895, May, 1986.

P.L. Airey and M. Ivanovich, Geochemical analogues of high-level radioactive waste repositories, in B. Come and N.A. Chapman, eds., CEC Natural Analogue Working Group, First Meeting, Brussels, November 5-7, 1985, pp. 57-85.

P.L. Airey, P. Duerden, D. Roman, C. Golian, T. Nightingale, T. Payne, B.G. Davey, D. Gray, A. Snelling, and D. Lever, Koongarra ore body: A natural analogue of radionuclide migration in the far field of HLW repositories, in B. Come and N.A. Chapman, eds., CEC Natural Analogue Working Group, First Meeting, Brussels, November 5-7, 1985, pp. 175-215.

B. Allard, Actinide and technetium solubility limitations in groundwaters of crystalline rocks, in G.L. McVay, ed., Scientific Basis for Nuclear Waste Management VII, North-Holland, New York, 1984, pp. 219-226.

A.O. Allen, The Radiation Chemistry of Water and Aqueous Solution, Van Nostrand, New Jersey, 1961.

C.C. Allen, Stability and alteration of naturally-occurring low-silica glasses: Implications for the long-term stability of waste form glasses, in W. Lutze, ed., Scientific Basis for Nuclear Waste Management V, Elsevier, New York, 1982, pp. 37-44.

M.K. Altenhofen, Waste package heat transfer analysis: Model development and temperature estimates for waste packages in a repository located in basalt, Rockwell Hanford Operations Report RHO-BWI-ST-18, 1981.

Analytic Sciences Corporation, User's guide to NUTRAN, EM Report 2107-5, July 1983.

M.P. Anderson, Geologic facies models: What can they tell us about heterogeneity, Eos Trans. AGU, vol. 68, p. 300 (1987). 
R.Y. Anderson, Deformation-dissolution potentat of bedded salt, Waste Lsolation Pilot Plant site, Delaware Basin, New Mexico, in W. Lutze, ed. Scientific Basis for Naclear Waste Management $V$, North-Holland, New York, 1982, pp. 449-458.

O. Andersson, A. Rasmuson, and 1. Neretnieks, Model for near field migration, in W. Lutze, ed. Scientific Basis for Nucleat Waste Management 1 , Elsevier, New York, 1982, pp. $539-548$.

F. Antonioli, M. D'Alessandro, F. Mousty, and A. Saltelli, About the permeability of faults and fractures in clay formations, in B. Come and N.A. Chapman, eds. CEC Natural Analogue Working Group, First Meeting, Brussels, November 5m, 1985, pp. 135-156

M.J. Apted, A.M. Liebetru, and D.W. Engel, Analysis of spent fuel performance in a geologic repository, Procedings of the Third Intemational Symposium on Nuclest Waste Disposal, American Ceramic Society, Chicago, April 1986, pp. 394 400.

R.C. Amett, R.G. Baca, J.A. Caggiano, S.M. Price, R.E. Gephart, and S.E. Logan,

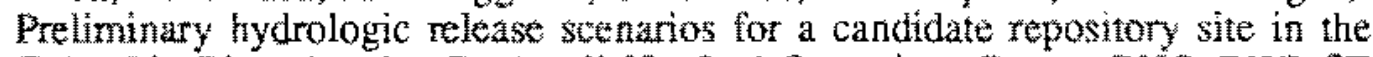
Columbia River basalts, Rockwell Hanford Operations Report RHO-BWI-ST-12, $19 \mathrm{so}$.

Arthur D. Little, Inc., Technical support of standards for high-level radioactive waste management, volume B: Engineering controls, U.S. Environmental Protection Agency Report EPA/520/479 OOTB, 1980.

ASTM, Annual Boak of ASTM Standards, Volume 03.02 Erosion, and Wear. Metal Corrasion, Standards $G 48$ and $G 746$, ASTM, Philadelphia, 1987, pp. 283-285 and pp. $526-530$.

A. Atkinson, D., Goult, and J.A. Hearne, An assessment of the long-term durability of concrete in radioactive waste repositories in LO. Weme, ed., Sclentific Bustif for Nuclear Waste Management IX, Materals Research Society, Pittsburgh, 1986, pp. $239-246$.

P. Ausloos, ed., Fundamental pyocess in Radiation Chemstry, Interscience, New York, 1968.

A. Avogadro, and G. de Marsily, The role of colloids in nuclear waste disposal, in G.L. MeVay, ed. Scientific Basts for Nuclear Waste Management Vl, Noth-Holland. New York. 1984 , pp. $495-505$.

R.G. Baca, R.C. Amel, and I.P. King, Numerical modeling of flow and transport procestes in a fractured-porous rock system, Rockwell Hanford Operations Report RHO-BWI-SA-113, 1981 .

J.M. Bah" and J. Rubin, Direct comparison of kinetic and local equiliorium formulations for solute trinsport affected by surface reactions, Water Resour. Res., vol. $23, \mathrm{pp}$. $438-452(1987)$.

G. Baldi, M. Borsetto, T. Hueckel, and A. Peano, Coupling of themoptastice and hydraulic effects in at clay repository: Near-field analysis, in C.-F. Tsang, ed, Cumped Processen Awotinted with Nuclear Waste kepositories, Academic, New York, 1987, pp. $565-579$. 
J.W. Ball, E.A. Jenne, and M.W. Cantrell, WATEQ3: A geochemical model with uranium added, U.S. Geological Survey Open-File Report 81-1183, 1981.

J.W, Ball, E.A. Jenne, and D.K. Nordstrom, WATEQ2 - A computerized geochemical model for trace and major element speciation and mineral equilibria of natural waters, in E.A. Jenne, ed., Chemical Modelling in Aqueous Systems, Amer. Chem. Soc. Symp. Series No. 93, pp. 815-835, 1979.

J.W. Ball, D.K. Nordstrom, and E.A. Jenne, Additional and revised thermochemical data and computer code for WATEQ2 - A computerized geochemical model for trace and major element speciation and mineral equilibria of natural waters: U.S. Geological Survey Water-Resources Investigations Report 78-116, 1980.

T. Banba, T. Murakami, and H. Kimura, The leaching behavior of a glass waste form Part 3: The mathematical leaching model, Nucl. Technol, vol. 76, pp. 84-90 (1987).

Aa. Barkatt, Al. Barkatt, and W. Sousanpour, Effects of gamma radiation on the leaching kinetics of various nuclear waste-form materials, Nature, vol. 300, pp. 339-341 (1982a).

Aa. Barkatt, Al. Barkatt, and W. Sousanpour, Gamma radiolysis of aqueous media and its effects on the leaching processes of nuclear waste disposal materials, Nucl. Technol,, vol. 60, pp. 218-227 (1982b).

G.S. Bamey and D.T. Reed, Effects of sorption hysteresis on radionuclide releases from waste packages, in H.C. Burkholder, ed., High-level Nuclear Waste Disposal, Battelle, Columbus and Richland, 1986, pp. 701-711.

N. Barton, Modeling rock joint behavior from in situ block tests: Implications for nuclear waste repository design, Office of Nuclear Waste Isolation Report ONWI-308, 1982.

J.A. Beavers and W.P. Thompson, Corrosion of materials for nuclear waste containers overpack corrosion, presented at Corrosion/85, Boston, NACE, Houston (1985).

BEIR, The Effects on Populations of Exposure to Low Levels of Ionizing Radiation, Report of the Advisory Committee on the Biological Effects of Ionizing Radiation, Division of Medical Sciences, National Academy of Sciences-National Research Council, National Academy Press, Washington, 1980.

M.S. Bensky and D.L. Oliver, Transient diffusional release from waste packages in a repository in basalt, in L.O. Werme, ed., Scientific Basis for Nuclear Waste

Management IX, Materials Research Society, Pittsburgh, 1986, pp. 779-787.

P. Berest, M. Ghoreychi, R.A. Jehan, and M. Kiener, Rocksalt solution and nuclear waste disposal - The concept of overburden, in H.C. Burkholder, ed., High Level Nuclear Waste Disposal, Battelle, Columbus and Richland, 1986, pp. 337-350.

U. Bertocci and J. Kruger, Studies of passive film breakdown by detection and analysis of electrochemical noise, Surface Sci., vol. 101, pp. 608-617 (1980). 
U. Bertocci, S. Leigh, A.C. Van Orden, and G. Yang, Statistics of pit initiation: Analysis of current transients during passive film breakdown, in J.K. Bates and W.B. Seefeldt, eds., Scientific Basis for Nuclear Waste Management X, Materials Research Society, Pittsburgh, 1987, pp. 251-259.

S.H. Bian, M.J. Budden, C.L. Bartley, and S.C. Young, GEOTHER evaluation, improvement and application to a two-dimensional BWIP model, Pacific Northwest Laboratory Report PNL-6245, July 1987.

R. Bibby, Mass transport of solutes in dual-porosity media, Water Resour. Res., vol. 17, pp. 1075-1081 (1981).

N.E. Bibler, Effect of alpha, gamma, and alpha-recoil radiation on borosilicate glass containing Savannah River Plant defense high-level nuclear waste, in S.V. Topp, ed., Scientific Basis for Nuclear Waste Management IV, North-Holland, New York, 1982, pp. 681-687.

N.E. Bibler and C.M. Jantzen, Materials interactions relating to long-term geologic disposal of nuclear waste glass, in J.K. Bates and W.B. Seefeldt, eds., Scientific Basis for Nuclear Waste Management X, Materials Research Society, Pittsburgh, 1987, pp. $47-66$.

F.W. Bingham and G.E. Barr, Scenarios for long-term-release of radionuclides from a nuclear-waste repository in the Los Medanos region of New Mexico, Sandia National Laboratories Report SAND78-1730, 1979.

L. Birgersson and I. Neretnieks, Diffusion in the matrix of granitic rockfield test in the Stripa mine, part 2, in G.L. McVay, ed., Scientific Basis for Nuclear Waste Management VII, North-Holland, New York, 1984, pp. 247-254.

S.G. Bloom and G.E. Raines, Analytical and semianalytical models for estimating temperature, brine migration, and radionuclide transport in a salt repository, in H.C. Burkholder, ed., High-level Nuclear Waste Disposal, Battelle, Columbus and Richland, 1986, pp. $689-700$.

E.J. Bonano and W,E. Beyeler, Transport and capture of colloidal particles in single fractures, in C.M. Jantzen, J.A. Stone, and R.C. Ewing, eds., Scientific Basis for Nuclear Waste Management VIII, Materials Research Society, Pittsburgh, 1985, pp. $385-392$.

W.L. Bourcier, Improvements in the solid solution modeling capabilities of the EQ3/6 geochemical code, Lawrence Livermore National Laboratory Report UCID-20587, 1985 .

J.W. Braithwaite and M.A. Molecke, High-level waste canister corrosion studies pertinent to geologic isolation, Conf. on High-Level Radioactive Solid Waste, Denver, December, 1978.

J.W. Braithwaite and F.B. Nimick, Effect of host-rock dissolution and precipitation on permeability in a nuclear waste repository in tuff, Sandia National Laboratories Report SAND84-0192, September 1984. 
A. Brecher and F.J. Pearson, Jr., WAPPA: A waste package performance assessment code, Office of Nuclear Waste Isolation Report ONWI-452, April 1983.

A. Brondi, F. Benvegnu, and C. Polizzano, Italian activity in the field of natural analogues and natural evidence, in B. Come and N.A. Chapman, eds., CEC Natural Analogue Working Group, First Meeting, Brussels, November 5-7, 1985, pp. 112-128.

D.G. Brookins, Coupled processes at the Oklo natural reactor, in C.-F. Tsang, ed., Coupled Processes Associated with Nuclear Waste Repositories, Academic, New York, 1987, pp. 237-248.

B.F. Brown, General assessment and critique of localized corrosion, in R. Staehle, B.F. Brown, J. Kruger, and A. Agarwal, eds., Localized Corrosion, NACE, Houston, 1974, pp. 15-19.

R. Brüggemann, G. Ohme, S. Hossain, F. Pattlock, B. Kaschanian, T. Podtschaske, T. Kuhle, D. Rinkus, A. Nies, N. Stelte, and R. Storck, Modellansätze und Ergebnisse zur Radionuklidfreisetzung aus einem Modellsalzstock, Projekt Sicherhertsstudien Entsorgung, Abschlussberichi, Fachband 16, January 1985.

B.C. Bunker, Waste glass leaching: Chemistry and kinetics, in J.K. Bates and W.B. Seefeldt, eds., Scientific Basis for Nuclear Waste Management X, Materials Research Society, Pittsburgh, 1987, pp. 493-507.

R.D. Burnett and E.O. Frind, Simulation of contaminant transport in three dimensions 1. The alternating direction Galerkin approach, Water Resour. Res., vol. 23, pp. 683-694 (1987).

W.G. Burns, A.E. Hughes, J.A.C. Marples, R.S. Nelson, and A.M. Stoneham, Effects of radiation on the leach rates of vitrified radioactive waste, J. Nuclear Materials, vol. 107, pp. 245-270 (1982a).

W.G. Burns, A.E. Hughes, J.A.C. Marples, R.S. Nelson, and A.M. Stoneham, Effects of radiation damage and radiolysis on the leaching of vitrified waste, in W. Lutze, ed., Scientific Basis for Radioactive Waste Management V, Elsevier, New York, 1982b, pp. 339-348.

C.D. Byers, M.D. Jercinovic, R.C. Ewing, and K. Keil, Basalt glass: an analogue for the evaluation of the long-term stability of nuclear waste from borosilicate glasses, in C.M. Jantzen, J.A. Stone, and R.C. Ewing, eds., Scientific Basis for Nuclear Waste Management VIII, Material Research Society, Pittsburgh, 1985, pp. 583-590.

J.E. Campbell, R.L. Iman and M. Reeves, Risk methodology for geologic disposal of radioactive waste: Transport model sensitivity analysis, Sandia National Laboratories Report NUREG/CR-1377, SAND80-0644, 1980.

J.E. Campbell, D.E. Longsine, and M. Reeves, Risk methodology for geologic disposal of radioactive waste: The NWFT/DVM computer code user's manual, U.S. Nuclear Regulatory Commission Report NUREG/CR-2081, November 1981a. 
J.E. Campbell, D.E. Longsine, and M. Reeves, Distributed velocity method of solving the convective-dispersion equation: 1. Introduction, mathematical theory, and numerical implementation, Adv. Water Resour., vol. 4, pp. 102-108 (1981b).

J.E. Campbell, D,E. Longsine, and M. Reexes, Distributed velocity method of solving the convective-dispersion equation: 2. Error analysis and comparison with other methods, Adv. Water Resour., vol, 4, pp. $109-116$ (1981c).

H.S. Carlsaw and J.C. Jaeger, Conduction of Heat in Solids, 2nd ed., Oxford University Press, Oxford, 1959.

C.L. Carnahan, Simulation of uranium transport with variable temperature and oxidation potential: the computer program THCC, in J.K. Bates and W.B. Seefeldt, eds., Scientific Basis for Nuclear Waste Management X, Materials Research Society, Pittsburgh, 1987, pp. 713721.

J.P. Carter, S.D. Cramer, and R.K. Conrad, Field stress corrosion tests in brine environments of the Salton Sea Known Geothermal Resource Area, Matls. Porf, wol 19, no. 9, pp. $13-16(1980)$.

M.B. Carver, D.V. Hanley, and K.R. Chaplin, MAKSIMA-CHEMIST: A program for mass action kinetics simalation by automatic chemical equation manipulation and integration using stift techniques, Atomic Energy of Canada Limited Report AECL-6413, 1979.

G.A. Cederberg, R.L. Street, and J.O. Leckie, A groundwater mass transport and equilibrium chemistry model for multicomponent systems, Water Resour. Res., vol. 21, pp. $1095-1104(1985)$.

P.L. Chambre and T.H. Pigford, Prediction of waste performance in a geologic repository, in G.L. MoVay, ed., Scientific Basis for Nuclear Waste Management vil, North-Hollend, New York, 1984, pp. 985-1008.

T. Chan, J.A.K. Reid, and V. Guvanasen, Numerical modelling of coupled fluid, heant, and solute transport in deformable fractured rock, in C.-F. Tsang, ed., Coupled Procerses Associated with Nuclear Waste Repositonies, Academic, Orlando, 1987, pp. 605-625.

N,A. Chapman. Analogue of elemental diffusion over 5000 years in sediments; close but not close enough?, in B. Come and N.A. Chapman, eds, CEC Natural Aralogue Working Group, First Meeting, Brussels, November 5-7, 1985, pp. 157-159.

N.A. Chapman, Natural analogue studies in Britain: Work in progress, June 1986, in B. Come and N.A. Chapman, eds., CEC Natural Analogue Working Group, Second Meeting, Interlaken (CH), June 17-19, 1986, pp. 19-21.

L. Chaturvedi and $\mathrm{K}$. Rehfeldt, Groundwater occurrence and the dissolution of salt at the WIPP radioactive waste repository site, Eos. Trans. AGU, wol. 65, pp. 457-459 (1984).

H. Christensen and E. Bjergbakke, Radiolysis of groundwater from spent fuel, Sudswik Energitenik Report \$tudvick/NW-82/364, 1982. 
H. Christensen and E. Bjergbakke, Radiolysis of groundwater from HLW stored in copper canisters, in D.G. Brookins, ed., Scientific Basis for Radioactive Waste Management VI, Elsevier, New York, 1983, pp. 429-436.

H. Christensen and E. Bjergbakke, Alpha-radiolysis of aqueous solutions, in L.O. Werme, ed., Scientific Basis for Nuclear Waste Management IX, Materials Research Society, Pittsburgh, 1985, pp. 401-408.

H. Christensen and E. Bjergbakke, Radiation induced dissolution of $\mathrm{UO}_{2}$, in J.K. Bates and W.B. Seefeldt, eds., Scientific Basis for Nuclear Waste Management X, Materials Research Society, Pittsburgh, 1987, pp. 115-122.

H.C. Claiborne, A.G. Croff, J.C. Griess, and F.J. Smith, Repository environmental parameters and models relevant to assessing the performance of high-level waste packages, U.S. Nuclear Regulatory Commission Report NUREG/CR-4134 (ORNL/TM-9522 Revision 1), October 1987.

P.M. Clifton, Groundwater travel time uncertainty analysis - Sensitivity of results to model geometry, and correlation and cross-correlations among input parameters, Rockwell Hanford Operations Report RHO-BW-ST-70P, March 1985.

P.M. Clifton and S.P. Neuman, Effect of kriging and inverse modeling on conditional simulation of the Avra Valley Aquifer in southern Arizona, Water Resour. Res., vol. 18, pp. 1215-1234 (1982).

P.M. Clifton, B. Sagar, and R.G. Baca, Stochastic groundwater travel time modeling using a Monte Carlo technique, Mem. Intl. Assn. Hydrogeologists, vol. 17, pp. 319-331 (1985).

W.G. Cochran, Sampling Statistics, second edition, John Wiley and Sons, New York, 1963.

W. Coffman, D. Vogt, and M. Mills, A summary of computer codes for waste package performance assessment, U.S. Nuclear Regulatory Commission Report NUREG/CR-3699, March 1984.

B.I. Cohen, Critique of the National Academy of Sciences study of the isolation systems for geologic disposal of radioactive waste, Nucl. Technol., vol. 70, p. 433 (1985).

C.R. Cole, Evaluation and status report on HYDROCOIN at midway, Pacific Northwest Laboratory Report PNL-6087, December 1986.

C.R. Cole and H.P. Foote, Use of a multigrid technique to study effects of limited sampling of heterogeneity on transport prediction, Pacific Northwest Laboratory Report PNL-SA-14270, February 1987.

C.R. Cole, T.J. Nicholson, P. Davis, and T.J. McCartin, Lessons learned from the HYDROCOIN experience, presented to GEOVAL - 87 Symposium on Verification and Validation of Geosphere Performance Assessment Models, Stockholm, 1987.

B. Come, Present developments of CEC activities in the field on natural analogues, in B. Come and N.A. Chapman, eds., CEC Natural Analogue Working Group, Second Meeting, Interlaken (CH), June 17-19, 1986, pp. 25-26. 
B. Come and N.A. Chapman, eds., CEC Natural Analogue Working Group, First Meeting. Brussels, November $5-7,1985$.

B. Come and N.A. Chapman, eds, Natural Analogues in Radioactive Waste Disposal, Brussels, 28 30th April, Symposiurm Proceedings, CEC Report EUR 11037, 1987.

A.]. Coyle, J.Eckert, and H. Kalia, Brine migration test report: Asse salt mine, Federal Republic of Germany, Offee of Nuclear Waste Isolation Report ONWI-624, January, $198 \%$.

J.J. Cramer, Cigar Lake Project: A U-deposit natumal analog, in B. Come and N.A. Chapman, eds, CEC Natural Analogue Working Group, First Meeting, Brussels, November $5-7,1985$, pp. $216-223$.

3. Cramer, P. Vilks, and I.P. A. Larocque, Near field analog features from the Cigar Lake urantum deposit, in B. Come and N.A. Chapman, eds., Natural Analogues in Radioactive Waste Disposal, Brussels, 28-30th April, Symposum Procedings, Vol. 2. 1987

R.M. Conwell, R.V. Guzowski, J.E. Campoell, and N.R. Ortiz, Risk methodology for geologic disposal of radioactive waste: Scenaro selection procedure, U.S. Nuwlear Regulatory Commission Report NUREG/CR-1667, December 1982.

DAppolonia Consulting Enginesers, Sealing considerations for repository drafts in bedded and dome salt, Office of Nuclear Waste Isolation Report ONWI-255, December 1981.

Q. Dagan, Solute transport in heterogeneous porous formations, J. Fuid Mech., vol, 145, pp. $151-177(1984)$.

A.D. Daus and E.O. Frind, An alternating drection Galerkin technique for simulation of contuminant transport in complex growndwater systems, Water Resour. Res, vol. 21, pp. $653-664(1985)$.

I.A. Davis and K.F. Hayes, Geochemical processes al minoral surfaces: An overview, in J.A. Davis and K.F. Hayes, eds. Geochemical Procusas at Mineral Surfaces, Amer. Chem. Soc. Symp. Series No. 323, 1986, pp. $2-19$.

J.A. Davis, R.O. James, and J.O. Leckie, Surface ionization and complexation at the oxide/water interface: I. Computation of electrical double layer propenties in simple electrolytes: ). Colloid Interface soin, vol. 63. pp. $480-499$ (1978).

J.D. Davis and A.K. Runchal, Disruption scenario analysis for a nuclear waste repusitory it Hanford Site basalts, Wastington State, in R.G. Post, ed., Waste Management " 24 , University of Arizona, Tucson, 1984, yol. 1, pp. $419-425$.

R. Dayal, B.S. Lee, R.J. Wike Swyler, P. Soo, T.M. Ahn, N.S. Melntyre, and l. Veakis, Nuckar waste managemen technical support in the development of nuclear waste form criteria for the NRC, wol. 1, Waste package overview, U.S. Nuclear Regulatory Commission Report NUREG/CR-2333, Febrary 1982

J.F. DeNatale, D.G. Howitt and D.K. McElfresh, Radiation effects in nuclear waste glasses, in S.V. Topp, et, Srientific Basis for Nuctatz Waste Management W. North-Holland, New York, 1982, pp. 697-702.

$$
\mathrm{R}-8
$$


J.M. Delaney, I. Puigdomenech, and T.J. Wolery, Precipitation kinetics option for the EQ6 geochemical rreaction path code, Lawrence Livermore National Laboratory Report UCRL $-53642,1986$.

J.P. Delhomme, Kriging in the hydrosciences, Adv. Water Resour., vol. 1, pp. 251-266 (1976).

J.L. Devary and P.G. Doctor, Pore velocity estimation uncertainties, Water Resour. Res., vol. 18(4), pp. 1157-1164 (1982).

P.G. Doctor, The use of geostatistics in high level radioactive waste repository site characterization, Radioactive Waste Management, vol. 1, pp. 193-210 (1980).

P.G. Doctor, E.A. Jacobson and J.A. Buchanan, A comparison of uncertainty analysis methods using a groundwater flow model, Pacific Northwest Laboratory Report PNL-5649, 1988.

F.H. Dove, C.R. Cole, M.G. Foley, F.W. Bond, R.E. Brown, W.J. Deutsch, M.D. Freshley, S.K. Gupta, P.J. Gutknecht, W.L. Kuhn, J.W. Lindberg, W.A. Rich, R. Schalla, J.R. Washburn, and J.T. Zellmer, AEGIS technology demonstration for a nuclear waste repository in basalt, Pacific Northwest Laboratory Report PNL-3632, 1982.

I.V. Draganic and Z.D. Draganic, The Radiation Chemistry of Water, Academic, New York, 1971 .

G. de Marsily, Quantitative Hydrogeology, Academic, Orlando, 1986.

W.L. Ebert, J.K. Bates, T.J. Gerding and R.A. Van Konynenburg, The effects of gamma radiation on groundwater chemistry and glass reaction in a saturated tuff environment, in J.K. Bates and W.B. Seefeldt, eds., Scientific Basis for Nuclear Waste Management $X$, Materials Research Society, Pittsburgh, 1987, pp. 613-622.

A.I. El-Kadi, Modeling variability in groundwater flow, Holcomb Research Institute Paper 31, June 1984.

W.A. Elders, A natural analogue for near field behavior in a high level radioactive waste repository in salt: The Salton Sea Geothermal Field, California, USA, in B. Come and N.A. Chapman, eds., Natural Analogues in Radioactive Waste Disposal, Brussels, 28-30th April, Symposium Proceedings, Vol. 2, 1987.

ELSAM, Disposal of high-level waste from nuclear power plants in Denmark: Salt dome investigations, volume 1, Summary, June 1981.

D. Elsworih, A boundary element-finite element procedure for porous and fractured media flow, Water Resour. Res., vol. 23, pp. 551-560 (1987).

E. Escalante and W.F. Gerhold, Galvanic coupling of some stainless steels to copper underground, Intl. Corr. Forum on Prot. and Perf. of Matls.: Corrosion/75, Toronto, Ont., NACE, Houston, 1975.

P.W. Eslinger and B. Sagar, EPASTAT: A computer code for estimating radionuclide releases at the accessible environment boundary from a repository in basalt, Rockwell Hanford Operations Report SD-BWI-TA-022, 1986.

$$
\mathrm{R}-9
$$


D.D. Evans, Unsaturated llow and transport through fractured rock-related to high-level waste repositories, U.S. Nuclear Regulatory Commission Report NUREG/CR-3206, March 1983.

D.D. Evans and T.J. Nicholson, eds, Flow and Transport through Unsaturated Fractured Rock, American Geophysical Union, Washington, 1987.

L.L. Eyler, D.S. Trent and M.J. Budten, A three-dimensional time-dependent computer program for hydrothermal analysis, volume II: Assessment and verification results, Pacific Northwest Laboratory Report PNL 4348, September 1983.

C. Fairhurst, Comments on the modeling of coupled thermomechanical fluid now behavior of rock masses, in C.-F. Tsang, ed., Coupled Processes Associated with Nuctear Waste Repositories, Academic, Now York, 1987, pp. 713-731.

A.R. Felmy, D.C. Girvin, and E.A. Jenne, MNTEQ: A computer program for calculating aqueous geochemical equilibria: Pacific Northwest Laboratories Report EPA $600 / 3-84-032$ (NTIS PB84-157148), 1984.

R.S. Fisher, Geochemical environment of the evaporite aquitard and deep-basin brine aquifer, Palo Duro Basin, Texas, The University of Texas at Austin, Bureau of Economic Geology Open File Report OF-WTWI-1984-26, p. 94.

G.E. Fogg, Groundwater flow and sand body interconnectedness in a thick. multiple-aquifer system, Water Resour. Res, vol. 22, pp. 679-694 (1986a).

G.E. Fogg, Srochastic analysis of aquifer interconnectedness with a test case in the Wilcox Group, East Texas, Eos Trans. AGU, vol, 67, p. 942 (1986b).

G.E. Fogg and F.J. Lucia, The role of geologic information in aquifer description: Comparison of two case studies, Eos Trans. AGU, vol. 68, p. 299 (1987).

M.G. Foley, Computer simulation of geologic systems, in RG. Post, ed., Waste Management '82, University of Arizona, Tueson, 1982, vol. 3, pp. 189-196.

M.G. Foley, G.M. Petrie, A.J. Baldwin, and R.G. Craig, Geologic simulation model for a hypothetical site in the Columbia Plateau: results, Pacific Northwest Laboratory Report PNL-3542-2, June 1982.

M.G. Fontana and N.D. Greene, Corrosion Engheering, McGraw Hill, New York, 1978.

M .G. Fontana, F.H. Beck and A.V. Flowers, Eftects of hydrogen on mechanical properties of various metals, Met. Prog., pp. 86-99 (1961).

R.S. Forsyth and L.O. Werme, The corrosion of spent $\mathrm{UO}_{2}$ fuel in synthetic groundwater, in L.O. Werme, ed., Scientific Bawis for Nuclear Waste Management $I$, Materisls Research Society, Pittsburgh, 1985, pp. 329 336.

M.D. Freshley, F.H. Dove, and J.A. Fernandez, Numerical analyses to evaluate backfilling repository drifts in unsaturated tuff, in R.G. Post, ed., Waste Management '85, University of Arizona, Tucson, 1985, vol. 1, pp, 413-420. 
E.O. Frind and D. Germain, Simulation of contaminant plumes with large dispersive contrast: evaluation of alternating direction Galerkin models, Water Resour. Res., vol. 22, pp. 1857-1873 (1986).

E.O. Frind and G.E. Hokkanen, Simulation of the Borden plume using the altemating direction Galerkin technique, Water Resour. Res., vol. 23, pp. 918-930 (1987).

E.O. Frind and G.B. Matanga, The duel formulation of flow for contaminant transport modeling, 1. Review of theory and accuracy aspects, Water Resour. Res. vol. 21, pp. 159-169 (1985).

B. Fritz, M. Kam and Y. Tardy, Geochemical modelling of the alteration of a granitic rock around a repository for spent nuclear fuel, in L.O. Werme, ed., Scientific Basis for Nuclear Waste Management IX, Materials Research Society, Pittsburgh, 1986, pp. $517-524$.

T. Furuya, S. Muraoka, S. Tashiro, K. Araki, H. Tomari, K. Fujiwara, and T. Fukuguka, Gamma-ray inadiation effects on stress corrosion cracking of alloys for high-level waste packages, Japan Atomic Energy Research Institute Report JAERI-M82-061 (in Japanese), 1982.

G. Gambolati, F. Sartoretto, and F. Uliana, A conjugate gradient finite element model of flow for large multiaquifer systems, Water Resour. Res., vol. 22, pp. 1003-1015 (1986).

N.C. Garisto, Modelling aspects in vault chemistry, Proc. Second International Conference on Radioactive Waste Management, Canadian Nuclear Society, Winnipeg, Sept. 7-11, 1986.

N.C. Garisto and F. Garisto, The effect of precipitation on the long-term release of radionuclides from used fuel, Ann. Nucl. Energy, vol. 13, pp. 591-596 (1986a).

N.C. Garisto and F. Garisto, The dissolution of $\mathrm{UO}_{2}$ : A thermodynamic approach, Nucl. Chem. Waste Manage., vol. 6, pp. 203-211 (1986b).

M. Gascoyne, The use of uranium-series disequilibrium for site characterization and as an analogue for actinide migration, in B. Come and N.A. Chapman, eds., Natural Analogues in Radioactive Waste Disposal, Brussels, 28-30th April, Symposium Proceedings, Vol. 2, 1987.

L.W. Gelhar and C.L. Axness, Three-dimensional stochastic analysis of macrodispersion in aquifiers, Water Resour. Res., vol. 19, pp. 161-180 (1983).

W.F. Gerhold, E. Escalante, and B.T. Sanderson, The corrosion behavior of selected stainless steels in soil environments, National Bureau of Standards Report NBS-IR $812243,1981$.

M.S. Giuffre, M.F. Kaplan, D.A. Ensminger, S.G. Oston, and J.Y. Nalbandian, Bedded-salt repository analysis: Final repon, Lawrence Livermore National Laboratory Report UCRL-15217, 1980.

M.N. Goltz and P.V. Roberts, Interpreting organic solute transport data by modeling diffusion into impermeable layers, Eos Trans. AGU, vol. 66, p. 274 (1985).

$$
\mathrm{R}-11
$$


B.A. Goodman, Adsortion of metal ions and complexes on aluminosilicate minerals, in J.A. Davis and K.F. Hayes ads, Geochemical Processes at Mineral Surfaces, Amer. Chem. Soc. Symp. Series No. 323, 1986, pp. 342-361.

B. Grambow, A physical-chemical model for the mechanism of glass corrosion, with particular consideration of stmulated radioactive waste glasses, doctoral dissertation, Free University of Berlin, translated as Savannah Rivar Laboratory Report $\mathrm{DP}^{3}-\mathrm{tr}-78$, 1904 .

B. Grambow, H.P. Hermansson, I.K. Bjomer, and L. Weme, Glass/water reaction with and without bentonite present experiment and model, in L.O. Werme, ed., Scientific Basis for Nuclear Woste Management IX, Materials Research Society, Pittsburgh, $1986 \mathrm{a}$, pp. $187-195$.

8. Grambow, MJ. Jercinovic, R.C. Ewing, and C.D. Byers, Weathered basalt glass: A natural analogue for the effects of reaction progress on nuelear waste glass alteration, in L.O. Werme, ed., Scientific Basis for Nuclear Waste Mamagement IX, Materials Research Society, Pittsburgh, 1986b, pp, 263-272.

R. Gratere, synthesis of recent investigations on corrosion behavior of radioactive waste glasses, Nationale Genossenschaft fur die lagerung radioaktiver Abfalle Technical Report NTB-85-27, March 1985 .

W.J. Gray, Gamma radolysis effects on Grande Ronde Basalt groundwater, in G.L. Mc Vay. ed., Scientific Basis for Nuclear Waste Managenent VII, North Holland, New York. 1944 , pp. $147-152$.

W.J. Gray, Comparison of uranium release from spent fuel and unimadiated $\mathrm{UO}_{2}$ in salt brine, in J.K. Bates and W.B. Seefeld, eds., Scientific Basis for Nuelear Wase Management X. Materials Research Sociery, Pittsburgh, 1987, pp. 141-152.

W.J. Gray and S.A. Simonson, Gamma and alpha radiolysis of salt brines, in C.M. Iantzen, J.A. Stone and R.C. Ewing, eds., Scientific Basis for Nuclear Waste Mantazentent VII, Materials Research Society, Pitsburgh, 1985, pp, 62 1 630 .

G.E. Grisak and J.F. Pickens, Solute ransport through tractured media: 1. The effect of matrix diffusion, Water Resour. Res., vol. 16, pp. 719-730 (1980),

S.K. Gupta, C.T. Kincaid, P.R. Meyer, C.A. Newoill, and C.R. Cole, A multi-dimensional finite element cole for the analysis of couplet fluid, energy and solute transport (CFEST), Parifie Northwest Laboratory Report PNL-4260, August 1982.

S.K. Gupta, A.M. Monti, and T.L. Steinborn, Salt dissolution assessment at seven potential nuclear waste repository locations in salt, Office of Nuclear Waste Isolation Report BMIONWI-567, April 1985.

S.K. Gupta, S.G. Bloom, A.M. Monti, and G.E. Raines, Coupled process analyses for salt repository performance assessment, in C-F. Tsang, ed. Couples Processes Associated with Nuclear Waste Repositories, Academic, New York, 1987.

A.B. Gureghisn and $G$. Junsen, One-dimensional analytical solutions for the migration of a three-member radionuclide decay chain in a multilayered geologic medim, Water Resour. Res., vol. 21, pp. 733-742 (1985).

$$
R-12
$$


A.B. Gureghian, L.A. Scott, and G.E. Raines, Performance assessment of a shaft seals system in a HLW repository in the Gibson Dome area, Office of Nuclear Waste Isolation Report ONWI-494, August 1983.

T.C. Gustavson, R.J. Finley, and K.A. McGillis, Regional dissolution of Permian salt in the Anadarko, Dalhart, and Palo Duro Basins of the Texas panhandle, Texas Bureau of Economic Geology Report of Investigations 106, 1980.

J.L. Haas, Thermodynamic properties of geologic materials: Status and future, in G.K. Jacobs and S.K. Whatley, eds., Proceedings of the Conference on the Application of Geochemical Models to High-Level Nuclear Waste Repository Assessment, Oak Ridge National Laboratory Report NUREG/CP-0062 (ORNL/TM-9585), pp. 81-83, 1985.

H. Hack ed., Galvanic Corrosion, ASTM-STP 572, ASTM, Philadelphia, 1986.

B. Haijtink and A. Accary, Joint European testing program on HLW container materials, in R.G. Post, ed., Waste Management '84, University of Arizona, Tucson, 1984, vol. 1, pp. 603-606.

R.O. Hallberg and I. Neretnieks, Investigations on old bronze cannons, in B. Come and N.A. Chapman, eds., CEC Natural Analogue Working Group, Second Meeting, Interlaken (CH), June 17-19, 1986, pp. 191-197.

R.O. Hallberg, P. Ostlund, and T. Wadsten, A 17th century cannon as analogue for radioactive waste disposal, in B. Come and N.A. Chapman, eds., Natural Analogues in Radioactive Waste Disposal, Brussels, 28-30th April, Symposium Proceedings, Vol. 2, 1987.

C.A. Handwerker, Diffusion induced grain-boundary migration and liquid film migration in ceramics and metals, in D. Gupta, ed., Diffusion in Thin Films, Noyes, New York, 1987.

M. Harada, P.L. Chambr , M. Fuglia, K. Kigashi, F. Iwamoto, D. Leung, T.H. Pigford, and D. Ting, Migration of radionuclides through sorbing media analytical solutions-I, Lawrence Berkeley Laboratory Report LBL-10500, February 1980.

C.J. Hardy, Radionuclide migration around uranium ore bodies - Progress report on the Alligator River analogue project and proposals for future work, in B. Come and N.A. Chapman, eds., CEC Natural Analogue Working Group, Second Meeting, Interlaken (CH), June 17-19, 1986, pp. 27-73.

W.V. Harper, Sensitivity/uncertainty analysis techniques for nonstochastic computer codes, Office of Nuclear Waste Isolation Report ONWI-444, 1983.

W.V. Harper and S.K. Gupta, Sensitivity/uncertainty analysis of a borehole scenario comparing Latin hypercube sampling and deterministic sensitivity approaches, Office of Nuclear Waste Isolation Report BMI/ONWI-516, October 1983.

C.E. Harvie and J.H. Weare, The prediction of mineral solubilities in natural waters: The $\mathrm{Na}-\mathrm{K}-\mathrm{Mg}-\mathrm{Ca}-\mathrm{Cl}-\mathrm{SO} 4-\mathrm{H} 2 \mathrm{O}$ system from zero to high concentration at $25^{\circ} \mathrm{C}$ : Geochim. Cosmochim. Acta, vol. 44, pp. 981-987 (1980). 
C.E. Harvie, N. Moller, and J.H. Weare, The prediction of mineral solubilities in natural waters: The $\mathrm{Na}-\mathrm{K}-\mathrm{Mg}-\mathrm{Ca}-\mathrm{H}-\mathrm{Cl}-\mathrm{SO}_{4}-\mathrm{OH}-\mathrm{HCO}-\mathrm{CO}_{3}-\mathrm{CO}_{2}-\mathrm{H}_{2} \mathrm{O}$ system to high ionic strengths at $25^{\circ} \mathrm{C}$, Geochim. Cosmochim. Acta, vol. 48, pp. 723-751 (1984).

M.A. Harwell, Reference site initial assessment for a salt dome repository, Pacific Northwest Laboratory Report PNL-2955, June 1982.

H.C. Helgeson, Evaluation of irreversible reactions in geochernical processes involving minerals and aqueous solutions -.. 1. Thermodynamic relations, Geochim. Cosmochim. Acta, vol. 32, pp. 853-877 (1968).

H.C. Helgeson, Thermodynamics of hydrothermal systems at elevated temperatures and pressures, Amer. J. Sci., vol. 267, pp. 729-804 (1969).

H.C. Helgeson, R.M. Gartels, and F.T. Mackenzic, Evaluation of irreversible reactions in geoshemical processes involving minerals and aqueous solutions - II. Applications, Geochim. Cosmochim. Acta, vol. 33, pp. 455 481 (1969).

J.C. Helton and R.L. Iman, Risk methodology for geologic disposal of radioactive waste: Sensitivity analysis of pathways model, Sandia National Laboratories Repori SAND79-1393, 1980.

J.C. Helton, R.L. Iman, J.D. Johnson and C.D. Leigh, Uncertainty and sensitivity analysis of a model for multicomponent aerosol dynamics, Nucl. Technol., vol. 73 , pp. 320-342 $(1986)$.

J.D. Hem, Study and interpretation of the chemical characteristics of natural water, third edition, U.S. Geological Survey Water-Supply Paper 2254, 1985.

\$. Hendrikson and K. Pettersson, Corrosion resistant canister for nuelear waste, Kürnbränslestikerhet Report, 1978.

F.E. Heuze, R.J. Schaffer, and A.R. Ingraffea, A coupled model for fluid-driven fractures, in C.-F. Tsang, ed. Coupled Processes Associated with Nuclear Waste Repositories, Academic, Otlando, 1987, pp. 655-661.

T.P. Hoar, On corrosion resistant materials, J. Electrochem. Soc., vol. 117, pp. 17-19 (1970).

C.F. Hochanadel and F.A. Ghormley, Effect of temperature on the decomposition of water by gumma rays, Radiat. Res.; vol. 16, p. 653 (1962).

P.J. Hooker, N.A. Chapman, A.B. MacKenzie, R.D. Scoth, and M. Ivanovich, Natural analogues of radionuclide migration in sediments in Britain, in B. Come and N.A. Chapman, eds, CEC Natural Analogue Working Group, Second Meeting, Interlaken (CH), June 17-19, 1987.

J.E. Horwedel and F.G. Pin, Upgrade of the GRESS (test version D) precompiler to allow triply dimensioned arrays, Oak Ridge National Laboratory Report ORNL/CSD/TM-240, 1986. 
A.B. Hull and J.R. Hull, Geometric modeling of dissolution kinetics: Application to apatite, Water Resour. Res., vol. 23, pp. 707-714 (1987).

R.L. Hunter, Preliminary scenarios for the release of radioactive waste from a hypothetical repository in basalt of the Columbia Plateau, U.S. Nuclear Regulatory Commission Report NUREG/CR-3353, October 1983.

R.L. Hunter, G.E. Barr, and F.W. Bingham, Scenarios for consequence assessments of radioactive-waste repositories at Yucca Mountain, Nevada Test Site, Sandia National Laboratory Report SAND82-1277, 1983.

R.L. Hunter, R.M. Cranwell, and C.J. Mann, Determining probabilities of geologic events and processes, in H.C. Burkholder, ed., High-level Nuclear Waste Disposal, Battelle, Columbus and Richland, 1986a, pp. 637-646.

R.L. Hunter, R.M. Cranwell, and M.S.Y. Chu, Assessing compliance with the EPA high-level waste standard: An overview, U.S. Nuclear Regulatory Commission Report NUREG/CR-4510, October $1986 \mathrm{~b}$.

P.S. Huyakom and G.F. Pinder, Computational Methods in Subsurface Flow, Academic, New York, 1983.

P.S. Huyakorn, B.H. Lester, and J.W. Mercer, An efficient finite element technique for modeling transport in fractured porous media, 1. Single species transport, Water Resour. Res., vol. 19, pp. 841-854 (1983).

P.S. Huyakorn, S.D. Thomas, and B.M. Thompson, Techniques for making finite elements competitive in modeling flow in variably-saturated porous media, Water Resour. Res., vol. 20, pp. 1099-1115 (1984).

P.S. Huyakorn, J.W. Mercer, and D.S. Ward, Finite element matrix and mass balance computational schemes for transport in variably saturated porous media, Water Resour. Res., vol. 21, pp. 346-358 (1985).

P.S. Huyakorn, B.G. Jones, and P.F. Andersen, Finite element algorithms for simulating three-dimensional groundwater flow and solute transport in multilayer systems, Water Resour. Res., vol. 22, pp. 361-374 (1986).

P.S. Huyakorn, P.F. Anderson, J.W. Mercer, and H.O. White, Jr., Saltwater intrusion in aquifers: Development and testing of a three-dimensional finite element model, Water Resour. Res., vol. 23, pp. 293-312 (1987).

J.C. Hwang, C.-J. Chen, M. Sheikloslamic, and B.K. Panigrahi, Finite analytic numerical solution for two-dimensional groundwater solute transpont, Water Resour, Res., vol. 21, pp. 1354-1360 (1985).

R.L. Iman and W.J. Conover, A distribution-free approach to inducing rank correlation among input variables, Communications in Statistics, vol. B11, pp. 311-334 (1982).

R.L. Iman and W.J. Conover, The use of rank transformation in regression, Technometrics, vol. 21, pp. $499-509$ (1979). 
R.L. Iman and J.C. Helton, A comparison of uncertainty and sensitivity analyşis techniques for computer models, Sandia National Laboratories Report NUREG/CR-3904. SAND84-1461, 1985.

R.L. Iman, J.C. Heiton and J.E. Campbell, Risk methodology for geologic disposal of radioactive waste: Sensitivity analysis techniques, Sandia National Laboratories Report SAND78-0912, 1978.

R.L. Iman, J.M. Davenport, R.K. Waddell, H.P. Stephens and D.I. Leap, Sensitivíly study of the parameters of the regional hydrology nodel for the Nevada Nuclear Waste Storage Investigations, Sandia National Laboratories Report SAND79-1097C, 1979.

R.L. Iman, J.M. Davenport and D.K. Zeigler, Latin hypercube sampling (program user's gubde), Sandia National Laboratories Report SAND79-1473, 1980.

R.L. Iman, M.S. Skortencarier and J.D. Johnson, A Fortran 77 progran and user's guide for the calculation of partial regression coefficients, Sandia National Laboratories Report NUREG/CR-4122, SAND83-2365, 1985.

J.W. Insalaco, Comparison of results for ten analytical heat conduction problems as solved by the general heat transfer code HEATING5, Office of Nuclear Waste Isolation Report BMI/ONWI-646, 1987

INTERA Environmental Consultants, Inc., GSM: Geologic simulation model for a hypothetical site in the Columbia Plateau large computer version, Office of Nuclear Waste Isolation Report ONWI-447, April 1983a.

INTERA Environmental Consultants, Inc, FFSM: Far-field state model, Office of Nuclear Waste lsolation Report ONWI-436, 1983b.

INTERA Environmental Consultants, Inc, SWENT: A three-dimensional tinite difference code for the simulation of fluid, energy, and solute radionuclide transport, office of Nuclear Waste Isolation Report ONWI-457, 1983c.

INTERA Environmental Consultants, Inc., WAPPA: A waste package performance assessrnent code, Office of Nuclear Waste Isolation Report ONW1-452, $1983 \mathrm{~d}$.

INTERA Enwironmental Consultants, Inc., GEOTHER: A two phase fluid flow and heat transport code, Office of Nuclear Waste Isolation Report ONWI-434, April 1983 e.

INTERA Envirormental Consultants, Inc., Workshop on uncertainty analysis of postclosure nuclear waste isolation system performance, Office of Nuclear Waste Isolation Repont ONWI-419, April 1983f.

INTERA Environmental Consultants, Inc., A proposed approach to uncertainiy analysis, Office of Nuclear Waste Isolation Report ONWI-488, July 1983g.

INTERA Environmentai Consultants, Inc., BORHOL: A computer code to evaluate dissolution, precipitation, creep, and temperature effects in boreholes in salt, Office of Nuclear Waste Isolation Report ONWI-547, October 1984. 
International Commission on Radiological Protection, Recommendations of the International Commission on Radiological Protection (ICRP Publication 26), Annals of the ICRP, vol. 1 , no. 3, 1977 .

International Commission on Rádiological Protection, Limits for intakes of radionuclides by workers (ICRP Publication 30), Arnals of the ICRP, vol, 2, no. 3/4 through vol. 8, no. $4,1979.82$.

Intemational Atomic Energy Agency, Concepts and examples of safety analysis for radioactive waste repositonies in continental geological formulations, Safety Series No. $58,1983$.

INTRACOIN, INTRACON level one report, Swedish Nuclear Power Inspectorate Report SKI 84:3, September 1984.

M. Ivanovich and $\mathrm{C}$. Hardy, Identification and measurement of colloids in groundwater, in B. Come and N.A. Chaprnan, eds. CEC Natural Analogue Working Group, Second Meeting, Interlaken (CH), June 17-19, 1986, pp. 227 260.

G. Izzo, Bacteria in ancient sediments, in B. Come and N.A. Chapman, eds, CEC Natural Analogue Working Group, Second Meeting, Interlaken (CH), June 17-19, 1986, pp. $138-152$.

K.J. Jackson and TJ. Wolery, Extension of the EQ3/6 computer codes to geochemical modelling of brines, in C.M. Jantzen, J.A. Stone and R.C. Ewing eds., Scientific Basis for Nuclear Waste Management VIII, Materials Research Sociely, Pittsburgh, 1985, pp, $507-514$

G.K. Jacobs and S.K. Whatley, Proceedings of the Conference on the Application of Geochemical Models to High-Level Nuelear Waste Repository Assessment, Oak Ridge National Laboratory Report NUREG/CP-0062 (ORNL/TM-9585), 1985.

E.A. Jacobson, M.D. Freshley and F.H. Dove, Investigations of sensitivity and uncertainty in some hydrologic models of Yucca Mountain and vicinity, Pacific Northwest Laboratory Report PNL 5306, SAND84-7212, 1985.

F.M. Jahnke and D.J. Radke, Electrolyte diffusion in compacted montomorillonite engineered barriers, in C.F. Tsang, ed., Coupled Processes Associated with Nuclear Waste Repasitories', Academic, Orlando, 1987, pp. 287-297.

C.M. Jantzen and N.E. Bibler, The role of groundwater oxidation potential and radiolysis on waste glass performance in crystalline repository environments, in L. O. Werme, ed., Scientific Basis for Nuclear Waste Management IX, Materials Research Soclety, Pittsburgh, 1985, pp. 219-229.

I. Javandel, C. Doughty, and C.F. Tsang, Groundwater Transport: A Handbook of Mathematical Models, American Geophysical Union, Washington, 1984.

R.O. Jeffrey and J.J.K. Daemen, Shaft or borehole plug-rock mechanical interaction, in R.G. Post, ed., Waste Monagement '81, Univ of Arizona, Tucson, 1981, vol. 2, pp. $865-879$. 
G.H. Jenks, Effects of temperature, temperature gradients, stress and irradiation on migration of brine inclusions in a salt repository, Oak Ridge National Laboratory Report ORNL-5526, 1979.

G.J. Jenks, Radiolysis and hydrolysis in salt-mine brines, Oak Ridge National Laboratory Repart ORNL-TM 3717, 1972.

G.J. Jenks, Review of infornation on the radiation chemistry of materials around waste canisters in salt and assessment of the need for additional experimental information, Oak Ridge National Laboratory Report ORNL $-5607,1980$.

E.A. Jenne, Geochemical modeling: A review, Pacific Northwest Laboratory Report PNL-3574, 1981.

E.A. Jenne and K.M. Krupka, Validation of geochemical models, in U.S. Dept. of Energy Report CONF-8406134, 1985, pp. 143-152.

D.I. Jensen and CJ, Radke, Steady radionuclide release rates from a bentonite-protected waste canister, in C.-F. Tsang, ed, Coupled Processes Assoctated with Nuclear Waste Repositories, Academic, Orlando, 1987, pp. 299-307.

N. Jockwer, Laboratory investigations on radiolysis effects on rock salt with regard to the disposal of high-level radioactive wastes, in G.L. McVay, ed., Scientific Basis for Nuclear Waste Management VI, Elsevier, New York, 1984, pp. 17-23.

N. Jockwer and S. Gross, Natural, thermal and radiolytical gas liberation in rock salt as a result of disposed high-level radioactive waste, in L.O. Werme, ed., Scientific Basis for Nuclear Waste Management IX, Materials Research Society, Pittsburgh, 1985, pp. $587-594$.

K.S. Johnson, Salt dissolution and collapse at the Wink Sink in West Texas, Office of Nuctear Waste Isolation Report ONWI..598, 1986.

L.H. Johnson, N.C. Garisto, and S. Stroes-Gascoyne, Used fuel dissolution studies in Canada, in R.G. Post, ed., Waste Management '85. University of Arizona, Tucson, 1985, vol. 1, pp. $479-482$.

N.M. Johnson and S.J. Dreiss, An indicator geostatistics approach to hydrostratigraphic interpretation, Eos Trans. AGU, vol. 68; p. 299 (1987).

H. Kaesche, Pitting susceptibility and surface potential, A. Physik. Chem., N.F., vol. 34, pp. $87-90(1962)$.

KBS, Handling of spent nuclear fuel and final storage of vitrified high-level reprocessing waste, Kränbränslesäkerher Report, 1978 a.

KBS, Handling and final storage of unreprocessed spent nuclear fuel, Kärnbränslesäkerhet Report, $1978 \mathrm{~b}$.

KBS, Final storage of spent nuclear fuei-KBS-3, Karnbränslesäkerhet Report, 1983. 
P.C. Kelsall, J.B. Case, and C.R. Chabannes, A preliminary evaluation of the rock mass disturbance resulting from shaft, tunnel, or borehole excavation, Office of Nuclear Waste Isolation Report 0NWI-411, November 1982.

O. Kempthorne, Design and Analysis of Experiments, John Wiley and Sons, New York, 1952.

Y.K. Kharaka and I. Barnes, SOLMNEQ: Solution-mineral equilibrium computations, U.S. Geological Survey Report, NTIS PB215-899, 1973.

A.W. Kharickhoff, Organic pollutant sorption in aquatic systems, J. Hydraulic Eng., vol. 110 , pp. 707-733 (1984).

C.L. Kim, P.L. Chambré, and T.H. Pigford, Mass-transfer-limited release of a soluble waste species, Lawrence Berkeley Laboratory Report LBL-20899, June 1986.

J.I. Kim, Colloid generation and migration of actinides in natural aquifer system, in B. Come and N.A. Chapman, eds., CEC Natural Analogue Working Group, Second Meeting, Interlaken (CH), June 17-19, 1986, pp. 271-278.

J.I. Kim, G. Backau, and R. Klenze, Natural colloids and generation of actinide pseudocolloids in groundwater, in B. Come and N.A. Chapman, eds., Natural Analogues in Radioactive Waste Disposal, Brussels, 28-30th April, Symposium Proceedings, Vol. 2, 1987.

J.I. Kim, C.H. Lierse, K. Buppelmann, and S. Magirius, Radiolytically induced oxidation reactions of actinide ions in concentrated salt solutions, in J.K. Bates and W.B. Seefeldt, eds., Scientific Basis for Nuclear Waste Management X, Materials Research Society, Pittsburgh, 1987, pp. 603-612.

U.J. Kim, Y.K. Hong, R.A. Oriani, and H.S. Isbin, The behavior of TI-CODE 12 in brine under gamma radiation, in R.G. Post, ed., Waste Management ' 84 , University of Arizona, Tucson, 1984, vol. 1, pp. 619-625.

J.K. Kimball, R.E. Jackson, A.J. Jelacic, and J. Rhoderick, The significance of tectonic events on processes on the long-term isolation of high-level radioactive wastes, in R.G. Post, ed., Waste Management '87, University of Arizona, Tucson, 1987, vol. 2, pp. $147-152$.

C.T. Kincaid, J.R. Morrey, S.B. Yabrusaki, A.R. Felmi, and J.E. Rogers, Geohydrochemical models for solute migration, volume 2: preliminary evaluation of selected computer codes, Electric Power Research Institute Report EA-3417, November 1984.

I.P.E. Kinnmark, A Taylor series expansion procedure for efficient groundwater flow simulation, Eos Trans. AGU, vol. 66, p. 906 (1985).

K.L. Kipp, Jr., Adaptation of the Carter-Tracy water influx calculation to groundwater flow simulation, Water Resour. Res., vol. 22, pp. 423-428 (1986a).

K.L. Kipp, Jr., Effect of topography on gas flow in unsaturated fractured rock - Numerical simulation, in D.D. Evans and T.J. Nicholson, eds., Flow and Transport Through Unsaturated Fractured Rock, American Geophysical Union, Washington, 1987, pp. $171-176$.

$$
\mathrm{R}-19
$$


E.A. Klavetter and R.R. Peters, Fluid flow in a fractured rock mass, Sandia National Laboratories Report SAND85-0855, March 1986.

N.W. Kline and R.G. Baca, CHAINT computer code: User's guide, Rockwell Hanford Operations Document RHO-BW-CR-144 P, 1985.

D.C. Kocher, A.L. Sjoreen, and C.S. Bard, Uncertainties in geologic disposal of high-level wastes-groundwater transport of radionuclides and radiological consequences, U.S. Nuclear Regulatory Commission Report NUREG/CR-2506, July 1983.

L.F. Konikow, Predictive accuracy of a ground-water model - lessons from a postaudit, Ground Water, vol. 24, pp. 173-184 (1986).

L.F. Konikow and J.D. Bredehoeft, Computer model of two-dimensional solute transport and dispersions in ground water, U.S. Geological Survey Techniques of Water Resources Investigations, vol. 7, 1978.

C.M. Koplik, M.F. Kaplan and B. Ross, The safety of repositories for highly radioactive wastes, Rev. Mod. Phys., vol. 54, pp. 269-310 (1982).

D.K. Krige, A statistical approach to some basic mine valuation problems on the Witwaterstrand, Journal of Chemical and Metallurgical Mining Society of South Africa, vol. 52(6), pp. 119-139 (1951).

J. Kruger and V.K. Hardman, Current understanding of pitting and crevice corrosion and its application to test methods for determining the susceptibility to such corrosion of nuclear waste metallic containers, National Bureau of Standards Report NBS-IR $1982-348,1982$.

K.M. Krupka and J.R. Morrey, MINTEQ geochemical reaction code: Status and applications, in G.K. Jacobs and S.K. Whatley, eds., Proceedings of the Conference on the Application of Geochemical Models to High-Level Nuclear Waste Repository Assessment, Oak Ridge National Laboratory Report NUREG/CP-0062 (ORNL/TM-9585), 1985, pp. 46-53.

K.M. Krupka, E.A. Jenne, and W.J. Deutsch, Validation of the WATEQ4 geochemical model for uranium, Pacific Northwest Laboratory Report PNL-4333, 1983.

O. Kubaschewski and B.E. Hopkins, Oxidation of Metals and Alloys, Butterworth and Co., London, 1962.

O.E. Lafe and A.H-D., Cheng, A perturbation boundary element code for steady state groundwater flow in heterogeneous aquifers, Water Resour. Res., vol. 23, pp. 1079-1084 (1987).

A. Lallemand-Barres and P. Peaudecerf, Recherche des relations entre la valeur de la dispersivité macroscopique d'un milieu aquifère, ses autres caractéristiques et les conditions de mesure, Bulletin du Bureau des Recherches Géologiques et Minières, Section III, Series 2, pp. 277-284 (1978).

S.J. Lambert, Evaporate dissolution relevant to the WIPP site, Northern Delaware Basin, Southeastern New Mexico, in D.G. Brookins, ed., Scientific Basis for Nuclear Waste Management VI, North-Holland, New York, 1983, pp. 291-298.

$$
\mathrm{R}-20
$$


D. Langmuir, Overview of coupled processes with emphasis in geochemistry, in C.-F. Tsang, ed., Coupled Processes Associated with Nuclear Waste Repositories, Academic, Orlando, 1987, pp. 67-101.

C.A. Langton and D.M. Roy, Longevity of borehole and shaft sealing materials: Characterization of ancient cement based building materials, in G.L. McVay, ed., Scientific Basis for Nuclear Waste Management VII, North-Holland, New York, 1984, pp. 543-549.

A.C. Lasaga, Chemical kinetics of water-rock interactions, J. Geophys. Res., vol. 89, pp. 4009-4025 (1984).

A.C. Lasaga, Dissolution and precipitation kinetics of minerals, in, G.K. Jacobs and S.K. Whatley, eds., Proceedings of the conference on the Application of Geochemical Models to the High-Level Nuclear Waste Repository Assessment, Oak Ridge National Laboratory Report NUREG/CP-0062 (ORNL/TM-9585), 1985, pp. 96-98.

A.C. Lasaga and R.J. Kirkpatrick, eds., Kinetics of Geochemical Processes, Mineral. Soc. Amer., Review in Mineral., vol. 8 (1981).

D.R. LeBlanc and S.P. Garabedian, Preliminary results of a natural-gradient tracer test in a sand and gravel aquifer, Cape Cod, Massachusetts, Eos Trans. AGU, vol. 67, p. 286 (1986).

D.M. LeNeveu and J.R. Walker, The vault submodel for the interim assessment of the Canadian concept for nuclear fuel waste disposal, in H.C. Burkholder, ed., High-level Nuclear Waste Disposal, Battelle, Columbus and Richland, 1986, pp. 647-657.

C.F. Lee, A case history on long-term effectiveness of clay sealant, in B. Come and N.A. Chapman, eds., CEC Natural Analogue Working Group, Second Meeting, Interlaken (CH), June 17-19, 1986, pp. 172-190.

D.H. Lester et al., Waste package performance evaluation, Office of Nuclear Waste Isolation Report ONWI-302, March 1983.

D.A. Lever, Natural analogues and radionuclide transport model validation, in B. Come and N.A. Chapman, eds., Natural Analogues in Radioactive Waste Disposal, Brussels, 28-30th April, Symposium Proceedings, Vol. 2, 1987.

P.W. Levy, Radiation damage studies on natural rock salt from various geologic localities of interest to the radioactive waste disposal program, Nucl. Technol., vol. 60, p. 231 (1983).

J. Lewi, M. Assouline, J. Bareau, and P. Raimbault, MELODIE: A global risk assessment model for radioactive waste repositories, presented to Symposium on High-Level Waste, Madrid, 1987.

B.D. Lewis and F.J. Goldstein, Evaluation of a predictive ground-water solute-transport model at the Idaho National Engineering Laboratory, Idaho, U.S. Geological Survey Water-Resources Investigation 82-25, 1982. 
M.A. Lewis and D.T. Reed, Effects of gamma radiolysis on waste package components, in J.K. Bates and W.B. Seefeldt, eds., Scientific Basis for Nuclear Waste Management X, Materials Research Society, Pittsburgh, 1987, pp. 623-634.

A.M. Liebetrau, M.J. Apted, D.W. Engel, M.K. Altenhofen, C.R. Reid, D.M. Strachan, R.L. Erikson, and D.H. Alexander, AREST: A probabilistic source-term code for waste package performance analysis, in R.G. Post, ed., Waste Management ' 87 , University of Arizona, Tucson, 1987 , vol. 2, pp. 535-544.

J.A. Ligget and P. Liu, The Boundary Integral Equation Method for Porous Media Flow, George Allen and Unwin, London, 1983.

R.D. Lindberg and D.D. Runnells, Ground water redox reactions: An analysis of equilibrium state applied to Eh measurements and geochemical modelling, Science, vol. 225, pp. 925-927 (1984).

K.E. Lindstrøm-Jensen, Dissolution rate of salt domes, ELSAM, notat nr. K79/193,22.721, November 1979.

K.E. Lindstrøm-Jensen, Dissolution rate of salt domes, part 2, ELSAM notat nr. K80/54, 22.721, February 1980.

K.E. Lindstrøm-Jensen, Dissolution rate of salt domes on the basis of measured salinity profiles, in W. Lutze, ed., Scientific Basis for Nuclear Waste Management V, North Holland, New York, 1982, pp. 429-438.

W. Lutze and B. Grambow, The use of natural analogues in the long-term extrapolation of glass corrosion processes, in B. Come and N.A. Chapman, eds., Natural Analogues in Radioactive Waste Disposal, Brussels, 28-30th April, Symposium Proceedings, Vol. 2, 1987.

P.B. Macedo, A. Barkatt, B.C. Gibson, and C.J. Montrose, Long-term release rates of borosilicate glass waste forms, Nucl, Technol., vol. 73, pp. 199-209 (1986).

P.B. Macedo and C.J. Montrose, Response to the paper 'Reliable predictions of waste performance in a geologic repository', in H.C. Burkholder, ed., High-Level Nuclear Waste Disposal, Battelle, Columbus and Richland, 1986, pp. 187-190.

R.E. Malenfant, QAD: A series of point-kernel general purpose shielding programs, Los Alamos National Laboratory Report LA-3572, 1967.

G. Matheron, Principles of geostatistics, Econ. Geol., vol. 58, pp. 1246-1266, 1963.

G. Matheron, The Theory of Regionalized Variables and Its Applications, Centre for Mathematical Morphology, Paris School of Mines, Fontainebleau, France, Vol. 5, 1971.

S.P. Mathis and J.J.K. Daeman, Rock damage induced by drilling: an experimental assessment of potential leakage around borehole seals, in R.G. Post, ed., Waste Management ' '82, University of Arizona, Tucson, 1982, vol. 2, pp. 393-404. 
R.A. McCann, HYDRA-I: A three dimensional finite difference code for calculating the thermohydraulic performance of a fuel assembly contained within a canister, Pacific Northwest Laboratory Report PNL-3367, 1980.

R.A. McCann, P.S. Lowery, and D.L. Lessor, HYDRA-II: a hydrothermal analysis computer code, volume II, user's manual, Pacific Northwest Laboratory Report PNL-6206, 1980 .

V.S. McCauley and G.E. Raines, Expected brine movement at potential nuclear waste repository salt sites, Office of Nuclear Waste Isolation Report ONWI-654, 1987.

R.D. McCright, Corrosion behavior of materials exposed to hypersaline geothermal brine, The International Corrosion Forum, NACE, Houston, 1981, pp. 138-145.

R.D. McCright, R.A. Van Konyenburg, and L.B. Ballou, Corrosion test plan to guide canister material selection and design for a tuff repository, in G.L. McVay, ed., Scientific Basis for Nuclear Waste Management VII, North-Holland, New York, 1984, pp. 309-318.

L.M. McDowell-Boyer, J.R. Hunt, and N. Sitar, Particle transport through porous media, Water Resour. Res., vol. 22, pp. 1901-1921 (1986).

B.P. McGrail, Hydrothernal waste package interactions with methane-containing basalt groundwater, in C.M. Jantzen, J.A. Stone and R.C. Ewing, eds., Scientific Basis for Nuclear Waste Management VIII, Materials Research Society, Pittsburgh, 1985, pp. $459-466$.

B.P. McGrail, L.A. Chick, and G.L. McVay, Initial results for the experimental evaluation of a nuclear waste repository source term model, Nucl. Technol., vol. 69, pp. 114-118 (1985).

M.D. McKay, W.J. Conover, and R.J. Beckman, A comparison of three methods for selecting values of input variables in the analysis of output from a computer code, Technometrics, vol. 21, pp. 239-245 (1979).

T.J. McKeon and W-S. Chu, A multigrid model for steady flow in partially saturated porous media, Water Resour. Res., vol. 23, pp. 542-550 (1987).

D.F. McTigue and E.J. Nowak, Brine transport in the bedded salt of the Waste Isolation Pilot Plant (WIPP): Field measurements and a Darcy flow model, in M.J. Apted and R.E. Westerman, eds., Scientific Basis for Nuclear Waste Management XI, Materials Research Society, Pittsburgh, 1988, pp. 209-218.

G.L. McVay and L.R. Pederson, Effects of gamma radiation on glass leaching, J. Am. Ceram. Soc., vol. 64, no. 3, pp. 154-158 (1981).

G.L. McVay, W.J. Weber, and L.R. Pederson, Effects of radiation on the leaching behavior of nuclear waste forms, Nucl. Chem. Waste Management, vol. 2, pp. 103-108 (1981).

J.L. Means, A.J. Markworth, J.K. McCoy, M.P. Farley, M.J. Stenhouse, R. Kohli, and G.C. Taylor, Long-term performance of spent fuel waste forms, U.S. Nuclear Regulatory Commission Report NUREG/CR-4954, 1987. 
J.E. Mendel, W.A. Ross, F.P. Roberts, R.P. Turcotte, Y.B. Katayama, and J.H. Westsik, Jr., Thermal and rdiation effects on borosilicate waste glass, in Proceedings Symp.

Management of Radioactive Wastes from the Nuclear Fuel Cycle, International Atomic Energy Agency Report IAEA-SM-207, vol. 2, pp. 49-54, 1976.

J.W. Mercer, C.R. Faust, W.J. Miller, and F.J. Pearson, Jr., Review of simulation techniques for aquifer thermal energy storage (ATES), Advances in Hydroscience, vol. 13, pp. $1-129(1982)$.

M.A. Molecke et al., Sandia high level waste canister/overpack studies applicable for a salt repository, Sandia National Laboratories Report SAND81-1585, 1981.

N. Moller, J.H. Weare, and J. Greenberg, Prediction of mineral solubilities and diagenesis in rock/water association at high temperature, in G.K. Jacobs and S.K. Whatley, eds., Proceedings of the Conference on the Application of Geochemical Models to High-Level Nuclear Waste Repository Assessment, Oak Ridge National Laboratory Report NUREG/CP-0062 (ORNL/TM-9585), 1985, pp. 31-36.

P.M. Montazer and W.A. Hustrulid, An investigation of fracture permeability around an underground opening in metamorphic rocks, Office of Crystalline Repository Development Repori BMI/OCRD-4(5), October 1983.

P. Montazer and W.E. Wilson, Conceptual hydrologic model of flow in the unsaturated zone, Yucca Mountain, Nevada, U.S. Geological Survey Water-Resources Investigations Report 84-4345, 1984.

J.B. Moody, Radionuclide migration/retardation: research and development technology status report, Office of Nuclear Waste Isolation Report ONWI-321, March 1982.

C.H. Moore, Flow/reaction models of natural systems, in, G.K. Jacobs and S.K. Whatley, eds., Proceedings of the Conference on the Application of Geochemical Models to High-Level Nuclear Waste Repository Assessment Oak Ridge National Laboratory Report NUREG/CP-0062 (ORNL/TM-9585), 1985 pp. 93-95.

L. Moreno, I. Neretnieks, and T. Eriksen, Analysis of some laboratory tracer runs in natural fissures, Water Resour. Res., vol. 21, pp. 951-958 (1985).

J.R. Morrey and C.J. Hostetler, Coupled geochemical and solute transport code development, in, G.K. Jacobs and S.K. Whatley, eds., Proceedings of the Conference on the Application of Geochemical Models to High-Level Nuclear Waste Repository Assessment, Oak Ridge National Laboratory Report NUREG/CP-0062 (ORNL/TM-9585), 1985, pp. 90-92.

A.B. Muller, D. Langmuir, and I. Neretnieks, Conclusions from an NEA workshop: The role of phenomenological sorption modelling in performance assessment of radioactive waste disposal systems, in G.L. McVay, ed., Scientific Basis for Nuclear Waste Management VII, North Holland, New York, 1984, pp. 817-826.

A. Muurinen, J. Rantanen, and P. Penttila-Hiltunen, Diffusion mechanisms of strontium, cesium, and cobalt in compacted sodium bentonite, in L.O. Werme, ed., Scientific Basis for Nuclear Waste Management IX, Materials Research Society, Pittsburgh, 1986, pp. 617-624. 
A. Muurinen, P. Penttila-Hiltunen, and J. Rantanen, Diffusion mechanisms of strontium and cesium in compacted sodium bentonite, in J.K. Bates and W.B. Seefeldt, eds., Scientific Basis for Nuclear Waste Management X, Materials Research Society, Pittsburgh, 1987, pp. 803-812.

NAGRA, Nuclear waste management in Switzerland: Feasibility studies and safety analyses, National Cooperative for the Storage of Radioactive Waste (Switzerland) Project Report NGB 85-09, June 1985.

T.N. Narasimhan and P.A. Witherspoon, An integrated finite difference method for analyzing fluid flow in porous media, Water Resour. Res., vol. 12, pp. 57-64 (1976).

T.N. Narasimhan, A.F. White, and T. Tokunaga, Groundwater contamination from an inactive uranium mill tailings pile: 2. Application of a dynamic mixing model, Water Resour. Res., vol. 22, pp. 1820-1834 (1986).

K.L. Nash, S. Fried, A.M. Friedman, N. Susak, P. Rickert, J.C. Sullivan, D.P. Karim, and D.J. Lam, The effect of radiolysis on leachability of plutonium and americium from 76-101 glass, in S.V. Topp, ed., Scientific Basis for Nuclear Waste Management VI, North-Holland, New York, 1982, pp. 661-666.

K.L. Nash, S. Fried, A.M. Friedman, N. Susak, P. Rickert, and J.C. Sullivan, Radiation effects in solution and on the solid/liquid interface, Nucl. Technol, vol. 50, pp. $257-266(1983)$.

I. Neretnieks, Transport of oxidants and radionuclides through a clay barrier, Kärnbränslesäkerhet Report KBS TR-79, 1978.

I. Neretnieks, Diffusion in the rock matrix: An important factor in radionuclide retardation., J. Geophys. Res., vol. 85, pp. 4379-4397 (1980)

I. Neretnieks, A note on fracture flow dispersion mechanisms in the ground, Water Resour. Res., vol. 19, pp. 364-370 (1983).

I. Neretnieks, Source term modeling in the Swedish KBS study, presented to the OECD/NEA Workshop on the Source Term for Radionuclide Migration, Albuquerque, November 13-15, 1984.

I. Neretnieks, Diffusivities of some constituents in compacted wet bentonite clay and the impact on radionuclide migration in the buffer, Nucl. Technol., vol. 71, pp. 458-470 (1985).

I. Neretnieks, Some aspects on the use of iron canisters for HLW, in L.O. Werme, ed., Scientific Basis for Nuclear Waste Management IX, Materials Research Society, Pittsburgh, 1986a, pp. 411-420.

I. Neretnieks, Some uses of natural analogues for safety analysis, in B. Come and N.A. Chapman, eds., CEC Natural Analogue Working Group, Second Meeting, Interlaken (CH), June 17-19, 1986b, pp. 9-15.

I. Neretnieks and A. Rasmuson, An approach to modeling radionuclide migration in a medium with strongly varying velocity and block sizes along the flow path, Water Resour. Res., vol. 20, pp. 1823-1836 (1984).

$$
\mathrm{R}-25
$$


S.P. Neuman, A statistical approach to the inverse problem of aquifer hydrology: 3. Improved solution method and added perspective, Water Resour. Res., vol. 16, pp. $331-346(1980)$.

S.P. Neuman, R.A. Feddes, and E. Bresler, Finite element analysis of two-dimensional flow in soils with water uptake by roots: I. Theory, Soil Sci. Soc. Amer. Proceedings, vol. $39,1975$.

T.J. Nicholson, T.J. McCartin, P.A. Davis, and W. Beyeler, NRC experiences in HYDROCOIN: An international project for studying ground-water flow modeling strategies, in R.G. Post, ed., Waste Management '87, University of Arizona, Tucson, 1987, vol. 2, pp. 201-208.

S.L. Nicolosi, A generalized model for the analysis of groundwater radiolysis, in C.M. Jantzen, J.A. Stone and R.C. Ewing, eds., Scientific Basis for Nuclear Waste Management VIII, Materials Research Society, Pittsburgh, 1985, pp. 631-640.

S.L. Nicolosi, A generalized model for the radiolysis of groundwater: bicarbonate chemistry and influences, in J.K. Bates and W.B. Seefeldt, eds., Scientific Basis for Nuclear Waste Management X, Materials Research Society, Pittsburgh, 1987, pp. 671-679.

S.L. Nicolosi, R.E. Kurth, S.F. Quayle, D.J. Hess, and A.J. Markworth, System performance of high-level waste package components, U.S. Nuclear Regulatory Commission Report NUREG/CR-4956, 1987.

J. Noorishad and M. Mehran, An upstream finite element method for solution of transient rransport equations in fractured porous media, Water Resour. Res., vol. 18, pp. 588-596 (1982).

J. Noorishad and C.-F. Tsang, Simulation of coupled thermal-hydraulic-mechanical interactions in fluid injection into fractured rocks, in C.-F. Tsang, ed., Coupled Processes Associated with Nuclear Waste Repositories, Academic, Orlando, 1987, pp. $673-678$.

D.K. Nordstrom, L.N. Plummer, T.M.L. Wigley, T.J. Wolery, J.W. Ball, E.A. Jenne, R.L. Bassett, D.A. Crerar, T.M. Florence, B. Fritz, M. Hoffman, G.R. Holdren, Jr., G.M. Lafon, S.V. Mattigod, R.E. McDuff, F. Morel, M.M. Reddy, G. Sposito, and J. Thrailkill, A comparison of computerized models for equilibrium calculations in aqueous systems, in E.A. Jenne, ed., Chemical Modelling in Aqueous Systems, Chem. Soc. Symp. Series, no. 93, pp. 857-892, 1979.

D.K. Nordstrom, S.D. Valentine, J.W. Ball, L.N. Plummer, and B.F. Jones, Partial compilation and revision of basic data in the WATEQ programs, U.S. Geological Survey Water-Resources Investigation Report 84-4186, 1984.

E.J. Nowak, The backfill barrier as a component in a multiple barrier nuclear waste isolation system, Sandia National Laboratories Report SAND 79-1109, October 1979.

Nuclear Energy Agency, Geological Disposal of Radioactive Waste: Geochemical Processes. Nuclear Energy Agency, Paris, 1982. 
Nuclear Energy Agency, Uncertainty Analysis for Performance Assessments of Radioactive Waste Disposal Systems, Organisation for Economic Co-operation and Development, Paris, 1987.

E.M. Oblow, Sensitivity theory for general nonlinear algebraic equations with constraints, Nucl. Sci. Eng., vol. 65, pp. 187-191 (1978).

E.M. Oblow, An automated procedure for sensitivity analysis using computer calculus, Oak Ridge National Laboratory Report ORNL/TM-8776, 1983a.

E.M. Oblow, GRESS gradient-enhanced software system: Version B user's guide, Oak Ridge National Laboratory Report ORNL/TM-8339, $1983 \mathrm{~b}$.

E.M. Oblow, GRESS gradient-enhanced software system: Version D user's guide, Oak Ridge National Laboratory Report ORNL/TM-9858, 1985.

E.M. Oblow, F.G. Pin and R.Q. Wright, Sensitivity analysis using computer calculus: A nuclear waste isolation application, Nucl. Sci. Eng., vol. 94, pp. 46-65 (1986).

G.D. O'Kelley and R.E. Meyer, The role of geochemical factors in the assessment and regulation of geologic disposal of high-level radioactive waste, Oak Ridge National Laboratory Report NUREG/CR-3490, 1984.

D.R. Olander, A study of thermal-gradient-induced migration of brine inclusions in salt: Final report, Office of Nuclear Waste Isolation Report ONWI-538, August 1984.

J.W. Oldfield and W.H. Sutton, An experimental and mathematical model for crevice corrosion, Brit. Corros. J., vol. 13, pp. 13-26 (1978).

ORNL, QAD-CG: A combinatorial geometry version of QAD-P5A, a point-kernel code for neutron and gamma-ray shielding calculations, Oak Ridge National Laboratory Report CCC-307, 1977.

ORNL, SCALE: A modular code system for performing standardized computer analyses for licensing evaluation, Oak Ridge National Laboratory Report NUREG/CR-0200, December 1984.

P. Ortoleva, Modelling water-rock interactions, in G.K. Jacobs and S.K. Whatley, eds., Proceedings of the Conference on the Application of Geochemical Models to High-Level Nuclear Waste Repository Assessment, Oak Ridge National Laboratory Report NUREG/CP-0062 (ORNL/TM-9585), 1985, pp. 87-89.

C.A. Oster, Review of ground water flow and transport models in the unsaturated zone, Pacific Northwest Laboratory Report PNL-4427, 1982.

W.M. Pardue, F.H. Beck, and M.G. Fontana, Properies of stress corosion cracking in magnesium base alloys as determined by several techniques, Trans. ASM, vol. 54, pp. 539-548 (1961).

D.L. Parkhurst, D.C. Thorstenson, and L.N. Plummer, PHREEQE - A computer program for geochemical calculations, U.S. Geological Survey Water-Resources Investigations Report 80-96, 1980. 
D.L. Parkhurst, L.N. Plummer, and D.C. Thorstenson, BALANCE - A computer program for calculation of chemical mass balance, U.S. Geological Survey Water-Resources Investigations Report 82-14, 1982.

N. Parkins, Development of strain rate testing and its implications, in G.M. Ugiansky and J.M. Payer, eds., Stress Corrosion Cracking The Slow Strain Rate Technique, ASTM STP 665, ASTM, Philadelphia, 1979, pp. 5-25.

J.H. Payer, W.E. Berry, and W.K. Boyd, Evaluation of slow strain rate stress corrosion tests results, in G.M. Ugiansky and J.H. Payer, eds., Stress Corrosion Cracking The Slow Strain Rate Technique, ASTM STP 665, ASTM, Philadelphia, 1979, pp. 61-75.

L.R. Pederson, Chemical implications of heat and radiation damage to rock salt, in C.M. Jantzen, J.A. Stone and R.C. Ewing., eds., Scientific Basis for Nuclear Waste Management VIII, Materials Research Society, Pittsburgh, 1985, pp. 701-708.

L.R. Pederson and G.L. McVay, Influence of gamma irradiation on simulated nuclear waste glass leaching: temperature and dose rate dependence in deaerated water, J. Am. Ceram. Soc., vol. 66, pp. 863-867 (1983).

L.R. Pederson, D.E. Clark, F.N. Hodges, G.L. McVay, and D. Rai, The expected environment for waste packages in a salt repository, in G.L. McVay, ed., Scientific Basis for Radioactive Waste Management VII, Elsevier, New York, 1984, pp. $417-426$.

D.L. Pentz, J.W. Voss, and D.H. Lester, Evaluation of engineered barrier design and performance in an underground basalt repository, to be published as U.S. Nuclear Regulatory Commission Report NUREG/CR, 1984.

S.R. Peterson, W.J. Martin, and R.J. Serne, Ptedictive geochemical modeling of contaminant concentrations in laboratory columns and in plumes migrating from uranium mill tailings waste impoundments, Pacific Northwest Laboratory Report PNL-5788, 1986.

J.-C. Petit, Analogue studies at the French atomic energy commission, in B. Come and N.A. Chapman, eds., CEC Natural Analogue Working Group, Second Meeting, Interlaken (CH), June 17-19, 1986, pp. 119-131.

G.M. Petrie, et al., Geologic simulation model for a hypothetical site in the Columbia Plateau, Pacific Northwest Laboratory Report PNL-4427, 1981.

F.M. Phillips and J.L. Wilson, The use of threshold crossing theory for estimation of spatial ln $\mathrm{K}$ correlation scales from geological characteristics, Eos Trans. AGU, vol, 68, p. 300 (1987).

J.F. Pickens and G.E. Grisak, Finite element analysis of liquid flow, heat transport and solute transport in a ground-water flow system: Governing equation and model formulation, Atomic Energy of Canada, Ltd. Report TR-81, September 1979.

T.H. Pigford, Response to B.L. Cohen's criticism of the report: 'A study of the isolation system for geologic disposal of radioactive wastes,' University of California Report $\mathrm{UCB}-\mathrm{NE}-4052,1985$. 
T.H. Pigford and P.L. Chambre, Reliable predictions of waste performance in a geologic repository, in H,C. Burkholder, ed. High-Level Nuclear Waste Disposal, Battelle, Columbus and Richland, $1986 a, p p .163-185$.

T.H. Pigford and P.L. Chambre, Response to comments by P.B. Macedo and C.J. Montrose about reliable predictions of waste performance in a geologic repository, in H.C. Burkholder, ed., High-Level Nuclear Waste Disposal, Battelle, Columbus and Richland, 1986b, pp. 191-201.

T.H. PIgford, P.L. Chambre, M. Alber, M. Fuglia, M. Harada, F. Iwamoto, T. Konki, D. Leung, S. Masuda, S. Muraoka, and D. Ting. Migration of radionuclides through sorbing media andytical solutions-II, Lawrence Berkeley Laboratory Report LBL-11616, Oktober 1980.

T.J. Pigford, I.O. Blomeke, T.L. Brekke, G.A. Cowan, W.E. Falconer, N.J. Grant, I.R. Iohnson, J.M. Matuszek, R.R. Parizek, R,L. Pigford, and D.E. White, A Study of the Solation System for Geologic Disposal of Radioactive Wastas, National Academy Press, Washington, 1983.

F.G. Pin and R.Q. Wright, GRESS translation of the ORIGEN2 code, Oak Ridge National Laboratory Report ORNL/TM-9694, May 1986.

F.G. Pin, E.M, Oblow, I.E. Horwedel and J.L. Lucius, ADGEN: an automated adjoint code generator for large-beale sensitivity analysis, Trans. Am. Nucl. Soc., vol. 55, p. 311 , 1987.

K.S. Pitzer, Thermodynamics of electrolytes: I. Theoretical basis and general equations, J. Phys. Chem., vol. 77, pp. 268-277 (1973).

M.J. Plodinec, C.M. Jantzen, and G.O. Wicks, Stability of radioactive waste glasses assessed from hydration thermodynarnics, in G.L. MeVay, ed. Scientific Basis for Nuclear Wase Management VH, North-Holland, New York, 1984, Pp. 755-762.

L.N. Plummer and D.L. Parkhurst, PHREEQE: \$tatus and applications, in G.K. Jacobs and S.K. Whatley, eds. Procedings of the Conference on the Application of Geochemical Models to High-Level Nuclear Waste Repository Assessment, Oak Ridge National Laboratory Report NUREG/CP O062 (ORNL/TM 9585), 1985, pp. 37-45.

L.N. Plummer, D.L. Parkhurst, and D.R. Kosiur, MLX2: A computer program por modelling chemical reactions in natural waters, U.S. Geological Survey water-Resources Investigutions Report $61 \cdots 75,1975$.

L.N. Plummer, B.F. Jones, and A.H. Truesdell, WATEQF -... A FORTRAN IV version of WATEQ, A computer program for calculating chemical cquilibria of natural waters, U.S. Geolozical Survey Wuter-Resources Investugations Report 76-13, 1976.

L.N. Plummer, D.L. Parkhurst, and D.C. Thorstenson, Development of reaction models for ground water systerns, Geochim. Cosmochim. Acta, vol. 47, pp. $665-686$ (1983).

D.W. Pollock, Find flow and energy transparent in a high-level radioactive waste repository in unsturated alluvium, Ph.D. dissertation, University of Illinois at Champatign-Uthana, 1982. 
D.W. Pollock, Simulation of fluid flow and energy transport processes associated with high-level radioactive waste disposal in unsaturated alluvium, Water Resour. Res., vol. 22, pp. 765-775 (1986).

K. Porn and O. Akerlund, Procedures for uncertainty and sensitivity analysis in repository performance assessment, Swedish Nuclear Fuel and Waste Managment Company Technical Report 85-18, 1985.

M. Pourbaix, The electrochemical basis for localized corrosion, in R. Staehle, B.F. Brown, J. Kruger, and A. Agarwal, eds., Localized Corrosion, NACE, Houston, 1974.

L. Prij and L.H. Vons, Numerical and experimental investigations on the time-dependent behavior of a salt dome with a high-level waste repository, in G.L. McVay, ed., Scientific Basis for Nuclear Waste Management VII, North-Holland, New York, 1984, pp. 1-8.

Probabilistic System Assessment Code (PSAC) User Group, PSACOIN level 0 intercomparison, Nuclear Energy Agency, Organisation for Economic Co-operation and Development, November 1987.

K. Pruess, TOUGH user's guide, Lawrence Berkeley Laboratory Report LBL-20700, 1986.

K. Pruess and R.C. Schroeder, SHAFT 79-user's manual, Lawrence Berkeley Laboratory Report LBL-10861, 1980.

E.N. Pugh, On the role of complex ions in the season cracking of alpha brass, Trans. ASM, vol. 58, pp. 473-482 (1966).

D. Rai, R.G. Strickert, and J.L. Ryan, Alpha radiation-induced production of $\mathrm{HNO}_{3}$ during dissolution of $\mathrm{Pu}$ compounds, Inorganic and Nuclear Chemical Letters, vol. 16, Pp. 551-555 (1980).

D. Rai, R.G. Strickert, and J.L. Swanson, Actinide solubility controls in performance assessment of nuclear waste repositories, in R.G. Post, ed., Waste Management '83, University of Arizona, Tucson, 1983, vol. 2, pp. 335-339.

P. Raimbault and P. Goblet, Results from the METIS code participation to the HYDROCOIN exercise, oral presentation to the 6th HYDROCOIN workshop and coordinating meeting, Washington, D.C., May 26-29, 1987.

A. Rasmuson, Migration of radionuclides in fissured rock: Analytical solutions for the case of constant source strength, Water Resour. Res., vol. 20, pp. 1435-1442 (1984).

A. Rasmuson, Analysis of hydrodynamic dispersion in discrete fracture networks using the method of moments, Water Resour. Res., vol. 21, pp. 1677-1683 (1985).

A. Rasmuson, T.N. Narasimhan, and I. Neretnieks, Chemical transport in a fissured rock: verification of a numerical model, Water Resour. Res., vol. 18, p. 1479, 1982.

T.C. Rasmussen, Computer simulation model of steady fluid flow and solute transport through three-dimensional networks of variably saturated, discrete fractures, in D.D. Evans and T.J. Nicholson, eds., Flow and Transport Through Unsaturated Fractured Rock, American Geophysical Union, Washington, 1987, pp. 107-114.

$$
\mathrm{R}-30
$$


J.L. Ratigan, A sensitivity study of brine transport into a borehole containing a commercial high-level waste canister, Office of Nuclear Waste Isolation Report ONWI-384, February, 1987.

E.J. Reardon, $K_{d}$ 's - Can they be used to describe reversible sorption reactions in contaminant migration, Oround Water, yol. 19, pp. 279-286 (1981).

D.R. Rector, J.M. Cuta, N.J. Lombardo, T.E. Michener, C.F, Wheeler, COBRA-SFS: A thermal hydraulic analysis computer code, volume II: User's manual, Pacific Northwest Laboratory Report, November 1986.

D.T. Reed and R.A. Van Konynenburg, Effect of lonizing radiation on moist air systems, in M.J. Apted and R,E, Westerman, eds., Scientific Basis for Nuclear Waste Management XI, Materials Research Society, Pittsburgh, 1988, pp. 393-404.

D.T. Reed, S.D. Bonar, and M.F. Weiner, Gamma and alpha radiation levels in basalt high-level waste repository; potential impact on container corrosion and packing properties, Rockwell Hanford Operations Report RHO-BW-SA-462P, 1985

M.H. Reed, Calculation of multicomponent chemical equilibria and reaction progresses in systems involving minerals, gases and an aqueous phase, Geochim. Cosmochim. Acta, vol. 46 , pp. $513-528(1982)$.

M. Reeves and R.M. Cranwell, User's manual for the Sandia waste-isolation flow and transport model (SWIFT), U.S. Nuclear Regulatory Commission Report NUREG/CR-2324, November 1981 .

M. Reeves, D.S. Ward, N.D. Johns, and R.M. Cranwell, Theory and implementation for SWIFT II: The Sandia waste-isolation flow and transport model for fractured media, U.S. Nuclear Regulatory Commission Report NUREC/CR-3328, 1986.

W.A. Rhoudes and R,L. Childs, An updated version of the DOT-4 one- and two-dimensional neutron/photon transport code, Oak Ridge National Laboratory Report ORNL $-5851,1982$.

T. Rhodin, Physical Metallurgy of Stress Corrosion Failute, Interscience, New York, 1959.

W.J. Roberds, R.J. Plum, and P.J. Visca, Proposed methodology for completion of scenario analysis for the Basalt Waste Isolation Project, Rockwell Hantord Operations Report RHO-BW-CR -147P, November 1984.

E.L.J. Rosinger and R.S. Dixon, Mathematical modeling of water radiolysis: A discussion of various methods, Atomic Energy of Canada Limited Report AECL-5958, 1977.

B. Ross, A review of the state of the art of civilian high-level nuclear waste repository performance assessments, Labat Anderson Inc. unpublished report, November 1984.

B. Ross, Disruption scenarios for a high--level waste repository at Yucca Mountain, Nevada, in R.G. Post, ed., Waste Managenent '86, University of Arizona, Tucson, 1986a, vol. 2, pp. 403-409. 
B. Ross, Dispersion in fractal fracture networks. Water Resour. Res., vol. 22, pp. $823-827$ $(1986 b)$.

B. Ross and C.M. Koplik, A new numerical method for solving the solute transport equation, Water Resour. Res., vol. 15, pp. 949-953 (1979).

B. Ross, L.E. Berman, M.E. Hough, and G.D. Pollak, Aspects of nuclear waste management, vol. 2: Post-emplacement hazards, Lawrence Livermore Laboratory Report UCRL-15167, April 1979.

T. Rothfuchs, Brine migration tests that are in progress at Asse mine in the Federal Republic of Germany, in H.C. Burkholder, ed., High-level Nuclear Waste Disposal, Battelle, Columbus and Richland, 1986, pp. 477-487.

R.W. Roussin, LS. Abbot, and D.E. Bartine, Nuctear Reactor Shielding, Oak Ridge National Laboratory, Oak Ridge, Tennessee, 1977.

B. Sagar and P.M. Clifton, Stochastic goundwater flow modeling using the second-order method, Rockwell Hanford Operations Report RHO-BW-SA-364P, March 1984.

B. Sagar, P.W. Eslinger, and R.G. Baca, Probabilistic modeling of radionuclide release at the waste package subsystem boundary of a repository in basalt, Nucl. Technol, vol. 75 , pp. $338-349(1986)$.

W.E. Sanford and LF. Konikow, A two-constituent solute-transport model for ground water having variable density, U.S. Geological Survey Water-Resources Investigations Report $85-4279,1985$.

F.P. Sargent and J.J. Cramer, Cigar Lake projet: a U-deposit natural analog, in B. Come and N.A. Chapman, eds., CEC Natural Analogue Working Group, Second Meeting, Interlaken (CH), June 17-19, 1986, pp. 93-100.

$\mathrm{K}$. Scheffler and U. Riege, Investigations on the long-term radiation stability of borosilicate glasses against alpha emitters, Kernforschungszentrum Karlsruhe Repon KDK -2422 , 1977.

1.1. Scott and CM. Koplik, Analytic models for assessing the performance of engineered barriers in a basalt repository, in 0.1. McVay, ed., Scientific Basis for Nuclear Waste Monagement VII, North-Holland, New York, 1984, pp. 1077-1084.

J.W. Shade, L.L. Ames, and J.E.W. McGarrath, Actinide and technetium sorption on Iron-silicate and dispersed clay colloids, in ACS Symposium Series 246:

Geochemical Behavior of Disposed Radioactive Waste, 1984.

M.E. Shea, Performance assessment input: Marysvale natural analog study, in $B$. Come and N.A. Chapman, eds., CEC Natural Analogue Working Group, Fírst Meeting, Brussels, November $5-7,1985$, pp. $157-163$.

D.W. Shoesmith, S. Sunder, L.H. Johnson, and M.G. Balley, Oxidation of CANDU UO, fuel by the alpha-radiolysis products of water, in L.O. Werne, ed., Scientific Busis for Nuciear Waste Management IX, Materials Research Sociely, Pittsburgh, 1985, pp. $309-316$. 
R.J. Silva, Temperature dependence of actinide solubilities and speciation, in G.K. Jacobs and $S . K$. Whatley, eds. Proceedings of the Conference on the Application of Geachemical Models to High-Level Nuclear Waste Repository Assessment, Oak Ridge National Laboratory Report NUREG/CP-0062 (ORNL/TM-9585), 1985, pp. 74-76.

S.A. Simonson and W.L. Kumn, Predicting amounts of radiolytically produced species in brine solutions, in G.L. McVay, ed, Scientific Basis for Nuclear Waste Management WII, North Holland, New York, 1984, pp. 781 -787.

S. Sinnock, Y.T. Lin, and J,P. Brannen, breliminary bounds on the expected postclosure perfomance of the Yucca Mountain tepository site, southern Nevada, Sandia National Laboratories Report SAND84-1492, December 1984.

V.V. Skorchelletti, Theory of Metal Corrosion, Leinigradskoe Otdelenie, 1973, translated from the Russian and published by Israel Program for Scientific Translations, Jerusalem, 1976.

Y. Smellie, Pocos de Caldas, Brazil, in B. Come and N.A. Chapman, eds, CEC Natural Analogue Working Croup, First Meeting, Brussels, November 5-7, 1985, pp. 171-174.

J. Smellie, Progress of the Pocos de Caldas project, in B. Come and N.A. Chapmar, eds, CEC Natural Analogue Working Group, Second Meeting, Interaken (CH), June $17-19.1986$, pp. 114-118.

J. Smellie, L.B. Magno, N.A, Chapman, 1.G. McKinley, and E.P. Franca, The Pocos de Caldas project feasibility study, 1986-7, in B. Come and N.A. Chapman, eds., Natural Analogues in Radioactive Waste Disposal, Brussels, 28-30th April, Symposium Proceedings, Vol. 2, 1987.

C.B3. Smith, D.J. Egan, Ir, W.A. Williams, J.M. Grunlke, C.W.Y. Hung, and B.L. Serini, population risks from disposal of high-level radioactive wastes in getologic repositories, U.S. Environmental Protection Agency, Office of Radintion Programs Repore EPA-520/3-80-006, December 1982.

S.C. Sneider and R.A. Craig, The LASSY model for simulating groundwater transport of radionuclides with chain decay, Eos Trans. AGU, vol. 66, p. 904 (1985).

P. Soo, in P. Soo, ed. Review of DOE waste package program, U.S. Nuclear Regulatery Commission Report NUREG/CR-2482, vol. 3, 1982.

P. SoO Review of DOE waste package program, U.S. Nuclear Regulatory Commission Report NUREG/CR 2482, vol, 5, August 1984.

D.L. Souh, S.L. Cobb, J.J.K. Daeman, Borehote plug performance, in R.G. Post, ed. Waste Management'81. Univ, of Arizona, Tucson, 1981, vol. 2, pp. $881-893$.

G. Sposito, Distingushing adsorption from surface prectpitation, in J.A. Davis and $\mathrm{K}_{\mathrm{k}}$. Hayes eds, Geochemical Processes at Mineral Suraces, Amer. Chem. Soc. Symp. Sertes No, 323, 1986, pp. $217-229$.

G. Sposito and S. V. Mattigod, GEOCHEM: A computer program for the calculation of chemical squilibria in soil solutions and other natural water systems, Dept. of Soil and Envirommenal Sciences, University of Catifornia, Riverside, unpuhlished report, 1979.

$$
\mathrm{R}--33
$$


D. Stahl and N.E. Miller, Long-term performance of materials used for high-level waste packaging, U.S. Nuclear Regulatory Commission Report NUREG/CR-4379, vol. 4, June 1986 .

J.A. Steadman, Archaeological concretes as analogues, in B. Come and N.A. Chapman, eds., CEC Natural Analogue Working Group, Second Meeting, Interlaken (CH), June $17-19,1986$, pp. $165-171$.

E.A. Straker, P.N. Stevens, D. C. Irving and V. R. Cain, The MORSE code - A multigroup neutron and gamma-ray Monte Carlo transport code, Oak Ridge National Laboratory Report ORNL-4885, 1970.

R.T. Stula, T.E. Albert, Kirstein, and D.H. Lester, Systems study on engineered barriers: Barrier performance analysis, Office of Nuclear Waste Isolation Report ONWI-211, September 1980 .

T.M. Sullivan and A.J. Machiels, Modeling chemical interactions in the hydrated layers of nuclear waste glasses, in G.L. McVay, ed., Scientific Basis for Nuclear Waste Mangement VII, North-Holland, New York, 1984, pp. 597-604.

S. Sunder, D.W. Shoesmith, L.H. Johnson, G.J. Wallace, M.G. Bailey, and A.P. Smaglewski, Oxidation of CANDU fuel by the products of alpha radiolysis of groundwater, in J.K. Bates and W.B. Seefeldt, eds., Scientific Basis for Nuclear Waste Management X, Materials Research Society, Pittsburgh, 1987, pp. 103-113.

W.G. Sutcliffe, Uncertainty analysis: An illustration from nuclear waste package development, Nucl. Chem. Waste Management, vol. 5, pp. 131-140, 1984.

W.G. Sutcliffe, K.G. Feller, N.K. Madsen and G.D. Pollak, Uncertainties and sensitivities in the performance of geologic nuclear waste isolation systems, volume II, Lawrence Livermore National Laboratory Report ONWI-352, UCRL-53142, April 1981.

Swanson Analysis Systems, Inc., ANSYS - engineering analysis system, revision 4.2., Houston, Pennsylvania, 1986

F.A. Swenson, Rates of salt solution in the Permian Basin, U.S. Geol. Surv. Jour. Research, vol. 2, pp. 253-257 (1974).

R.E. Thomas, Uncertainty analysis, Office of Nuclear Waste Isolation Report ONWI-380, March 1982.

R.E. Thomas, A feasibility study using hypothesis testing to demonstrate containment of radionuclides within waste packages, Office of Nuclear Waste Isolation Report BMI/ONWI-599, April 1986.

S.D. Thomas and S. Gopal, ERG review of containment failure probability and repository functional design criteria, Office of Nuclear Waste Isolation Report BMI/ONWI-608, June 1986.

S.D. Thomas, B. Ross, and J.W. Mercer, A summary of repository siting models, U.S. Nuclear Regulatory Commission Report NUREG/CR-2782, July 1982. 
E.C. Thornton and W.E. Seyfried, Jr., Chernical and diffusional effects in a thermal gradient; results of recent experimental sudics and implications for subsealed disposal of nuelear waste, in C.-F. Tsang, ed., Coupled Processes Associated with Niclear Waste Repositones, Academic, Orlando, 1987 , pp. 355-361.

D.C. Thorstenson, E.P. Weeks, H. Hass, and D.W. Fisher, Distribution of gaseous $12 \mathrm{CO}_{2}$, $13 \mathrm{CO}_{2}$ and ${ }^{14} \mathrm{CO}_{2}$ in the sub soil unsaturated zone of the westem U.S. Great Plains, Radiocarbon, vol. 25 , pp. $315-346(1983)$.

R. Tomovic and M. Vukobratoric, Generni Sensituity Theory, Elsevier, New York, 1972.

B.I. Travis and H.E. Nuttall, A transport code for radiocolloid migration: with an assessment of an actual low-level waste site, in C.M. Jantzen, J.A. Stone, and R.C. Ewing, eds., Sctentific Basis for Nuclear Wate Management VII, Materials Research Society, Pitsburgh, 1985 , pp. $969-976$.

B.J. Traviz and H.E, Nuttall, Analysis of colloid transport, in L.O. Werme, ed., Scientiffe Basis for Nuclear Waste Manduenem IX, Materials Research Society, Pittsburgh, 1986, pp, 737-745.

B.J. Travis, S.W. Hodson, H.E. Nutall, T.L. Cook, and R.S. Rundberg, Numerical simulation of flow and transport in fractured tuft, in G.L. McVay, et. Sctentific Basis for Nuclear Waste Management VI, Nonb-Holland, New York, 1984, pp. 1039-1046.

Y.S. Thipathi and G,T. Yel, HYDROGEOCHEM: A new model for transport of reacive multi-species contaminants, Eos Trans. AGU, vol. 66, p. 905 (1985).

A.H. Truestel and B.F. Jones, WATEQ: A computer program for calculating chemical equilibria of natural waters; U.5. Geol. Surv., Jour. Research, vol. 2, pp. 233248 (1974).

W.D. Tumer, D.C. Elrod, and I.I. Siman-Tov, HEATING5 - An IBM 360 heat conduction program, Oak Ridge National Laboratory Report ORNL/CSD/TM-15, Mareh 1977.

B. Tylock, G. Jansen, and G, R. Raines, Verification of the 2. W WAPPA-B code, Office of Nuclear Waste Isolation Report ONWI-653, Jnly. 1987.

H.H. Uhig, Corrosiom and Corrosion Control, Butterworth, London, 1972.

A.M.J. Umati and S.M. Gorelick, The problem of complex eigensystems in the semianalytical soiution for advancenent of time in solute transport simulations: $A$ new methot using real arithmetic, Water Resour. Res, vol. 22, pp. 1149-1154 (1986).

UNSCEAR, Sowces and Effects of Lonizing Radiation, United Nations Scientific Committee on Atomic Radiation (UNSCEAR), United Nations, New York, 1977.

U.S. Dept. of Energy, A muttatribute utihty analysis of sites nominated for characterization for the first radioactive waste repository $-A$ decision-aiding methodology, U.S. Dept. of Energy Report DOE/RW-O074, May $1986 \mathrm{a}$.

U.S. Dept. of Energy, Environmental assessment; Deaf Smith County stet, Texas, Report $\mathrm{RW}-0069,19800$ 
U.S. Dept. of Energy, Environmental assessment, Reference Repository Location, Hanford Site, Washington, Report DOE/RW-0070, May 1986c.

U.S. Dept. of Energy, Disposal of Hanford defense high-level, transuranic, and tank wastes, Report DOE/EIS-0113, vol. 3, Appendix N, 1986d.

U.S. Environmental Protection Agency, Environmental radiation protectionstandards for management and disposal of spent nuclear fuel, high-level and transuranic radioactive wastes, Federal Register, vol. 50, pp. 38084-38089 (1985).

U.S. Nuclear Regulatory Commission, Proceedings of the symposium on uncertainties associated with the regulation of geologic disposal of high-level radioactive waste, Report NUREG/CP-0022/CONF-810372, 1982.

U.S. Nuclear Regulatory Commission, Health effects model for nuclear power plant accident consequence analysis, Report NUREG/CR-4214, vol. 2, 1985.

U.S. Nuclear Regulatory Commission, Disposal of high-level radioactive wastes in geologic repositories; conforming amendments, Federal Register, vol. 51, pp. 22288-22301 (1986).

P. van der Heijde, Y. Bachmat, J. Bredehoeft, B. Andrews, D. Holtz, and S. Sebastian, Groundwater Management: The Use of Numerical Models, American Geophysical Union, Washington, 1985.

A.C. Van Orden, Dealloying of silver-gold alloys, Ph.D. thesis, University of Maryland, College Park, 1988.

P.J. Vaughan, Analysis of permeability reduction during flow of heated, aqueous fluid through Westerly Granite, in C.-F. Tsang, ed., Coupled Processes Associated with Nuclear Waste Repositories, Academic, Orlando, 1987, pp. 529-539.

A. Verma and K. Pruess, Effects of silica redistribution on performance of high-level nuclear waste repositories in saturated geologic formations, in C.-F. Tsang, ed., Coupled Processes Associated with Nuclear Waste Repositories, Academic, Orlando, 1987, pp. 541-563.

C.I. Voss, A finite-element simulation model for saturated-unsaturated, fluid-density-dependent ground-water flow with energy transport of chemically-reactive single-species solute transport, U.S. Geological Survey Water-Resources Investigations Report 84-4369, 1985.

C. Wagner, Studies of stress corrosion cracking phenomena, J. Electrochem. Soc., vol. 63, pp. 354-360 (1933).

C. Wang, N.Z. Sun, and W.W-G. Yeh, An upstream weight multiple-cell balance finite-element method for solving three-dimensional convection-dispersion equations, Water Res. Res. vol 22, pp. 1574-1589 (1986).

J.S.Y. Wang and T.N. Narasimhan, Hydrologic mechanisms goveming fluid flow in a partially saturated, fractured, porous medium, Water Resour. Res., vol. 21, pp. $1861-1874(1985)$.

$$
\mathrm{R}-36
$$


D.S. Ward, D.R. Buss, J.W, Mercer, and S.S. Hughes, Evaluation of a groundwater corrective action at the Chem-Dyne hazardous waste site using a telescopic mesh refinement modeling approach, Water Resour. Res., vol. 23, pp. 603617 (1987).

W.J. Weber, R.P. Turcotte, L.R. Bunnell, F.P. Roberts, and J.H. Westsik, Jr, Radiation effects in vitteous and devitrified simulated waste glass, in Ceramics in Nuclear Waste Management, U.S. Dept of Energy Report CONF-790420, 1979, pp. 294-299.

E.P. Weeks, Effect of topography on gas now in unsaturated tractured rock - Concepts and observations, in D.D. Evans and T.J. Nicholson, eds., Flow and Transport Through Unsaturated Fractured Rack, American Geophycial Union, Washington, 1987 , pp. $165-170$.

J.R. Welty, C.E. Wicks, and R.E. Wilson, Fundamentals of Monentum, Heat, and Mass Transfer, 2nd ed., John Wiley \& Sons, New York, 1976.

L.O. Werme and R.S. Forsyth. Spent fuel as a waste form, the Swedish program for studies and evaluation of spent fuel for direct disposal, in R.G. Post, ed., Waste Management' 85 , University of Arizona, Tucson, 1985, vol. 1, pp. 483-488.

J.M. West, Corrosion Principles, Wiley, New York, 1975, pp. 123-130.

J.C. Westall, J.L. Zachary and F.M.M. Morel, MINEQL - A computer program for the calculation of chemical equilibrium composition of aqueous systems: MIT, Dept. of Civil Eng. Technical Note No. 18, 1976.

R.E. Westerman, J.L. Nelson, S.G. Pitman, W.L. Kuhn, S.J. Basham, and D.P. Moak, Evaluation of iron-base materials for waste package containers in a salt repository, in G.L. McVay, ed., Scientiflc Basis for Nuclear Waste Monagement Vit, North Holland Press, New York, 1984, pp. 427-436.

C.L. Wheeler, M.J. Thurgood, T.E. Guinoti, and D.E. DeBellis, COBRA-NC, A thermal hydro code for transient analysis on NUC reactor comporents, Pacific Northwest Laboratory Report PNL-4710, volume 1, March 1986.

T.M.L. Wigley, WATSPEC: A computer program for determining the equilibrium speciation of aqueous solutions, British Geomorphological Research Group Technical Bulletin 20, 1977.

T.P. Wilcox, MORSE L, a special version of the MORSE program designed to solve neutron, gamma, and coupled neutron-gamma penetration problems, Lawrence Livermore Laboratory Report UCID-16680, September 1972.

B.E. Wilde and E. Williams, The relevance of accelerated electrochetnical pitting tests to the long-term pitting and crevice corrosion hehavior of stainless steels in marine environments, J. Electrochem. Soc., vol. 118, pp. 1058-1067 (1974).

T.J. Wolery, Calculation of chemical equilibrium between aqueous solution and minerals: The EQ3/6 software packstge, Lawrence Livermore National Laboratory Report UCRL $-52658,1979$.

T.J. Wolery, EQ3NR, a computer program for geochemical aqueous speciation-solubility calculations: User's guide and documentation, Lawrence Livermore National Laboratory Report UCRL 53414,1983 .

$$
\mathrm{R}-37
$$


T.J. Wolery, EQ6, a computer program for reaction-path modelling of aqueous geochemical systems: User's guide and documentation, Lawrence Livermore National Laboratory, in preparation.

T.J. Wolery, D.J. Isherwood, K.J. Jackson, J.M. Delany, and I. Puigdomenech, EQ3/6: status and applications, Lawrence Livermore National Laboratory Report UCRL-91884, 1984.

B.J. Wood, Backfill performance requirements - Estimates from transport models, Nucl. Technol., vol. 59, pp. 390-404 (1982).

S.W. Woolfolk and W. Baer, General radiological consequences of brine release by human intrusion into WIPP, in R.G. Post, ed., Waste Management '83. Univ. of Arizona, Tucson, 1983, vol. 2, pp. 387-391.

B.A. Worley, Deterministic uncertainty analysis, Oak Ridge National Laboratory Report ORNL-6428, 1987.

B.A. Worley, R.Q. Wright and F.G. Pin, A finite-line heat transfer code with automated sensitivity-calculation capability, Oak Ridge National Laboratory Report ORNL/TM-9975, September 1986.

G.T. Yeh, An orthogonal-upstream finite element approach to modeling aquifer contaminant transport, Water Resour. Res., vol. 22, pp. 952-964 (1986).

G.T. Yeh and D.S. Ward, FEMWATER, a finite element model of water flow through saturated-unsaturated porous media, Oak Ridge National Laboratory Report ORNL-5601, 1980.

G.T. Yeh and D.S. Ward, FEMWASTE, a finite element model of waste transport through saturated-unsaturated porous media, Oak Ridge National Laboratory Report ORNL-5601, 1981.

H. Yokoyama, H.-P. Hermansson, H. Christensen, I.-K. Bjömer, and L. Werme, Corrosion of simulated nuclear waste glass in a gamma radiation field, in C.M. Jantzen, J.A. Stone and R.C. Ewing, eds., Scientific Basis for Nuclear Waste Management VIII, Materials Research Society, Pittsburgh, 1985, pp. 601-608.

S.M. Zand, Dissolution of evaporites and its possible impact on the integrity of the waste isolation pilot plant (WIPP), New Mexico, USA, in W. Lutze, ed., Scientific Basis for Nuclear Waste Management V, North-Holland, New York, 1982, pp. 429-438.

S.J. Zavoshy, P.L. Chambré, and T.H. Pigford, Mass transfer in a geologic environment, in C.M. Jantzen, J.A. Stone, and R.C. Ewing, eds., Scientific Basis for Nuclear Waste Management VIII, Materials Research Society, Pittsburgh, 1985, pp. 311-322. 
PNL 6608

UC -510

\section{DISTRIBUTION}

No. ot

Copies

OFFSTE

10 DOE/Office of Scientific and Technical Information

2

U. S. Department of Energy

Office of Civilian Radioactive

Waste Management, RW-24

Washington, $\mathrm{DC} 20545$

ATTN: D. H. Alexander

R. Strein

S. Russo, Acting Director

U. S. Deparment of Energy

Office of Civilian Radioactive Waste

Managenent, RW.1

Washington, DC 20585

2 U. S. Department of Energy

Office of Civilian Radioactive

Waste Management, RW-20

Forresta Building

Washington, DC 20585

ATTN: T. H. Isatacs

S. H. Kale

3 U.S. Department of Energy

Office of Civilian Radionctive Waste

Management, RW-222

Forrestal Building

Washington, DC 20585

ATTN: I. F. Daly

M. W. Frei

J. L. Maris

B. G. Gale

U. S. Deparment of Energy

Offce of Civilian Radioactive

Waste Management, RW-223

Forrestal Building

Washington, DC 20585
No. of

Copies

C. L. Carnahan

Lawrence Berkelay taboratory

MS 50E

1 Cyclotron Road

Berkeley, CA 94720

K. Chang

U.S. Nuclear Regulatory

Commestion

Division of Waxte Managenent

MS $623-5 S$

Silver Springs, MD 2010

W. J. Conover

College of Business

Adninistration

Texas Tech University

Lubhock, TX 79409

S. Coptan

U. S. Nuclear Regulatory

Commission

MS $623-5 S$

Washington, DC 20555

G. A, Dinwiddie

U. 3 , Department of the Interior

U. S. Geological Survey

National Center, MS.410

12202 Sunnese Valky Drive

Reston, VA $220 \%$

Document Control Center

U. S. Nuclear Regulalory

Conmmission

Division of Waste Minatemen

Washingtor, DC 20555

W. Harrison

Argonne National Laboritory

6700 South Cass Averue

Argonne, IL 60439

Distr. 1 
No. of

Copies

G. Jacobs

Oak Ridge National Laboratory

P.O. Box X

Bethel Balley Road

SM 039, Bldg. 1505

Oak Ridge, TN 37831

C. M. Jantzen

E. I. du Pont de Nemours \& Co., Inc.

Savannah River Laboratory

Aiken, SC 29808

J. K. Kerrisk

Los Alamos National Laboratory

Los Alamos, NM 87545

H. J. Machiels

Electric Power Research Institute

P.O. Box 10412

Palo Alto, CA 94303

D. L. Oliver

University of Toledo

Mechanical Engineering Department

Toledo, $\mathrm{OH} 43606$

C. Pescatore

Brookhaven National Laboratory

Upton, NY 11973

T. J. Nicholson

U. S. Office of Nuclear

Regulatory Research

Waste Management Branch

5650 Nicholson Lane

Rockville, MD 20582

L. R. Rickertson

Weston

955 L'Enfant Plaza

Washington, DC 20024

Disposal Safety Inc.

1629 K Street NW, Suite 600

Washington, DC 20006

ATIN: S. Amter

B. Ross
No. of

Copies

K. W. Stephens

Stephens \& Associates

10424 Windfall Court

Damascus, MD 20872

4 Lawrence Livermore National

Laboratory

P.O. Box 808

Livermore, CA 94550

ATTN: W. J. O'Connell

M. Revelli

H. Shaw

R. Silva

3 Office of Waste Technology

Development

7000 South Adams Sureet

Willowbrook, ПL 60521

ATTN: H. Avci
A. Branstetter

J. Cunnane

2 University of California

Department of Nuclear

Engineering

Berkeley, CA 94720

ATTN: W. W.-L. Lee

T. H. Pigford

$2 \quad$ U. S. Department of Energy

Chicago Operations Office

6800 South Cass Avenue

Argonne, IL 60439

ATTN: R. Baker

T. Bendokas

5 Sandia National Laboratory

P.O. Box 5800

Albuquerque, NM 87185

ATTN: F. Bingham

E. J. Bonano

R. W. Cranwell

T. O. Hunter

R. L. Iman 
No. of

Copies

4

U. S. Department of Energy

Nevada Operations Office

P.O. Box 14100

Las Vegas, NV 89114-4100

ATTN: H. Ahagan

M. Blanchard

D. livingston

C. Gertz:

2 I. T. Corporation

2340 Alamo $S$. E.

Albuquerque, NM 87106

ATIN: W. W. Ballard, Ir. I. Myers

RE/SPEC

D.O. Box 14984

Albuguerque, NM 87191

ATTN: P. Gnirk

RE/SPEC Inc*

P.O. Box 725

Rapid City, SD 57709

ATTN: W. E. Coons

J. Heman

2565 Wyngate Road

Chariotteswille, YA 22901

A. C. Van Orden

9217 Longbranch larkway

Sitver Spring, MD 20901

\section{FOREIGN}

G. Bidoglio

Joint Research Centre

Radiochemistry Division

210201 spra (V)

ITALY

N. C. Garjsto

AECL - Whiteshell Nuclear

Researeh Establishment

Pinawa, Manitoba

CANADA ROE $1 L O$
No. of

Copies

\section{B. Grarabow \\ Hakn-Meitner-Institut \\ GMBH, Postfach 390128 \\ Clienteker Str. 100 \\ D-1000 Berlin 39 \\ FEDERAL REPUBLIC OF \\ GERMANY}

J. Hadernann

Institut Federal de Recherches en Matiere de Reaeteurs

CH-5303 Wurenlingen

SWTTZERLAND

D. Hodgkinson

Theoretical Physics Division

Atomic Energy Research

Establishment

Harwell

Oxon OX11 ORA

UNITED KINGDOM

L. H. Johnson

AECL - Whiteshell Nuclear

Research Establistment

Pinawa, Manitoba

CANADA ROE ILO

N. Kjellbert

SKB AB

P.O. Box 5864

S-102 48 Stockholm

SWEDEN

D. M. LeNeven

AECL - Whiteshell Nuclear

Research Establishment

Pinawa, Maniloba

CANADA ROE 110

W. Lutz

HatmuMeiner Institut

Department of Ceramic Materiats

Posfact 390128

Glienicker Str. 100

D. 1000 Perin 39

FEDERAL REPUBLIC OF

GERMANY 
No. of

Copies

2 NAGRA

Parkstrasse 23

CH-5401 Baden

SWITZERLAND

ATTN: C. McCombie

1. McKinley

T. Mishima

Power Reactor and Nuclear Fuel

Development Corporation

Deputy General Manager

Waste Isolation Offices

Waste Management and Row

Materials Division

1-9-13 Akasaka, Minato-ku

Tokyo 107

IAPAN

1. Neretnieks

Royal Institute of Technology

Department of Chemical

Engineering

\$-100 44 Stockholn

SWEDEN

E. Peltonen

TVO Industrial Power Co. Ltd

Fredrikinkatu $\$ 1.53$

Helsinki

FINLAND

S. Sharland

Atomic Energy Research

Establishment

Theoretical Physics Division

Harwell

Oxon OX11 ORA

UNITED KINGDOM

C. Thergerstrom

OECDN Nuclear Energy Agency

Division of Radiation

Protection and Waste

Munagement

38 Boulevard Sucher

$\mathrm{F}-75016$ Paris

FRANCE
No. of

Copies

H. Wanner

Nuclear Lnergy Agency

Data Bank

Batiment 445

91191 Git-sur-Yvente Cedex

FRANCE

L. O. Werme

Swedish Nuclear Fuel and Waste

Management $\mathrm{Co}$.

P.O. Box 4864

S-102, 48 Stockholm

SWEDEN

\section{QNSTIE}

3 DOE Richland Operations Office

D.C. Langstaff

D. L. Sours

J. I. Sutey

Wesinghouse Hanford Compary

J. D. Davis

54 Paciffe Northess Laboratore

M. K. Altenhofen

M. I. Apted

R. C. Anthur

D. I. Bradley

1. A. Buchanan

R. L. Cheatham

C. R. Cole

L. J, Criscenti

P. G. Doctor

C. E. Ekderkin

D. M. Elwood

D. W. Engel

P. W. Eslinger

J. W. Falco

M. G. Foley

M. D. Frashley

R. O. Giber

M. J. Grahan

J. M. Hales 
No. of

Copies

K. R. Hanson

P. C. Hays

E. R. Hill

C. T. Kincaid

M. R. Kreiter

J. C. Laul

J. A. Mahaffey

T, B, Miley

R. W. Nelson

A. R. Olsen

P. J. Pelto

M. G. Piepho

P. W. Reimus

B. Sagar

R. L. Skaggs

R. I. Seme

R. L. Skaggs
No. of

Copies

B. D. Slonecker

G. M. Stokes

1. A. Stottlemyre

D. M. Strachan

D. L. Strenge

A. E. Yan Luik

C. F. Voss

W. H. Walters

R. E. Westeman

R. E. Wildung

Publishing Coordination

Technical Report Files (5) 


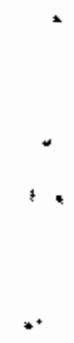

